\title{
ULTRASONIC SPOT WELDING OF LIGHTWEIGHT ALLOYS
}

by

\author{
VIKAS PATEL \\ Bachelor of Engineering in Mechanical Engineering \\ Veer Narmad South Gujarat University, Surat, GJ, India, 2007 \\ Master of Industrial Technology and Operations \\ Illinois Institute of Technology (IIT), Chicago, IL, USA, 2010
}

\author{
A dissertation \\ presented to Ryerson University \\ in partial fulfillment of the \\ requirements for the degree of \\ Doctor of Philosophy \\ in the Program of \\ Mechanical and Industrial Engineering
}

Toronto, Ontario, Canada, 2014

CVikas Patel, 2014 


\section{AUTHOR'S DECLARATION}

I hereby declare that I am the sole author of this dissertation. This is a true copy of the dissertation, including any required final revisions, as accepted by my examiners.

I authorize Ryerson University to lend this dissertation to other institutions or individuals for the purpose of scholarly research

I further authorize Ryerson University to reproduce this dissertation by photocopying or by other means, in total or in part, at the request of other institutions or individuals for the purpose of scholarly research.

I understand that my dissertation may be made electronically available to the public. 


\title{
ULTRASONIC SPOT WELDING OF LIGHTWEIGHT ALLOYS
}

\author{
(C) Vikas Patel, 2014 \\ Doctor of Philosophy \\ Department of Mechanical and Industrial Engineering \\ Ryerson University
}

\begin{abstract}
Automotive and aerospace sectors have a pressing need for structural components that are lighter and stronger, aiming to improve energy efficiencies and reduce anthropogenic environment. Steel has already a wide variety of structural applications in the transportation industry due to its excellent properties. To further reduce $\mathrm{CO}_{2}$ emissions, lightweight magnesium ( $\mathrm{Mg}$ ) and aluminum (Al) alloys have increasingly been used in the vehicle fabrication due to their lower density, higher specific strength and stiffness, excellent size stability and process ability. The structural application of these alloys inevitably involves welding and joining of similar Mg-to-Mg and Al-to-Al, and dissimilar Mg-to-Al, Mg-to-steel and Al-to-steel. Resistance spot welding produces coarse grains, large defects and thick brittle intermetallic compounds (IMCs) in the weld metal. Alternative solid-state welding processes are being considered such as ultrasonic spot welding (USW), which produces coalescence through the simultaneous application of localized high-frequency vibratory energy and moderate clamping forces. In this study, USW was successfully carried out on similar Mg alloy and dissimilar Mg-to-Al, Mg-to-steel and Al-to-steel alloys. The overall
\end{abstract}


objective of this work is to gain a better understanding of the dominant factors determining the joint performance, with particular emphasis on the microstructural evolution, crystallographic texture, micro-hardness, lap shear strength, fatigue resistance, fatigue life prediction model and fracture analysis of similar and dissimilar USWed joints. Overall, USWed Mg-to-Mg is stronger and more consistent in terms of weldability than the dissimilar USWed Mg-to-Al, Mg-to-steel and Al-to-steel. This was attributed to the large volume of thick brittle IMCs and significantly higher welds center hardness in dissimilar metals welding, which is the main cause of joint failure. The IMCs were confirmed by XRD, EDS and microhardness measurement tests.. Therefore, another objective of this study is to minimize the presence of brittle IMCs and engineer an acceptable intermetallic layer to produce sound joints between Mg-to-Al, Mg-to-steel and Al-to-steel. A third material (tin foil or zinc coating) was placed in-between the work pieces. With this procedure, the lap shear strength of the welded samples was increased. The detailed microstructural characterization and mechanical properties of welded joints with an interlayer are presented. 


\section{ACKNOWLEDGEMENTS}

First of all, I wish to praise and thank God for all his/her blessings. I would not have made any progress without his/her providence.

I would like to express my sincere thanks to my supervisors Dr. D.L. Chen and Dr. S.D. Bhole, who gave me this great opportunity not only to support this work, but also to discover the great features of high power ultrasonic welding technology. They continuously encouraged and supported me through my research program and enabled me to know many things. I am indebted to them for their insightful discussions, guidance, support, and encouragement during my studies at Ryerson University. I will be eternally grateful to my supervisors for transforming my mechanical engineering and industrial technology background to material science and engineering. Undoubtedly, they have been instrumental in shaping my knowledge and my abilities as a researcher.

I would also like to thank the Natural Sciences and Engineering Research Council of Canada (NSERC) and AUTO21 for providing financial support. This investigation involves part of the Canada-China-USA Collaborative Research Project on the Magnesium Front End Research and Development (MFERD).

I am grateful to my committee members for their precious time in evaluating and subsequently raising several valuable points during the course of this work. I would like to extend my thanks to all my friends and colleagues at Ryerson University for helping me and keeping my spirits up. Special thanks are owed to A. Machin, J. Amankrah, Q. Li and R. 
Churaman for their strong support in providing easy access to the facilities. Further I would like to extend my thanks to my mentor and guru Prof. M.G. Suthar who has constantly encouraged me for graduate study.

I would also like to thank Mississauga Transit (MiWay) and Toronto Transit Commission (TTC) for providing excellent transportation service and a better environment in the coach for study. It is worth mentioning that most of the ideas of my research came during my commuting time.

Finally, I cannot forget the great struggle of my loving wife, Hinal Patel. Words alone cannot express what I owe her for her persistent encouragement, understanding, emotional support, and great patience during my six years of graduate study. Last but not least, how can I forget the sacrifices of my parents (Prof. K.C. Patel \& H.K. Patel) and sister (Niketa). They are the only one, who constantly supported and encouraged me to complete this work. 
To

My Grandmothers

Late Mrs. Santaben Patel

\&

Mrs. Jamnaben Patel 


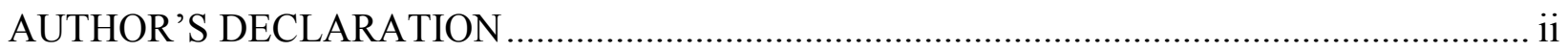

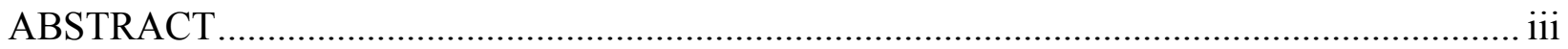

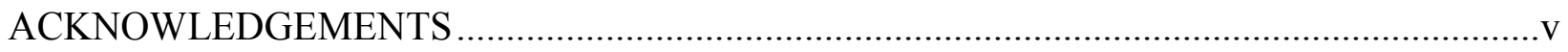

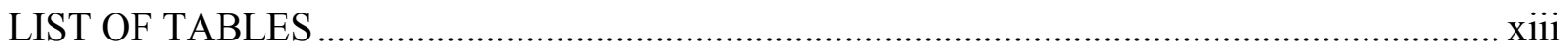

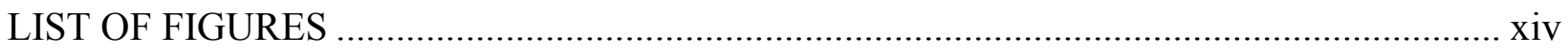

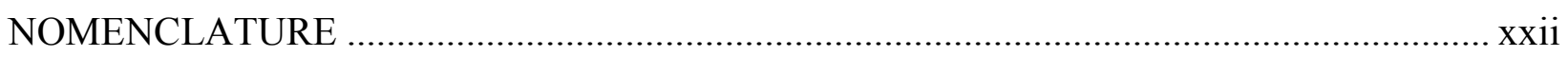

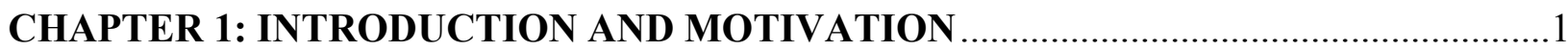

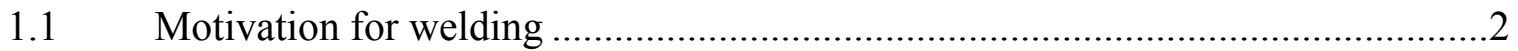

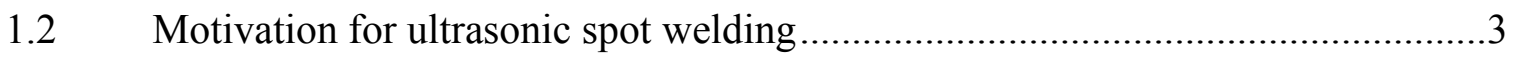

$1.3 \quad$ Objective and scope of this dissertation.........................................................

$1.4 \quad$ Structure of the dissertation ..........................................................................

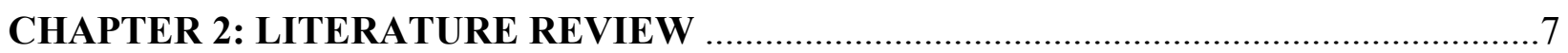

$2.1 \quad$ Principles and fundamentals of USW ……………........................................

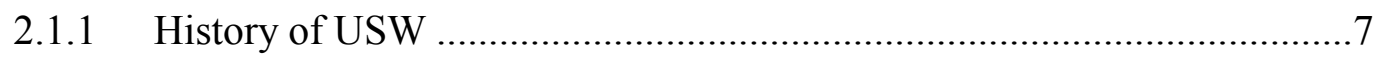

2.1.2 USW equipment .........................................................................

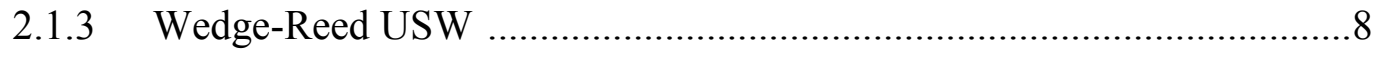

2.1.4 Lateral drive USW ….......................................................................10

2.1.5 Principles of USW ………………………................................10

2.1.6 Application of USW ………………………..................................13

2.1.7 Advantages of USW system ………………..................................14 


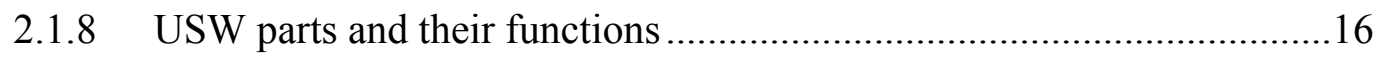

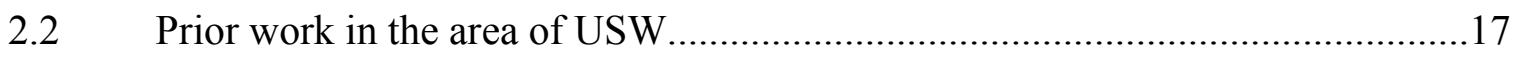

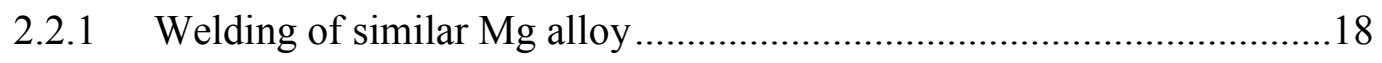

2.2.1.1 Microstructure, grain size and recrystallization ...........................19

2.2.1.2 Crystallographic texture of welded Mg alloy..............................24

2.2.1.3 Fatigue behavior of welded Mg alloy .......................................25

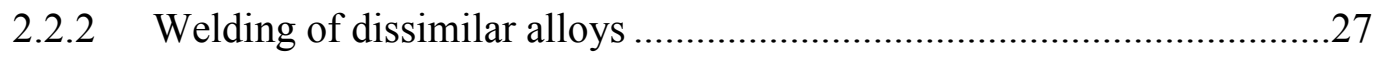

2.2.2.1 Welding of dissimilar Mg-to-Al alloys ........................................27

2.2.2.2 Welding of dissimilar Mg-to-Steel alloys ...................................29

2.2.2.3 Welding of dissimilar Al-to-Steel alloys........................................30

2.3 Summary of the literature review ………………..........................................30

CHAPTER 3: MATERIALS AND EXPERIMENTAL PROCEDURE …………..................33

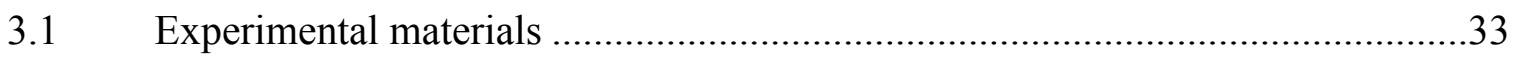

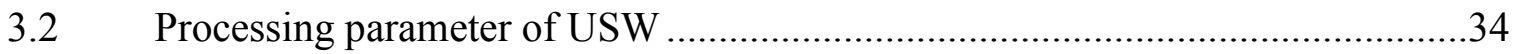

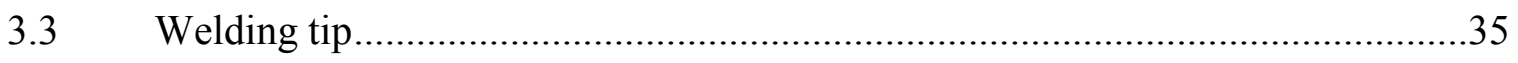

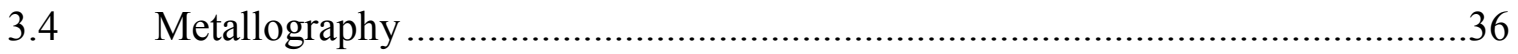

3.5 Quantitative image analysis .............................................................................

3.6 X-Ray diffraction for phase identification .......................................................37

3.7 Temperature profile during USW ……………................................................

3.8 Crystallographic texture measurement.............................................................38

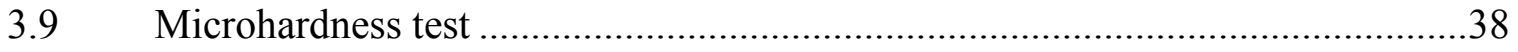

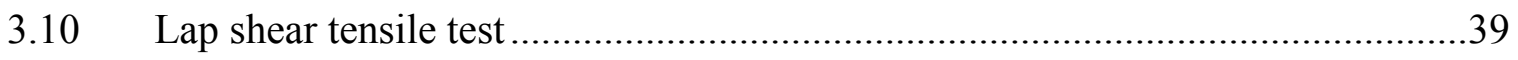

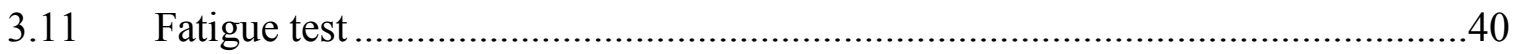


4.1 Microstructure and grain size measurement

4.2 Relationship between Zener-Hollomon parameter and grain size 44

4.2.1 Shear strain rate calculation 44

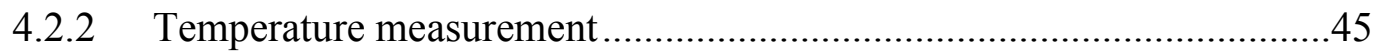

4.2.3 Zener-Hollomon parameter analysis and calculation...........................47

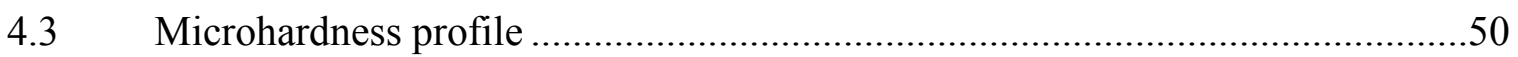

4.3.1 Effects of USW on microhardness ..................................................50

4.3.2 Hall-Petch type relationship of microhardness of USWed Mg alloy......51

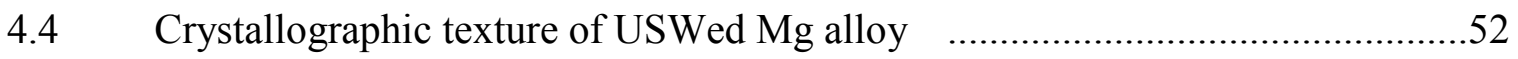

4.4.1 Crystallographic texture by X-ray diffraction profiles ........................53

4.4.2 Crystallographic texture by pole figures profiles...............................56

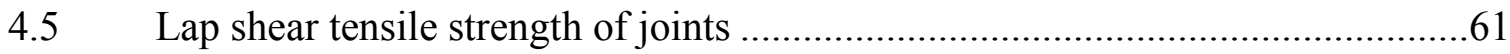

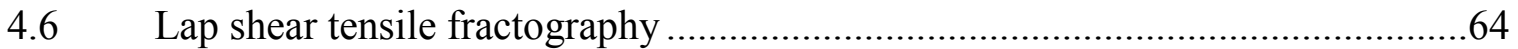

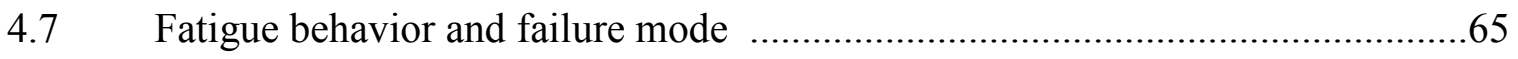

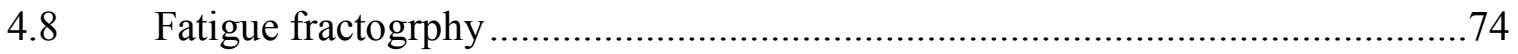

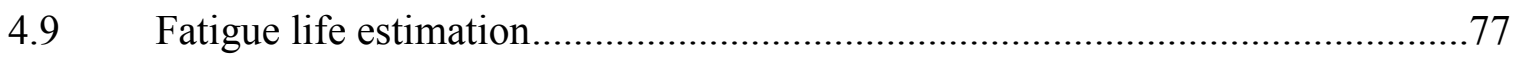

4.9.1 Global stress intensity factor solutions for main cracks ......................78

4.9.2 Local stress intensity factors solutions for kinked cracks .....................80

4.9.3 A fatigue crack growth model ....................................................... 82

4.9.4 Applicability of the fatigue model ................................................82

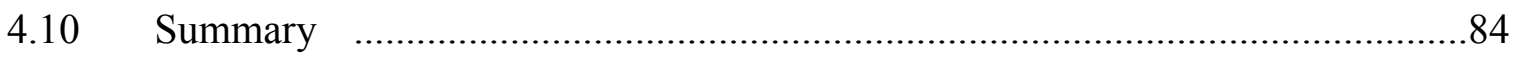




\section{CHAPTER 5: ULTRASONIC SPOT WELDING OF MAGNESIUM-TO-ALUMINUM}

ALLOYS

$5.1 \quad$ Without interlayer in-between the faying surface ............................................8

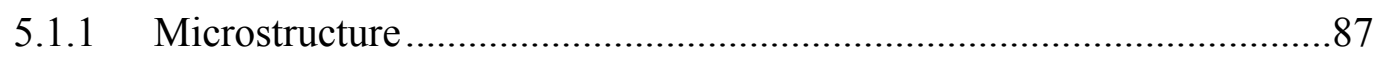

5.1.2 Energy-dispersive X-ray spectroscopy analysis .................................90

5.1.3 X-ray diffraction analysis..............................................................92

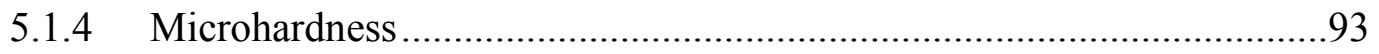

5.1.5 Lap shear tensile strength of joints ......................................................94

5.2 With tin $(\mathrm{Sn})$ as an interlayer in-between the faying surface...............................96

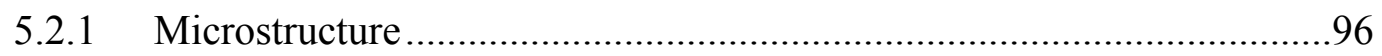

5.2.2 Energy-dispersive X-ray spectroscopy analysis ..................................97

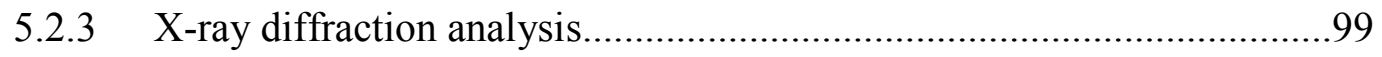

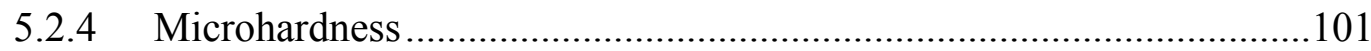

5.2.5 Lap shear tensile strength of joints ....................................................102

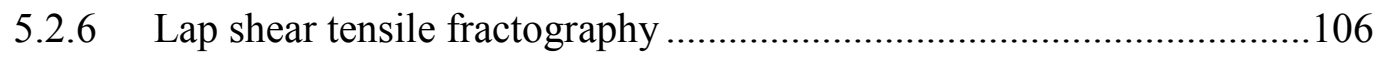

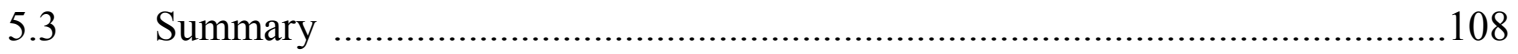

\section{CHAPTER 6: ULTRASONIC SPOT WELDING OF MAGNASIUM-TO-STEEL}

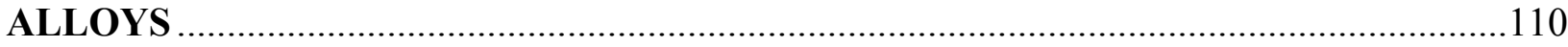

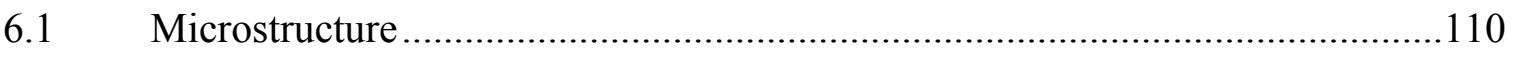

6.2 Energy-dispersive X-ray spectroscopy analysis ...............................................112

6.3 X-ray diffraction analysis …………………...............................................117

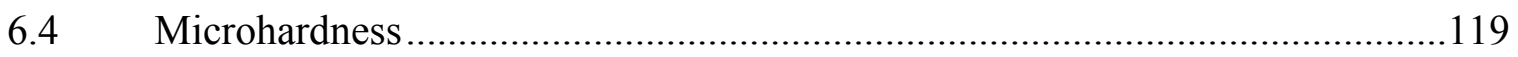

6.5 Lap shear tensile strength of joints ...............................................................120 


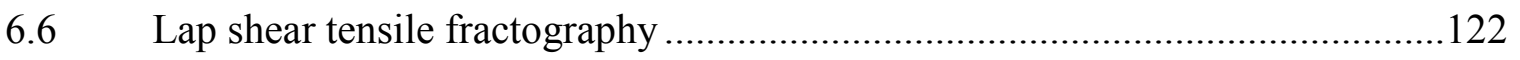

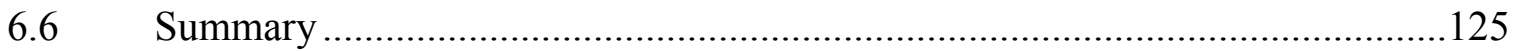

CHAPTER 7: ULTRASONIC SPOT WELDING OF ALUMINUM-TO-STEEL

ALLOYS

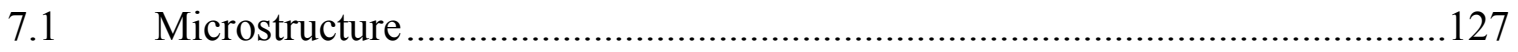

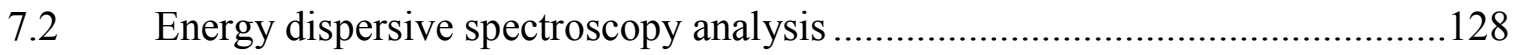

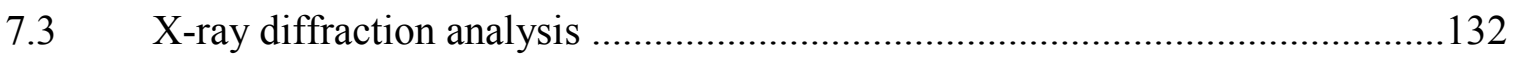

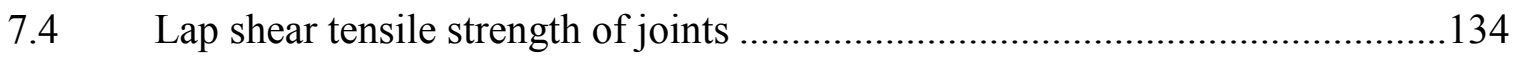

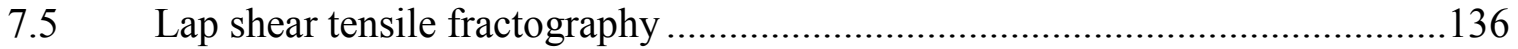

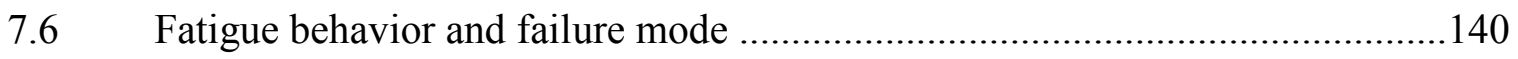

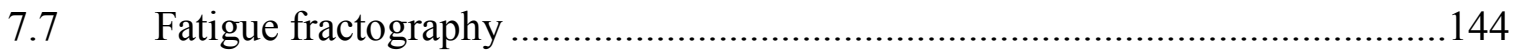

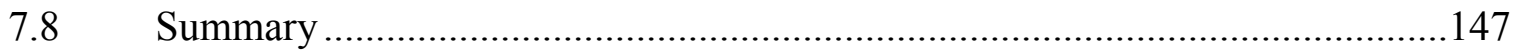

CHAPTER 8: SUMMARY, CONCLUSIONS AND FUTURE WORK...........................148

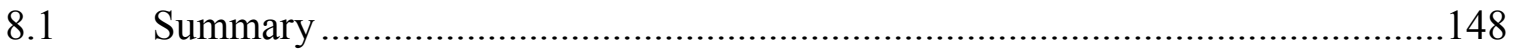

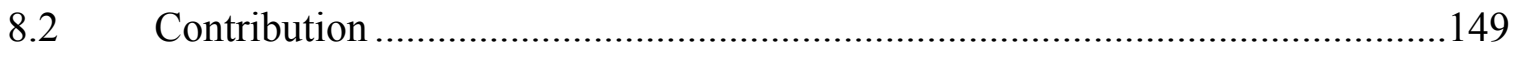

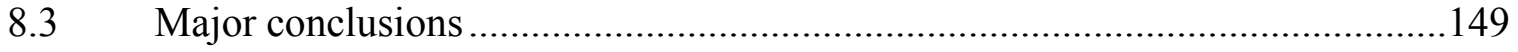

8.4 Recommendations for future work ................................................... 151

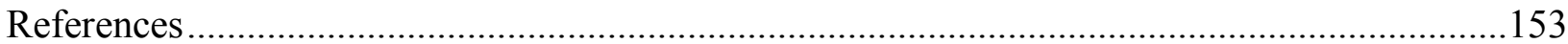




\section{LIST OF TABLES}

Table 2.1 Comparison of the approximate requirement and weld cycle times for different spot joining process in $1 \mathrm{~mm}$ aluminum sheet [35]............................ 14

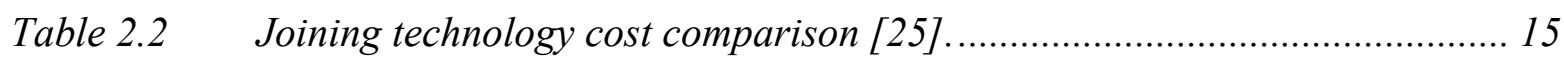

Table $3.1 \quad$ Chemical composition of the AZ31B-H24 Mg alloy (wt \%)........................ 33

Table 3.2 Chemical composition of the Al5754-O Mg alloy (wt \%). ........................... 34

Table 3.3 Chemical composition of the HSLA 340 steel (wt \%). ................................. 34

Table 3.4 Physical properties of the material being used in this experiment............... 34

Table 4.1 A summary of measured grain size, calculated peak temperature, strain rate, Zener-Hollomon parameter for USW joints. ..................................... 47

Table 4.2 Summary of parameters $\alpha$ and $\beta$ between grain size and Zener-Hollomon parameter for different processing .................................................. 49

Table 7.1 Elemental composition of different regions in Figure 7.5(c) and (d), in at.\%. 139 


\section{LIST OF FIGURES}

Figure 2-1 USW systems with transverse vibration pattern (a) Wedge-Reed and (b) Lateral-Drive [41]. 9

Figure 2.2 Schematic diagram of the dual-reed USW machine with a schematic model of the weld development at interface. 12

Figure 2.3 USW machine with an image with its different parts. . 17

Figure 2.4 Cellular dendritic structures at edge of weld nuggets at different welding times (a) 2 cycle (b) 16 cycles, equiaxed dendritic structures in central portion of weld nuggets at different welding times (c) 2 cycle (d) 16 cycles [52].

Figure 2.5 (a) Overview of the FSLWed $M g / M g$ joint obtained at a tool rotational rate of $1000 \mathrm{rpm}$ and a welding speed of $20 \mathrm{~mm} / \mathrm{s}$ with (b) to (g) showing the microstructures in the different regions as indicated in (a) [53]. 21

Figure 2.6 Microstructures of friction weld AZ31 near friction weld interface, $t 1=1.5 \mathrm{~s}$ $P 1=50 \mathrm{MPa}$ and $\mathrm{P2}=100 \mathrm{MPa}$ and $\mathrm{N}=40 \mathrm{~s}-1$ (a) $x=0 \mathrm{~mm}$, (b) $x=2 \mathrm{~mm}$, (c) $x=5 \mathrm{~mm}$, (d) $x=11 \mathrm{~mm}[54]$. 23

Figure $3.1 \quad$ Schematic diagram of the lap joint .......................................................... 35

Figure $3.2 \quad$ Images of the welding tip with its knurl pattern. .................................... 35

Figure 3.3 Inserted thermocouple in the groove of the sheet for temperature measurement. 38

Figure 3.4 Microhardness indentation made diagonally across the welded joints. ....... 39

Figure 3.5 A $3 D$ view of the lap shear tensile and fatigue test specimen ..................... 40 
Figure 4.1 Optical micrograph of AZ31 BM and welded samples at different energy levels. (a) AZ31 BM, (b) $500 \mathrm{~J}$, (c) $1000 \mathrm{~J}$, (d) $1500 \mathrm{~J}$ (e) $2000 \mathrm{~J}$ (f) $2500 \mathrm{~J}$ and (g) $3000 \mathrm{~J}$ welding energy inputs. 42

Figure 4.2 (a): Temperature at the center of the weld recorded during USW with different energy levels, (b) peak temperatures at the center of the weld recorded during USW with different energy levels. 46

Figure 4.3 Relationship between grain size and Zener-Hollomon parameter. 49

Figure 4.4 Microhardness at the center of the USW welds with different energy levels. 51

Figure 4.5 Hall-Petch type relationship of hardness and the grain size of USW samples. 52

Figure 4.6 Schematic diagram of the lap joint with indicating different zone where crystallographic texture measured 53

Figure 4.7 Simulated X-ray diffraction pattern for the completely random Mg powder using $\mathrm{Cu}$-Ka radiation. The vertical axis is for the X-ray intensity. Within the $2 \theta$ angles of $30-40^{\circ}$, the $\left(10^{1} 0\right)$ and (0002) peak heights are about one half of the (1011) peak heights. 54

Figure 4.8 X-ray diffraction patterns obtained from BM, HAZ, NZ and FS at (a) 1000 (b) $2000 \mathrm{~J}$ USWed AZ31B-H24 Mg alloy. 55

Figure 4.9 (0002) basal plane (10 $\left.{ }^{\overline{1}} 0\right)$ prismatic plane and (10 $10^{\overline{1}}$ ) pyramidal plane pole figures of USWed AZ31B-H24 Mg alloy obtained from BM, HAZ, NZ and FS at (a) $1000 \mathrm{~J}$ (b) $2000 \mathrm{~J}$ energy inputs. 58

Figure 4.10 Lap shear strength of USWed similar AZ31-H24 Mg alloy at different energy inputs. 62 
Figure 4.11 Effect of the knurl pattern on the USWed sample at (a) $1000 \mathrm{~J}$ (b) $2000 \mathrm{~J}$ and bending effect during the failure at (c) $1000 \mathrm{~J}$ and (d) $2000 \mathrm{~J}$ and nugget pull out effect (e) energy inputs. 63

Figure 4.12 Typical SEM images of tensile fracture surface of USWed similar AZ31-H24 Mg alloy, (a) and (b) overall view, (c) and (d) at lower magnification, (e) and (f) at higher magnification of $1000 \mathrm{~J}$ and $2000 \mathrm{~J}$ energy inputs, respectively.

Figure 4.13 Experimental results of fatigue life for the USWed Mg-to-Mg joints 67

Figure 4.14: (a) Schematic diagrams of a lap shear specimen after the USW process with kinked crack at both notch tips, (b) overall view of SEM micrographs after fatigue testing of the USWed Mg-to-Mg joints made using an energy input if $1000 \mathrm{~J},(\mathrm{c})$ magnified image near the notch tip indicated by a dashed box. . 68

Figure 4.15 Comparison of fatigue life of the welded Mg-to-Mg joints with different welding techniques. 70

Figure 4.16 Typical fatigue failure modes at different Pmaxvalues of the USWed Mg-toMg joints made at a welding energy of $1000 \mathrm{~J}$, (a) $3.5 \mathrm{kN}$ (interfacial), (b) 3 kN (interfacial), (c) $2.5 \mathrm{kN}$ (partially interfacial-partially TTT crack growth), (d) $2.0 \mathrm{kN}$ (partially interfacial-partially TTT crack growth), (e) $1.5 \mathrm{kN}$ (partially interfacial-partially TTT crack growth), (f) $1 \mathrm{kN}$ (TTT crack growth), (g) $0.5 \mathrm{kN}$ (TTT crack growth). 71

Figure 4.17: Typical fatigue failure modes at different Pmax values of the USWed Mg-to-Mg joints made at a welding energy of $2000 \mathrm{~J}$. Here, (a) $3.5 \mathrm{kN}$ was experienced partially interfacial-partially TTT crack growth failure mode, while (b) to (g) 
for the load of 3.0 to $0.5 \mathrm{kN}$ with decrement of $0.5 \mathrm{kN}$ show the failure occurred predominantly in the mode of TTT crack growth. ......................... 72

Figure 4.18 The maximum tensile shear cyclic stress vs. the number of reversals to failure (2Nf) in the double-log scale for the USWed Mg-to-Mg joints made at an energy input of $1000 \mathrm{~J}$, where different failure modes are indicated. 73

Figure 4.19 Typical SEM images of a fatigue fracture surface of a USWed Mg-to-Mg joint made with a welding energy of $1000 \mathrm{~J}$, tested at a Pmaxof 0.5kN, (a) overall view, (b) crack initiation area from the top, (c) magnified image of crack initiation area, (d) fatigue striations in the crack propagation zone at a higher magnification, (e) final fast crack propagation area, (f) crack initiation area from the bottom in (a), and (g) fatigue striations at a higher magnification area in $(f)$. 75

Figure 4.20 A schematic illustration of a main crack and a kinked crack with a kink length aanda kink angle 77

Figure 4.21: Experimental results and fatigue life estimations for theUSWed Mg-to-Mg joints, where the symbols denote the experimental results of fatigue life and various curves represent the fatigue life estimation using Newman and Dowling (ND) model based on the global stress intensity factors solutions of Eqns. of Lin et al. [79], Swellam et al. [83], Zhang [81, 82] and Pook [80]. 83

Figure 5.1 Microstructures of AZ3-H24 and Al5754-O welded samples at (a) 1500J, (b) $3000 \mathrm{~J}$ energy inputs and (c) relation between IMC thickness and different energy inputs. 88 
Figure 5.2 EDS analysis: (a) area analysis of the fracture surface on the $1500 \mathrm{~J}$ energy input welded sample and (b) SEM micrograph of $3000 \mathrm{~J}$ welded sample (c) is EDS line scan across the center of layer in (b). 91

Figure 5.3 XRD on the fracture surface of the $1500 \mathrm{~J}$ energy input welded sample. ..... 92

Figure 5.4 Microhardness profile in welded joints at different energy inputs. 94

Figure 5.5 (a) Lap shear strength and (b) failure energy of welded joints at different energy inputs levels. 95

Figure 5.6 Microstructure of the dissimilar USW Mg/Al joints made with a welding energy of $1500 \mathrm{~J}$ in the middle of weld nugget (a) without and (b) with a Sn interlayer. 97

Figure 5.7 (a) Microstructure of the dissimilar USW Mg/Al joints made with a Sn interlayer at a welding energy of $1500 \mathrm{~J}$ in the middle of weld nugget at higher magnification, and (b) EDS line scan across the welded joint as indicated by the dashed line. 98

Figure 5.8 XRD patterns obtained from the matching fracture surfaces of (a) Al side and (b) Mg side at a welding energy of $1000 \mathrm{~J}$. 100

Figure 5.9 Microhardness profile across the welded joints at different energy inputs. 101

Figure 5.10 Comparison of (a) lap shear strength with and without a Sn interlayer as a function of energy input, (b) failure energy with and without a Sn interlayer as a function of energy input, (c) lap shear strength among different welded joints at an energy input of $1000 \mathrm{~J}$, (d) lap shear strength of the dissimilar Mg-to-Al welded joints made with different welding techniques. 104 
Figure 5.11 Matching fracture surfaces of (a) Al side and (b) Mg side of a welded sample (c) and (e) magnified image of region of (a), and (d) and (f) magnified image of region of (b) with a Sn interlayer at a welding energy of $1000 \mathrm{~J}$. 106

Figure 6.1 SEM micrograph of the dissimilar USWed (a) Mg-to-bare steel (b) Mg-togalvanized steel and (c) Mg-to-bare steel with Sn interlayer using $1000 \mathrm{~J}$ welding energy. 111

Figure 6.2 Magnified SEM micrograph at the center of USWed joint of (a) Mg-to-bare steel, (c) Mg-to-galvanized steel, (e) Mg-to-bare steel with Sn interlayer joints using $1000 \mathrm{~J}$ welding energy, and their respective (b), (d) and (f) are EDS line scan across the center of layer in (a), (c) and (e), respectively. 114

Figure 6.3 XRD patterns obtained from the matching fracture surfaces of Mg-togalvanized steel and Mg-to-bare steel with Sn interlayer joints at a welding energy of $1000 \mathrm{~J}$, (a) Mg side and (b) Fe side 118

Figure 6.4 Microhardness profiles across the USWed Mg-to-galvanized steel and Mg-tobare steel with a Sn interlayer joints at a welding energy of 1000 and $2000 \mathrm{~J}$ joint. 119

Figure 6.5 (a) Comparison of a lap shear strength of USWed Mg-to-galvanized steel and Mg-to-bare steel with an Sn interlayer joints as a function of energy input, (b) comparison of the highest lap shear tensile strength achieved by similar and dissimilar joints of Mg and steel using USW. 121

Figure 6.6 Matching fracture surfaces of (a) Mg side (b) bare steel side of a welded sample with Sn interlayer at a welding energy of $1000 \mathrm{~J}$, (c) flat and grey region at a larger magnification of $M g$ side (d) the corresponding region of 
bare steel, (e) pull-out (or black) region at a larger magnification of Mg side, (f) the corresponding region of bare steel side, (h) overall fracture surface of USWed Mg-to-galvanized steel of Mg side, (h) and (i) are magnified image at region $h$ in $(g)$ and $i$ in $(h)$, respectively. 124

Figure 7.1 SEM micrograph of the dissimilar USWed Al-to-galvanized steel using (a) $1000 \mathrm{~J}$ (b) $2000 \mathrm{~J}$ energy inputs in the middle of weld nugget (c) magnified SEM micrograph of (a), and (d) EDS line scan across the interlayer in (c), (e) SEM micrograph of Al-Zn eutectic liquid at the edge of the joint. 129

Figure 7.2 Schematic illustration of the bonding process of USWed Al-to-galvanized steel joint. 131

Figure 7.3 XRD patterns obtained from the matching fracture surfaces of (a) Al side and (b) Fe side at a welding energy of $2000 \mathrm{~J}$....... 133

Figure 7.4 Lap shear tensile strength of USWed dissimilar Al-to-galvanized steel at different energy inputs. 135

Figure 7.5 Typical SEM images of tensile fracture surface of USWed dissimilar Al-togalvanized steel (a) overall view Al side (b) galvanized steel side of $2000 \mathrm{~J}$, respectively, (c) and (d) shown in (a) and (b), respectively, are the magnified area (image rotated at $90^{\circ}$ ). (e) EDS line scan analysis across the line shown in (c) Al side, and (f) shown in (d) galvanized steel side. (g), (h) and (i) were higher magnification images of (c), and (j), (k) and (l) higher magnification images of $(d)$. 137

Figure 7.6 (a) S-N curves of the USWed Al-to-galvanized steel joint tested at $R T, R=0.2$, and a frequency of $50 \mathrm{~Hz}$, (b) the maximum tensile shear cyclic stress vs. the 
number of reversals to failure (2Nf) in the double-log scale for USWed Al-togalvanized steel joint at $2000 \mathrm{~J}$ energy input. 141

Figure 7.7 Typical fatigue failure locations at different $P_{\max }$ values of USWed Al-togalvanized steel at $1000 \mathrm{~J}$ energy input (a) $3 \mathrm{kN}$ (interfacial failure mode) (b) $2.5 \mathrm{kN}$ (interfacial failure mode) (c) $2 \mathrm{kN}$ (interfacial failure mode, initiation of crack) (d) $1.5 \mathrm{kN}$ ((interfacial failure mode, crack start to propagating perpendicular to the loading direction) (e) $1 \mathrm{kN}$ (transverse through-thickness crack growth mode). 143

Figure 7.8 Typical SEM images of fatigue fracture surface of a USWed Al-to- steel joint using $1000 \mathrm{~J}$ tested at a $P_{\max } 1.0 \mathrm{kN}$, (a) overall view, (b) crack initiation area, (c) magnified image of crack initiation area, (d) final fast crack propagation area, (e) fatigue striations in the crack propagation zone at a higher magnification, $(f)$ overall view of shear fracture surface at a higher $P_{\max }=3.0$ $k N$, and (g) shear fracture of region $g$ in (f) at a higher magnification, and (h) small isolated dimple-rapture failure zone of region $h$ in (g) at a higher magnification. 145 
NOMENCLATURE

\begin{tabular}{ll} 
Acronym & Definition \\
ASTM & American Society for Testing of Materials \\
AWS & American Welding Society \\
BCC & Body Centered Cubic \\
BM & Base Metal \\
FCC & Face Centered Cubic \\
FS & Fracture Surfaces \\
FSW & Friction Stir Welding \\
FSLW & Friction Stir Lap Welding \\
FSP & Friction Stir Processing \\
FSSW & Folling Direction \\
NDS & Fiction Stir Spot Welding \\
HAZ & Noristance Spot Welding \\
HCP & Heat Affected Zone \\
\hline
\end{tabular}




$\begin{array}{ll}\text { SEM } & \text { Scanning Electron Microscope } \\ \text { SZ } & \text { Stir Zone } \\ \text { TD } & \text { Transverse Direction } \\ \text { TMAZ } & \text { Thermo-mechanically affected zone } \\ \text { TTT } & \text { Transverse Through Thickness } \\ \text { UTS } & \text { Ultimate Tensile Strength } \\ \text { USAMP } & \text { United States Automotive Materials Partnership } \\ \text { USW } & \text { Ultrasonic Spot Welding } \\ \text { USWed } & \text { Ultrasonic Spot Welded } \\ \text { XRD } & \text { X-ray Diffraction }\end{array}$

\section{Symbol Definition}

Z Zener-Holloman parameter

$\dot{\varepsilon} \quad$ Strain rate

$Q \quad$ Activation Energy

$R \quad$ Gas Constant

$T \quad$ Temperature

$\dot{r} \quad$ Shear strain rate

$f \quad$ Frequency

A Amplitude

$h_{o} \quad$ Thickness of the weld nugget between plates

E Energy 


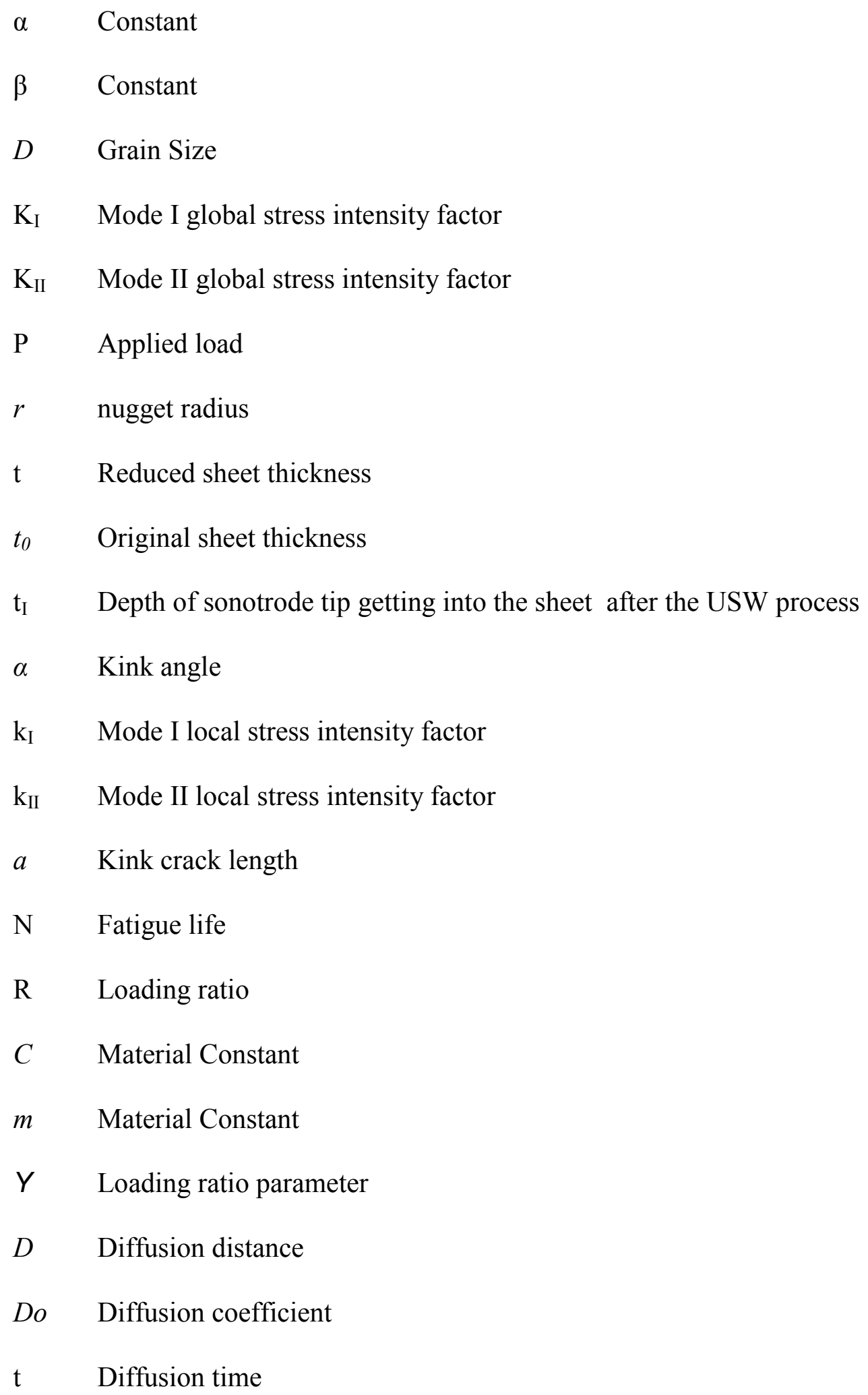




\section{CHAPTER 1}

\section{INTRODUCTION AND MOTIVATION}

Environmental pollution may be attributed to a large extent to the transportation industry, predominantly $\mathrm{CO}_{2}$ emissions produced by automotive vehicles. These can have devastating effects on human society and the environment [1-9]. This problem can be resolved by considering such as use of alternate fuel sources, aerodynamic improvements, and powertrain enhancements. However, lightweighting of auto-body seems to be the best cost effective option for significantly decreasing $\mathrm{CO}_{2}$ emissions and improving fuel efficiency [10]. It is projected a $22.5 \mathrm{~kg}$ reduction in mass would improve fuel efficiency by approximately $1 \%$ [1]. Thus, currently, the application and development of the ultralightweight magnesium (Mg) alloys have been considerably growing in the transportation industry due to its low density, superior damping capacity and high strength-to-weight ratio [1,11-17]. Similarly, because of the lightweight and good mechanical strength properties of aluminum (Al) alloys, there usage is it is becoming progressively substantial in high-speed passenger rail bodies and heavyweight vehicles $[18,19]$. In addition, currently, steel is the most common metal used for the automotive vehicle industries. In order to achieve the desired properties of these multi-materials, welding and joining of these metals is essential. This dissertation represents a contribution to novel ultrasonic spot welding (USW) technique to join similar and dissimilar lightweight alloys. Specifically, USWed Mg alloys' deformation mechanisms, dynamic recrystallization, its influence on crystallographic texture formation, and mechanical properties such as tensile and fatigue properties are studied. Furthermore, characterization of challenging dissimilar USW of Mg-to-A1, Mg-to-steel and 
Al-to-steel, respectively were performed, where the formation of intermetallic compounds (IMCs) during dissimilar USW has been systematically studied. To improve the mechanical properties like lap shear tensile and fatigue, IMCs of dissimilar USWed joints were engineered with the help of a Sn interlayer and $\mathrm{Zn}$ coating. The remainder of this Chapter establishes the motivation and framework for welding and particular USW process.

\subsection{Motivation for welding}

Unfortunately, to this point, research has not yet reached to print automobile vehicles by 3DPrinting. Thus, one has to rely on the joining technologies, which are inevitably involved in the structural application of the transportation industry. Amongst all joining technologies, welding is the most cost effective, efficacious, fast and reliable method to permanently join materials. According to the document, Vision of Welding, by American Society of Welding [20], welding is a critical technique and typically the final step in the assembly, and plays a major role in ensuring structural performance. So far, no other technique is as widely used by manufacturers for joining metals. By considering only spot-weld industry, more than 5000 spot welds are required to manufacture a single car. Thus, the development of reliable spot weld method is essentially required. In spot welding industries, there are three major welding technologies available in the current market, which are resistance spot welding (RSW),

friction stir spot welding (FSSW) and USW. Among them USW has several wide range of advantages compared to that of RSW and FSSW (discussed later in section 2.1.7). 


\subsection{Motivation for ultrasonic spot welding}

Conventional fusion welding techniques produce large grains, porosity, voids and other defects in the weld zone that seriously degrades mechanical properties of joints. In the auto body manufacturing for the steel car bodies, RSW has been a predominant process [21, 22]. Unfortunately, RSW is challenging and costly to apply to $\mathrm{Mg}$ and other alloys such as $\mathrm{Al}$ alloys owing to their tendency to degrade the electrodes, low strength at high temperature, and high conductivity [23]. In RSW, the high-energy requirement (50-100 kJ per weld) [24, 25] and formation of large heat affected zone (HAZ) are main concerned. Recently, attention has been paid to two solid-state welding processes, namely FSSW and USW, because the liquid phase reaction in the fusion zone during RSW can be avoided. Although FSSW has the potential to produce effective welds between similar and dissimilar materials, a relatively long welding cycle (or time) would be a limiting factor for its widespread adoption in automotive manufacturing [22]. A different solid-state spot welding process that has not attracted much attention is ultrasonic spot welding (USW) [24-27]. Due to the limited high power availability, USW has lately become cost-effective to apply for thicker sheet of metals, though it was discovered in 1950 to join thin foils [28]. USW is extra effective than FSSW, since it generates energy at the joining line (in-between the faying surfaces) [29] rather than at only top surfaces as in FSSW [30, 31]. Further, with regards to welding energy, it uses only 0.6 to $1.5 \mathrm{~kJ}$ per weld, while RSW uses $50-100 \mathrm{~kJ}$ per weld. In comparison with FSSW, USW has been shown to have a shorter weld cycle (typically $<0.5 \mathrm{~s}$ ) and produces high quality joints that are stronger than FSSW when compared on the basis of the same nugget area [32,33]. Further, the normal FSSW leaves an exit hole after welding [34]. From 
the point of view of energy consumption, USW has more advantages. For example, welding of aluminum alloys using a USW process consumes only about $0.3 \mathrm{kWh}$ per 1000 joints [22,35] compared to $20 \mathrm{kWh}$ with RSW, and $2 \mathrm{kWh}$ with FSSW [22].

\subsection{Objective and scope of this dissertation}

A number of papers have recently reported the joining of similar alloys by FSW, FSSW, laser welding, and RSW, especially for steel and Al alloys. However, very limited studies have been reported for the welding of similar Mg alloy, and no study with USW technique is available in the literature. Thus, critical information is still not available in the open literature, such as the optimum welding parameters, microstructural studies, mechanical properties like tensile, fatigue and hardness, thermal profile and crystallographic texture. It is well known that to weld similar alloys is relatively straightforward, but it is fairly challenging to join dissimilar alloys, since the differences in their physical and chemical properties such as, melting point, electric conductivity and thermal-physical properties are large. Furthermore, in the welding of dissimilar metals a rapid formation of brittle IMCs occurs, which can highly degrade the mechanical properties of welded joints [36]. Some limited work on the USW of dissimilar Mg-to-steel and Al-to-steel has recently been reported [37, 38]. However, ways of enhancing the USW joint strength have not been systematically studied.

In this regard, microstructure and mechanical properties such as tensile and fatigue, of all welded joints used in structural applications must be evaluated to ensure the integrity and safety of the joints and structures. However, until now, the evaluation of differently welded 
joints in $\mathrm{Mg}$ and $\mathrm{Al}$ alloys using novel welding techniques in terms of mechanical properties is very limited.

The overall objective of this work is, therefore, to gain a better understanding of the principal factors of USW of similar and dissimilar lightweight alloys. The specific objectives include the following:

- To evaluate the influence of USW in a Mg alloy on microstructure, crystallographic texture, lap shear tensile strength, fatigue resistance, and failure mode.

- To study the microstructure and mechanical properties of dissimilar USWed Mg-toAl joints and evaluate the influence of introducing an interlayer on the mechanical properties.

- To characterize USWed joints of Mg-to-galvanized and ungalvanized steel with and without a interlayer.

- To study microstructure, tensile and fatigue properties of USWed joints of Al-to-steel alloy.

\subsection{Structure of the dissertation}

This dissertation has been structured as follows: A literature survey is discussed in Chapter 2 on the principal and fundamental study of USW, and some prior works on welding of similar and dissimilar joints of lightweight materials. Chapter $\mathbf{3}$ gives the experimental procedures involved in this study. Chapter 4 is on USW of similar Mg alloy, where microstructure evolution, relationship between Zener-Hollomon parameter and grain size, 
microhardness profile, crystallographic texture, lap shear tensile and fatigue properties and fatigue life prediction model of USW joints are discussed. Chapters 5, 6, 7 are on USW of challenging dissimilar Mg-to-Al, Mg-to-steel and Al-to-steel, respectively, where all dissimilar combinations of USW joints were characterized and enhanced lap shear weld strength by $\mathrm{Sn}$ interlayer and $\mathrm{Zn}$ coating placed in-between the faying surfaces. Chapter 8 presents summary, contribution and future scope of the relevant work. 


\section{CHAPTER 2}

\section{LITERATURE REVIEW}

In this section, a literature review is presented to facilitate a concise overview of the USW of lightweight alloys, and to identify areas where further research is needed. The focus of this Chapter is to provide a review of the published research relevant to the topic of USW of lightweight alloys. This review is divided into two sections: the principles and fundamentals of USW system and prior work in the area of welding of $\mathrm{Mg}, \mathrm{Al}$ and steel.

\subsection{Principles and fundamentals of USW}

While USW is extensively used in applications ranging from plastic industries, tube sealing, welding microscopic connections on microchips to, including electrical interconnections, the focus of this work is limited to the sheet metal welding, where the welding mechanism is thought to be different from that for thins foils, wires and plastics. In the following subsections, a brief outline of the USW process is presented.

\subsubsection{History of USW}

Some 60 years ago ultrasound was used to improve grain refinement in fusion welding and brazing [39]. Ultrasonic welding process was discovered in the late 1940s when, in research at the Aeroprojects Company of West Chester, Pennsylvania (the forerunner of the current Sonobond Corporation), ultrasonic vibrations were applied to conventional resistance 
welding equipment with the objective of decreasing surface resistance in spot welding of aluminium [39]. During this work, it was found that ultrasound alone was capable of producing a bonding of the metals. Similar work on welding by mechanical vibration was reported by Willrich in 1950, who obtained cold weld in the region of resistance welding by applying low frequency vibration to the tool that was designed for this purpose [40]. Ultrasonic metal welding equipment was first patented in 1960 [25].

\subsubsection{USW equipment}

In USW, there are numerous variations of the process available, such as those based on geometry, type of the weld and the metals to be joined. Among several different variations are, for example ring, torsion, seam, and line [41]. This study is focused on USW for sheet metals, which is most common to build automotive vehicle structure. This kind of weld typically used welding area of up to $50 \mathrm{~mm}^{2}$ (in this study, $8 \mathrm{~mm} \times 6 \mathrm{~mm}$ ). Figure 2.1 shows two general configurations of USW system that can be used, namely a wedge-reed system and a lateral-drive system. Both systems work with similar vibrations mechanisms. However they are different in their application and shape [42]. The components of the both systems are briefly discussed in the following two sections.

\subsubsection{Wedge-reed USW}

In the wedge-reed system shown in Figure 2-1 (a), the components are the power supply, transducer, and wedge and reed. These components produce and transmit high frequency 


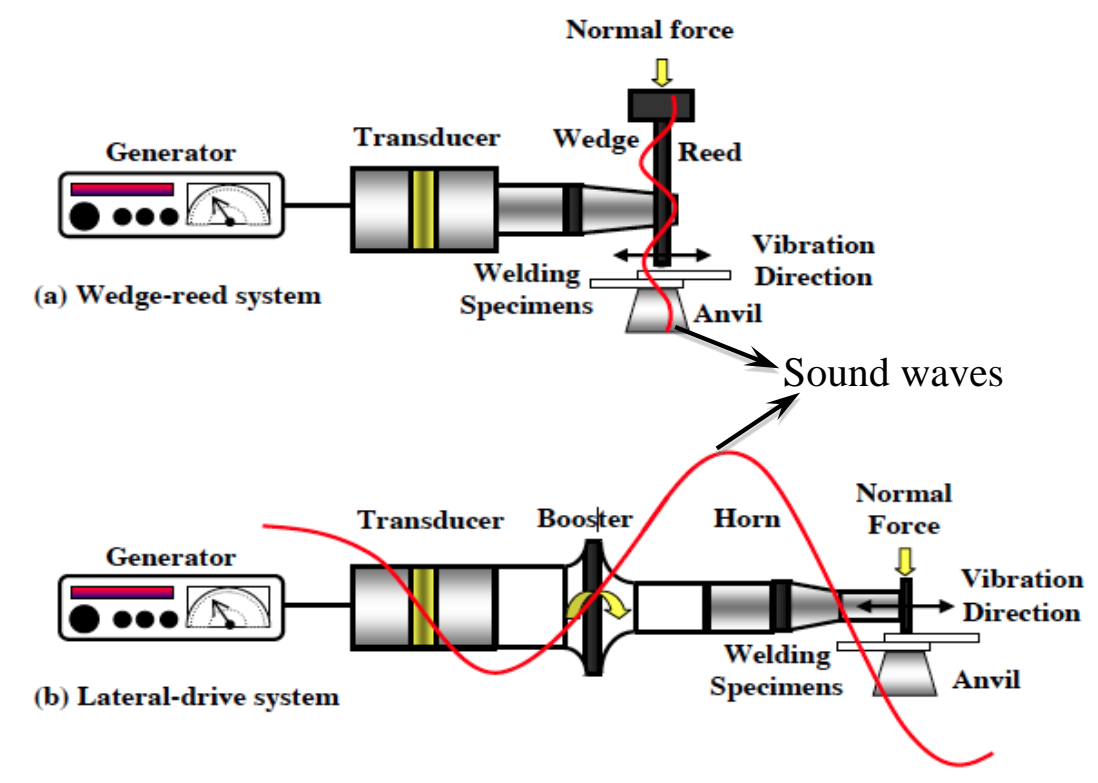

Figure 2-1 USW systems with transverse vibration pattern (a) Wedge-Reed and (b) Lateral-Drive [41]

ultrasonic vibration energy to the work piece that is fastened between the welding tip and the anvil. In this study, dual wedge-reed system was used (no anvil is present, rather it has wedge-reed configuration on both sides). The transducer produces a vibration from the piezoelectric disks. Clamping force is applied along the longitudinal axis of the reed. In this technique, the anvil is often a vibrating member, thus the overall motion across the interface increase [41]. Therefore, wedge-reed system is well known for joining higher-strength alloys. The generation of amplitude in this system is in the range of 10 to $100 \mu \mathrm{m}$ (peak to peak) [43]. In wedge-reed system, as the transducer is straightly brazed or welded to the reed and reed to the welding tip (via threaded screw), the transducer is only capable of driving the welding tip, and it has no control on weld parameters. Hence no resistance is directly received by it. 


\subsubsection{Lateral-drive USW}

This system consists of a transducer, booster and horn with a welding tip, as seen in Figure 2-1(b). The combination of booster and horn sometimes known as 'welding stack,' which is connected together to the transducer. In a similar manner to the wedge-reed system, the transducer generates a vibration from the piezoelectric disks. When a voltage potential is applied across the piezoelectric crystals, a small mechanical displacement occurs. When the voltage is applied at high frequencies, the transducer produces a corresponding highfrequency mechanical displacement. Then, booster modifies mechanical amplitude produced by the transducer. The horn can further modify the amplitude of the vibration to meet the weld requirements [42]. The ultrasonic vibration of the welding horn is in a parallel direction to the specimen surface as shown in the Figure 2.1(b), creating a scrubbing motion at faying surfaces. This leads the friction, causing shear deformation and a flattening of the surface asperities and then subsequent weld formation. Unlike wedge-reed system, this system is suitable for joining thin gauges. This system can allow for measurement of process parameters, such as actual welding energy, mechanical amplitude and clamping force, more accurately than the wedge-reed system. These accurate values help to correlate the weld strength to the different welding conditions [41].

\subsubsection{Principles of USW}

The principles of USW and its range of applications remain not fully understood because most studies predominantly focus on ultrasonic plastic welding and its applications. For 
proper understanding of USW process, the schematic diagram of USW is shown in Figure 2.2. The welding process can be subdivided into four main phases:

(i) A compressive static clamping force is applied by the sonotrode to the workpieces to be joined. The protuberances (bumps) of the two surfaces come in contact, but contaminants and oxides layer still avoid the workpieces from bonding.

(ii) Ones the power supply gives electrical energy, the transducer converts this electrical energy into mechanical energy with the same frequency and transmits mechanical vibration via the wedge and reed to the work pieces. Now, the protuberances in contact undergo a shear deformation (Figure 2.2). At first, these contact areas are localized in correspondence to very few irregularities, which grow in number and size during the further vibration cycles.

(iii) Now, this process breaks the oxide and contaminates layers and brings fresh metalto-metal contact and adhesion can occur (Figure 2.2). The plastic shear deformation produces heat due to the friction generation, which lowering the yield strength of the material while the weld area grows. Thus, the material becomes soft not only due to temperature but also to preferential absorption of acoustic energy at the material dislocations: the ultrasonic wave transferred into the metal lattice, and it absorbed the acoustic energy where the defects present (such as dislocation).

(iv) Finally, after the last welding cycle, area under the welding tips is completely 

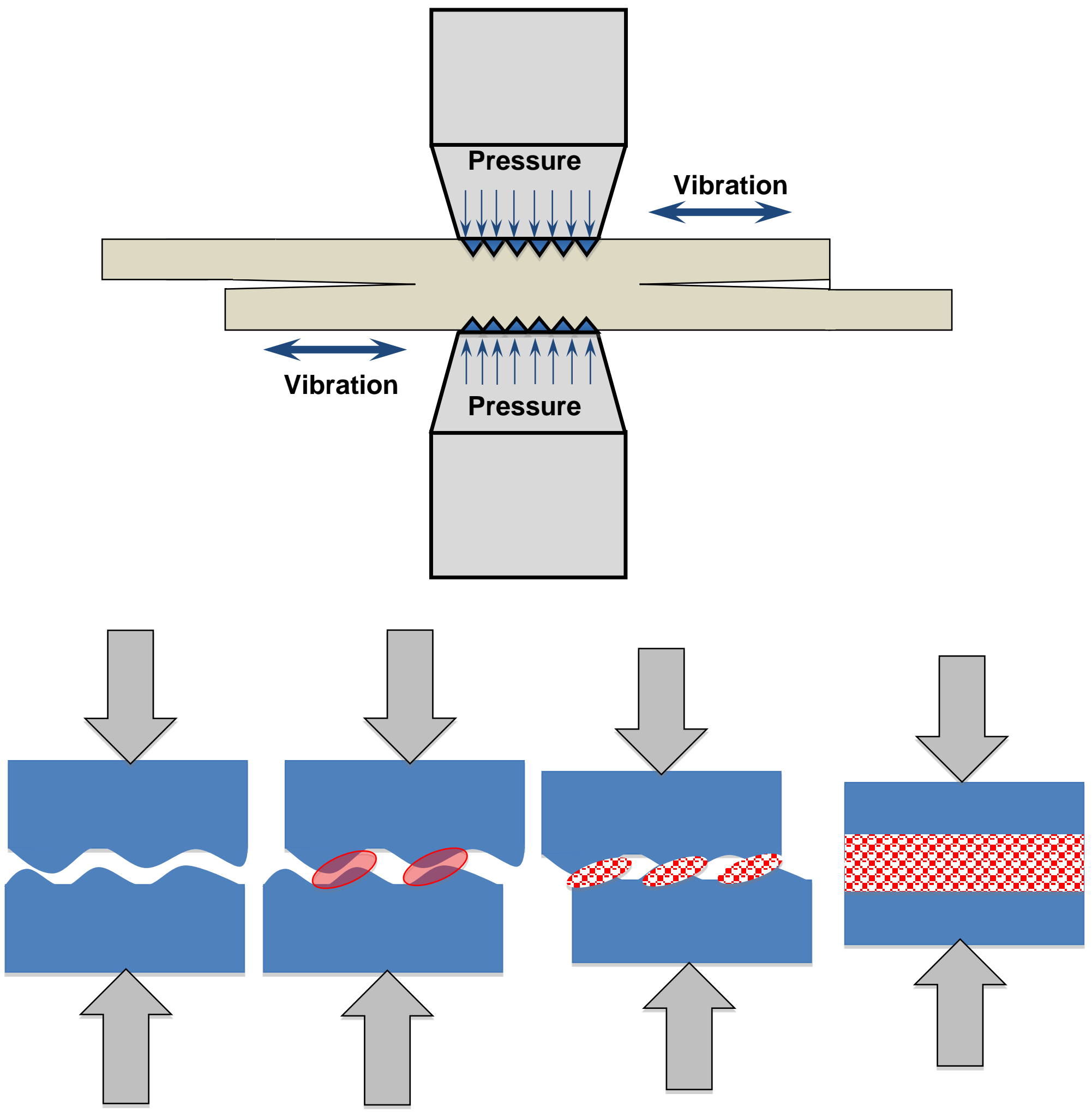

Figure 2.2: Schematic diagram of the dual-reed USW machine with a schematic model of the weld development at interface 
plastically deformed and composed by recrystallized grains. At last, metallic bonding takes place all over the weld zone under the sonotrode. This description of the USW phenomenon provides a microstructural interpretation, which is drawn by DeVries[39].

\subsubsection{Applications of $U S W$}

USW has extensive application in the industry such as automotive, electronics/electrical appliances, medical instruments and packaging. Conceivably the most common application of USW is in the automobile manufacturing industry, where it is used to weld the sheet metal to form a car. Most of the spot-welding, nowadays can be performed by completely automated industrial robots. Recently, the technique has been adopted for lightweight-softer sheet metal welding in aerospace fields. Another potential application of USW is to join LiIron battery cells. Generally, harder metals are more problematic to weld by technique, since more energy is required for achieving optimum weld, which can potentially damage the tool

properties. These harder and thicker metals are welded by the so-called dual wedge-reed USW system, in which two transducers are installed to generate supplementary power (which is used in this study). Environments such as in water or a vacuum are also suitable for this process $[41,44]$. Currently, USW technique is used for alloys of copper, magnesium, aluminum, silver, titanium, nickel, and gold. Along with the spot welding, ultrasonic metal welding systems can be used successfully in different welding applications, such as ring welding, line welding, continuous seam welding $[45,46]$ 


\subsubsection{Advantages of USW}

In the spot welding industries, there are various types of joining techniques available in today's market such as RSW, FSSW, USW. and they all have some drawbacks and some advantages compared to USW. Several challenges are associated with the application of joining lightweight $\mathrm{Al}$ and $\mathrm{Mg}$ alloys in automotive body construction. In addition, because of the high heat input in RSW, it causes dimensional problems and a weakened HAZ. FSSW consumes much time ( 1 to $5 \mathrm{sec})$ compared to the USW $(0.5$ to $1 \mathrm{sec})$. Laser-welding equipment is costly and requires skilled operators. In today's aluminum vehicles, clinching, riveting, adhesive bonding find applications but they come with added complexity and cost or weight penalties [25]. Moreover, it can be seen from Table 2.1 that USW needs very small energy compared to the other joining techniques.

As discussed earlier in section 1.2 and as seen from Table 2.1, USW is more efficient than RSW since it uses only $0.6-1.5 \mathrm{~kJ}$ per weld compared to the RSW (50-100 kJ per weld)

Table 2.1 Comparison of the approximate requirement and weld cycle times for different spot joining process in $1 \mathrm{~mm}$ aluminum sheet [35].

\begin{tabular}{|c|c|c|}
\hline Process & Energy per weld (kJ) & Weld time (s) \\
\hline RSW & $50-100$ & $0.15-0.3$ \\
\hline FSSW & $3-6$ & $1.0-5.0$ \\
\hline USW & $0.6-1.5$ & $0.25-0.6$ \\
\hline
\end{tabular}


and FSSW (3-6 kJ per weld). In FSSW, welding energy is predominantly generated between the faying surfaces (joining line) rather than at the top surface as in FSSW. Moreover, USW has the same advantages as FSSW, in that it is solid-sate friction joining process, but has a shorter welding time with good mechanical performance and no HAZ damage [35]. In comparison with FSSW, USW has been shown to have a shorter weld cycle (typically $<0.5 \mathrm{~s}$ ) and produce high quality joints that are stronger than FSSW when compared on basis of the same nugget area [24, 25]. Besides, the normal FSSW leaves an exit hole after welding [34]. From the point of view of energy consumption, USW is far more advantageous. For example, welding aluminum alloys using a USW process consumes only about $0.3 \mathrm{kWh}$ per 1000 joints $[35,22]$ compared to $20 \mathrm{kWh}$ with RSW, and $2 \mathrm{kWh}$ with FSSW [22]. It is worth to mention that the Ford Motor Company has recently $(2005,2007)$ considered the feasibility of applying USW to Al body assemblies with promising results [24, 25]. Some of the direct and relative costs of joining technologies such as RSW, SPR, GMAW, Adhesive bonding, USW, when applied to aluminum joining, are shown in Table 2.2. Among them, USW offers the

Table 2.2 Joining technology cost comparison [25]

\begin{tabular}{cccc}
\hline Joining methods & $\begin{array}{c}\text { Average } \\
\text { equipment } \\
\text { cost }\end{array}$ & $\begin{array}{c}\text { Relative } \\
\text { energy } \\
\text { consumption }\end{array}$ & $\begin{array}{c}\text { Variable cost per } \\
\text { joint }\end{array}$ \\
\hline RSW (8 mm welding & $\$ 16,000$ & 6 & 5 \\
cap) & $\$ 60,000$ & 1 & 10 \\
SPR (3 mm rivet) & $\$ 12,000$ & 18 & 3 \\
GMAW (25 mm) & $\$ 85,000$ & 1 & 2 \\
Adhesive Bonding & & & 1 \\
$(25 \times 13$ mm) & $\$ 28,000$ & 1 & \\
USW (8x6mm) & &
\end{tabular}


possibility of joining aluminum automotive body structures in an environmentally friendly and cost-efficient manner.

\subsubsection{USW parts and their functions}

As shown in Figure 2.3, USW typically contains five key parts: (1) power supply, (2) piezoelectric transducer (3) wedge (4) reed, and (5) pneumatic cylinder. The power supply delivers electrical energy of the order of 2-3 kW [25] at a high frequency of about $20 \mathrm{kHz}$. A piezoelectric transducer converts this electrical energy into the linear mechanical vibrations of the identical frequency. A wedge intensifies the mechanical vibration amplitude. A reed transfers this vibratory energy into the welding sample, and pneumatic cylinder supplies clamping pressure to bring two metals into the intimate contact. In a dual reed welder, two transducers with two welding tips are used as discussed earlier, which introduces a small amplitude of $\sim 20-40 \mu \mathrm{m}[46]$ under a moderate clamping force. 


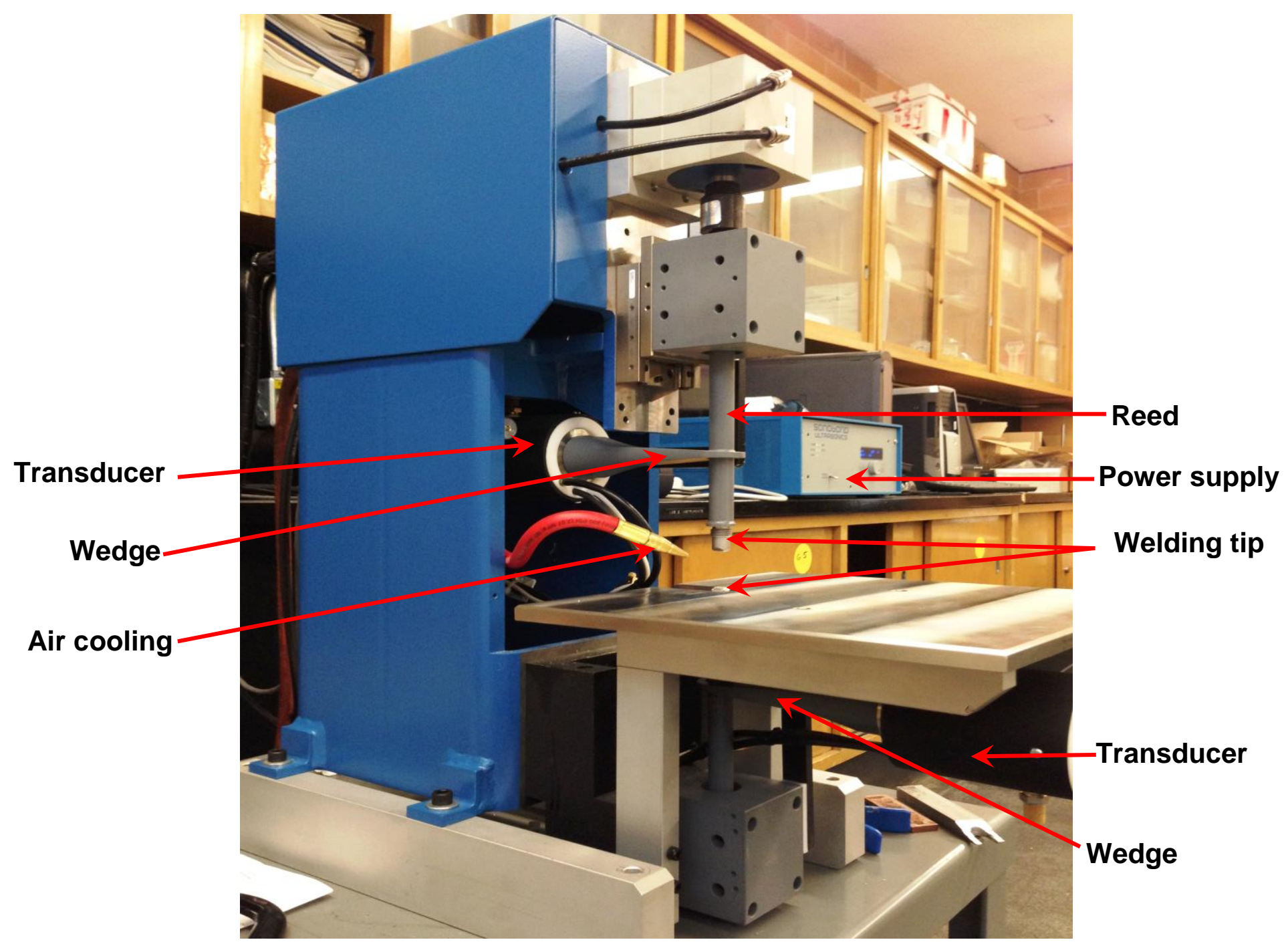

Figure 2.3: USW machine with an image with its different parts

\subsection{Prior works in the area of USW}

Although USW technique found much earlier in 1950, its use was limited to the thin foils and wires within the electronics industry due to the inadequate power availability [28, 22, 46-48]. Therefore, a substantial amount of information is still lacking for the sheet metal joining industry. Except the work published by Jahn et al. [24] and a few other authors [26, 27, 35] there has been little research published on the microstructure and mechanical 
properties of the USWed thicker automotive sheet metal. Elangovan et al. [29] have performed FEM based study to measure the thermal profile during the USW, where they found that temperature reaches as high as $300{ }^{\circ} \mathrm{C}$ within just $0.5 \mathrm{sec}$. In agreement with this study, most research on conventional low energy USW assumes that welding occurs at relatively low temperatures $\left(<300{ }^{\circ} \mathrm{C}\right)[28,46,49]$. They also found that temperature gradient is much higher in a center of the welded joint along with the thickness of the welded samples. However, the actual temperature at the center of the welded joint during the USW process by experimental method is still elusive. Jahn et al. [24] and Bakavos and Prangnell [35] have studied the USWed Al alloy, where they studied the microstructure and mechanical properties of the joints. Bakavos and Prangnell [35] have found that USWed Al alloy can achieve as high as $3.5 \mathrm{kN}$ lap shear fracture load within as short of $0.3 \mathrm{~s}$. Jahn et al. [24] have also worked on the USWed Al alloys and investigated the influence of the anvil geometry and welding energy on microstructures of the welded joints. Since welding and joining of dissimilar metals are bound to involve in the structure of automotive vehicle body, Watanabe et al. [26], have investigated the feasibility of joining of Al-to-steel by USW process. However, so far, significant research is still absent for joining similar and dissimilar ultra lightweight $\mathrm{Mg}$ alloy. Thus, the following sections are briefly discussed on the prior work on the welding of Mg alloy by other welding technologies.

\subsubsection{Welding of similar Mg Alloy}

Because of specific physical and chemical properties of $\mathrm{Mg}$, its welding requires less and precise power input. The solid-state reaction with oxygen forms an oxide layer immediately, 
when it is exposed to the open environment. This oxide layer is thermodynamically stable, which inhibits the joining process $[50,51]$. Mg has very low melting point, but the melting point of the oxide is very high. Therefore, prior to the welding of $\mathrm{Mg}$, the oxide coating from the faying surfaces must be removed. Many of the joining technologies failed to remove the oxide layer while USW has potential to remove in first initial cycles due to higher shear force cause by the high frequency vibration. Further, $\mathrm{Mg}$ is a very active metal with high thermal conductivity, relatively high thermal expansion coefficient [50] and the rate of oxidation increases as the temperature is increased. Thus, welding of $\mathrm{Mg}$ is different from the welding of steels. In the following subsection, the feasibility of joining process of $\mathrm{Mg}$ alloy is briefly discussed.

\subsubsection{Microstructure, grain size and recrystallization}

The microstructure of a material can intensely influence the physical properties of materials such as, hardness, ductility, toughness, strength, wear resistance, corrosion resistance, high/low temperature behavior, and so on. Lang et al. [52] studied the RSW of AZ31 sheet and examined the effects of welding times on the microstructure. Metallographic examination showed that weld nuggets contain two distinct structures. A cellular dendritic structure grows at the edge of the nuggets (Figures 2.4(a) and (b)), and an equiaxed dendritc structure appears in the central portion of the nuggets, as shown in Figures 2.4(c) and (d). The alteration from cellular dendritic to equiaxed dendritc structures in the nuggets is attributed to the changes of solidification conditions. It can be seen from Figure 2.4 that with increasing welding times from one to 16 cycles, the cellular dendritic and equiaxed dendritc 

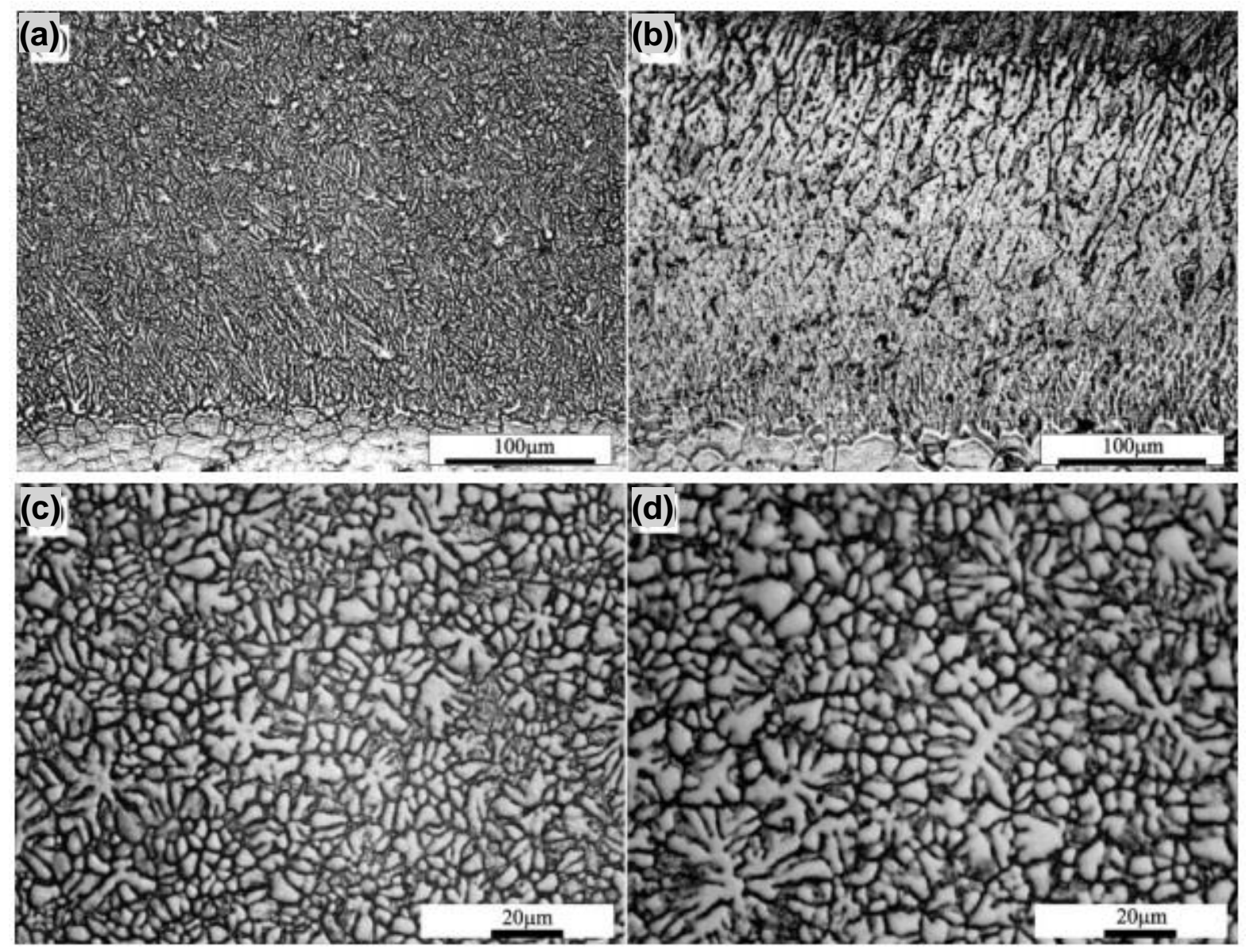

Figure 2.4: Cellular dendritic structures at edge of weld nuggets at different welding times (a) 2 cycle (b) 16 cycles, equiaxed dendritic structures in central portion of weld nuggets at different welding times (c) 2 cycle (d) 16 cycles [52].

crystals in the nuggets become coarser, which has a negative effect on the mechanical properties of the joints.

Naik et al. [53] studied the microstructure of FSLW of AZ31B-H24 Mg alloy, resulted in the formation of distinct regions in the weldmelt, namely the stir zone (SZ), the thermo mechanically affected zone (TMAZ) on both sides of the SZ, and the heat affected zone (HAZ) surrounding between the TMAZ and BM, as shown in Figure 2.5. The as-received 

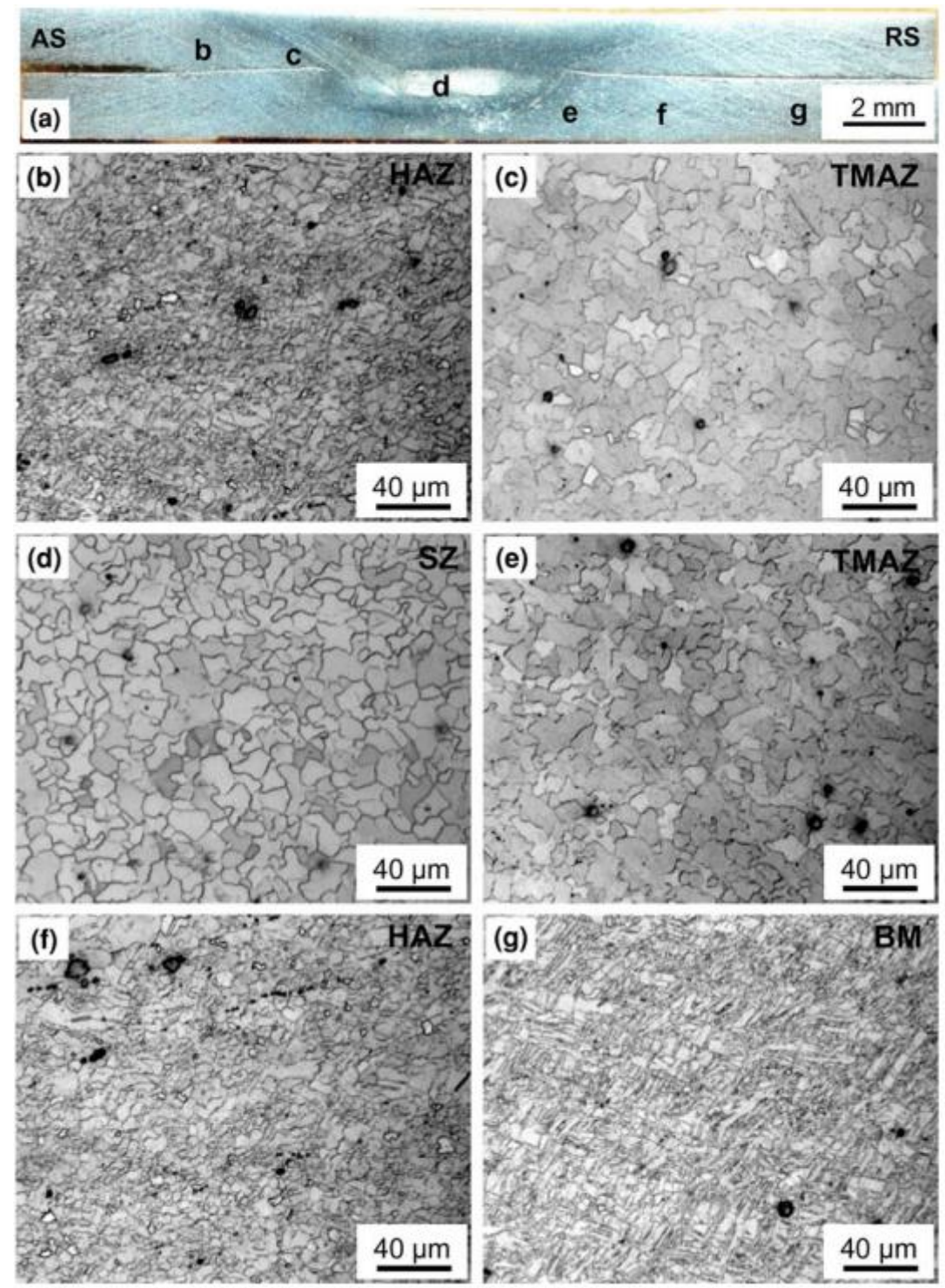

Figure 2.5-(a) Overview of the FSLWed $\mathrm{Mg} / \mathrm{Mg}$ joint obtained at a tool rotational rate of $1000 \mathrm{rpm}$ and $a$ welding speed of $20 \mathrm{~mm} / \mathrm{s}$ with (b) to (g) showing the microstructures in the different regions as indicated in (a) [53].

microstructure of the BM consisted of mainly elongated grains in conjunction with fine equiaxed and recrystallized grains, as shown in Figure 2.5(g). In the SZ and TMAZ (Figures 2.5(c) to (e)), the severe plastic deformation and the elevated temperature resulted in the dynamic recrystallization of the AZ31B-H24 Mg alloy, and the grains became predominately equiaxed in both regions. However, relative to the BM, the grains in the SZ and TMAZ were 
larger in size, indicating the concomitant occurrence of grain coarsening under the welding conditions in the present study. The HAZ microstructure lay in between those of TMAZ and BM. In comparison with the $\mathrm{BM}$, the $\mathrm{HAZ}$ contained a greater fraction of equiaxed grains and a slightly coarser grain size (Figures $2.5(\mathrm{~b})$ and (f)) due to the dominating effect of frictional heating, which resulted in the partial recrystallization of the elongated/deformed grains and the coarsening of the original equiaxed recrystallized grains in the $\mathrm{BM}$ microstructure in the $\mathrm{H} 24$ temper.

Fukumoto et al. [54] worked on linear friction welding of AZ31 alloy. The typical macroscopic view of a friction welded AZ31 is shown in Figure 2.6. They also found different microstructure at different location near to the weld. Since there are no specific regions defined in linear friction welding, distance from the weld interface is taken as a ' $\mathrm{x}$ ' parameter. In other words, $\mathrm{x}=0 \mathrm{~mm}$ indicates the weld interface. Microstructural flow from center to the periphery was observed. It can be seen from Figure 2.6 that BM microstructures gradually changed toward the weld interface. As shown from Figure 2.6, cross sections of weld showed four characteristic regions, that is, fine-grain $(x=0 \mathrm{~mm})$, mixed-grain $(x=2$ $\mathrm{mm})$ and twin regions $(\mathrm{x}=5 \mathrm{~mm})$ and large grain region $(\mathrm{x}=11 \mathrm{~mm})$. Fine grain region is located at the weld interface and consists of new fine grains. They were formed by dynamic recrystallization due to a hot heavy work process. Mixed-grain region adjoins the fine-grain region and consists of small and large grains (Figures 2.6(b) and (c)). Large grains were surrounded by small grains (Figure 2.6(d)), which showed mesh structure. It is believed that the mesh structure was originally from shear band. Recrystallized grains were born at the shear bands as the nucleation site. 

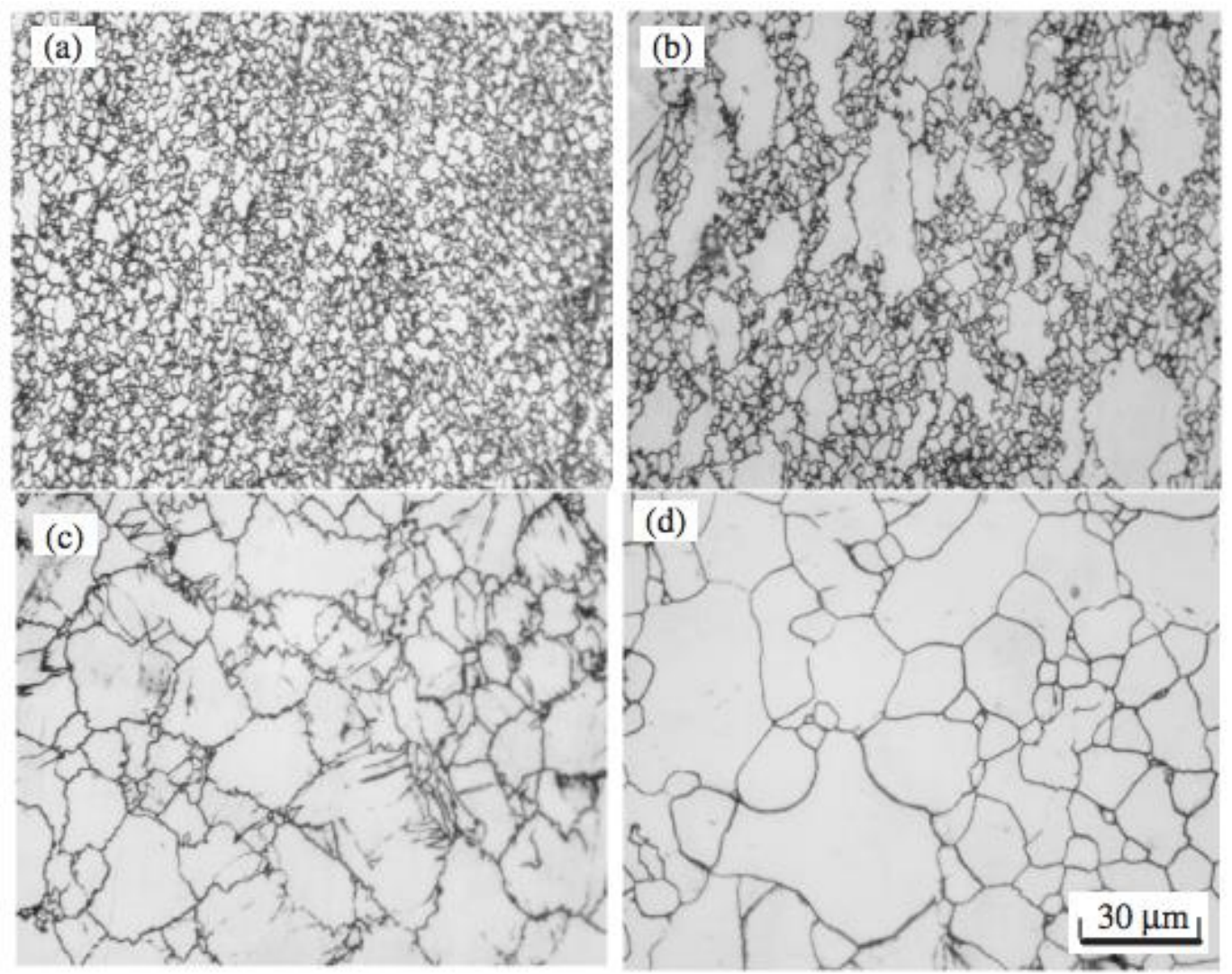

Figure 2.6: Microstructures of friction weld AZ31 near friction weld interface, $t 1=1.5 \mathrm{~s} P 1$ $=50 \mathrm{MPa}$ and $\mathrm{P} 2=100 \mathrm{MPa}$ and $N=40 \mathrm{~s}^{-1}$ (a) $x=0 \mathrm{~mm}$, (b) $x=2 \mathrm{~mm}$, (c) $x=5 \mathrm{~mm}$, (d) $x$ $=11 \mathrm{~mm}$ [54].

From these three studies and other similar works [55-57], it is seen that due to the higher heat generation in fusion welding, and high strain rate of solid state welding severely changes microstructure. Recently, Santella et al. [38] showed that during the USW of AZ31B-H24 Mg alloy-to-steel, the microstructure of AZ31B-H24 experienced dynamic recrystallization and grain growth. Dynamic recrystallization during USW of Al alloy was also reported by Bakavos and Prangnell [35]. However, it is still not known how the USW parameters influence on the microstructure of $\mathrm{Mg}$ alloy, whether it creates the distinct regions like several processes as stated earlier. 
It is well known that the grain refinement is controlled by the strain rate and peak temperature. Generally, average grain size decreases with decreasing working temperature and increasing strain rate $[58,59-61]$. In order to understand the simultaneous effect of both parameters, Zener and Hollomon [62] developed the Zener-Hollomon (Z) parameter which is expressed as,

$$
Z=\dot{\varepsilon} \cdot e^{\frac{Q}{R T}},
$$

where $\dot{\varepsilon}$ is the strain rate, $\mathrm{R}$ is the universal gas constant, $\mathrm{T}$ is the temperature, and $\mathrm{Q}$ is the related activation energy [58,61-62]. This $\mathrm{Z}$ parameter appears to be useful in predicting the resulting grain size and has been widely used to combine the temperature and strain rate $[59$, 60]. There are many studies indicating the dependence of product quality and internal structure performance on Z. Recently, Chang et al. [58] developed the relationship between grain size and Zener-Holloman parameter (Z) of friction stir processed (FSP) AZ31 Mg alloy, but information is missing in this respect for USW of Mg alloy.

\subsubsection{Crystallographic texture of welded Mg alloy}

In addition to the microstructure, mechanical properties are also closely related to crystallographic texture. Many chemical, mechanical and physical properties of crystals depend on their crystalline orientations, and wherever a crystallographic texture exists in polycrystalline materials, directionality or anisotropy of these properties are different [63]. Preferred orientations of the unit cells of the atoms called crystallographic texture, sometimes plays a vital role in many physical and mechanical behaviors. Since the active use of $\mathrm{Mg}$, Titanium, $\mathrm{Zn}$, crystallographic textures in the hexagonal metals have attracted 
significant interest over the years [64]. It is noted that, for hcp crystalline structure, such as Mg alloys, deformation is dominated by the active deformation modes of slip or twinning, and, hence, the development of texture [65]. The large difference in the critical resolved shear stress between the basal and non-basal slip result in significant anisotropic mechanical properties of Mg alloys [66], and hence the textures that develop during USW would have a strong influence on the mechanical properties. A number of researcher have studied the crystallographic texture (at different positions within the work piece, namely SZ, TMAZ, HAZ and BM) of FSP, FSW, RSW. and their influence on the mechanical properties such as compression and tensile behavior [67-71]. In addition, except for the work done by Zhu et al. $[72,73]$ on the texture evolution of the USWed aluminum foil, most research in the area of USW have worked on the microstructure and the tensile properties of the USWed joints. However, studies so far have not led to a fundamental understanding of crystallographic texture formation and their influence on mechanical properties of USW Mg alloys.

\subsubsection{Fatigue behavior of welded Mg alloy}

The process optimization for most of the welding techniques has been mainly determined via the lap shear tensile failure loads. However, the structural applications of these welded joints would inevitably involve dynamic loading in service. In view of the durability and safety of vehicles, the fatigue resistance of the welded joints is of vital importance. In the studies of Chowdhury et al. for FSSW [34], Naik et al. for friction stir lap welding (FSLW) [53] and Chen et al. for friction stir lap welding (FSLW) [74] of an AZ31B-H24 Mg alloy, it was observed that the existence of hooking defects in the friction stir lap welds was a key factor 
that significantly reduced the fatigue strength or life due to the sharp tips causing severe stress concentration and subsequently reduced load-bearing capacity. In the study of Liu et al. [75] for the RSW of AZ31B-H24 Mg alloy, it was reported that the crack initiation occurred due to the combined effect of grain growth and stress concentration in the HAZ, and the presence of Al-rich phases at HAZ grain boundaries. However, it is still elusive how and where the crack initiates and how it propagates up to the failure in the fatigue testing of USWed joints. On the other hand, it is also vital to estimate the fatigue life of welded joints. There are five main methods to predict fatigue life for spot welding, reference strain approach, local strain-based approach, stress intensity approach, structural stress model approach and crack growth approach. Reference and local strain based methods must be used with care because strain changes rapidly near spot-welds. Exact placement of strain gauges, as well as the size of the strain gauges used, which is critical and needs to be standardized. Stress intensity factor methods limits for the sample fails through the main crack. Tran et al. [76] adopted a structured stress model to correlate their experimental fatigue data based on the closed-form and computational stress intensity factor solutions for spot welds in the lapshear and cross-tension specimens. Recently, a similar model has been adopted by the Franklin et al. [77] to predict the fatigue lives of dissimilar USWed Mg-to-steel joints. However, the estimation of fatigue life was not fully in agreement with the experimental results. Thus, kink crack growth approach developed by Newman and Dowling (ND) [78] is needed to apply for USW of Mg joints. Basically, Newman and Dowling (in spot-weld) [78] and Lin et al. (in FSSW) [79], adopted Pook's [80] and Zhang's [81, 82] global stress intensity factor equations, respectively, to develop a model for predicting the fatigue lives of lap-shear work piece based on a crack growth approach with consideration of the local stress 
intensity factors for kinked cracks (i.e., cracks which initiate and propagate from the main crack tip or notch in the lap shear specimens). However, it is unclear if this method can be used to predict the fatigue life of the USWed Mg alloy joints. Therefore, it is necessary to evaluate the fatigue behavior, examine failure mode, and predict the fatigue life of USWed AZ31B-H24 Mg alloy joints. Several fatigue life prediction approaches, including the global stress intensity factor of Pook [80], Zhang [81, 82], Swellam et al. [83] and Lin et al. [79], and kinked fatigue crack growth model as described by Newman and Dowling [78] and Lin et al. [79] are compared and discussed.

\subsubsection{Welding of dissimilar alloys}

There are many structure applications in which two or more metals are required. This brings about the need for joining dissimilar metals. Two factors are really important in the dissimilar welding of metals: intimate contact between two surfaces and IMCs of the welded samples. IMCs are extremely important, since it is closely related to the mechanical properties of the joints. In the following subsection, the feasibility of joining process of $\mathrm{Mg}$ to-Al, Mg-to-steel and Al-to-steel alloys are briefly discussed.

\subsubsection{Welding of dissimilar Mg-to-Al alloys}

There are a number of lightweight materials available for use in automobiles, but $\mathrm{Al}$ stands out for many applications due to its high corrosion resistance, recyclability and compatibility with existing manufacturing techniques. In order to achieve a good combination of the 
properties of $\mathrm{Mg}$ and $\mathrm{Al}$ alloys, owing to their lightweight nature, high strength-to-weight ratio, good castability and workability [84-88], the development of reliable joints between $\mathrm{Mg}$ and $\mathrm{Al}$ alloys is required. Fusion welding of $\mathrm{Al}$ and $\mathrm{Mg}$ alloys always produces large brittle IMCs and coarse grains, voids, porosities, distortions, large defects in a weld region. This implies that conventional fusion welding process cannot be practically useful to join $\mathrm{Mg}$ and $\mathrm{Al}$ alloys. According to Rathod and Kutsuna [36] in situation of dissimilar welds such as Al-to-steel and Al-to-titanium, it is easy to understand solid/liquid state reaction at the faying surfaces of two metals, where only the metal with a lower melting temperature is melted. However, it is problematic to apply this method to Mg-to-Al alloy joint, where difference between their melting points is minor (melting points of $\mathrm{Al}$ is $\sim 660^{\circ} \mathrm{C}$ and $\mathrm{Mg}$ is $\sim 650^{\circ} \mathrm{C}$ ). While joining $\mathrm{Mg}$ and $\mathrm{Al}$ alloys, the main disadvantage is the formation of brittle IMCs of $\mathrm{Al}_{12} \mathrm{Mg}_{17}$ and $\mathrm{Al}_{3} \mathrm{Mg}_{2}$, and this degrade the mechanical properties of the joint [89]. These phases are brittle and lead to fracture, making it difficult to obtain a non-brittle and strong joint between $\mathrm{Mg}$ and $\mathrm{Al}$ alloys. Thus, many studies failed to achieve a sound joint between dissimilar welding of $\mathrm{Mg}$ and $\mathrm{Al}$. A possible approach to improve the joint strength by reducing the tendency for the formation of brittle IMC would be to consider a third material as an interlayer which could interact with both $\mathrm{Mg}$ and $\mathrm{Al}$ from their respective binary diagrams $[90,91]$ Several researchers have used third material (interlayer) between the two faying surface of the weld metals in lap joining $[86,88,89,92,93]$ for increasing the lap shear strength of the weld joint. 


\subsubsection{Welding of dissimilar Mg-to-steel alloys}

Joining Mg alloys to steel is challenging since the difference between the two is substantial physically, chemically and mechanically. According to the phase diagram of $\mathrm{Mg}$ and $\mathrm{Fe}$, there are no intermediate phases in their binary system that would allow chemical reaction to promote bonding. According to Santella et al. [38], below $900^{\circ} \mathrm{C}$, only about $\sim 0.02 \mathrm{wt} \% \mathrm{Mg}$ dissolve in $\mathrm{Fe}$, and this limit rapidly decreases at lower temperatures. Similarly, the maximum solubility of $\mathrm{Fe}$ in $\mathrm{Mg}$ is only $\sim 0.001 \mathrm{wt} \%$ at $640^{\circ} \mathrm{C}$, which further decreases at lower temperatures. Various methods such as laser welding [94], arc welding [95], friction stir welding (FSW) [85], and resistance spot welding [96] have been explored for dissimilar welding of Mg-to-steel. Liu and Zhao [95] studied the dissimilar lap joining of AZ31B Mg alloy-to-stainless steel 304 using laser-GTA and found poor mechanical properties of the joints due to the metallic oxides produced at the Mg-Fe interface. Wei et al. [97] studied the dissimilar lap joining of AZ31 Mg alloy-to-stainless steel SUS302 and found void and micro type defects at the interface. Chen and Nakata [85] reported that FSWed AZ31 Mg alloy-tozinc coated steel joints showed higher fracture loads than the FSWed AZ31 Mg alloy-tobrushed finish steel joints (without $\mathrm{Zn}$ coating), which demonstrates that the presence of a $\mathrm{Zn}$ coating considerably improved the weldability of Mg-to-steel. In most studies, $\mathrm{Zn}$ coated steel has been used for the welding of dissimilar Mg alloys to steel and the joints achieved higher lap shear tensile strength than the joints made with uncoated or bare steel. This study could be extended to some other interlayer, which could interact with both $\mathrm{Mg}$ and $\mathrm{Fe}$ elements. Liu et al. [92] in the hybrid laser-TIG welding of Mg-to-steel have used Sn as an interlayer and showed the improvement of the mechanical properties. 


\subsubsection{Welding of dissimilar Al-to-steel alloys}

Many studies have shown that the major metallurgical problem of joining Al alloys with steel is the formation of brittle IMCs such as $\mathrm{Fe}_{3} \mathrm{Al}, \mathrm{FeAl}, \mathrm{FeAl}_{2}, \mathrm{Fe}_{2} \mathrm{Al}_{5}$ and $\mathrm{FeAl}_{3}$. at the faying interface $[76,83-87]$, which can seriously degrade the mechanical properties of the joint. To minimize the formation of IMCs during the welding, Chen et al. [98] have used nickel foil as an interlayer in-between the faying surfaces of Al and steel and obtained relatively higher tensile lap shear tensile load and lower microhardness compared to joints formed in the absent of nickel foil. Watanabe et al. [37] used $1.2 \mathrm{~mm}$ thick commercially pure $\mathrm{Al}$ sheet $(\mathrm{A} 1050-24 \mathrm{H})$ as an insert metal in the USW of Al-to-mild steel. However, the samples exhibited only about $2 \mathrm{kN}$ maximum lap shear tensile load. Maldonado et al. [99] have investigated the microstructure of friction weld with silver interlayer in-between the $\mathrm{Al}$ and steel and showed the presence of the $\mathrm{Ag}_{3} \mathrm{Al}$ phase along with the brittle Al-Fe IMCs. Haddadi et al. (in USW) [100], Chen et al. (in friction stir welding) [101], Ueda et al. (in RSW) [102] have used $\mathrm{Zn}$ coated steel to minimize the reaction between $\mathrm{Al}$ and Fe during the welding and showed the improvement of the mechanical properties.

\subsection{Summary of the literature review}

Based on the above literature survey, it is clear that many researchers have worked on the different welding techniques such as FSSW, RSW, FSW, USW, GMAW to weld lightweight alloys (Mg and $\mathrm{Al}$ alloys). Along with the optimum parameters for similar and dissimilar 
joints of USW, very few studies have been reported so far on the USW of lightweight alloys in areas listed below:

- For the similar USW of Mg-to-Mg, the information is still lacking on the effect of higher shear strain rate (caused by the simultaneous application of vibration and pressure) and welding temperature on the dynamic recrystallization of grains. There have been no studies so far on a fundamental understanding of the deformation mechanism and dynamic recrystallization and their influence on crystallographic texture formation and mechanical properties of USW Mg alloys. Similarly, studies are lacking on the fatigue properties of USWed joints, in particular on crack initiation and propagation to failure. Furthermore, it is not known if the Newman and Dowling [78] method can be used to predict the fatigue life of the USWed Mg alloy joints.

- For the challenging dissimilar USW of Mg-to-Al, Mg-to-steel and Al-to-steel, so far, it is also not known whether engineering the brittle IMCs via insertion of interlayer during USW would increase the mechanical properties of the joints.

Therefore, the present work on similar and dissimilar USW of lightweight alloys was undertaken to gain a better understanding of the dominant factors determining the joint performance with particular emphasis on the microstructural evolution and mechanical properties. A number of experiments were undertaken to achieve the listed objectives (section 1.3):

- USW of similar Mg alloy on microstructure evolution, grain size measurement, temperature measurement during USW, microhardness profile, crystallographic texture, lap shear tensile and fatigue properties and fatigue life prediction model of 
USW joints

- USW of dissimilar Mg-to-Al, Mg-to-steel and Al-to-steel, respectively, where all dissimilar combinations of USW joints were characterized and the role of $\mathrm{Sn}$ interlayer and $\mathrm{Zn}$ coating in enhancing mechanical strength were also systematically studied. 


\section{CHAPTER 3}

\section{MATERIALS AND EXPERIMENTAL PROCEDURE}

This Chapter provides details about the materials and experimental procedures used in this research. Specifically, details are presented for the equipment and methods that are used for the characterization of the USWed joints.

\subsection{Experimental materials}

The current research involves commercial $2 \mathrm{~mm}$ thick sheet AZ31B-H24 rolled $\mathrm{Mg}$ alloy with the composition listed in Table 3.1. This alloy is selected as model material because it has many structural applications in the automobile and aerospace industries. For dissimilar Mg-to-Al, Mg-to-steel and Al-to-steel joints, $1.5 \mathrm{~mm}$ thick sheet of A15754-O rolled Al alloy with the composition listed in Table 3.2 and $0.8 \mathrm{~mm}$ thick sheet of galvanized HSLA 340 steel with the composition listed in Table 3.3 were selected. For the interlayer studies, a 50 $\mu \mathrm{m}$ thick pure $\mathrm{Sn}$ interlayer was used for placement between the work pieces. The physical properties of materials used in this research are shown in Table 3.4.

Table 3.1: Chemical composition of the AZ31B-H24 Mg alloy (wt \%).

\begin{tabular}{|c|c|c|c|c|c|}
\hline $\mathrm{Al}$ & $\mathrm{Zn}$ & $\mathrm{Mn}$ & $\mathrm{Ni}$ & $\mathrm{Fe}$ & $\mathrm{Mg}$ \\
\hline 3 & 1 & 0.6 & 0.005 & 0.005 & Bal. \\
\hline
\end{tabular}


Table 3.2: Chemical composition of the A15754-O Al alloy (wt \%).

\begin{tabular}{|c|c|c|c|c|}
\hline $\mathrm{Mg}$ & $\mathrm{Mn}$ & $\mathrm{Sc}$ & $\mathrm{Zr}$ & $\mathrm{Al}$ \\
\hline 3.42 & 0.63 & 0.23 & 0.22 & Bal. \\
\hline
\end{tabular}

Table 3.3: Chemical composition of the HSLA 340 steel (wt \%).

\begin{tabular}{|c|c|c|c|c|c|c|c|c|c|c|c|c|}
\hline $\mathrm{C}$ & $\mathrm{Si}$ & $\mathrm{Mn}$ & $\mathrm{P}$ & $\mathrm{S}$ & $\mathrm{Ni}$ & $\mathrm{Cr}$ & $\mathrm{Mo}$ & $\mathrm{Cu}$ & $\mathrm{Al}$ & $\mathrm{Ti}$ & $\mathrm{Nb}$ & $\mathrm{Fe}$ \\
\hline 0.06 & 0.227 & 0.624 & 0.006 & 0.004 & 0.013 & 0.041 & 0.005 & 0.044 & 0.039 & 0.003 & 0.021 & $\mathrm{Bal}$. \\
\hline
\end{tabular}

Table 3.4: Physical properties of the material being used in this experiment*

\begin{tabular}{|c|c|c|c|c|c|c|c|}
\hline Materials & $\begin{array}{c}\text { Density, } \\
\mathrm{g} / \mathrm{cm}^{3}\end{array}$ & $\begin{array}{c}\text { Modulus of } \\
\text { elasticity, } \\
\mathrm{GPa}\end{array}$ & $\begin{array}{c}\text { Yield strength, } \\
\mathrm{MPa}\end{array}$ & $\begin{array}{c}\text { Ultimate tensile } \\
\text { Strength, MPa }\end{array}$ & $\begin{array}{c}\text { Elongation, \% } \\
\begin{array}{c}\text { Thermal } \\
\text { conductivity, } \\
\mathrm{W} / \mathrm{m} . \mathrm{K}\end{array}\end{array}$ & $\begin{array}{c}\text { Melting } \\
\text { point, }{ }^{\circ} \mathrm{C}\end{array}$ \\
\hline $\begin{array}{c}\text { AZ31B- } \\
\mathrm{H} 24\end{array}$ & 1.77 & 45 & 220 & 290 & 15 & 96 & $605-630$ \\
\hline $\begin{array}{c}\text { Al5754- } \\
\text { O }\end{array}$ & 2.71 & 71 & 96 & 220 & 26 & 125 & $640-660$ \\
\hline $\begin{array}{c}\text { HSLA } \\
340 \text { steel }\end{array}$ & 7.87 & 205 & 370 & 445 & 26.7 & 43 & $1500-$ \\
\end{tabular}

*Data taken from (www.matweb.com)

\subsection{Processing parameters of USW}

The USW system employed was a dual wedge-reed, Sonobond-MH2016 machine. The samples were welded at energy levels from 500 to $3000 \mathrm{~J}$ at a constant power setting of 2000 $\mathrm{W}$, an impedance setting of 8 on the machine, and a pressure of $0.414 \mathrm{MPa}$. The specimens were $80 \mathrm{~mm}$ long and $15 \mathrm{~mm}$ wide as shown in Figure 3.1. To remove the oxide layer on the 


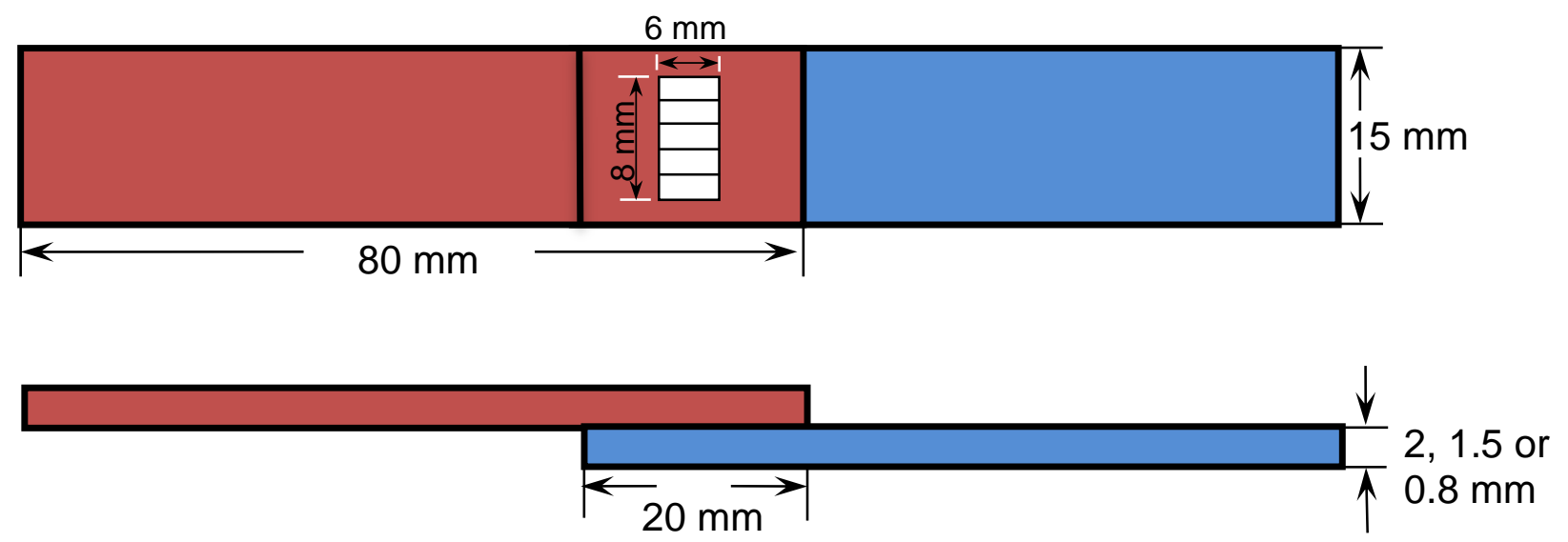

Figure 3.1: Schematic diagram of the lap joint

faying surfaces, the specimen were ground using 120 emery papers perpendicular to the ultrasonic vibration direction, and then washed using acetone and dried before welding.

\subsection{Welding tip}

Ultrasonic vibration is applied to the welding tip. When clamping force is applied to the tip, the texture of tool grips the weld specimens, which effectively isolates the relative motion to the joint interface. A sound joint could be formed with the proper welding tip's texture and geometry. Numerous welding tips available in the market, depending on

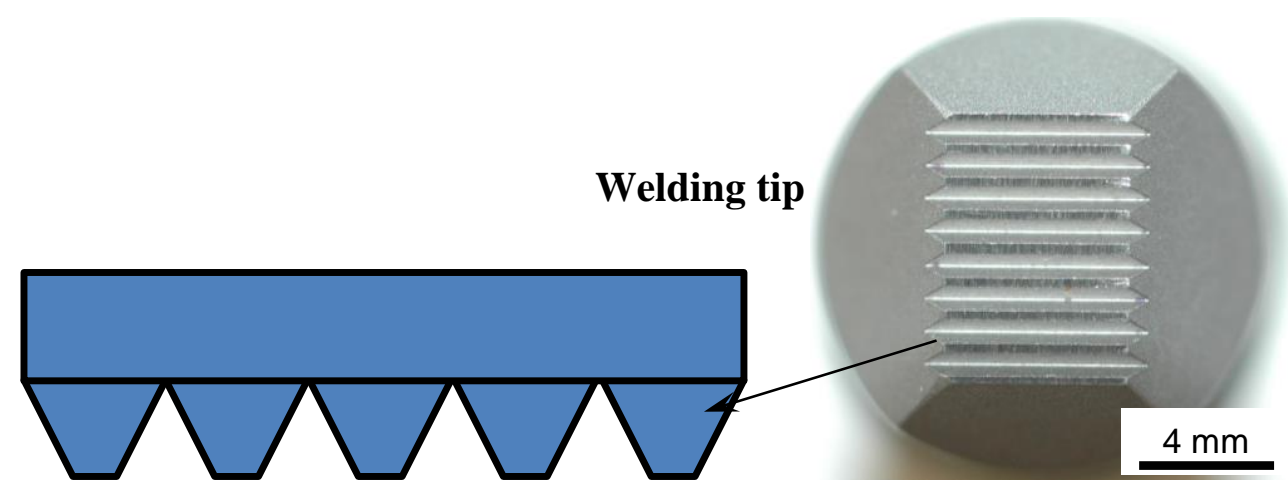

Figure 3.2: Images of the welding tip with its knurl pattern 
the texture and geometry. The contact area of the flat tip was much greater than with the spherical tips, and therefore a lower applied power density was needed to apply. Thus, in this

study, flat standard serrated (kurnl pattern) tip was used in all experiments as shown in the Figure 3.2.

\subsection{Metallography}

Cross-section samples for optical microscopy (OM) and JSM-6380LV Scanning electron microscope (SEM) were prepared from the welded lap joint coupons by sectioning through the weld region parallel to the vibration direction of USW. The mounted samples were manually ground with $\mathrm{SiC}$ papers up to a grit of \#1200 with water as the lubricant and then polished using 6,3 and $1 \mu \mathrm{m}$ diamond paste followed by the $0.05 \mu \mathrm{m}$ MASTERPREP solutions. The polishing lubricant for the diamond paste was a mixture of rust inhibiting solution and distilled water (10\% solution by volume). Ethanol was used as a cleaning agent during the polishing stages. To reveal the microstructure of USWed $\mathrm{Mg}$, etching was done using a solution of ethanol $(10 \mathrm{ml})$, picric acid $(5 \mathrm{~g})$, acetic acid $(5 \mathrm{ml})$ and water $(10 \mathrm{ml})$.

\subsection{Quantitative image analysis}

Microscopic images were taken using an OM and SEM. Image analysis was performed using routine Clemex software to obtain the grain size. The Clemex image analysis system was composed of Clemex CMT software adaptable to ASTM standards, a Nikon optical microscope $(10 \times$ eye piece, five different object lenses with magnifications of $5 \times, 10 \times, 20 \times$, 
$40 \times$, and $100 \times$ ), a high-resolution digital camera, and a high performance computer to carry out the detailed analysis. Five images were taken at the center of the weld to calculate the average grain size of each welded sample. Point and line analysis was conducted on the welded joint using SEM, equipped with Oxford EDS.

\subsection{X-ray diffraction for phase identification}

For USWed Mg-to-Mg joints, XRD (machine manufactured by Panalytical )was carried out on top surfaces of BM, HAZ (5 mm away from the NZ) and NZ, fracture surface (FS). And for USWed dissimilar joints, XRD was performed on both matching fracture surfaces of welded joints after tensile shear tests, using $\mathrm{CuK} \alpha$ radiation at $45 \mathrm{kV}$ and $40 \mathrm{~mA}$. The diffraction angle $(2 \theta)$ of the incident $\mathrm{X}$-ray beam varied from $20^{\circ}$ to $100^{\circ}$ with a step size of $0.05^{\circ}$ and a dwell time of $2 \mathrm{~s}$ per step.

\subsection{Temperature profile during USW}

The temperature profile during USW was measured using a K-type thermocouple ( $\mathrm{Ni}-\mathrm{Cr}$ vs $\mathrm{Ni}-\mathrm{Al}$ ). In order to eliminate the effect on the welding process, a groove was made on the lower piece of each pair of weld samples. The thermocouple was laid into the groove and parallel to the vibration direction as shown in the Figure 3.3. The thermocouple was coupled with a data acquisition instrument for collecting the temperature data during the USW. 


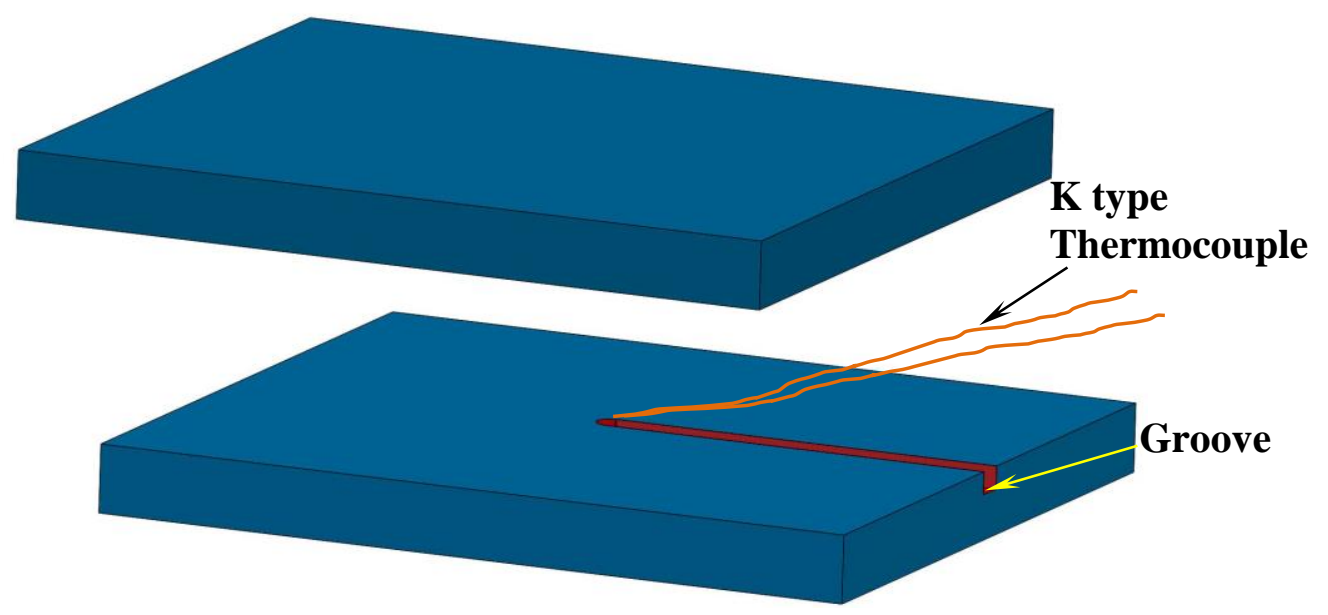

Figure 3.3: Inserted thermocouple in the groove of the sheet for temperature measurement

\subsection{Crystallographic texture measurement}

Crystallographic texture distribution of USWed samples was be measured by a Panalytical XRD via micro-diffraction with an incident beam of $300 \mu \mathrm{m}$ in diameter using $\mathrm{CuK} \alpha$ radiation (wavelength $\lambda=0.15406 \mathrm{~nm}$ ) at $45 \mathrm{kV}$ and $40 \mathrm{~mA}$ with a sample tilt angle ranging from 0 to $70^{\circ}$ with step size of $5^{\circ}$ and time per step $3 \mathrm{~s}$. The pole figures were measured and analyzed by 'X-pert texture' software. The results were represented as (0002), (10ī0), and (1011) color-scale intensity pole figures. Coordinate axes selected for the pole figures were the rolling direction (RD), transverse direction (TD), and normal direction (ND) of the plate.

\subsection{Microhardness test}

A computerized Buehler microhardness testing machine was used for the micro indentation hardness tests at the center of the welded joint in USW of similar Mg alloy study, using a 
load of $100 \mathrm{~g}$ for $15 \mathrm{~s}$. The average of ten indentations was used for accuracy in microhardness test of USWed similar Mg alloys. In dissimilar welding study, as shown in Figure 3.4, the microhardness indentations were made diagonally across the welded joints using a load of $100 \mathrm{~g}$ for $15 \mathrm{~s}$ except for the thin IMC interlayer (around 10 to $30 \mu \mathrm{m}$ ), where a load of $10 \mathrm{~g}$ was used for $15 \mathrm{~s}$. The mean of three indentations along the IMC interlayer was taken for accuracy with the low indentation load of $10 \mathrm{~g}$.

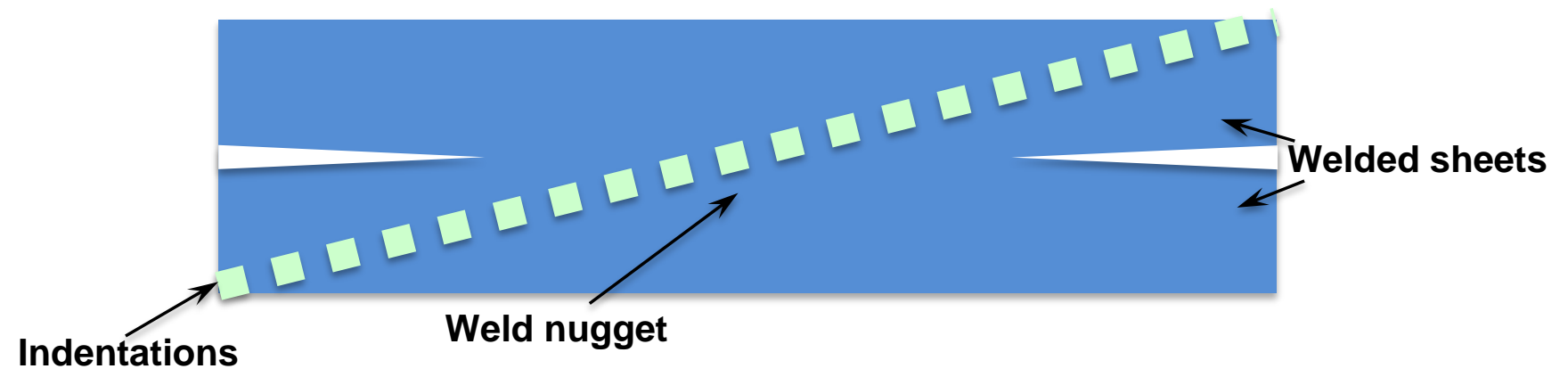

Figure 3.4: Microhardness indentation made diagonally across the welded joints

\subsection{Lap shear tensile test}

To evaluate the mechanical strength of the joints and establish the optimum welding conditions, tensile shear tests of the welds (samples dimensions is shown in Figure 3.1) were conducted to measure the lap-shear failure load using a fully computerized United testing machine with a constant crosshead speed of $1 \mathrm{~mm} \mathrm{~min}^{-1}$ in air at room temperature. As shown in the Figure 3.5, in the tensile lap shear testing, restraining shims or spacers were used to minimize rotation of the joints and maintain the shear loading as long as possible. 


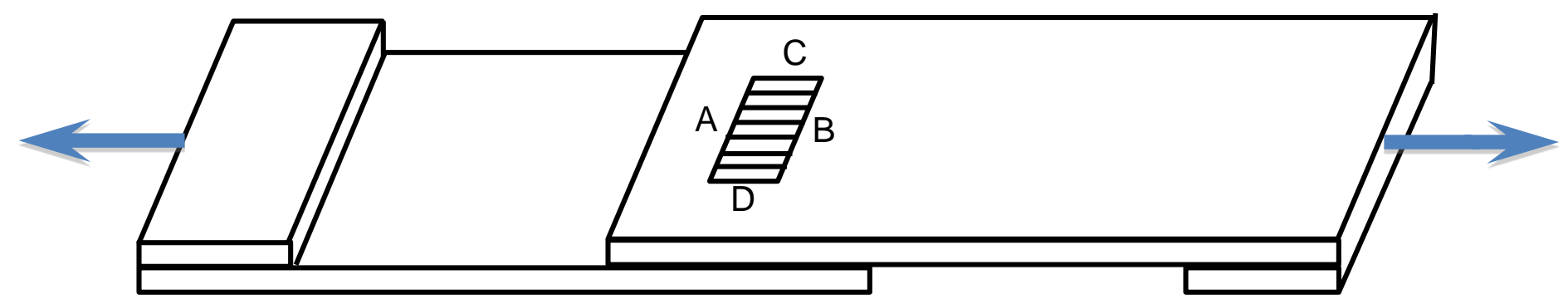

Figure 3.5: A 3D view of the lap shear tensile and fatigue test specimen.

\subsection{Fatigue Test}

Fatigue tests were conducted on the welded joint (Figures 3.1 and 3.5) using an Instron 8801 servo-hydraulic testing system (fully computerized) under load control at different maximum loads ranging from $3.5 \mathrm{kN}$ to $0.5 \mathrm{kN}$. A load ratio of $\mathrm{R}\left(\mathrm{P}_{\min } / \mathrm{P}_{\max }\right)=0.2$, sinusoidal waveform and frequency of $50 \mathrm{~Hz}$ were used in all the tests. Two samples were tested at each chosen load level. The fracture surfaces of the welded joints after fatigue tests were examined via a SEM and EDS. 


\section{CHAPTER 4}

\section{ULTRASONIC SPOT WELDING OF MAGNESIUM ALLOY*}

In this Chapter, USW of similar Mg-to-Mg lap joints is discussed. Microstructure changes, crystallographic texture, tensile, fatigue and their fractures at different welding energy inputs were systematically studied. The influence of the welding energy input on the strain rate and temperature generated during USW was evaluated and modeled. A life prediction model for lap joints developed to estimate the fatigue lives of the USWed Mg alloy joints.

\subsection{Microstructure and grain size measurement}

Microstructure characterization was focused on the nugget zone (NZ) at the center of the weld samples. Figure 4.1 depicts the typical grain structure of the AZ31-H24 base metal (BM) and $500 \mathrm{~J}, 1000 \mathrm{~J}, 1500 \mathrm{~J}, 2000 \mathrm{~J}, 2500 \mathrm{~J}$ and $3000 \mathrm{~J}$ welded samples. The mean grain size across all welded samples was coarser than the mean grain size of the as-received samples $(5.36 \mu \mathrm{m})$. It can be seen that the grain size increases with welding energy from 6.36 to $9.57 \mu \mathrm{m}$ owing to an increase in temperature as will be shown later (Sec. 4.2.2) and the effect of the dynamic recrystallization. Dynamic recrystallization of $\mathrm{Mg}$ alloy (HCP crystal structure) during high temperature deformation can be attributed by the lack of easily activated slip systems in contrast to Al alloys, which possess FCC crystal structure [103].

\footnotetext{
* This chapter is based on the following publications of the author:

V.K. Patel, S.D. Bhole, D.L. Chen: 'Influence of ultrasonic spot welding on microstructure in a magnesium alloy', Scripta Materialia, 2011, Vol 65, 911-914.

V.K. Patel, S.D. Bhole, D.L. Chen: 'Ultrasonic spot welded AZ31 magnesium alloy: Microstructure, texture and lap shear strength', Materials Science \& Engineering: A, 2013, Vol 569, 78-85.

V.K. Patel, S.D. Bhole, D.L. Chen: 'Fatigue life estimation of ultrasonic spot welded Mg alloy joints', Materials and Design, 2014, Vol 62, 124-132.
} 
Another reason is because, unlike $\mathrm{Al}, \mathrm{Mg}$ has low stacking fault energy, in the range of 60$78 \mathrm{MJ} / \mathrm{m}^{2}$ for pure $\mathrm{Mg}$ [103]. Additional possible factor is the high grain boundary diffusion rate of $\mathrm{Mg}$ compared to $\mathrm{Al}$ [58]. These three factors explain why dynamic recrystallization can take place in AZ31-H24 alloy during welding. Dynamic recrystallization during USW was also reported by Bakavos and Prangnell [35] and Allameh et al. [104]. A large shear strain rate is introduced by the high frequency vibration and high temperatures developed from friction and plastic deformation during USW; combination of both factors generate dynamic recrystallization and grain growth in the weld.

In addition, as energy inputs increase from $500 \mathrm{~J}$ to $3000 \mathrm{~J}$, aspect ratio of the grains also increases from 1.54 to 1.63. During USW of sheet metal, normal and shear forces act on the parts to be welded and the weld interface. These normal and shear forces are the result of clamping pressure and the ultrasonic vibrations of the tool, respectively, which transferred onto the parts to be welded. It is believed that the reason behind the increasing aspect ratio is

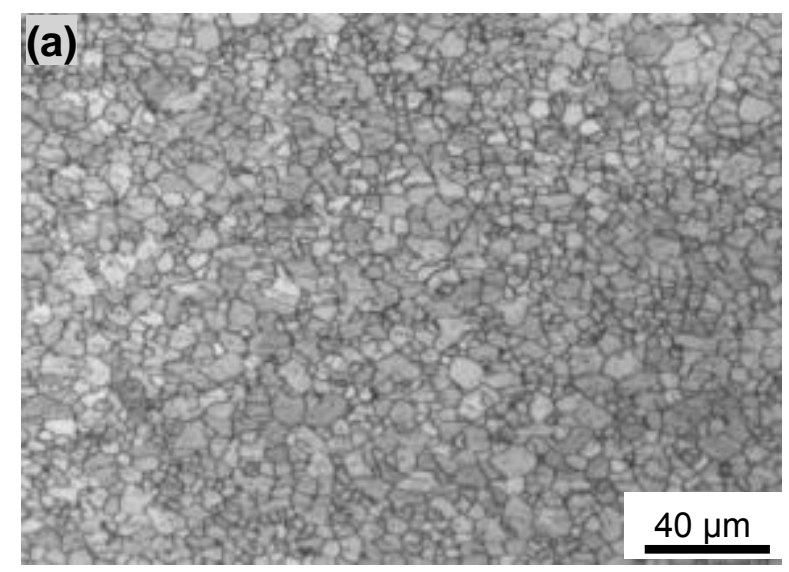

Figure 4.1: Optical micrograph of AZ31 BM and welded samples at different energy levels, (a) AZ31 BM, (b) $500 \mathrm{~J}$, (c) $1000 \mathrm{~J}$, (d) $1500 \mathrm{~J}$ (e) $2000 \mathrm{~J}$ (f) $2500 \mathrm{~J}$ and (g) $3000 \mathrm{~J}$ welding energy inputs. 

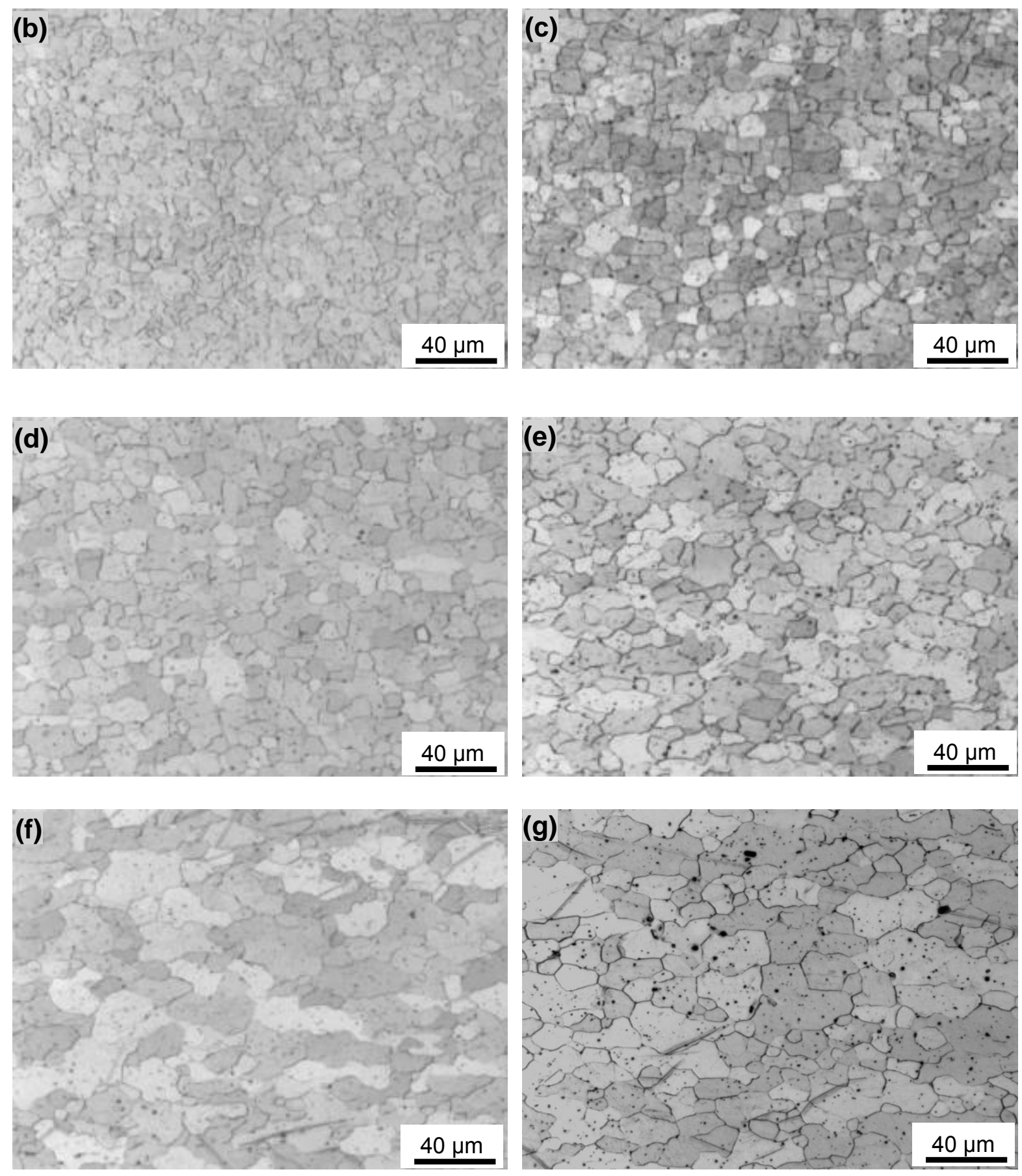

Figure 4.1 (cont'd): Optical micrograph of AZ31 BM and welded samples at different energy levels, (a) AZ31 BM, (b) $500 \mathrm{~J}$, (c) $1000 \mathrm{~J}$, (d) $1500 \mathrm{~J}$ (e) $2000 \mathrm{~J}$ (f) $2500 \mathrm{~J}$ and (g) $3000 \mathrm{~J}$ welding energy inputs. 
the higher energy input, which creates higher shear force resulting in elongated grains.

Grains with large aspect ratio, dispersed along the flow lines, dominate the deformation microstructure. Similar microstructure was also observed by Jahn et al. [24].

\subsection{Relationship between Zener-Hollomon parameter and grain size}

As mention earlier in the literature review (section 2.2.1.1), Zener-Hollomon (Z) parameter appears to be useful in predicting the resulting grain size and has been widely used to combine the temperature and strain rate $[59,60]$. There are many studies indicating the dependence of product quality and internal structure performance on $Z$. The effect of grain refinement is controlled by the strain rate and the peak temperature; information is lacking in this respect for USW of AZ31B-H24 alloy. An objective of this chapter was to investigate the relationship between grain size and the Zener-Hollomon parameter. From Eqn. 2.1, in order to develop this relationship, shear strain rate and thermal profile of the USW of Mg alloy need to be identified. Thus, in following sub-sections, shear strain rate is calculated and thermal profile is measured.

\subsubsection{Shear strain rate calculation}

Using a frequency of $20 \mathrm{kHz}$ in USW, very high strain rates and strains can develop during shearing of the small (micron-sized) asperities between the welding samples. Gunduz et al. showed that USW produces plastic strains in the materials being joined at very high strain rates $\left(10^{3} \mathrm{~s}^{-1}\right)$ in a fraction of a second [105]. The strain rate estimated by Shriraman et al. in 
USW was $10^{4}-10^{5} \mathrm{~s}^{-1}[106]$. In this study, shear strain rate $\dot{\gamma}$ was calculated as Bates et al.[107] estimated in vibration welding as,

$$
\dot{\gamma}=\frac{2 f A}{h_{o}},
$$

where, $f$ is the frequency, $h_{0}$ is the thickness of the weld nugget between the plates and $A$ is the amplitude of USW machine. The amplitude generated using USW ranges from 30-60 $\mu \mathrm{m}$ $[26,35,37,108,109]$ and the relationship between energy input and amplitude is given by $P \propto A^{2}[110]$. As a first approximation, $P=A^{2}$ was used to calculate the amplitude (Table 4.1). The strain rates in the present experiments calculated using Eqn. 4.1 range from $478.3 \mathrm{~s}$ ${ }^{1}$ to $1022.2 \mathrm{~s}^{-1}$ for energy inputs from $500 \mathrm{~J}$ to $2500 \mathrm{~J}$, respectively.

\subsubsection{Temperature measurement}

During USW, heat is generated at the weld interface and the surrounding area as well as at the sonotrode (welding tip) surface owing to plastic deformation and friction. Plastic deformation in the specimen is caused by two different phenomena, namely, surface friction dissipation and volume ultrasonic softening effects. Temperature plays an important role in bond strength in the initial period [29]. There is limited published data on thermal measurements in USW because of the small size of the welds and rapid weld times [35]. Results from temperature measurements of the USW, using thermocouples that are placed at the center of the weld, are depicted in Figure 4.2(a) and (b). It can be seen from Figure 4.2(a) that the temperature rises very rapidly, in less than $0.5 \mathrm{~s}$, to the peak value, and then decreases much for different energy levels. Theoretically, rate of increase curve of all welding energies' temperature measurement should align top of each other. However, due to 

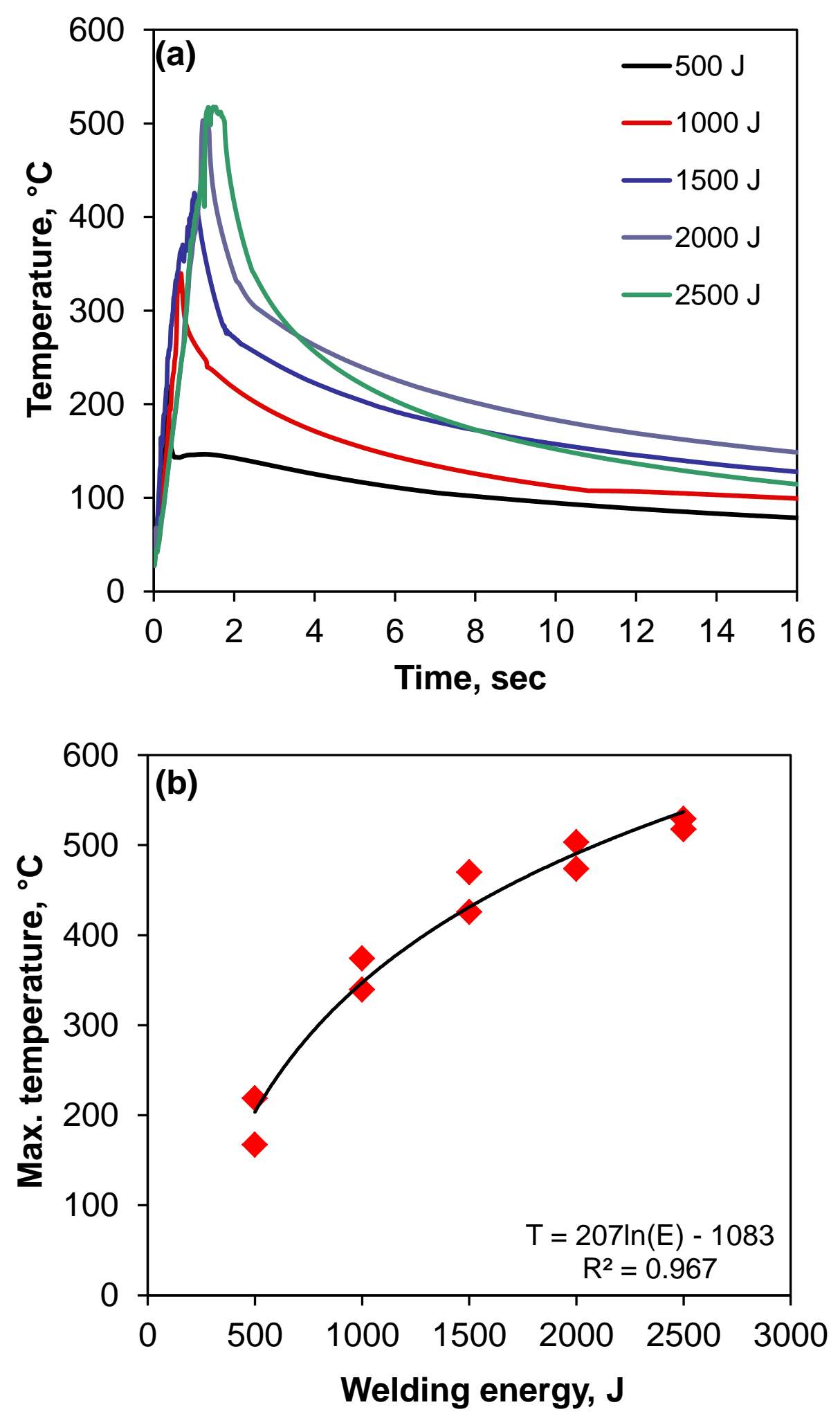

Figure 4.2: (a): Temperature at the center of the weld recorded during USW with different energy levels, (b) peak temperatures at the center of the weld recorded during USW with different energy levels. 
the experimental error and thermocouple sensitivity slope of curve is bit scattered. It can be seen that higher energy input results in higher temperature at the center of the weld line. The temperature results are also in agreement with model predictions [29] and the experimental results of Bakavos and Prangnell [35]. For temperature measurement accuracy, two USW samples' temperature profile were recorded as shown in the Figure 4.2(b), which shows the relationship between peak temperatures at the center of the weld recorded during USW with different energy levels.

\subsubsection{Zener-Hollomon parameter analysis and calculation}

Table 4.1 shows the calculated Zener-Hollomon parameter for different energy inputs using Eqn. 2.1 and Eqn. 4.1, where the activation energy $Q$ for $\mathrm{Mg}$ lattice diffusion is about 135 $\mathrm{kJ} / \mathrm{mol}$ during the dynamic recrystallization $[58,60]$, the value of universal gas constant is 8.314 J/mol K and welding temperature was calculated as shown in Figure 4.2(a, b).

Table 4.1: A summary of measured grain size, calculated peak temperature, strain rate, Zener-Hollomon parameter for USW joints.

\begin{tabular}{|c|c|c|c|c|c|c|}
\hline $\begin{array}{c}\text { Energy } \\
(E), \mathrm{J}\end{array}$ & $\begin{array}{c}\text { Temp. } \\
(T), \mathrm{K}\end{array}$ & $\begin{array}{c}\text { Amplitude } \\
(A), \mu \mathrm{m}\end{array}$ & $\begin{array}{c}\text { Melt layer } \\
\text { thickness } \\
\left(h_{0}\right), \mu \mathrm{m}\end{array}$ & $\begin{array}{c}\text { Shear strain } \\
\text { rate } \\
(\dot{\gamma}), \mathrm{s}^{-1}\end{array}$ & $\begin{array}{c}\text { Zener- } \\
\text { Holloman } \\
\text { arameter }(Z), \mathrm{s}^{-1}\end{array}$ & $\begin{array}{c}\text { Grain size } \\
(D), \mu \mathrm{m}\end{array}$ \\
\hline 500 & 466.13 & 44.72 & 3740 & 478.30 & $6.43 \times 10^{17}$ & 6.36 \\
\hline 1000 & 629.94 & 44.72 & 3420 & 523.06 & $8.19 \times 10^{13}$ & 7.82 \\
\hline 1500 & 720.73 & 44.72 & 2560 & 698.77 & $4.25 \times 10^{12}$ & 8.77 \\
\hline 2000 & 761.40 & 44.72 & 2370 & 754.79 & $1.38 \times 10^{12}$ & 9.07 \\
\hline 2500 & 796.35 & 44.72 & 1750 & 1022.20 & $7.33 \times 10^{11}$ & 9.57 \\
\hline
\end{tabular}

* Gas constant (R), $8.314 \mathrm{~J} / \mathrm{mol} . \mathrm{K}$

* Activation Energy $(Q), 135000 \mathrm{~J} / \mathrm{mol}$

* Frequency(f), $20000 \mathrm{~Hz}$

* Power, $2000 \mathrm{~W}$ 
The relationship between the Zener-Hollomon parameter $(Z)$ and the dynamic recrystallized grain size $(D)$ for different processing techniques under various material conditions is shown in Table 4.2 and has been characterized as,

$$
\ln D=\alpha-\beta \ln Z,
$$

where $D$ is the dynamically recrystallized grain size, $Z$ is the Zener-Hollomon parameter, $\alpha$ and $\beta$ are constants [58, 59]. Figure 4.3 shows the Z-D relationship for the present investigation, which can be expressed by,

$$
\ln D=3-0.03 \ln Z \text {. }
$$

The previous studies on compression test, tensile test and FSP show that the average recrystallized grain size increases with increasing working temperature and decreasing strain rate $[58,59]$. However, in this investigation both temperature and strain rate increase dramatically as the energy input is increased from $500 \mathrm{~J}$ to $2500 \mathrm{~J}$, resulting in an increase in grain size due to the effect of the temperature overwhelming the opposing effect of the strain rate. It should be noted that the dynamic recrystallized grains developed at higher $Z$ values are much smaller than those generated at lower $Z$ values (Figure 4.3). It can be seen from Table 4.2 that the value of $\beta$ of the present experiment is lower than those of other processing techniques due to higher strain rate generated in USW. It is interesting to note that the relationship between Zener-Hollomon parameter and dynamic recrystallized grain size for USW follows similar trends to those in FSW, tension test, and compression test. Therefore, it can be concluded that temperature and strain rate are both responsible for controlling the dynamically recrystallized grain size in USW. 


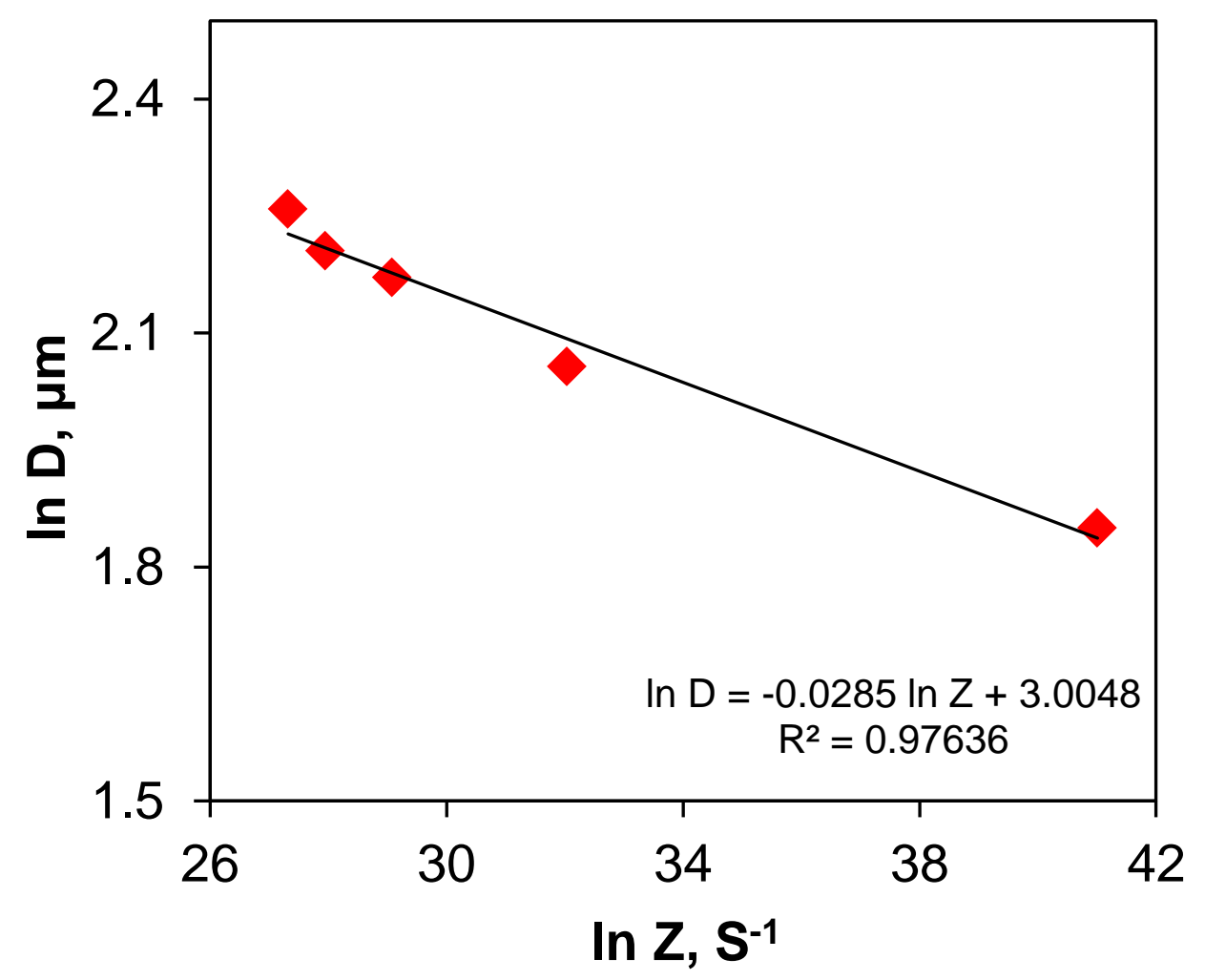

Figure 4.3: Relationship between grain size and Zener-Hollomon parameter.

Table 4.2: Summary of parameters $\alpha$ and $\beta$ between grain size and Zener-Hollomon parameter for different processing.

\begin{tabular}{|c|c|c|c|c|c|c|}
\hline Materials & Processing & Temperature, ${ }^{\circ} \mathrm{C}$ & Strain rate, $\mathrm{s}^{-1}$ & $\alpha$ & $\beta$ & Ref. \\
\hline $\begin{array}{c}\text { AZ31B } \\
\text { Hot rolled }\end{array}$ & $\begin{array}{c}\text { Compression (through- } \\
\text { hickness compression) test }\end{array}$ & 300 to 450 & $10^{-3}$ to $10^{1}$ & 3.98 & 0.07 & {$[59]$} \\
\hline $\begin{array}{c}\text { AZ31B } \\
\text { Hot rolled }\end{array}$ & $\begin{array}{c}\text { Compression (in-plane } \\
\text { compression) test }\end{array}$ & 300 to 450 & $10^{-3}$ to $10^{1}$ & 6.03 & 0.15 & {$[59]$} \\
\hline $\begin{array}{c}\text { AZ31B } \\
\text { Semi } \\
\text { continuous cast }\end{array}$ & $\begin{array}{c}\text { FSP } \\
(180-1800 \text { RPM) } \\
(90 \mathrm{~mm} / \mathrm{min})\end{array}$ & 250 to 450 & 5 to 50 & 9 & 0.27 & {$[58]$} \\
\hline $\begin{array}{c}\text { AZ31 } \\
\text { Extruded }\end{array}$ & Tensile test & 300 & $2 \times 10^{-4}$ & 6 & 0.17 & {$[58]$} \\
\hline $\begin{array}{c}\text { AZ31 } \\
\text { H24 }\end{array}$ & $\begin{array}{c}\text { USW } \\
\text { (500J to 2500J) }\end{array}$ & 160 to 530 & 239 to 1143 & 3 & 0.03 & $\begin{array}{c}\text { Present } \\
\text { Study }\end{array}$ \\
\hline
\end{tabular}




\subsection{Microhardness profile}

Another mechanical property that may be important to consider is hardness, which is a measure of a material's resistance to localized plastic deformation. For welds, microhardness testing is an easy way to measure a specimen's hardness. Hardness testing is performed on welds to evaluate the strength of the weld. In particular, the hardness at the center of the weld and around the HAZ is of interest, which can be helpful to estimate the brittleness of the weld. Here, to develop Hall-Petch type relationship between grain size and hardness, microrhardness test was only performed at the center of the nugget zone. The average of 10 indentations was used for accuracy.

\subsubsection{Effects of USW on microhardness}

Unlike RSW, USW displays no clearly discernible fusion zone or heat affected zone that can degrade the strength of the metals being joined $[24,25]$. It can be inferred that the HAZ is small, because of poor conductivity of the sonotrode material (steel) compared to the thermal conductivity of the samples. Hardness values over the entire area of USW fall within $10 \%$ of each other [25]. Similar variations were found in the base metal itself. The maximum hardness in the welded samples ranges from HV55 to HV72 and is lower than that found in base metal (HV73). It can be seen in Figure 4.4(a) that hardness decreases with increasing energy input due to increasing grain size. 


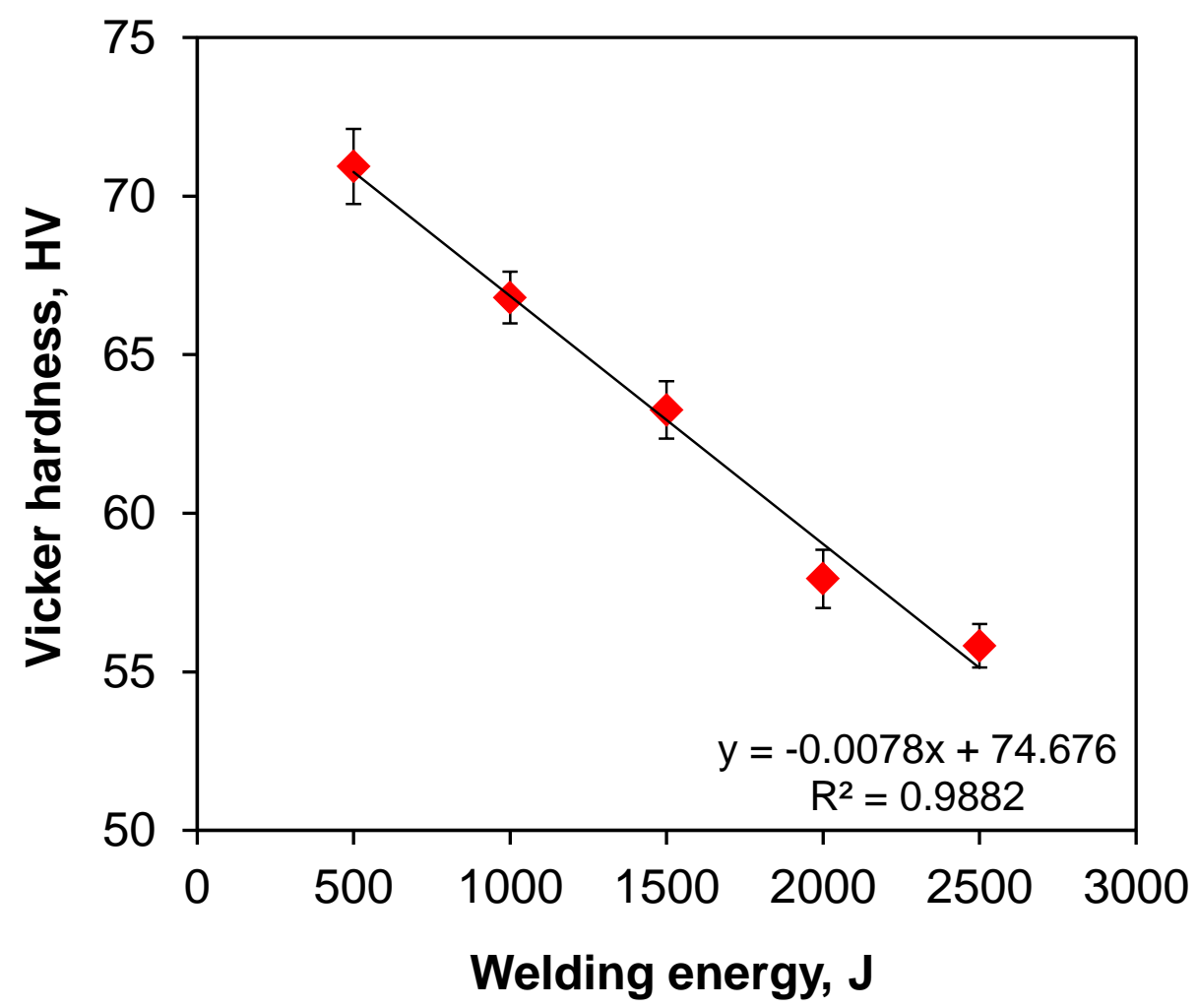

Figure 4.4: Microhardness at the center of the USW welds with different energy levels.

\subsubsection{Hall-Petch type relationship of microhardness of USWed Mg alloys}

The well-known "Hall-Petch relationship" (relationship between yield strength and grain size) style was adopted to show the effect of grain size on hardness. Here, it is called as a "HallPetch type" relationship of hardness and grain size. As calculated, the linear relationship from the graph of Figure 4.5, the Hall-Petch type relationship of hardness and grain size is indicated as,

$$
H V=199.05 D^{-1 / 2}-6.62
$$




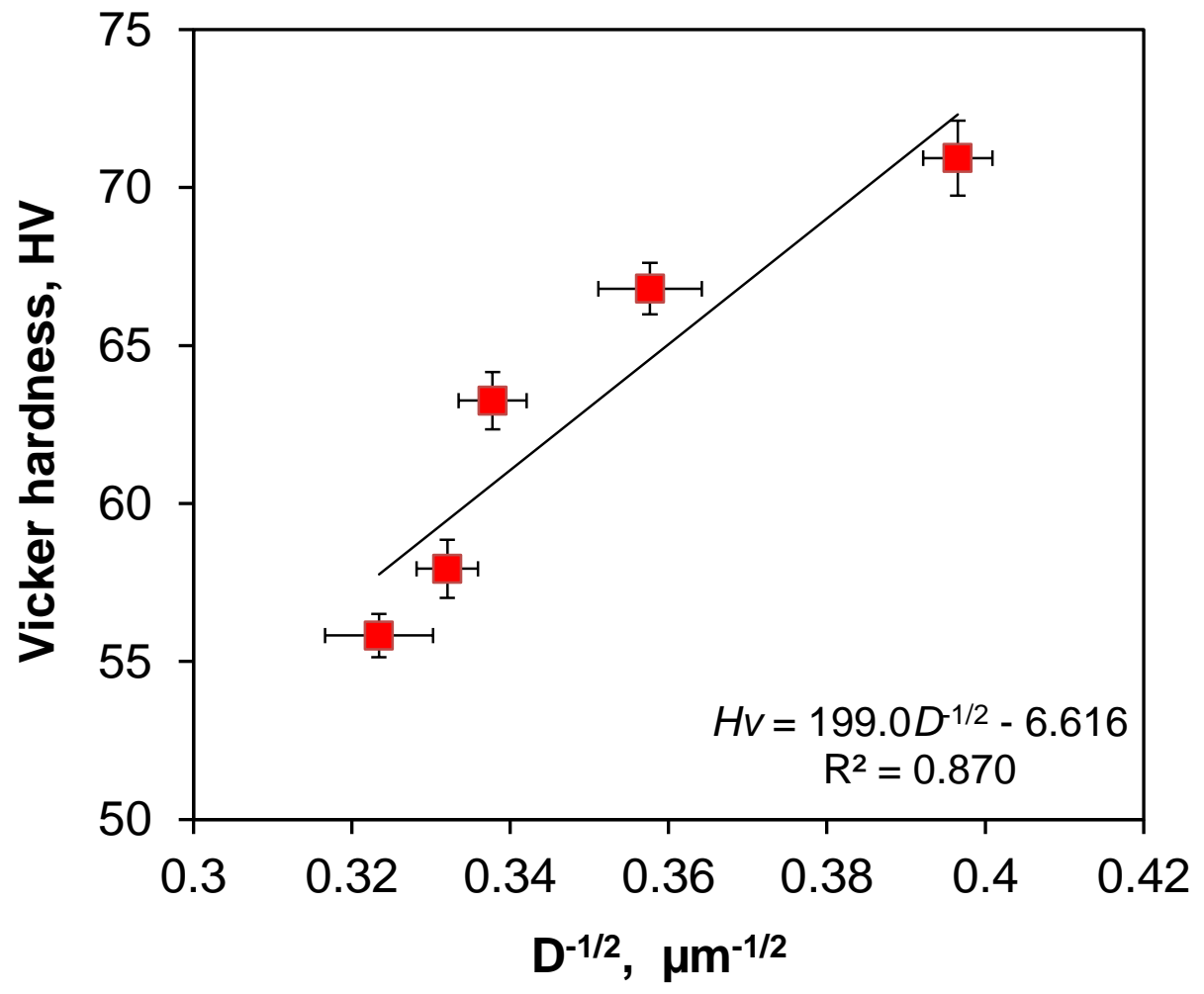

Figure 4.5: Hall-Petch type relationship of hardness and the grain size of USW samples

where, $H V$ is the Vickers hardness and $D$ is the grain size of USWed samples.

\subsection{Crystallographic texture of USWed Mg alloy}

It is well know that the tensile properties of the weld depend on several microstructural factors, such as dislocation density and grain size, second phase particle [68]. However, besides these, crystallographic orientation also intensely influences plastic deformation during the tensile or compressive test because the plastic deformation arises from slip on the close-packed planes with the maximum critical resolved shear stresses [68]. 


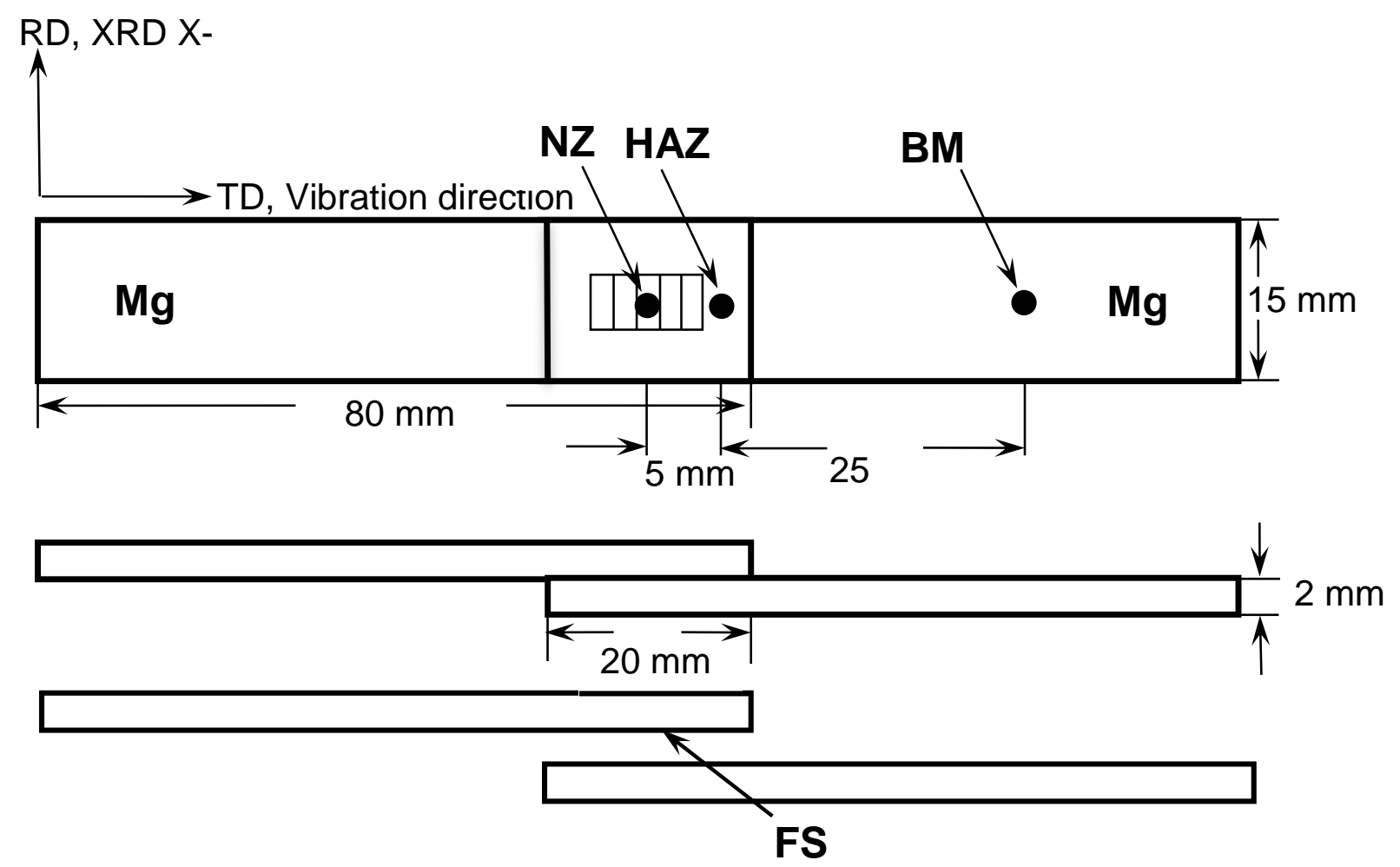

Figure 4.6: Schematic diagram of the lap joint with indicating different zone where crystallographic texture measured

\subsubsection{Crystallographic texture by $X$-ray diffraction profiles}

Initially, effort has been taken to analyze the texture behavior by XRD on the top surface (at different locations such as BM, HAZ (for the sake of simplicity, $5 \mathrm{~mm}$ from the center of the NZ called here as HAZ), and NZ of the USWed joint made at 1000 and $2000 \mathrm{~J}$ energy inputs, along with the fracture surface (FS) of the USWed sheet (Figure 4.6)). HAZ and BM analysis points were located at $5 \mathrm{~mm}$ and $30 \mathrm{~mm}$ from the center of the NZ (Figure 4.6), while the FS point was located at the center of the NZ in-between the coupons. Figure 4.7 shows the computer simulated X-ray diffraction for completely random Mg powder. The 


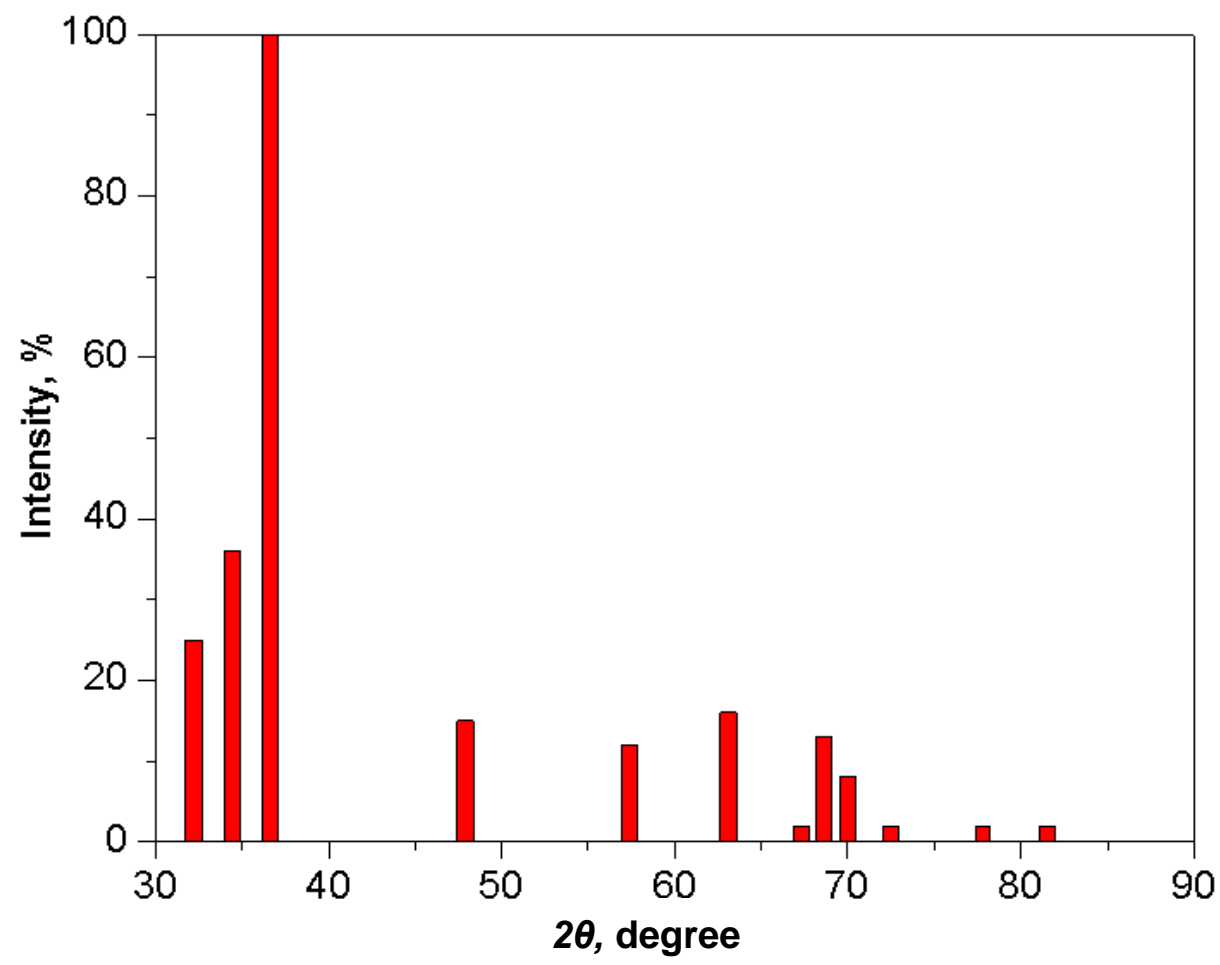

Figure 4.7: Simulated X-ray diffraction pattern for the completely random Mg powder using $\mathrm{Cu}-\mathrm{K \alpha}$ radiation. The vertical axis is for the $X$-ray intensity. Within the $2 \theta$ angles of $30-40^{\circ}$, the (1010) and (0002) peak heights are about one half of the (1011) peak heights.

$(10 \overline{1} 0)$ and (0002) peak heights are about one half of the (10i1) peak height, all being present within the $2 \theta$ angles of $30^{\circ}$ to $40^{\circ}$. The XRD diffraction patterns of the as-received BM, HAZ, NZ and FS at 1000 and $2000 \mathrm{~J}$ energy inputs are shown in Figure 4.8(a) and (b). In the BM, intensity of (0002) basal plane is higher than any of other planes, which is in complete contrast to the $\mathrm{Mg}$ powder data. This suggests that the BM itself exhibits a typical basal rolling texture, owing to the mechanical deformation during the cold rolling of $\mathrm{Mg}$ sheet. It can be seen from Figure 4.8(a) that in NZ and FS (1000 J), the intensity of (0002) plane was approximately two times higher than that in the BM, suggesting, basal texture became stronger after the welding at $1000 \mathrm{~J}$ energy input. Similarly, at $2000 \mathrm{~J}$ energy input 

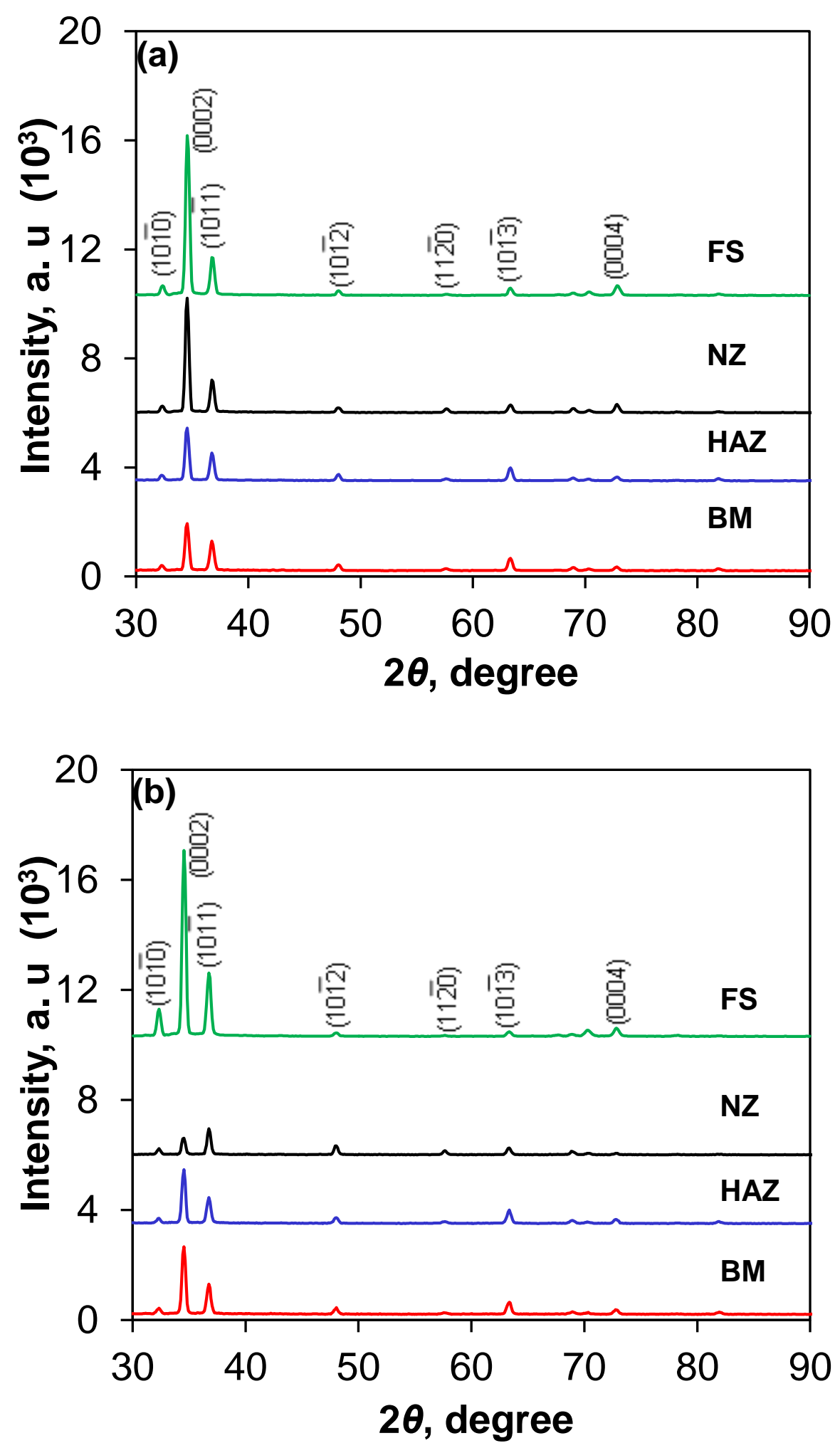

Figure 4.8: X-ray diffraction patterns obtained from BM, HAZ, NZ and FS at (a) 1000 (b) $2000 \mathrm{~J}$ USWed AZ31B-H24 Mg alloy 
(Figure 4.8(b)) on the FS, the intensity of (0002) plane was approximately two times higher than that in the BM, which could be the cause of lap shear tensile deformation. However, in $\mathrm{NZ}$, the intensity of (10 $\overline{1} 1)$ plane was higher than the intensity of (0002) plane (similar like $\mathrm{Mg}$ powder data), which indicates nearly random grain orientation, reflecting its fully recrystallized coarse grain structure as shown in Figure 4.1. Similar result was also reported by Chang et al. in the FSP of the Mg alloy with increasing rotational speed from 800 to 1800 rpm [58]. It can be noticed that HAZ does not exhibit the texture changing, hence, it has similar texture profile as BM which is in agreement with some literatures reported that USW does not produce HAZ [24, 25].

\subsubsection{Crystallographic texture by pole figures profiles}

For more detailed analysis of the above mentioned results, pole figures have been plotted for all region of the welded joint (NZ, HAZ, BM and FS (Figure 4.6)) and shown in Figures 4.9(a) and (b). The (0002) basal, (1010) prismatic, and (10 $\overline{1} 1)$ pyramidal plane pole figures obtained from the top surface of the USWed joint made at 1000 and $2000 \mathrm{~J}$ energy inputs. It can be seen from Figures 4.9(a) and (b) that the BM region in the USWed weld coupon of 1000 and $2000 \mathrm{~J}$ samples have a typical strong basal texture, where basal plane (0002) normal was largely parallel to the ND with some grains slightly tilted in the RD (Figures 4.9(a) and (b)), which is in agreement with the XRD results. It has been reported that two major types of texture components, $(0002)<11 \overline{2} 0>$ and $(0002)<10 \overline{1} 0>$, are available, depending on the activation of slip systems in the basal plane (either $<11 \overline{2} 0>$ single slip or $<10 \overline{1} 0>$ double slip oriented in the RD) in the Mg alloys $[63,111]$. The combination of the 

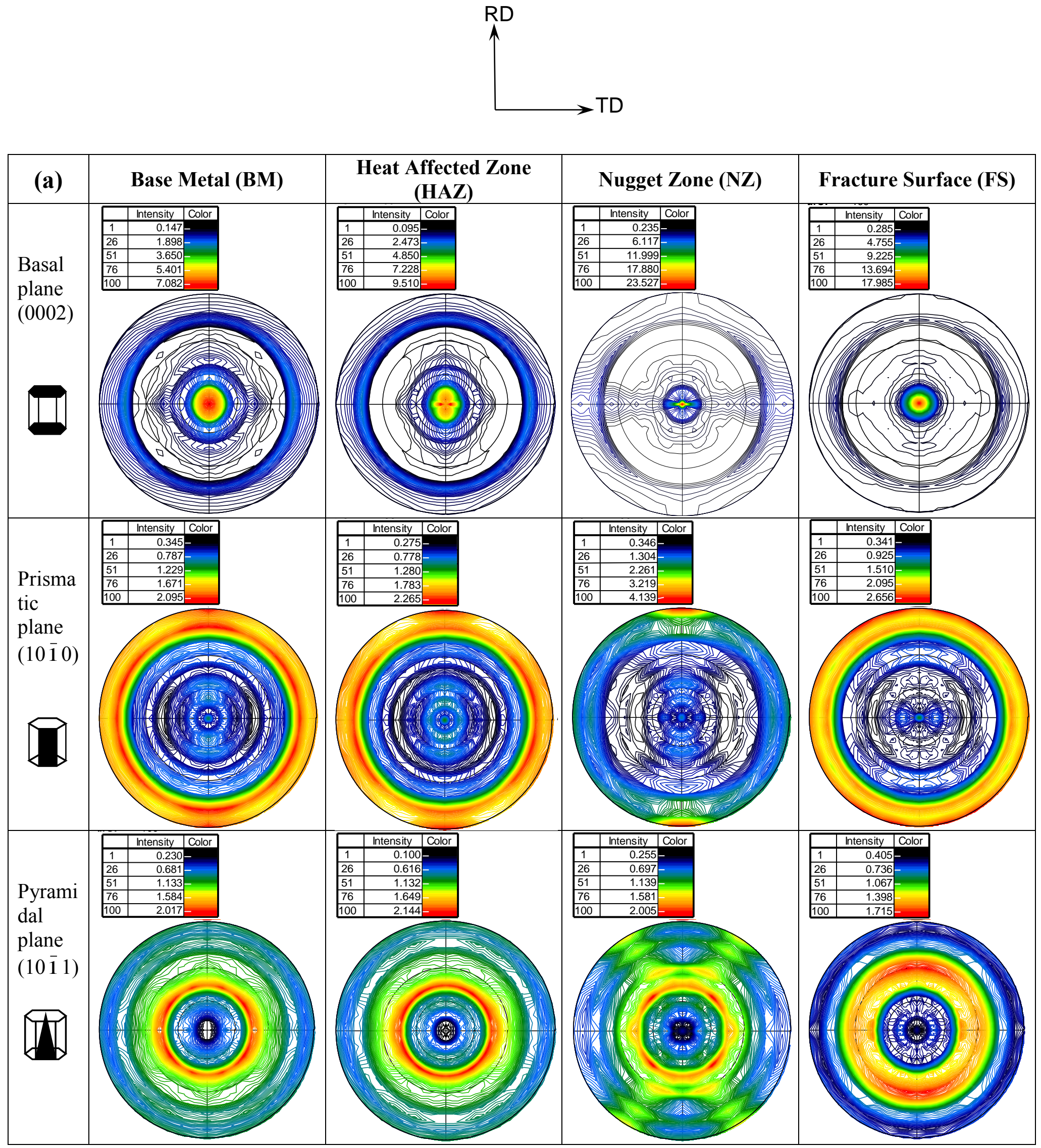

Figure 4.9:(0002) basal plane (1010) prismatic plane and (1011) pyramidal plane pole figures of USWed AZ31B-H24 Mg alloy obtained from BM, HAZ, NZ and FS at (a) $1000 \mathrm{~J}$ (b) $2000 \mathrm{~J}$ energy inputs 


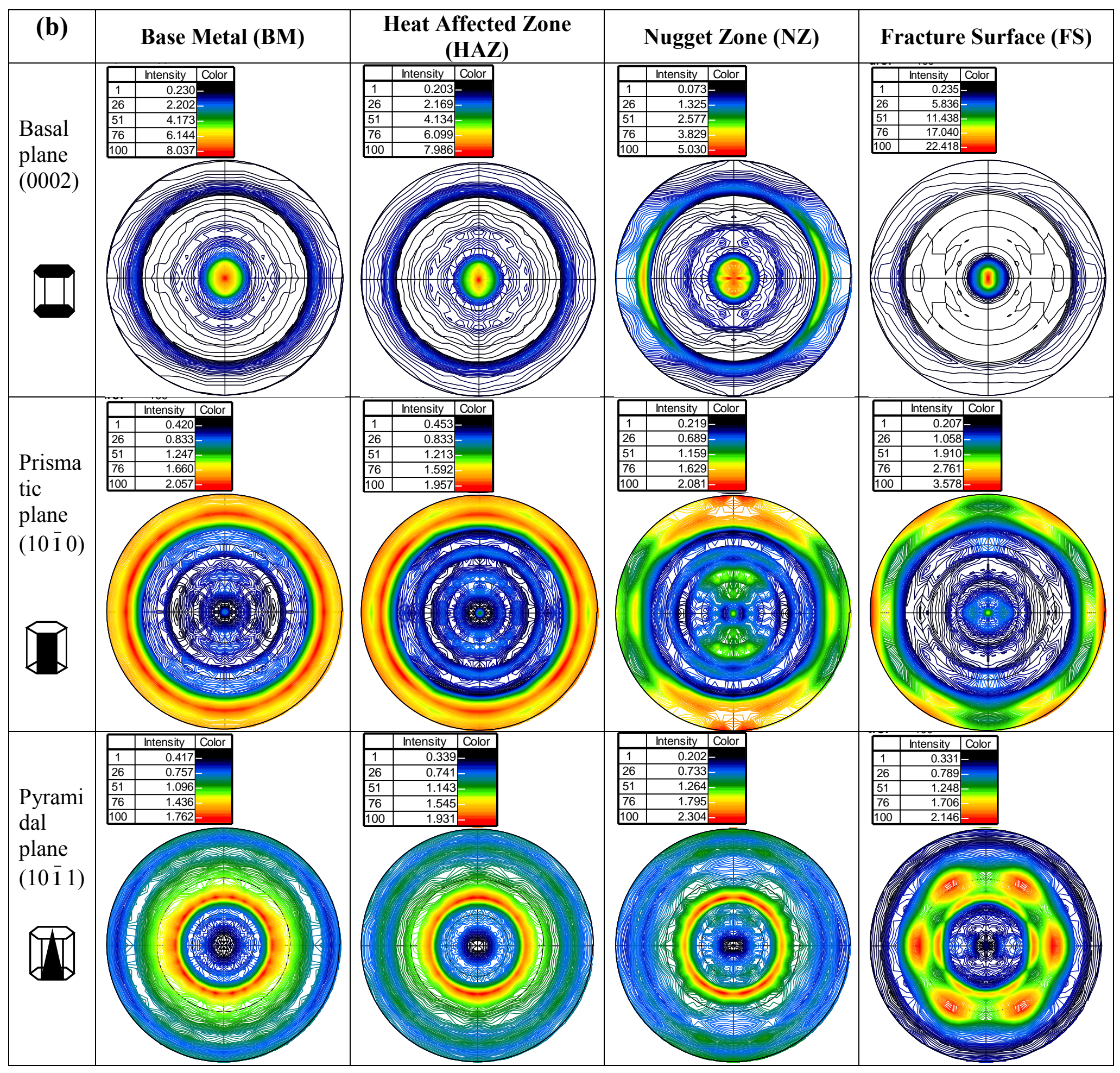

Figure 4.9(cont'd):(0002) basal plane (1010) prismatic plane and (1011) pyramidal plane pole figures of USWed AZ31B-H24 Mg alloy obtained from BM, HAZ, NZ and FS at (a) $1000 \mathrm{~J}$ (b) $2000 \mathrm{~J}$ energy inputs 
two components generates a pole figure of rolled $\mathrm{Mg}$ (BM of USW) that is almost a (0001) fiber texture. This (0001) fiber texture can be easily seen by prismatic (1010) plane (circular ring type structure at $90^{\circ}$ from the center of the pole figure). Moreover, the crystallographic fibering in the BM could be even better seen from the pyramidal planes (10i 1), where the pyramidal planes $(10 \overline{1} 1)$ formed a nearly complete ring at approximately $45^{\circ}$ from the center of the pole figure. Similar (0001) fiber texture component in the rolled AZ31 Mg alloy has also been reported in $[112,113]$. From the $(0002)$ basal $(10 \overline{1} 0)$ prismatic and pyramidal $(10$ 11) planes of the HAZ region, similar like BM (0001) a fibering characteristic has been observed. It should be noted that both BM and HAZ crystallographic texture results obtained from the pole figures are in agreement with the peak intensities observed from the XRD analysis (Figure 4.8).

In NZ of $1000 \mathrm{~J}$ energy input, a strong basal texture with (0002) normal parallel to the ND was found (Figure 4.9(a), NZ-(0002) plane). The intensity of (0002) plane was much higher than that of the BM, suggesting that after the welding more grains followed the basal texture. Such a texture change occurring in the NZ was attributed to the intense localized shear plastic flow during USW. It can be seen from the (10 $\overline{1} 0)$ prismatic plane pole figure of the NZ for $1000 \mathrm{~J}$ USWed sample (Figure 4.9(a), NZ-(10 $\overline{1} 0)$ plane) that it breaks the fiber texture (which was in BM) and the prismatic plane with $<10 \overline{1} 0>$ becomes parallel to the RD of the sheet surface. Interestingly, after the lap shear tensile test, on the fracture surface, all the grains take their original orientation (as in the BM) 1dand exhibit a fiber basal texture with higher intensity than that in the BM (Figure 4.9(a), FS-(10 $\overline{1} 0)$ and (10 $\overline{1} 1)$ planes). 
In NZ of $2000 \mathrm{~J}$ (Figure 4.9(b), NZ-(0002) plane), intensity became very low and creates $90^{\circ}$ rotation of the basal plane so that its normal is parallel to the TD at an angle of $60^{\circ}$ and slightly tilted at an angle of 5 to $10^{\circ}$ towards the RD. Since the crystallographic texture changed from BM to $1000 \mathrm{~J}$ to $2000 \mathrm{~J}$ USWed samples, it could be noted that the texture at $\mathrm{NZ}$ is affected by welding heat input. As discussed earlier in section 4.2.2, temperature increases from $357{ }^{\circ} \mathrm{C}$ to $488{ }^{\circ} \mathrm{C}$ with increasing energy input from $1000 \mathrm{~J}$ to $2000 \mathrm{~J}$, respectively. In $2000 \mathrm{~J}$ energy input sample, with high temperature and slow cooling rate, more complete dynamic recrystallization occurred. Thus, some new grains may nucleate and grow as shown in Figure 4.1 with the result that the texture becomes weak. Dynamic recrystallization is produced by the large strain introduced by the ultrasonic vibration and high temperatures developed from friction and plastic deformation during USW. Moreover, dynamic recrystallization promotes stress concentration at grain boundaries [114], which is effective for the activation of non-basal slip system and serves to break down the basal texture. In addition, Jain and Agnew [115] stated that critical resolved shear stresses (CRSS) of non-basal slip systems decline dramatically at elevated temperatures, and non-basal slip systems are more easily activated and tend to split the basal texture. Eventually, in the present study, the basal texture at the NZ becomes weak. Similar results were also found by Chang et al. in FSP [58] and Yu et al. in fiber laser welding [116] of Mg alloys. It is suggested here that in USW the plastic deformation due to the ultrasonic vibrations leads to texture formation while the increase in temperature due to the USW heat generation leads to dynamic recrystallization and randomization of texture; these two phenomena are in competition with one another. Thus, in $1000 \mathrm{~J}$ USWed sample the plastic deformation dominates giving a sharp texture while in $2000 \mathrm{~J}$ USWed sample the dynamic 
recrystallization dominates giving a weak texture.

The pole figure of prismatic plane of NZ in $2000 \mathrm{~J}$ sample (Figure 4.9(b), NZ-(1010) plane) is almost like to that of the $1000 \mathrm{~J}$ sample. However, the prismatic plane is more concentrated along the RD in the $1000 \mathrm{~J}$ sample than the $2000 \mathrm{~J}$ sample. As a result, its intensity was one half of the prismatic plane of NZ in $1000 \mathrm{~J}$ USWed sample. By observing the texture on the fracture surface of $2000 \mathrm{~J}$ USWed sample (Figure 4.9(b), FS-(0002), (10ī0) planes), it seems that the basal plane regained their original orientation (as in the BM) with higher intensity than BM and NZ. However, from (1011) pyramidal plane of fracture surface, $(0002)<11 \overline{2} 0>$ texture component was mainly observed (Figure 4.9(b), FS-(10 $\overline{1} 1)$ ).

\subsection{Lap shear tensile strength of joints}

It is known that the structural application of any new materials' components requires proper welding and tensile resistance to guarantee their durability and safety. Thus, here, the lap shear strength test of the USWed Mg alloy was conducted and the result were plotted against welding energy inputs as shown in Figure 4.10. The maximum lap shear strength was found to be $89 \mathrm{MPa}$ at $2000 \mathrm{~J}$ energy input (calculated as the maximum lap shear fracture load divided by the nugget area of $(8 \times 6 \mathrm{~mm})$. As shown in Figure 4.10, with increasing energy input, lap shear strength increased in the beginning owing to high temperatures and strain rate, which accelerate diffusion between the Mg alloy sheets, but at very high energy inputs, it was decreased. This may be because, at low welding energies (1000 J), Mg has not been sufficiently deformed plastically to fill the valleys of the knurl patterns of the sonotrodes, as 


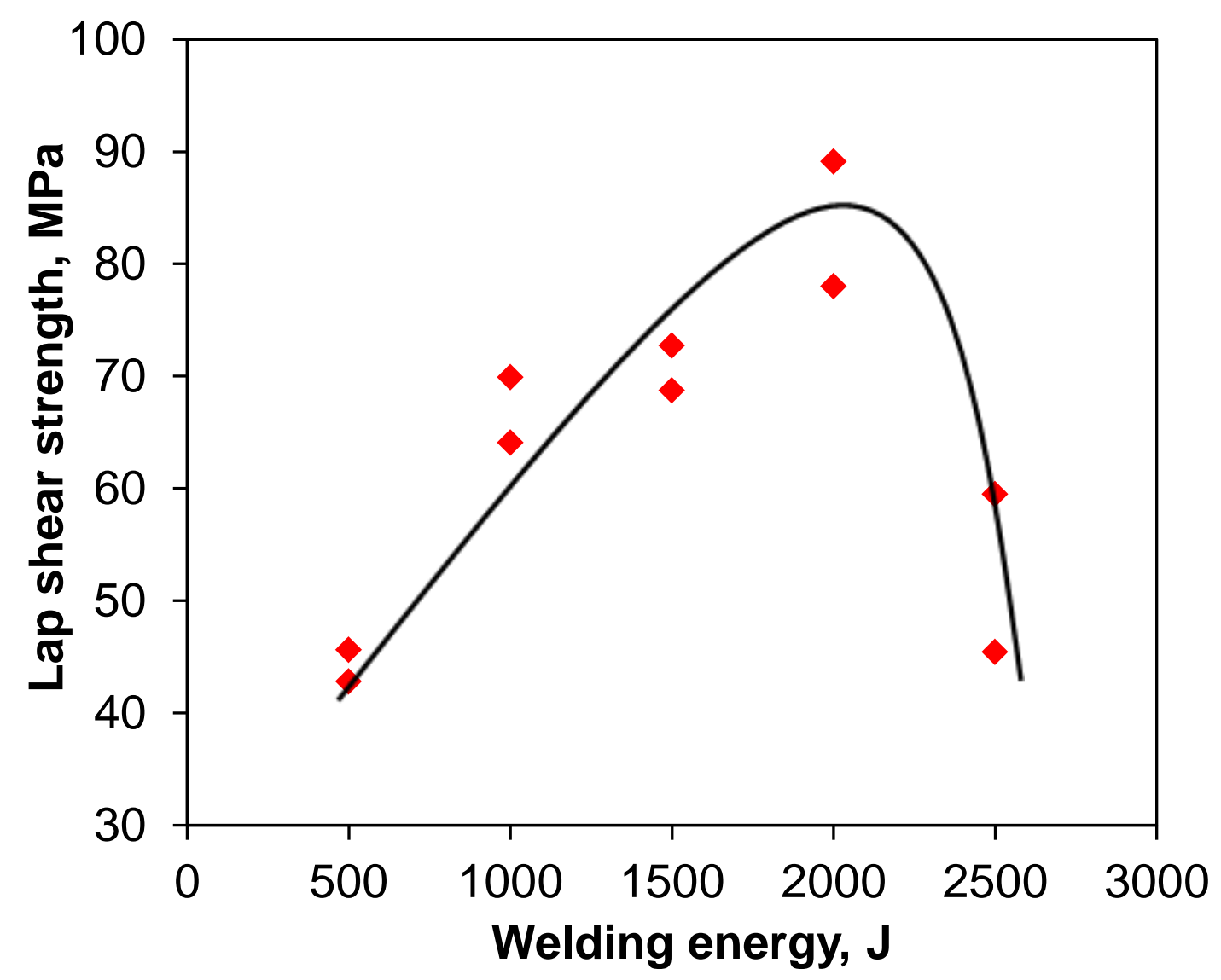

Figure 4.10: Lap shear strength of USWed similar AZ31-H24 Mg alloy at different energy inputs.

shown in Figure 4.11(a). In contrast, at $2000 \mathrm{~J}$ energy input (Figure 4.11(b)), the knurl pattern valleys fill up with the plastically deformed Mg alloy. Further, it may also be because $2000 \mathrm{~J}$ welded samples experienced almost random type texture than that of $1000 \mathrm{~J}$ welded sample, which led to higher lap shear tensile strength. In addition, Yu et al. [59], correlated Zener-Hollomon parameter $(\mathrm{Z})$ (widely used to show the combined effect of temperature and strain rate $[59,60,62])$ with the tensile properties of FSPed Mg alloy, indicating that samples with high $Z$ value show low strength/high ductility and samples with low $Z$ value show high strength/low ductility. Similar relationship has also been established in the present study, where the values of $\mathrm{Z}$ for $1000 \mathrm{~J}$ and $2000 \mathrm{~J}$ were $8.19 \times 10^{13}$ and $1.38 \times 10^{12}$ (Table 4.1), with 

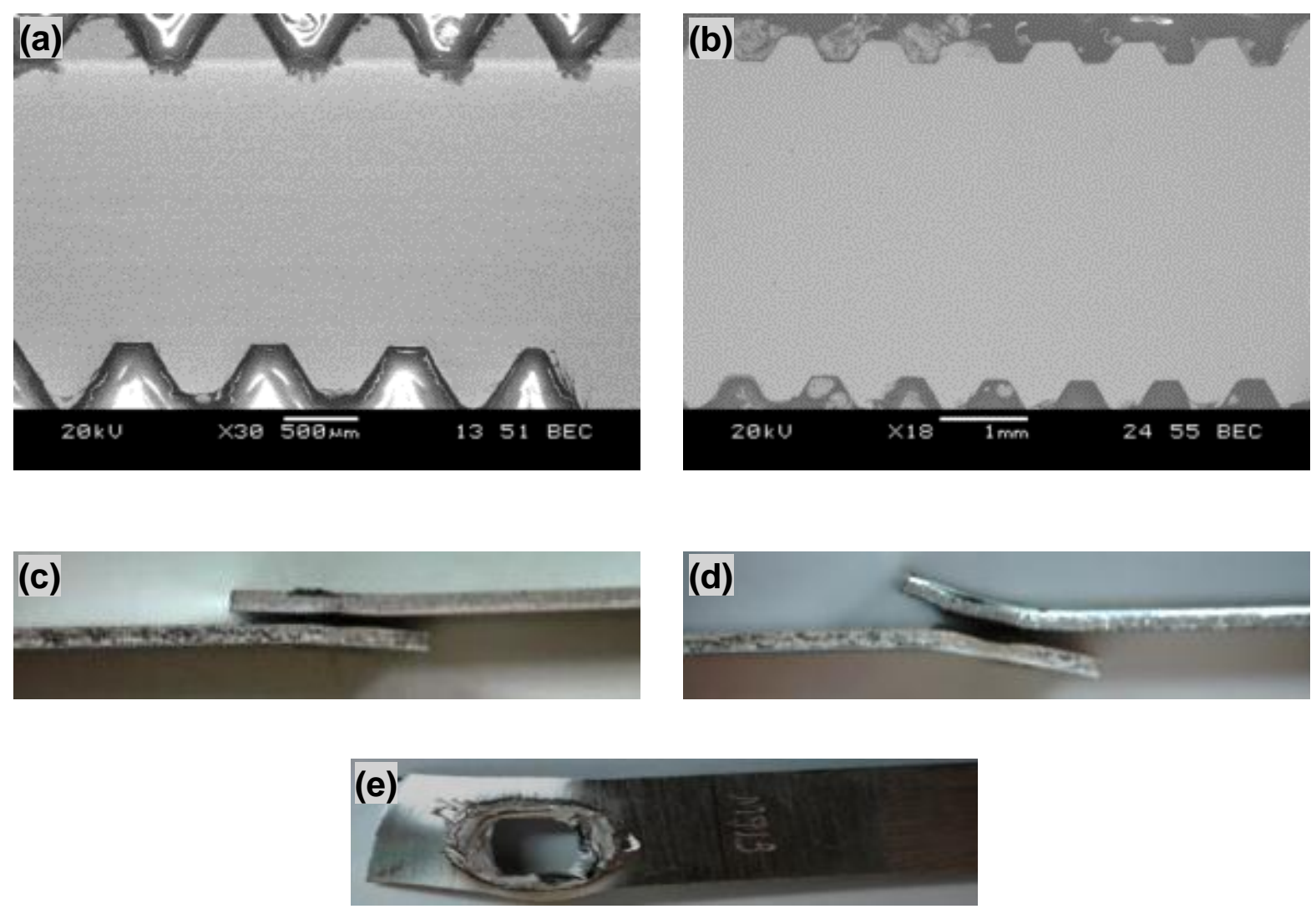

Figure 4.11: Effect of the knurl pattern on the USWed sample at (a) $1000 \mathrm{~J}$ (b) $2000 \mathrm{~J}$ and bending effect during the failure at (c) $1000 \mathrm{~J}$ and (d) $2000 \mathrm{~J}$ and nugget pull out effect (e) 2500 J energy inputs.

the strength being 67 and $89 \mathrm{MPa}$, respectively. It can be seen from Figure 4.11(c) and (d), at $2000 \mathrm{~J}$ energy input, more severe bending takes place, while for the weld produced by lower energy inputs $(1000 \mathrm{~J})$, the separated sheets remain almost flat. Interestingly, at the highest energy input of $2500 \mathrm{~J}$, weld specimens experienced large compressive stress developed at the edge of the weld spot (Figure 4.11(e)), resulting in extensive local plastic deformation and nugget pull-out during the lap shear test experiments. The generation of the compressive force at high welding energy (in this case $2500 \mathrm{~J}$ ) between weld and coupon is attributed to the bending of the free hand coupon during the USW. 


\subsection{Lap shear tensile fractography}

In lap-shear tensile tests, the welds generally fracture along the weld interface for input energies of less than and equal to $2000 \mathrm{~J}$, while fracture occurs at the periphery of the weld (button pullout) for input energies of greater than $2000 \mathrm{~J}$. The typical failure locations for the USWed of AZ31B-H24 Mg alloy are shown in Figure 4.12. It can be seen from Figure 4.12(a) that in $1000 \mathrm{~J}$ energy input sample the whole fracture surface is flat. In contrast, a big crack was found (Figure 4.12(b)) at the periphery of the sonotrode tip indent in $2000 \mathrm{~J}$ energy input sample due to the large compressive stress as mention earlier. This crack can penetrate into the material more deeply with higher energy. In particular, due to this crack, the base materials were partly pulled out from the welded interface. Thus, further increase in energy input $(2500 \mathrm{~J})$ resulted in the whole nugget pull out as shown in Figure 4.11(e). Similar nugget pull out phenomenon in the USW process was also reported in [22]. A magnified region for $1000 \mathrm{~J}$ energy input sample (Figure 4.12(c) and (e)) shows the failure mode in the center region of the fracture surface. Apart from some small isolated dimplerupture failure zone, the dominant feature of the region is the parallel scrubbing lines. Owing to high frequency ultrasonic vibration, these scrubbing lines resulted from abrasion or galling

of the sheet surfaces. In contrast, a characteristic dimple-rupture failure mode was found at $2000 \mathrm{~J}$ energy input as shown in Figure 4.12(d) and (f). 

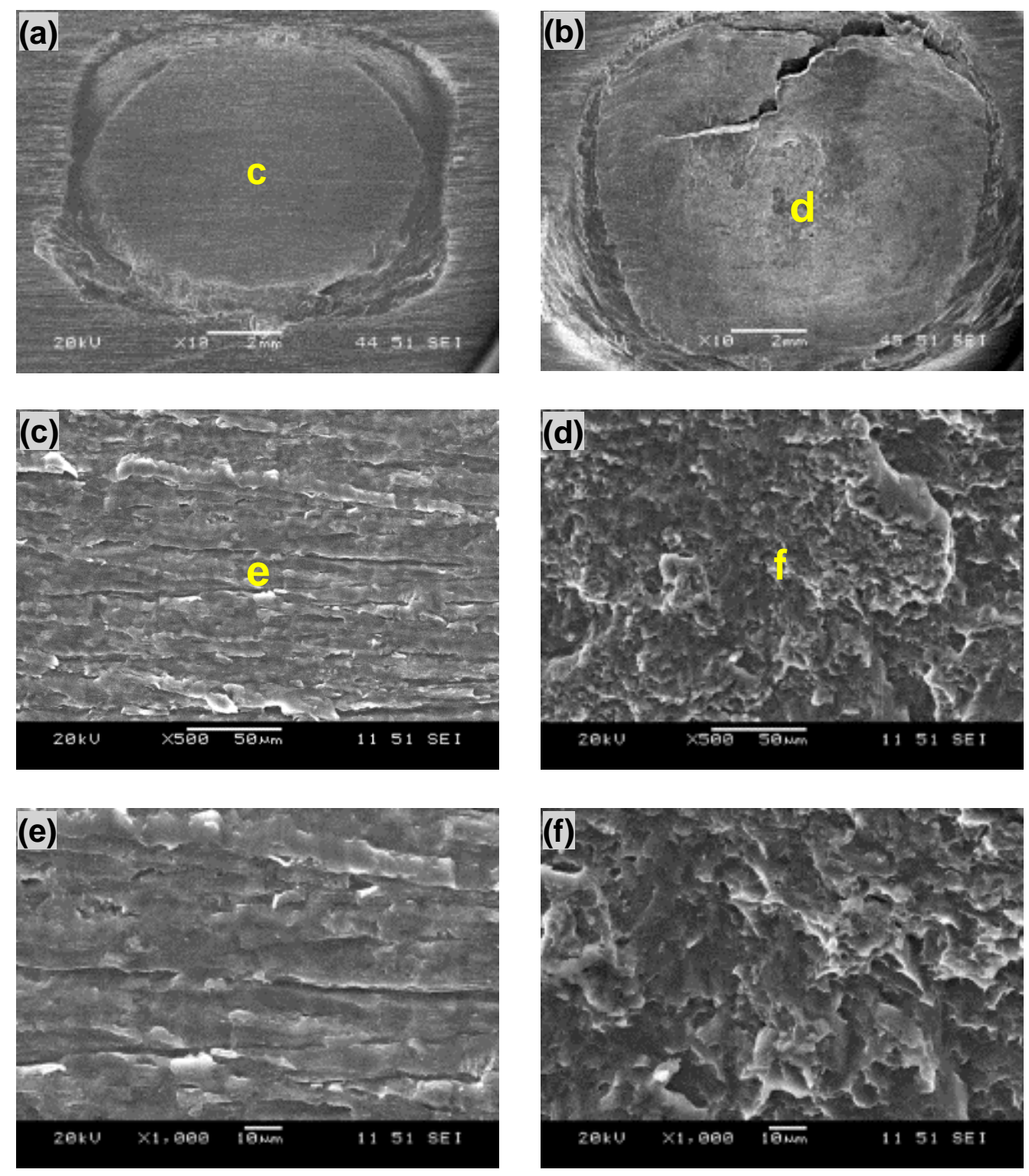

Figure 4.12: Typical SEM images of tensile fracture surface of USWed similar AZ31-H24 $\mathrm{Mg}$ alloy, (a) and (b) overall view, (c) and (d) at lower magnification, (e) and (f) at higher magnification of $1000 \mathrm{~J}$ and $2000 \mathrm{~J}$ energy inputs, respectively

\subsection{Fatigue behavior and failure mode}

Today, fatigue of materials and structures, is the main cause of failures and accidents. In order to understand the fatigue behavior of USWed Mg alloy, fatigue test was performed at room temperature, $\mathrm{R}=0.2$, and a frequency of $50 \mathrm{~Hz}$. As seen in earlier lap shear tensile 
section 4.5, the average tensile failure loads, defined as the maximum loads of the loaddisplacement curves, obtained from two USWed AZ31B-H24 lap-shear specimens with a welding energy of $2000 \mathrm{~J}$ was $4.2 \mathrm{kN}$. This failure load was used as a reference load to determine the load levels applied in the present fatigue tests.

The fatigue test data are plotted in Figure 4.13. It can be seen that at the higher $P_{\max }$ loads of 3.5 and $3.0 \mathrm{kN}$, the $2000 \mathrm{~J}$ welded samples showed a longer fatigue life compared with the $1000 \mathrm{~J}$ welded samples. However, at the load level of $\mathrm{P}_{\max }=2.5 \mathrm{kN}$ and below, the $2000 \mathrm{~J}$ welded samples showed a shorter fatigue life compared to the $1000 \mathrm{~J}$ welded samples. This is because at the lower $\mathrm{P}_{\max }$ loads premature fatigue fracture, referred to as transverse-throughthickness (TTT) crack growth mode, occurred at the crack tips on the either side of the $\mathrm{Mg}$ sheet (Figure 4.14(a)), unlike the interfacial fracture (in-between Mg sheets) which occurred at the higher $\mathrm{P}_{\max }$ loads. In order to demonstrate the TTT crack growth mechanism, the SEM micrograph of fatigue tested USWed Mg-to-Mg joint is shown in Figure 4.14(b). The TTT crack started to grow from the crack tips (both sides) at an angle of $\sim 45^{\circ}$ to the loading direction as indicated in Figure 4.14(b). Higher welding energy values led to substantially higher temperatures and, the resulting softer $\mathrm{Mg}$ sheet experiences a greater level of bending deformation in the weld zone compared with the base metal due to the outward flow of the 


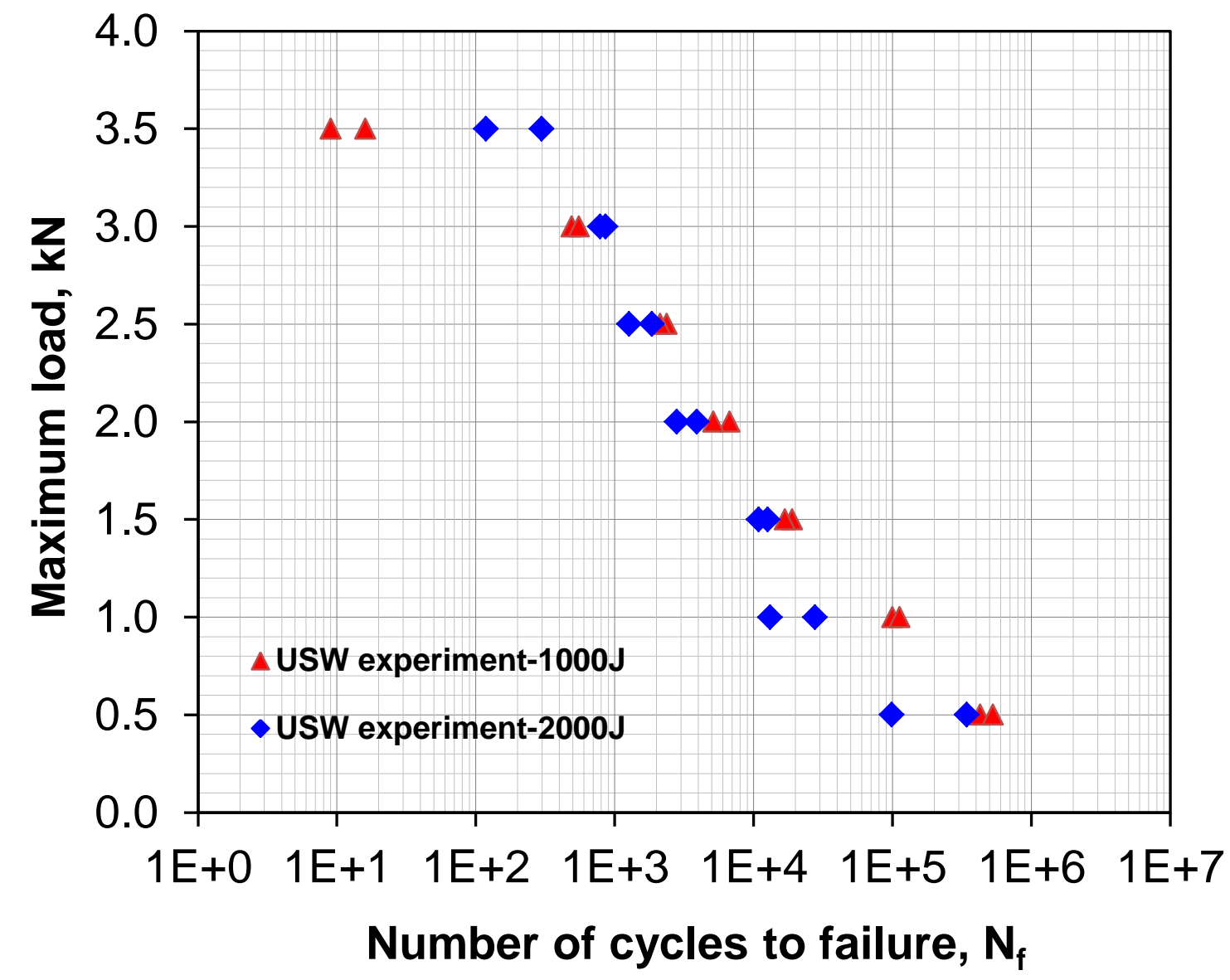

Figure 4.13: Experimental results of fatigue life for the USWed Mg-to-Mg joints

material under the sonotrode tool indentation. This action of bending produced a small micro level crack at the notch of two sheets as seen at a higher magnification in Figure 4.14 (c), and also observed in [117]. Finite element simulation showed that the normal tensile stress concentration at the periphery of the nugget could reach as high as more than five times the average stress under tensile-shear loading [117]. Thus, this micro level crack experienced higher stress concentration effect during cyclic loading which allowed the cracks to grow toward the outward Mg sheet. By closely observing Figure 4.14(b), it can be seen that the crack propagated from the notch tip at an angle of $\sim 45^{\circ}$ only up to about a half of the 

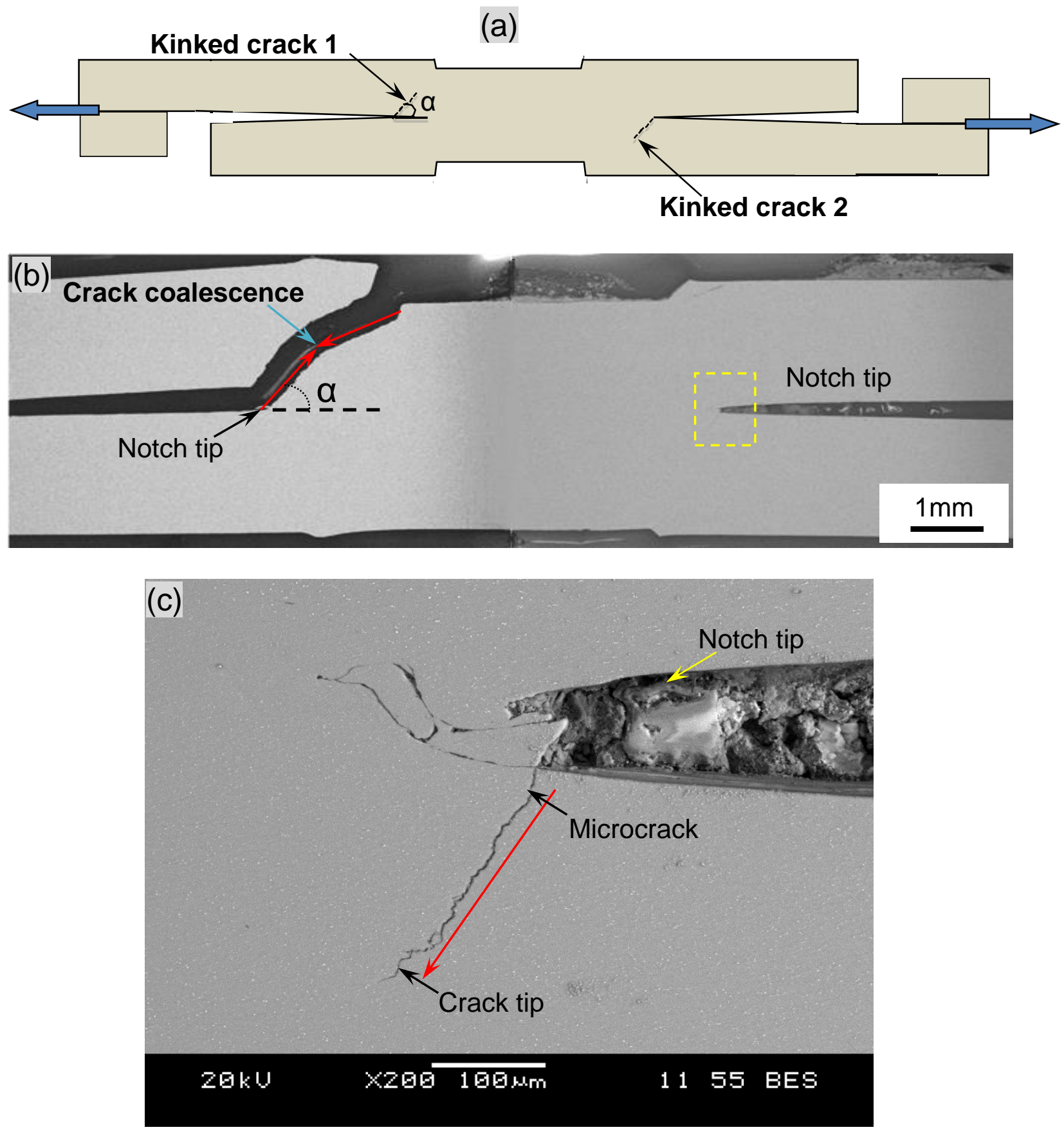

Figure 4.14: (a) Schematic diagrams of a lap shear specimen after the USW process with kinked crack at both notch tips, (b) overall view of SEM micrographs after fatigue testing of the USWed Mg-to-Mg joints made using an energy input if $1000 \mathrm{~J}$, (c) magnified image near the notch tip indicated by a dashed box. 
Mg sheet thickness. Then, the crack path had a different angle, which indicated the crack propagation from the upper location, i.e., from the corner/edge of the sonotrode nugget footprint. This crack is generated due to a simultaneous application of high-frequency vibrations $(20 \mathrm{kHz})$ under pressure $(0.4 \mathrm{MPa})$, which led to large deformation from the sonotrode (normal and shear forces) into the Mg sheet. Thus, it would be reasonable to assume that in the USW of Mg-to-Mg joints fatigue crack propagation occurred from two different locations, one from the notch tip and the other from the edge of sonotrode indentation-footprint region. As mentioned earlier, from previous section 4.5 lap shear tensile tests, the $2000 \mathrm{~J}$ welded sample showed a high lap shear fracture load $(4.2 \mathrm{kN})$ compare with that of $1000 \mathrm{~J}$ energy input. However, fatigue life of the $1000 \mathrm{~J}$ welded samples was observed to be longer than that of the $2000 \mathrm{~J}$ welded samples in most of the cyclic loading levels (i.e., $\mathrm{P}_{\max }$ from $0.5 \mathrm{kN}$ to $2.5 \mathrm{kN}$, Figure 4.13). From this it can be concluded that to guarantee the structural integrity and safety, one has to consider both lap shear tensile fracture load and cyclic behavior of the welded joints.

Figure 4.15 shows a comparison of fatigue lives of the welded AZ31B-H24 Mg alloy joints using different welding processes (USW in the present study (2 mm thick sheet); FSSW [34] (2 mm thick sheet); FSLW [53] (2 mm thick sheet); and RSW [75] (1.5 mm thick sheet). It should be noted that direct comparisons are not straightforward as all the welds have different geometries, where USW and FSLW have rectangular, and RSW and FSSW have circular footprints. In addition, the optimum set-up is different in each process. However, to compare the USW fatigue life data with those of other welding processes, the applied fatigue loads of USWed Mg-to-Mg joints were converted to the applied stress by using a nominal 


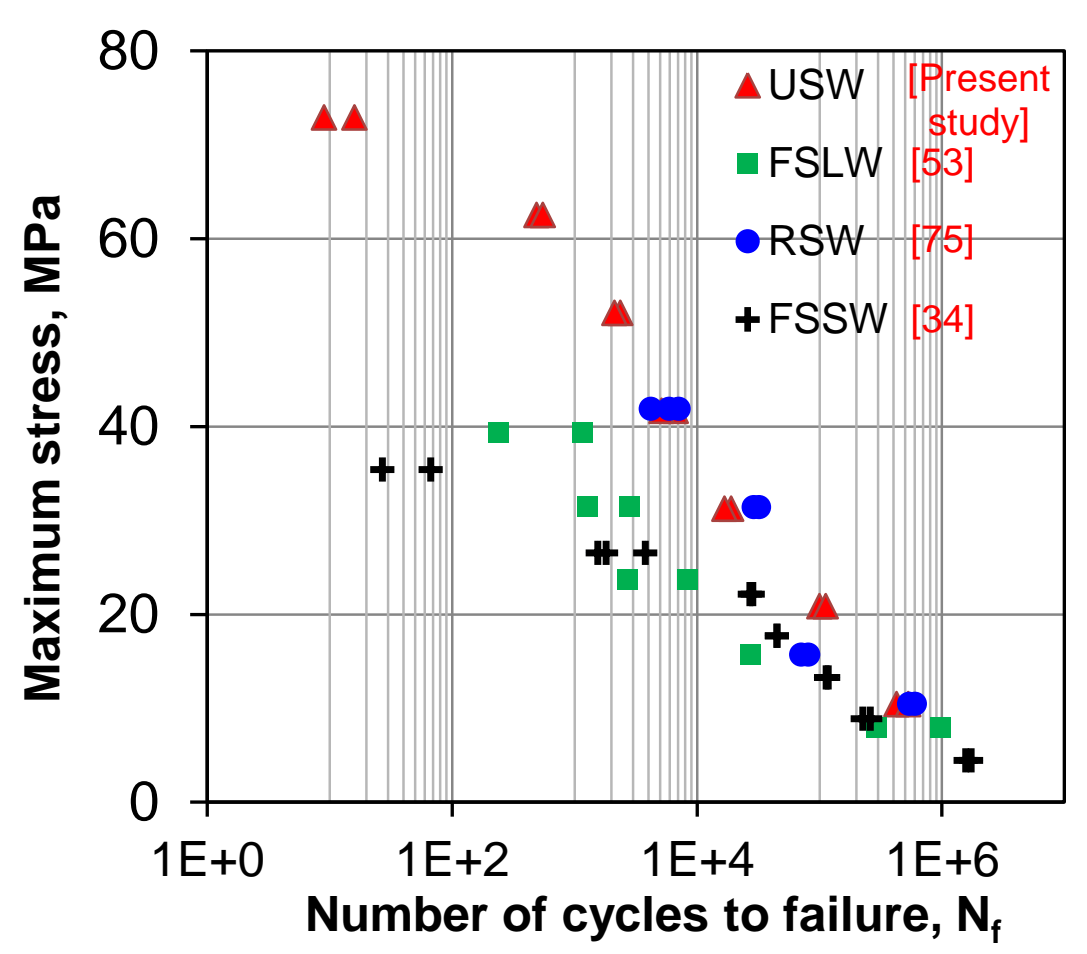

Figure 4.15: Comparison of fatigue life of the welded Mg-to-Mg joints with different welding techniques.

welding area corresponding to the area of the USW tip $\left(8 \times 6 \mathrm{~mm}^{2}\right)$. Likewise, for the FSSW, the hollow cylindrical area has been used (pin diameter was $5 \mathrm{~mm}$ and shoulder diameter was $13 \mathrm{~mm}$ ) [34]; for the RSW the area of the electrode (electrode diameter $7.8 \mathrm{~mm}$ ) has been used [75] and for the FSLW the product of pin diameter $(6.35 \mathrm{~mm})$ and sample width $(20 \mathrm{~mm})$ has been used [53]. It is seen that the USWed joints displayed a higher fatigue strength compared with other welding techniques. However, at a stress level of $\sim 10 \mathrm{MPa}$ and $\sim 31 \mathrm{MPa}$, RSWed samples showed a slightly longer fatigue life compared with that of the USWed samples. This would partially related to the experimental scatter. It is worthwhile to mention that a USW process consumes only about $0.3 \mathrm{kWh}$ per 1000 joints, compared to 20 $\mathrm{kWh}$ with RSW [32]. 
Figures 4.16 and 4.17 show typical fatigue failure modes at varying cyclic stress levels of the USWed Mg-to-Mg joints made at a welding energy of $1000 \mathrm{~J}$ and $2000 \mathrm{~J}$, respectively, and Figure 4.18 presents the failure modes in conjunction with a logarithmic S-N plot in the form of the maximum tensile shear cyclic stress versus the number of reversals to failure $\left(2 \mathrm{~N}_{\mathrm{f}}\right)$ in terms of a Basquin type relationship. For the $1000 \mathrm{~J}$ welded samples, interfacial failure mode (Figures 4.16(a) and (b)) was observed at the higher cyclic load levels corresponding to a flatter slope (Figure 4.18), while partially interfacial and partially TTT crack growth failure (Figures 4.16(c)-(e)) were observed corresponding to a less flatter (or steeper) slope in
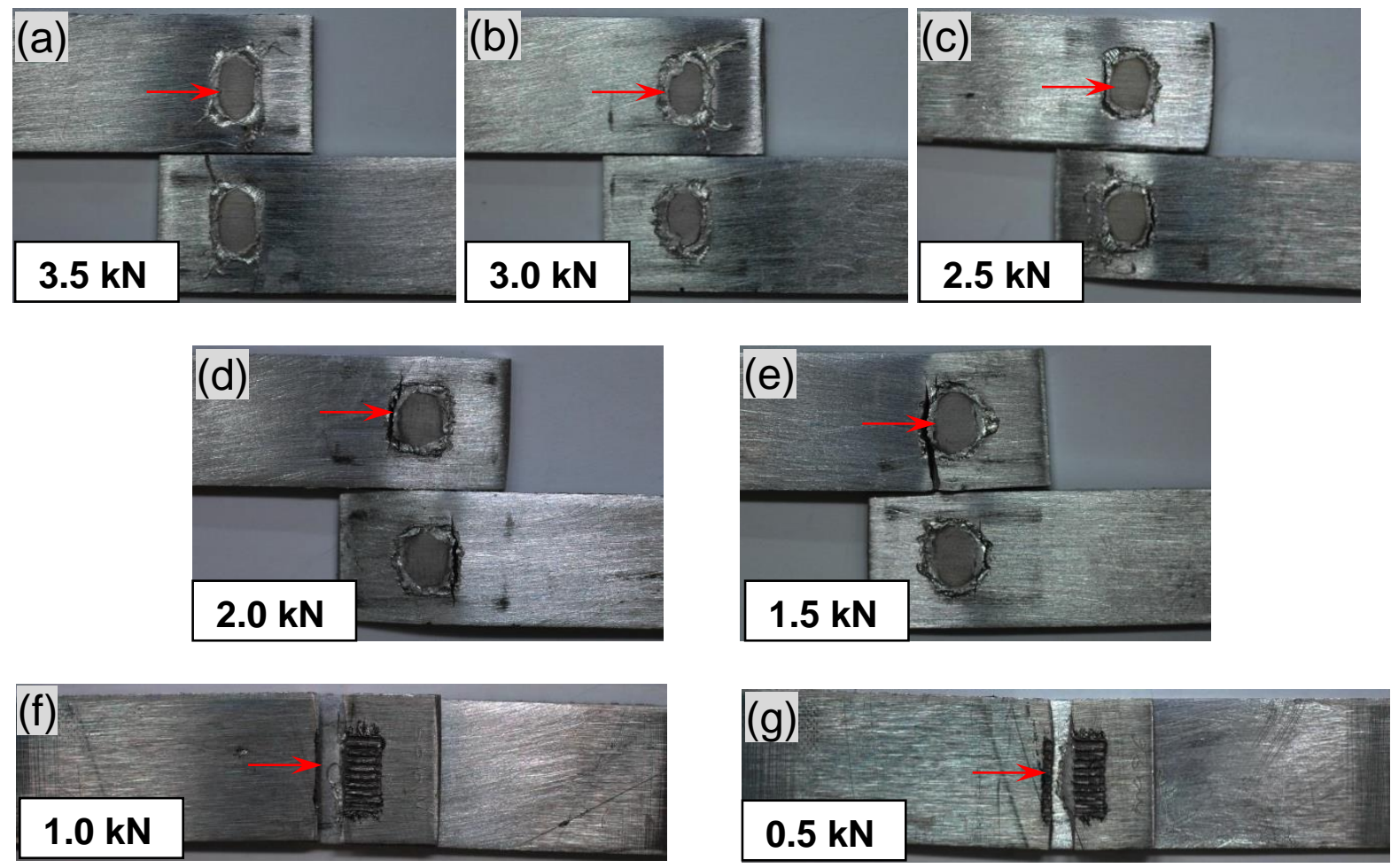

Figure 4.16: Typical fatigue failure modes at different $P_{\max }$ values of the USWed Mg-to-Mg joints made at a welding energy of $1000 \mathrm{~J}$, (a) $3.5 \mathrm{kN}$ (interfacial), (b) $3 \mathrm{kN}$ (interfacial), (c) $2.5 \mathrm{kN}$ (partially interfacial-partially TTT crack growth), (d) $2.0 \mathrm{kN}$ (partially interfacialpartially TTT crack growth), (e) $1.5 \mathrm{kN}$ (partially interfacial-partially TTT crack growth), (f) $1 \mathrm{kN}$ (TTT crack growth), (g) $0.5 \mathrm{kN}$ (TTT crack growth). 
Figure 4.18. Complete TTT crack growth failure (Figures 4.16(f) and (g)) occurred at the lower cyclic load levels where the slope became further steeper. In this case the remaining cross section could no longer sustain the shear overload, then the heavily deformed nugget edge eventually experienced TTT crack growth failure. However, in the $2000 \mathrm{~J}$ USWed joints, except the samples subjected to the highest cyclic load at $\mathrm{P}_{\max }=3.5 \mathrm{kN}$ where the
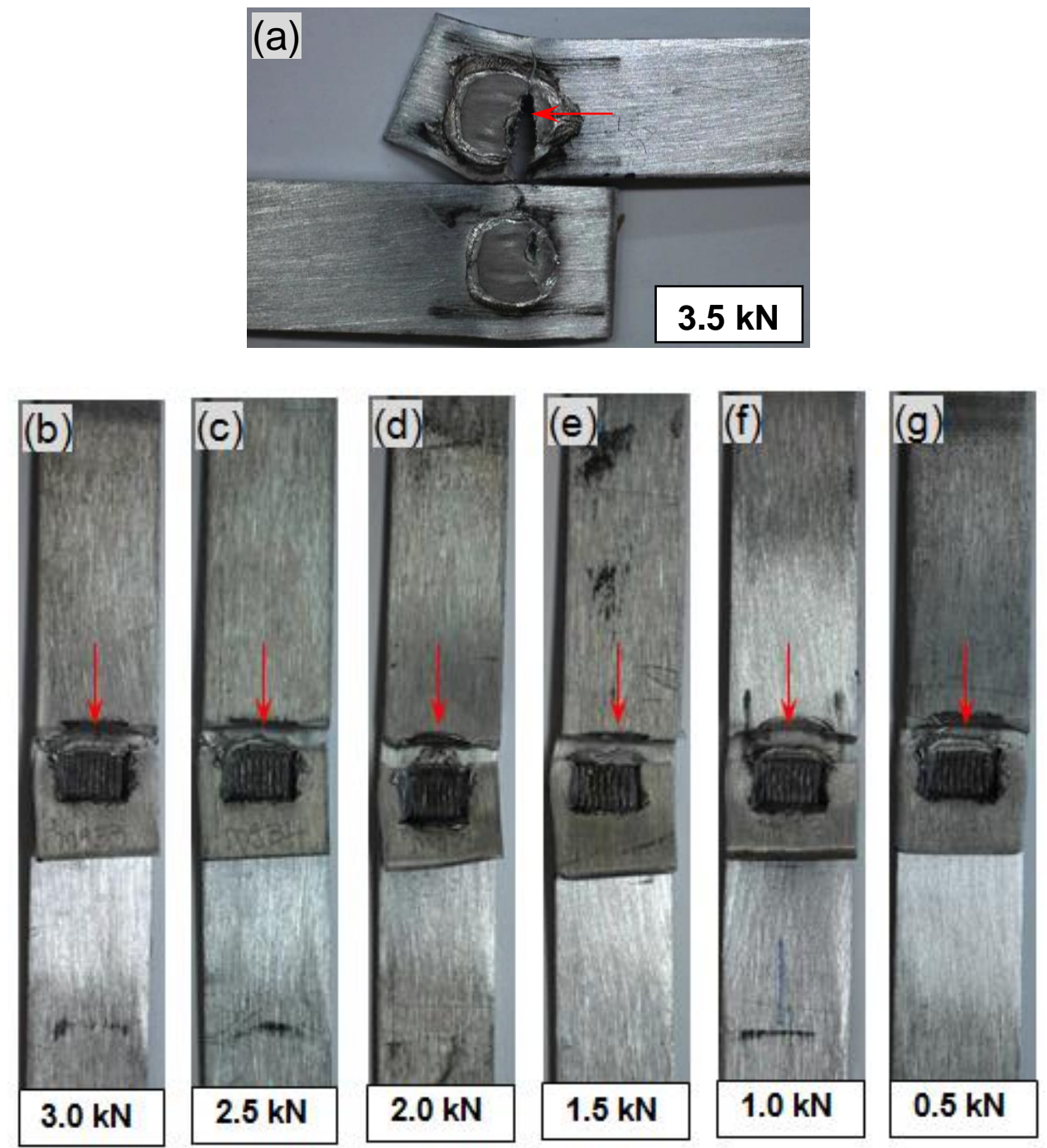

Figure 4.17: Typical fatigue failure modes at different $P_{\max }$ values of the USWed Mg-to-Mg joints made at a welding energy of $2000 \mathrm{~J}$. Here, (a) $3.5 \mathrm{kN}$ was experienced partially interfacial-partially TTT crack growth failure mode, while (b) to (g) for the load of 3.0 to 0.5 $\mathrm{kN}$ with decrement of $0.5 \mathrm{kN}$ show the failure occurred predominantly in the mode of TTT crack growth 
failure was partially interfacial and partially TTT crack growth (Figure 4.17(a)). As a result, for the USWed Mg-to-Mg joints made with a welding energy of $2000 \mathrm{~J}$, the change of failure mode from the TTT crack growth to the partially interfacial-partially TTT crack growth failure occurred at about $\log \sigma_{\max }=1.8$ or $\left(\sigma_{\max }=63 \mathrm{MPa}\right)$. It can be seen from Figure 4.18, for the USWed Mg-to-Mg joints made with a welding energy of $1000 \mathrm{~J}$ the change of failure mode from the TTT crack growth to the partially interfacial-partially TTT crack growth failure occurred at about $\log \sigma_{\max }=1.32$ or $\left(\sigma_{\max }=21 \mathrm{MPa}\right)$. The transition of failure mode from the partially interfacial-partially TTT crack growth failure to the interfacial failure mode occurred at about $\log \sigma_{\max }=1.7$ (or $\sigma_{\max }=52 \mathrm{MPa}$ ). Thus, the fatigue failure mode of the

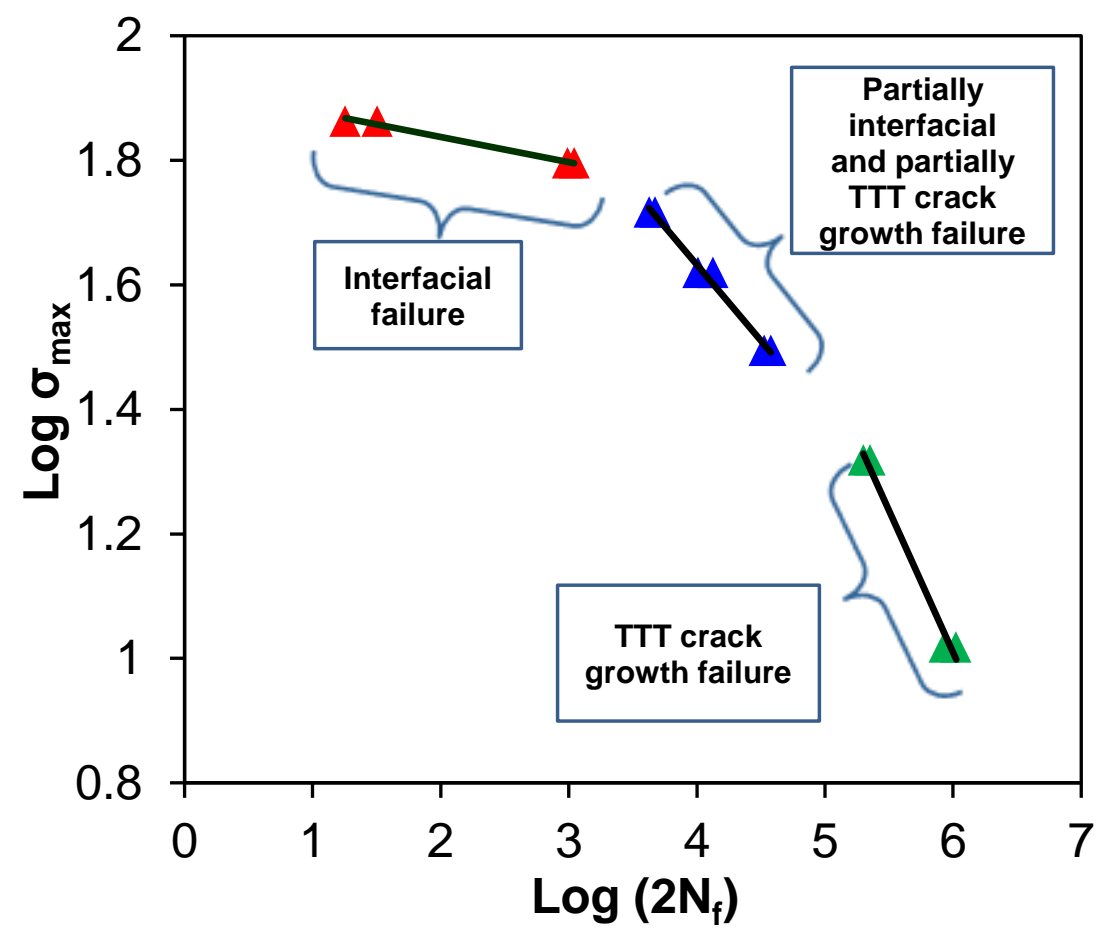

Figure 4.18: The maximum tensile shear cyclic stress vs. the number of reversals to failure $\left(2 N_{f}\right)$ in the double-log scale for the USWed Mg-to-Mg joints made at an energy input of $1000 \mathrm{~J}$, where different failure modes are indicated. 
USWed Mg-to-Mg joints are dependent on both welding energy and applied cyclic load level. With increasing cyclic load level, the failure mode tended to change from the TTT crack growth failure to the partially interfacial-partially TTT crack growth failure, and to the interfacial failure.

\subsection{Fatigue fractography}

SEM images of the fracture surface of a failed $1000 \mathrm{~J}$ welded sample of AZ31B-H24 Mg alloy tested at a cyclic load level of $\mathrm{P}_{\max }=0.5 \mathrm{kN}$ are shown in Figure 4.19. In general, fatigue fracture surface can be divided into three regions: crack initiation, crack propagation and final rapid failure. It can be seen from Figure 4.19(a) that fatigue crack developed from the region " $b$ " at the top of the sonotrode indentation area. Figure 4.19(b) shows the location of crack initiation and Figure 4.19(c) shows the magnified image of region "c" in Figure 4.19(b). Fatigue crack propagation was mainly characterized by the formation of fatigue striations (Figure 4.19(d)), which usually appeared perpendicular to the fatigue crack propagation direction (as shown by the arrows). Fatigue striations typically arise by a repetitive plastic blunting-sharpening procedure in the FCC materials, stemming from the

glide of dislocations on the slip plane along the slip direction within the plastic zone ahead of the fatigue crack tip [13, 118-120]. This observation confirmed that crack initiation occurred inside the sonotrode indentation area near the edge of sonotrode indentation-footprints. Final rapid propagation areas exhibited a tensile-like fracture surface feature, as shown in Figure 

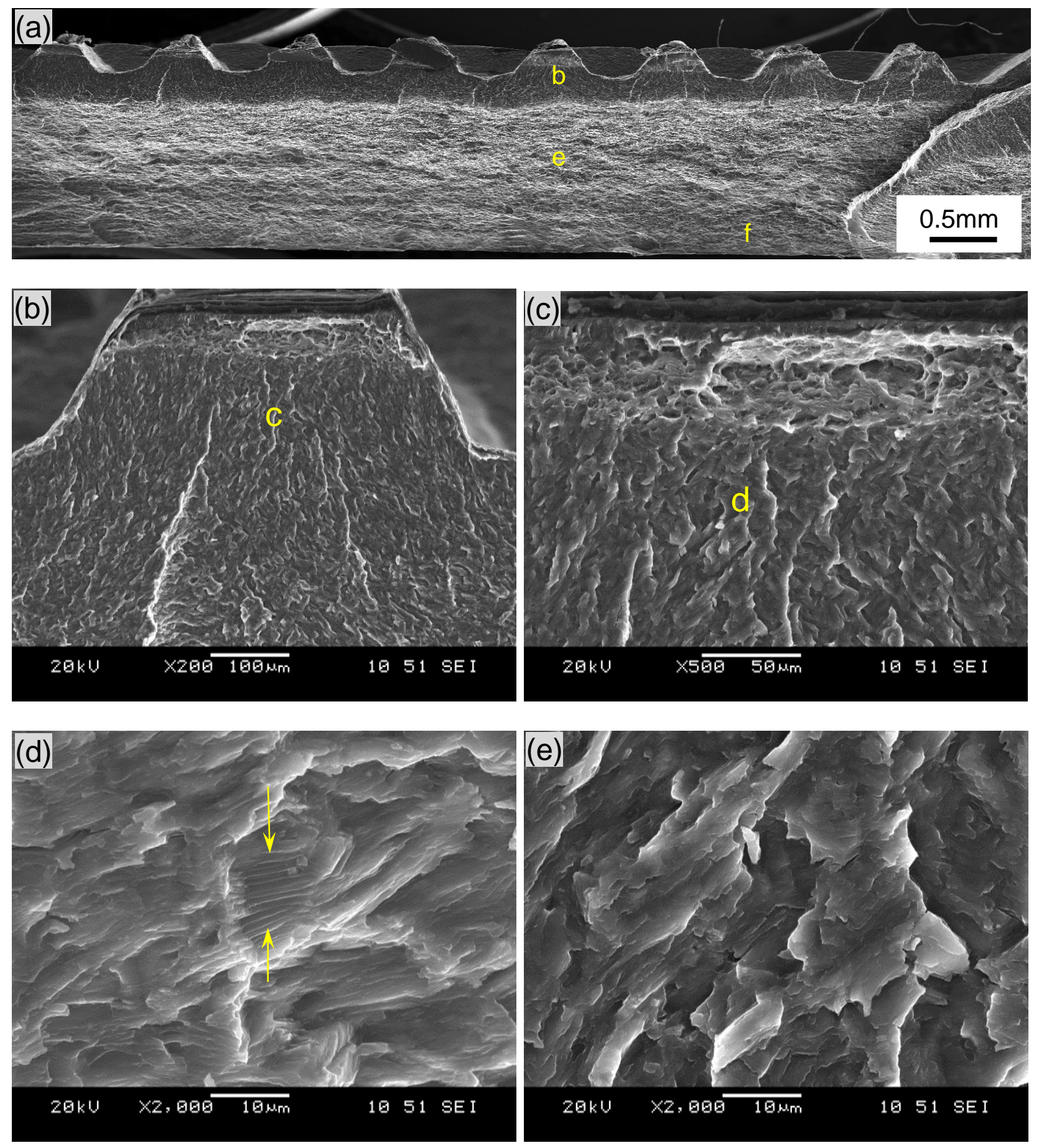

Figure 4.19: Typical SEM images of a fatigue fracture surface of a USWed Mg-to-Mg joint made with a welding energy of $1000 \mathrm{~J}$, tested at a $P_{\max }$ of $0.5 \mathrm{kN}$, (a) overall view, (b) crack initiation area from the top, (c) magnified image of crack initiation area, (d) fatigue striations in the crack propagation zone at a higher magnification, (e) final fast crack propagation area, (f) crack initiation area from the bottom in (a), and (g) fatigue striations at a higher magnification area in (f). 

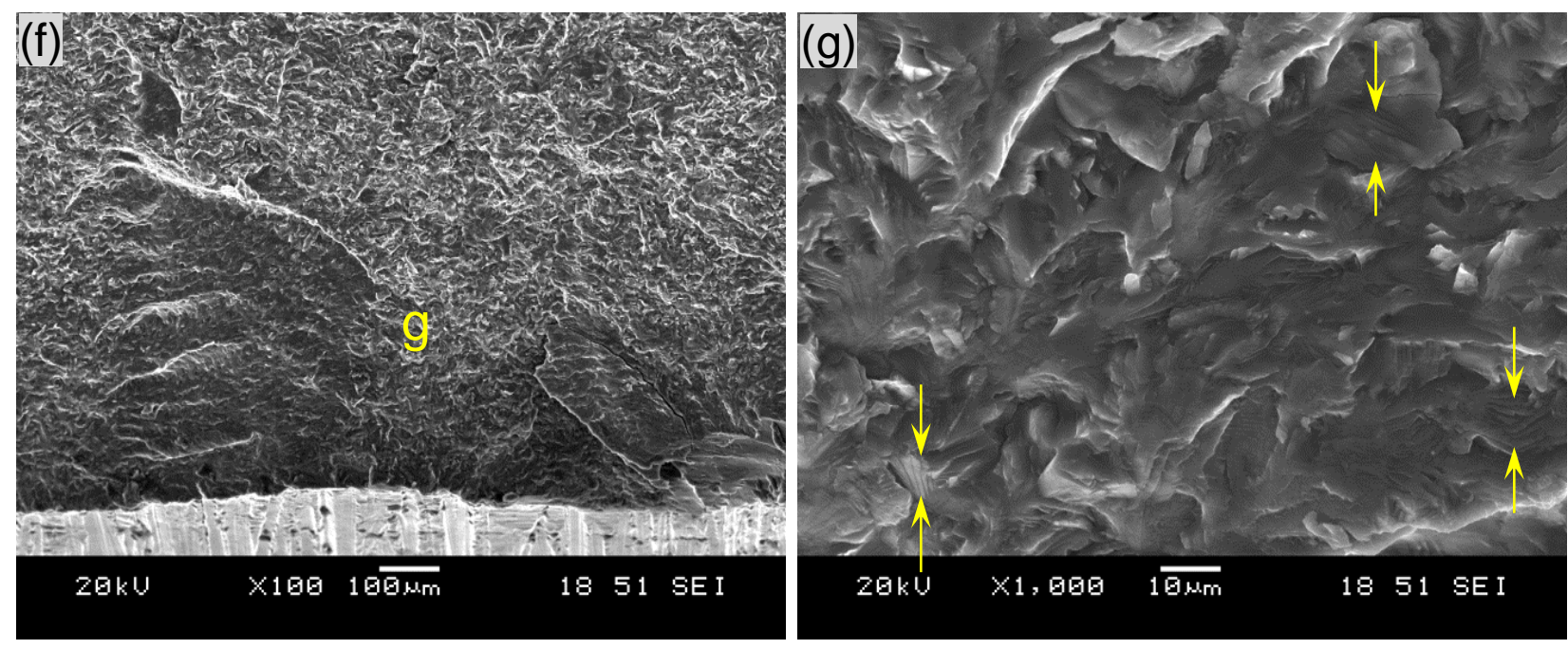

Figure 4.19 (cont'd): Typical SEM images of a fatigue fracture surface of a USWed Mg-toMg joint made with a welding energy of $1000 \mathrm{~J}$, tested at a $P_{\max }$ of $0.5 \mathrm{kN}$, (a) overall view, (b) crack initiation area from the top, (c) magnified image of crack initiation area, (d) fatigue striations in the crack propagation zone at a higher magnification, (e) final fast crack propagation area, $(f)$ crack initiation area from the bottom in (a), and (g) fatigue striations at a higher magnification area in $(f)$.

4.19(e). This was due to the fact that the load-carrying capacity of the final remaining crosssection was exhausted at the final stage of fatigue crack propagation. Figure 4.19(f) and (g) show the magnified region of ' $\mathrm{f}$ ' in Figure 4.19(a) and ' $g$ ' in Figures 4.19(f), respectively. It can be seen from Figure 4. 19(g) that the fatigue striations also can be found from the bottom of the $\mathrm{Mg}$ sheet, which confirmed that crack initiation and propagation also occurred from a natural notch tip. From this observation, it can be concluded that one crack initiated and propagated from the crack notch and the other from the sonotrode indentation-footprint region initiated and propagated, and coalesced approximately half of the Mg sheet thickness. 


\subsection{Fatigue life estimation}

The purpose of estimating the fatigue life of USWed Mg alloy is to develop a simple singledegree-of-freedom model that can be used by design engineers to predict fatigue lives of three-dimensional spot-welded lap joints when only the crack growth behavior (interface crack, kinked crack) of the base metal is known. In general, there are two main failure modes of the spot welds in lap-shear specimens under cyclic loading conditions, (I) the fatigue crack propagating along the interface of the welded joints (interfacial failure or main crack (Figure 4.20)), and (II) the kinked fatigue crack (TTT crack, Figure 4.20) propagating through the top or bottom Mg sheet. As shown in Figures 4.16 and 4.17, most of the welded samples failed in the mode of TTT crack growth. Thus, the modeling approach presented here is based on the assumption that the majority of the samples failed from the kinked crack growth mode. This assumption is also supported by previous studies on FSSW [79, 120, 78, $121]$

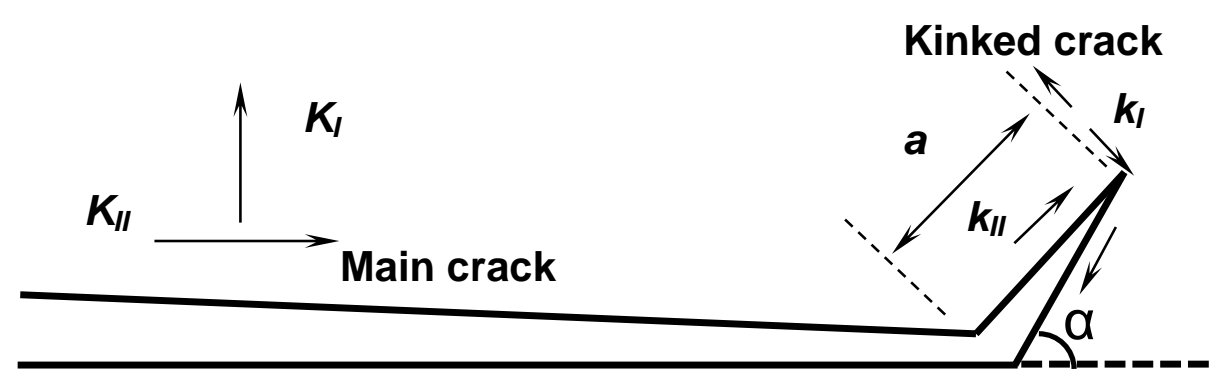

Figure 4.20: A schematic illustration of a main crack and a kinked crack with a kink length and a kink angle 


\subsubsection{Global stress intensity factor solutions for main cracks}

To develop an engineering spot welding fatigue model, the three-dimensional spot weld problem can be idealized as a two-dimensional crack problem as reported by Newman and Dowling (ND) [78] and Lin et al.[79]. In order to estimate the fatigue life, it is first necessary to examine the global stress intensity factor solutions for the main notch tips treated as a crack in the lap shear specimens based on the studies of Pook [80], Swellam et al. [83], Zhang [81, 82] and Lin et al.[79].

Pook [80] presented the global stress intensity factor solution for two circular plates with connection under uniform distributed loads along the clamped outer edges (here in this case point A and point B as shown in Figure 3.5) in the lap-shear specimens of thickness $t$ and nugget radius $r$ under the applied force $P$ as,

$$
\begin{gathered}
K_{I}=\frac{P}{r^{3 / 2}}\left[0.341\left(\frac{2 r}{t}\right)^{0.397}\right], \\
K_{I I}=\frac{P}{r^{3 / 2}}\left[0.282+0.162\left(\frac{2 r}{t}\right)^{0.710}\right] .
\end{gathered}
$$

Pook [80] indicated that Eqns. 4.5 and 4.6 are applicable for $r / t \leq 5$.

As reported by Swellam et al. [83], the mode I global stress intensity factor solution for spot welds was obtained from the solutions for two semi-infinite half spaces joined by a circular patch under an axial force and a moment. The mode II global stress intensity factor solution for spot welds was approximated from the mode III global stress intensity factor solution for 
two semi-infinite half spaces joined by a circular patch under a twisting moment. For lapshear specimens, the stress intensity factor solutions at the critical locations (here in this case point A and point B as shown in Figure 3.5) were proposed by Swellam et al. [83] as,

$$
\begin{gathered}
K_{I}=\sqrt{\frac{2}{\pi}} \times \frac{1.061 P(t)}{r^{5 / 2}}, \\
K_{I I}=\sqrt{\frac{2}{\pi}} \times \frac{0.354 P}{r^{3 / 2}} .
\end{gathered}
$$

Zhang $[81,82]$ obtained the global stress intensity factor $K_{\mathrm{I}}$ and $K_{\mathrm{II}}$ solutions at the critical locations (point A and point B as shown in Figure 3.5) for lap-shear specimens as,

$$
\begin{aligned}
& K_{I}=\frac{P \sqrt{3}}{4 \pi r \sqrt{t}}, \\
& K_{I I}=\frac{P}{\pi r \sqrt{t}} .
\end{aligned}
$$

Lin et al. [79] have modified Zhang's global stress intensity factor $\mathrm{K}_{\mathrm{I}}$ and $\mathrm{K}_{\mathrm{II}}$ solutions at the critical locations (point A and point B as shown in Figure 3.5) for lap-shear specimens as,

$$
\begin{gathered}
K_{I}=F_{I} \frac{P \sqrt{3}}{4 \pi r \sqrt{t}}, \\
K_{I I}=F_{I I} \frac{P \sqrt{3}}{4 \pi r \sqrt{t}} .
\end{gathered}
$$

where $F_{I}$ and $F_{I I}$ are the geometric correction functions, where $F_{I}$ is the ratio of global stress intensity factor $\left(K_{I}\right)$ of main crack of Wang et al. [122] and Zhang et al. [81] ((K $K_{I(\text { Wang et }}$ al.) $/ K_{I(\text { (Zhang et al.) })}$ and $F_{I I}$ is the ratio of global stress intensity factor $\left(K_{\mathrm{II}}\right)$ of main crack of

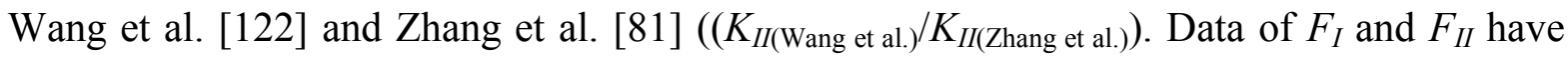


been taken from the Lin et al. [79], where graph of $F_{I}$ and $F_{I I}$ vs. W/d have been plotted, where $W$ is the width of the sample and $d$ is the diameter of the nugget.

In order to use these equations for the fatigue life estimation of USWed samples, the radius for the USW footprint is essential to be estimated. In the USW, sonotrode tip creates a rectangular indentation on both (top and bottom) sides of $\mathrm{Mg}$ sheet surface as shown in Figures 3.1 and 3.5. However, the real welded region is slightly larger than the area of the sonotrode tip with rounded corners. The radius of an equivalent circular weld was estimated in the present case, $\pi r^{2}=48$ where $48 \mathrm{~mm}^{2}$ is the rectangular area of the sonotrode tip ( 8 $\mathrm{mm}$ in length $\times 6 \mathrm{~mm}$ in width). Then, $r=3.91 \mathrm{~mm}$. Furthermore, since in most of the USW samples kinked crack propagated through the sheet inside the indentation area, here in this present study the reduced thickness of the $\mathrm{Mg}$ sheet $\left(t=t_{o}-t_{I}\right)$ is used, where $t_{o}$ is the original $\mathrm{Mg}$ sheet thickness and $t_{\mathrm{I}}$ is the depth of sonotrode tip getting into the sheet after the USW process.

\subsubsection{Local stress intensity factors solutions for kinked cracks}

Figure 4.20 shows a schematic illustration of a kinked crack with a kink angle $\alpha$ and kink length $a$. Here, $K_{\mathrm{I}} \& K_{\mathrm{II}}$ and $k_{\mathrm{I}} \& k_{\mathrm{II}}$ denote the global and local stress intensity factors for the main crack and the kinked crack, respectively. The arrows in the Figure 4.20 signify the positive values of the global and local stress intensity factors. For kinked cracks, when kink length (TTT crack) $a$ approaches to 0 , the local stress intensity factors $\mathrm{k}_{I}$ and $\mathrm{k}_{I I}$ can be expressed as a function of the kink angle $\alpha$ and global stress intensity factors $\left(K_{I}\right.$ and $\left.K_{I I}\right)$ for 
the main crack. In the USW process, because of the vibration in the longitudinal direction and bending in the normal direction due to the normal force of sonotrode tip, the microcrack generates at the notch tip between the two sheets (Figures 4.14(a) and (b)), which is similar to a kinked crack. Thus, the local $k_{I}$ and $k_{I I}$ solutions can be expressed as [78],

$$
\begin{aligned}
& \Delta\left(k_{I}\right)_{0}=\frac{\Delta K_{I}}{4}\left(3 \cos \frac{\alpha}{2}+\cos \frac{3 \alpha}{2}\right)-\frac{3 \Delta K_{I I}}{4}\left(\sin \frac{\alpha}{2}+\sin \frac{3 \alpha}{2}\right), \\
& \Delta\left(k_{I I}\right)_{0}=\frac{\Delta K_{I}}{4}\left(\sin \frac{\alpha}{2}+\sin \frac{3 \alpha}{2}\right)+\frac{\Delta K_{I I}}{4}\left(\cos \frac{\alpha}{2}+3 \cos \frac{3 \alpha}{2}\right),
\end{aligned}
$$

where $\left(k_{I}\right)_{0}$ and $\left(k_{I I}\right)_{0}$ represent the local $k_{I}$ and $k_{I I}$ solutions for the kink length $a$ approaching 0 . In order to calculate the local stress intensity factors for the kinked crack, crack angle $\alpha=$ $45^{\circ}$ has been used (Figure 4.14(b)). Since the kinked crack growth is under local combined mode I and mode II loading conditions, an equivalent stress intensity factor, $k_{e q}$, can be defined as [78],

$$
\Delta\left(k_{e q}\right)_{0}=\sqrt{\Delta\left(k_{I}\right)_{0}^{2}+\beta \Delta\left(k_{I I}\right)_{0}^{2}},
$$

where $\beta$ is an empirical constant to account for the sensitivity of materials to mode II loading conditions. In the absence of any further information in the literature for the value of $\beta$ of $\mathrm{Mg}$ alloys, here in this study, $\beta$ as 1 has been taken for the USWed Mg alloy joints $(\beta=1$ fits much better than other value). 


\subsubsection{A fatigue crack growth model}

A Paris crack growth relation as a function of $\Delta k_{e q}$ could be expressed with an adjustment for the $R$-ratio effect as suggested by Walker [123],

$$
\frac{d a}{d N}=C\left(\frac{\Delta k_{e q}}{(1-R)^{(1-\gamma)}}\right)^{m},
$$

where $N$ is the number of fatigue cycles, $C$ and $m$ are the material constants, and $\Delta k_{e q}$ is the equivalent stress intensity range. As with Newman and Dowling [78], it is assumed that the local stress intensity factors remain almost constant throughout fatigue crack progress. Thus, the local stress intensity factor solutions considered in this study are assumed to be independent of the kink length $a$. Integrating Eqn. 4.16 gives,

$$
N_{\text {total }}=\frac{t}{C \sin \alpha}\left[\frac{(1-R)^{1-\gamma}}{\Delta k_{e q}}\right]^{m} .
$$

Since the fatigue crack will align and grow at an angle of $\alpha, t / \sin \alpha$ is substituted for the crack length $a$ in Eqn. 4.17, where $t$ is $\left(t_{o}-t_{I}\right)$ as discussed earlier.

\subsubsection{Applicability of the fatigue model}

To demonstrate the applicability of the proposed fatigue model for spot welds, the estimated fatigue lives based on the kinked fatigue crack growth model for the USWed AZ31B-H24 Mg alloy were compared with the experimental results of USWed Mg-to-Mg joints, as plotted in Figure 4.21. The predicted fatigue lives were obtained from the following 


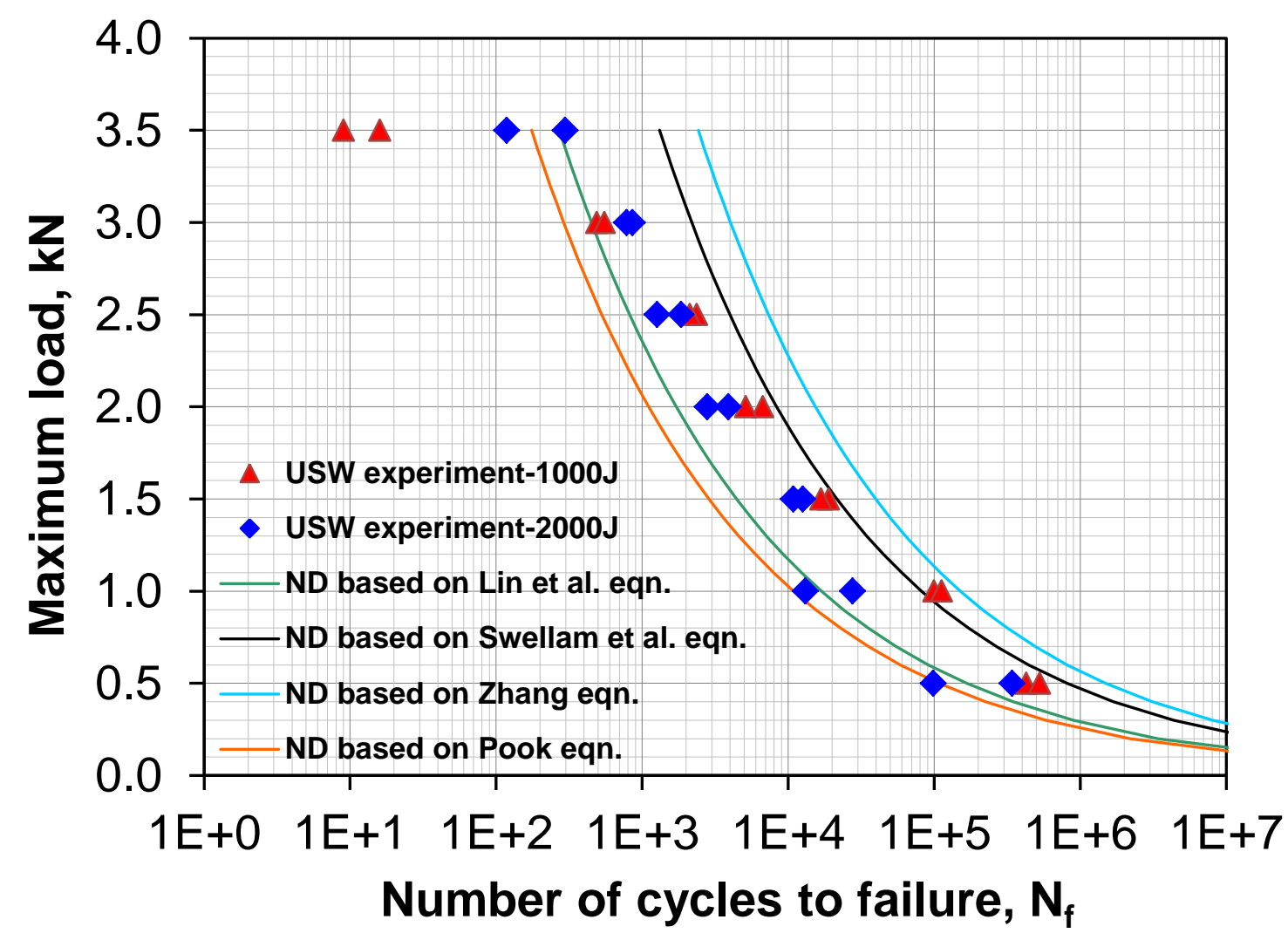

Figure 4.21: Experimental results and fatigue life estimations for theUSWed Mg-to-Mg joints, where the symbols denote the experimental results of fatigue life and various curves represent the fatigue life estimation using Newman and Dowling(ND) model based on the global stress intensity factors solutions of Eqns. of Lin et al. [79], Swellam et al. [83], Zhang [81, 82] and Pook [80].

parameters: a reduced thickness of the failed sheet $\left(t=t_{o}-t_{I}=2-0.3=1.7 \mathrm{~mm}\right)$ under the sonotrode tip indentation, the weld nugget radius $r=3.91 \mathrm{~mm}$, specimen width $W=15 \mathrm{~mm}$, and kink angle $\alpha \approx 45^{\circ}$ (approximated from the micrographs shown in Figure 4.14(b) for the USWed AZ31B-H24 Mg alloy). The material constants $C$ and $m$ for the AZ31 Mg alloy are chosen to be $2.4 \times 10^{-10} \mathrm{MPa} \cdot \mathrm{m}^{1 / 2}$ [124] and 3.3 [120], respectively, loading ratio parameter $\gamma$ $=0.75$ was taken from literature [78], and finally the fatigue load ratio $R=0.2$. It can be seen from Figure 4.21 that the predicted fatigue lives, based on the fatigue crack growth model with the global and local stress intensity factors as a function of the kink length (here $t / \sin \alpha$ ) 
and the experimentally determined kink angle, agree fairly well with the experimental results. The predicted fatigue lives based on the global stress intensity factor solutions of Swellam et al. [83] (Eqns. 4.7 and 4.8) and Lin et al. [79, 125] (Eqns. 4.11 and 4.12) appear to be closer to the experimental results. However, the predicted fatigue lives of the USWed Mg-to-Mg joints based on the global stress intensity factor solutions of Pook [80] and Lin [79] provide more conservative curves compared with those of Swellam [83] and Zhang [81, 82]. While some differences between the predicted fatigue lives and experimental data for the USWed Mg-to-Mg joints are still there, the present study in the fatigue life estimation seems to be somewhat better than the prediction using a structural stress model for the USWed Mg-tosteel samples [77]. Further studies in developing more accurate fatigue life prediction models are needed.

\subsection{Summary}

- USW of similar AZ31B-H24 Mg alloy sheets was successfully achieved.

- The influence of the input energy on the strain rate and temperature generated during USW was evaluated. After USW, the grain size was observed to increase with increasing welding energy.

- A higher welding energy input caused greater shear strain rate and higher peak temperatures. These both factors were mostly accountable for controlling the dynamically recrystallized grain size.

- A relationship was obtained for the variation in dynamically recrystallized grain size with the Zener-Hollomon parameter. A Hall-Petch type relationship was established 
and the microhardness tests showed that hardness decreased with increasing energy input due to increasing grain size.

- The scatter of the $(0002)<10 \overline{1} 0>$ and $(0002)<11 \overline{2} 0>$ generate a pole of rolled Mg that is almost a (0001) fiber texture, which was mainly observed in the BM region of the USWed Mg alloys. After USW of Mg alloy at $2000 \mathrm{~J}$,dynamic recrystallization creates $90^{\circ}$ rotation of the basal plane in the $\mathrm{NZ}$ so that its normal is parallel to the $\mathrm{TD}$ in the $\mathrm{NZ}$ at the angle of $60^{\circ}$ and slightly tilted at the angle of 5 to $10^{\circ}$ towards the RD. This may because the induced higher temperature rise due to the friction results in more complete dynamic recrystallization.

- With increasing energy input, lap shear strength increased and failure occurred by interface fracture. However, at very high energy inputs, the lap shear strength decreased and failure occurred by weld button pullout. This research shows a good correlation among the deformation mechanism, texture development and welding parameter for the USWed Mg alloy AZ31B-H24.

- In this study, a life prediction model for spot welded lap joints developed by Newman and Dowling is adopted to estimate the fatigue lives of the USWed Mg-toMg joints. The fatigue life estimation based on the fatigue crack growth model with the global and local stress intensity factors as a function of kink length and the experimentally determined kink angle agrees well with the experimental results.

- The fatigue failure mode of the USWed Mg-to-Mg joints changed from the interfacial failure to the TTT crack growth failure with decreasing cyclic load level from the maximum applied load $P_{\max }=3.5$ to $0.5 \mathrm{kN}$. 
- After converting the maximum applied load into the maximum stress using the nominal welding nugget area in different welding techniques, the USWed joints displayed a longer fatigue life compared with other welding processes.

- In the USWed Mg-to-Mg joints fatigue crack initiation and propagation were observed to occur from both the notch tip in-between the two sheets and the edge of sonotrode indentation-footprints due to the presence of stress concentration. Fatigue crack growth was mainly characterized by the formation of characteristic fatigue striations.

In this Chapter, it is seen that USW process has successfully achieved sound joints of similar Mg-to-Mg alloys, which shows the potential of USW process to join Mg alloy in spot welding industry. However, $\mathrm{Al}$ has already a wide variety of structural applications in the transportation industry due to their excellent properties, such as good ductility, formability and thermal conductivity. To achieve the combined properties of both alloys, recently, demand for dissimilar metal joints of Mg-to-Al alloy has risen. Thus, it is worth to develop some new potential welding process, since many other welding techniques failed to produce sound joints for this kind of challenging combination of materials. Chapter 5, will characterize the USW of Mg-to-Al joints and show how a Sn interlayer can increase the lap shear tensile strength of Mg-to-Al joints. 


\section{CHAPTER 5}

\section{ULTRASONIC SPOT WELDING OF MAGNESIUM-TO-ALUMINUM ALLOYS ${ }^{\dagger}$}

The aim of this Chapter is to characterize the weld of Mg-to-Al joints, to study the cause of the failure in detail, and to improve the lap shear fracture strength by using a Sn interlayer inserted between the faying surfaces during USW. The selection of $\mathrm{Sn}$ in the present study was based on the Mg-Sn and Al-Sn binary phase diagrams [91, 126], which show that Sn may interact with $\mathrm{Mg}$ and generate IMCs, while $\mathrm{Sn}$ is dissolved into Al to form a solid solution of Sn-Al. Furthermore, Sn was selected on the basis of the findings that it improved the wettability of $\mathrm{Mg}$ and $\mathrm{Al}$ during the welding process [127] and also refined the grain size in the $\mathrm{Mg}$ alloy [128].

\subsection{Without interlayer in-between the faying surface}

\subsubsection{Microstructure}

Microstructural characterization was conducted across the welding line of the samples. Figures 5.1(a) and (b) depict the typical microstructure of the welded sample of AZ31-H24 and A15754-O at $1500 \mathrm{~J}$ and $3000 \mathrm{~J}$ energy inputs, respectively. The weld had no large

\footnotetext{
${ }^{\dagger}$ This chapter is based on the following publications of the author: V.K. Patel, S.D. Bhole, D.L. Chen: 'Microstructure and mechanical properties of dissimilar welded Mg-Al joints by ultrasonic spot welding technique', Science and Technology of Welding and Joining, 2012,Vol 17-No 3,202-206.

V.K. Patel, S.D. Bhole, D.L. Chen: 'Improving weld strength of magnesium to aluminium dissimilar joints via tin interlayer during ultrasonic spot welding', Science and Technology of Welding and Joining, 2012, Vol 17No 5, 342-347.
} 

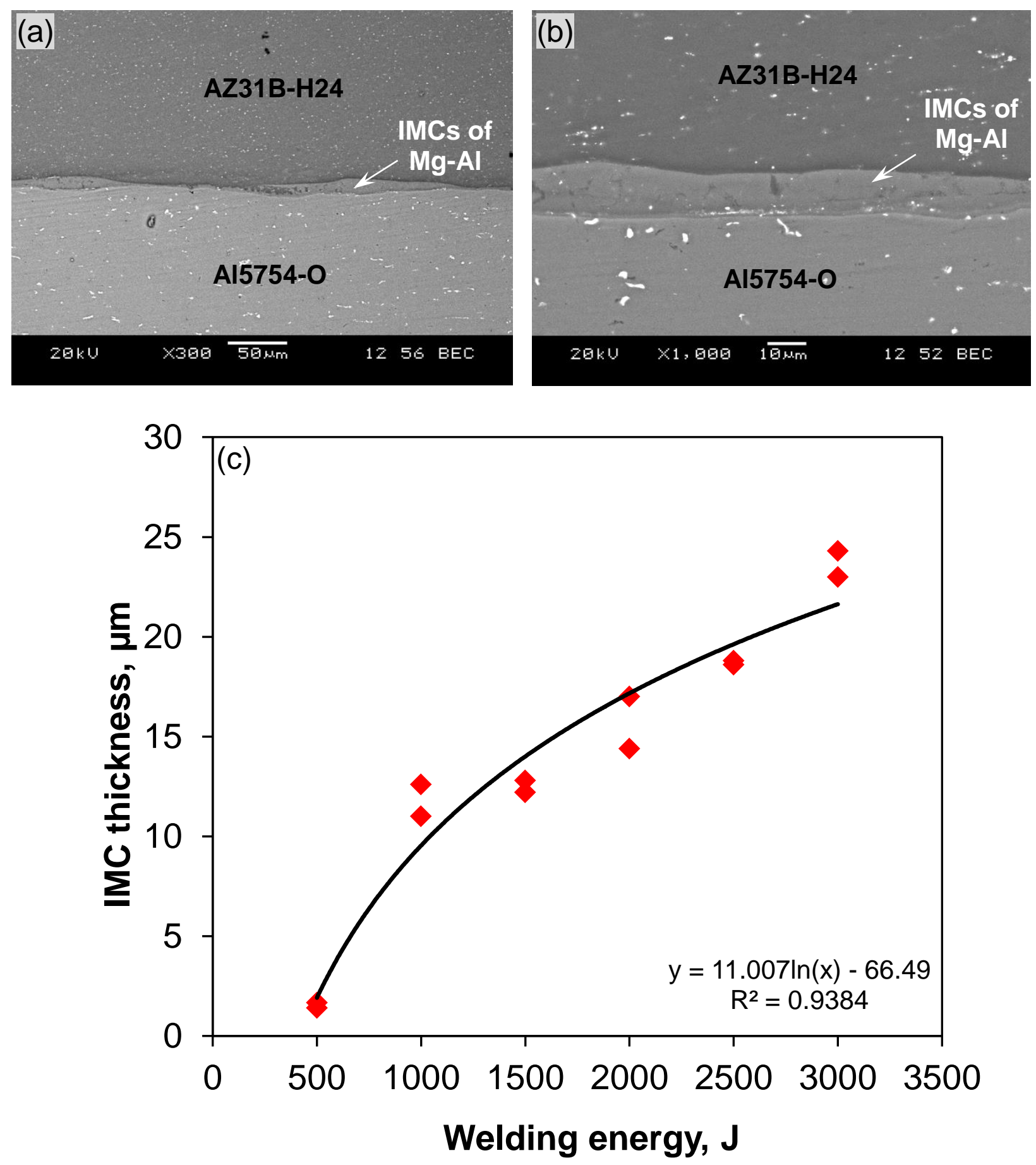

Figure 5.1: Microstructures of AZ3-H24 and Al5754-O welded samples at (a) 1500J, (b) $3000 \mathrm{~J}$ energy inputs and (c) relation between IMC thickness and different energy inputs. 
defects, such as crack or tunnel type defects. A sound joint was obtained under most of the welding conditions, but a crack was observed on the weld surface at energy inputs of $2500 \mathrm{~J}$ and above (similar crack as shown in 4.12 (b)). This crack was thought to be related to frictional heat generated between the welding tip (made of steel) and welded sheets and the restraint between them leading to tensile residual stresses in the sheet. It can be seen from Figure 5.1(a) that there is an IMC layer between the two alloys which is distributed heterogeneously. This may be because the temperature distribution is not homogenous across the welding line owing to the short initial welding time. In the $500 \mathrm{~J}$ energy input sample, discontinuous layers of IMC have been found while in the $3000 \mathrm{~J}$ energy input sample continuous layers of IMC have been observed owing to the equal distribution of the temperature at the higher-energy input (Figure 5.1(b)). High local temperatures and strain rate and pressure promote chemical reaction and accelerate diffusion, leading to metallic bonding between the two sheets [129]. The diffusion and chemical reaction between the $\mathrm{Mg}$ and Al alloys result in the formation of IMC. During the USW, in first initial cycles, oxide films at the faying surfaces first breaks down locally at asperities on the contacting surfaces and bring fresh metal-to-metal contact. Now, by continuing applying high frequency vibratory energy for longer period of time permit inter-diffusion of $\mathrm{Mg}$ and $\mathrm{Al}$ to occur. If the kinetics is adequately rapid, it creates the simultaneous formation of IMCs throughout the faying surfaces. Several previous works on the dissimilar welds have suggested that the weld strength is seriously affected by the thickness of the IMC layer formed at the weld interface. On examination of the cross sections of the Mg-to-Al welds, the IMC layer was evidently observable at the weld interface even after short welding times . Figure 5.1(c) shows that the IMC thickness increses with increasing welding energy input. At $500 \mathrm{~J}$ welding energy input, 
a discontinuous IMC layer with a maximum thickness of $2 \mu \mathrm{m}$ was already present. With higher weld energy input (3000 J), the thickness of the IMC layer increased to $25 \mu \mathrm{m}$.

\subsubsection{Energy-dispersive $X$-ray spectroscopy analysis}

To identify the IMC phase in the interface layer formed between the $\mathrm{Mg}$ and $\mathrm{Al}$ alloy during the USW, EDS has been conducted at the center of the cross section and on the fracture surface of the weld on the $1500 \mathrm{~J}$ energy input samples. Figure 5.2(a) shows the area analysis of the fracture surface (Mg side). The EDS results showed that 58.7 at. $\%$ of $\mathrm{Mg}$ and 41.3 at. \% of $\mathrm{Al}$ were present which indicates that the reaction interlayer is mainly comprised of a single IMCs of $\mathrm{Al}_{12} \mathrm{Mg}_{17}$. Similar EDS area analysis on the fracture surface of the $\mathrm{Al}$ side was also performed. However, IMCs of $\mathrm{Al}_{12} \mathrm{Mg}_{17}$ were not found, which indicating that the failure predominantly occurred in-between the Al alloy and the intermetallic layer, which normally stayed at the Mg side or from the cracks of the IMCs in the reaction layer. The present dissimilar USW is likely exposed to peak temperatures above $460{ }^{\circ} \mathrm{C}$ as confirmed by thermocouple measurements at the center of the weld of similar Mg alloy in earlier section 4.2.2. This peak temperature is sufficient for mutual diffusion between $\mathrm{Mg}$ and $\mathrm{Al}$. Even though USW is a solid-state joining process, in dissimilar USW it may be possible that constitutional liquation occurs due to the high frequency vibration and resulting heating. After constitutional liquation, the liquid-phase solidifies during the cooling cycle of USW. In the binary Al-Mg system, there are two low melting point eutectic reactions [130] - one between the $\mathrm{Mg}$ solid solution and $\mathrm{Al}_{12} \mathrm{Mg}_{17}$ at $437^{\circ} \mathrm{C}$, and the other between $\mathrm{Al}$ and 


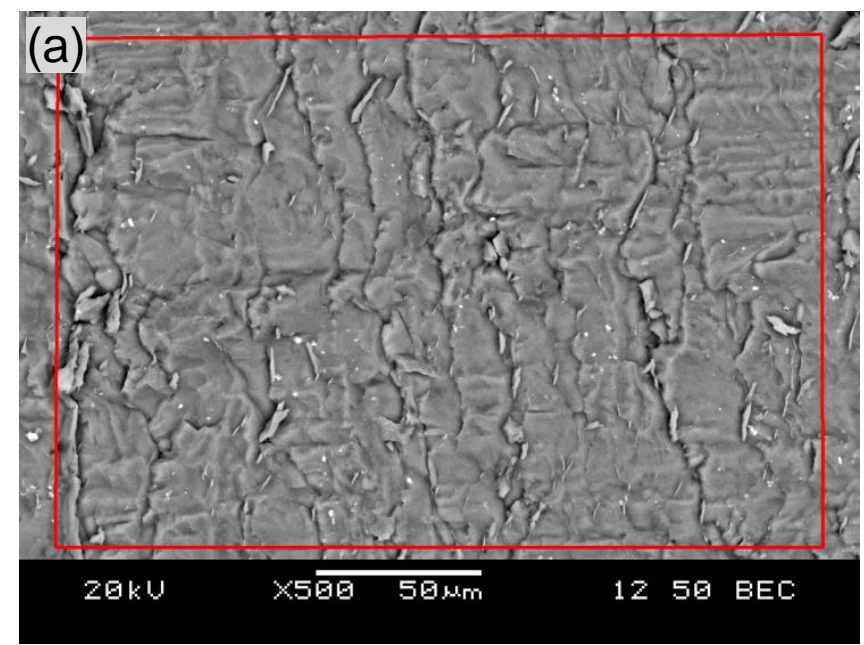

\begin{tabular}{ccc} 
Elements & wt\% & at\% \\
\hline $\mathrm{Mg}$ & 56.2 & 58.7 \\
$\mathrm{Al}$ & 43.8 & 41.3 \\
\hline
\end{tabular}
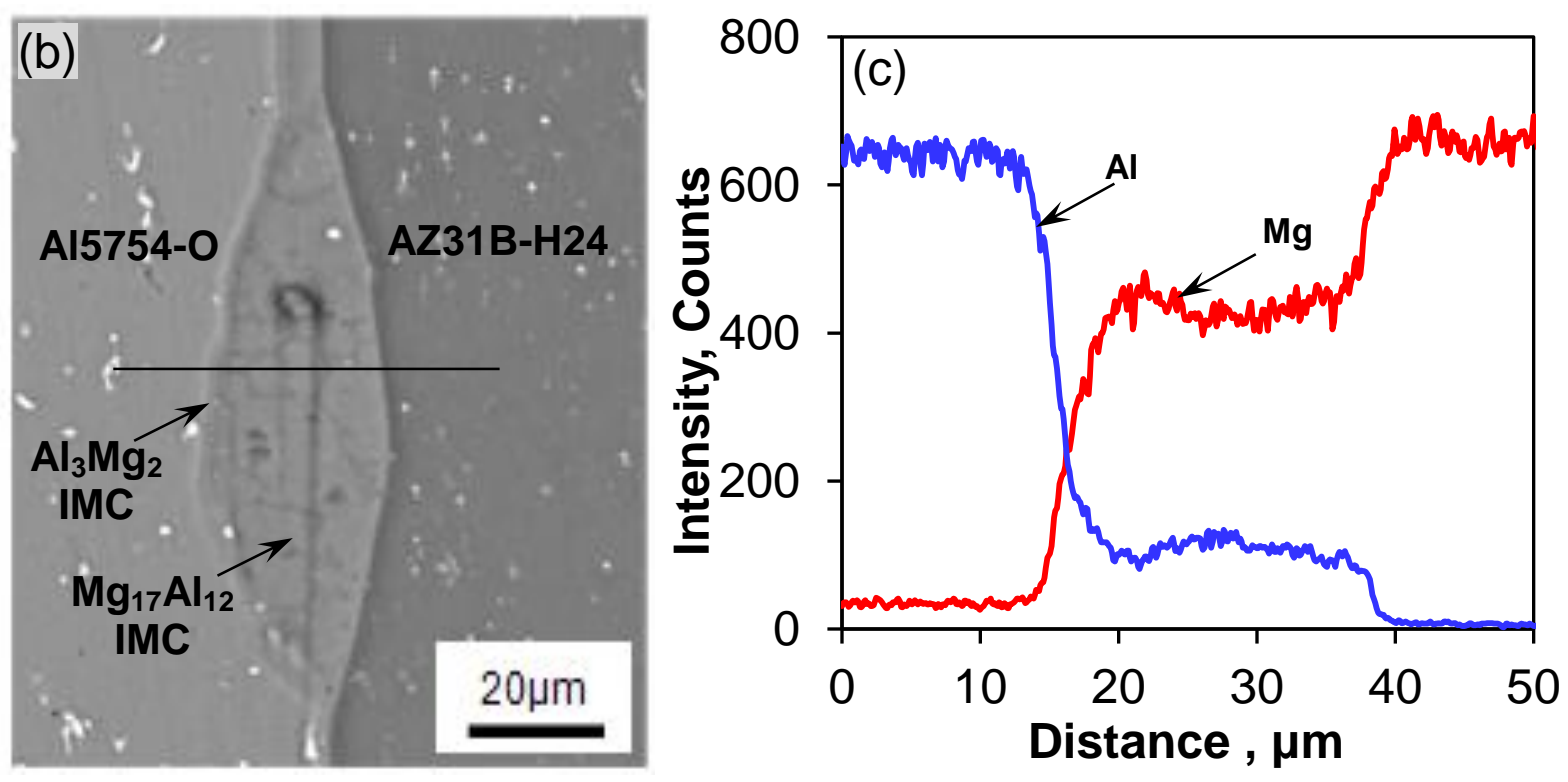

Figure 5.2: EDS analysis: (a) area analysis of the fracture surface on the $1500 \mathrm{~J}$ energy input welded sample and (b) SEM micrograph of $3000 \mathrm{~J}$ welded sample (c) is EDS line scan across the center of layer in (b).

$\mathrm{Al}_{12} \mathrm{Mg}_{17}$ at $460^{\circ} \mathrm{C}$. This clearly indicates that $\mathrm{Al}_{12} \mathrm{Mg}_{17}$ is formed first by solid state reaction on $\mathrm{Mg}$ side at $437^{\circ} \mathrm{C}$ and then it creates an interface layer, which penetrates along grain boundaries into the $\mathrm{Mg}$ sheets to resolidfy as $\mathrm{Al}_{12} \mathrm{Mg}_{17}$ and $\mathrm{Mg}$ eutectic structure. A second interlayer is also visible in Figure 5.2(b) (indicated by arrow) on the $\mathrm{Al}$ side of the $\mathrm{Al}_{12} \mathrm{Mg}_{17}$ layer. This layer has not yet been identified but may be indicative of the formation of the 
$\mathrm{Al}_{3} \mathrm{Mg}_{2}$. This phase has also been reported in the literature [88]. Thus, the results of SEM, EDS and Al-Mg phase diagram all suggest that the non-uniform IMC layer has a solidified microstructure experiencing the eutectic reaction, liquid $\rightarrow \mathrm{Al}_{12} \mathrm{Mg}_{17}+\mathrm{Mg}$, after the primary solidification of $\mathrm{Al}_{12} \mathrm{Mg}_{17}$. EDS line analysis across the interface in a $3000 \mathrm{~J}$ energy welded sample is shown in Figure 5.2(b). Both $\mathrm{Mg}$ and $\mathrm{Al}$ are present in fairly constant concentrations across the entire IMC layer. This also indicates the $\mathrm{Al}_{12} \mathrm{Mg}_{17}$ phase

\subsubsection{X-ray diffraction analysis}

For further separate verification of IMCs, the fracture surface of the Mg side of the welded sample was analyzed by XRD. Figure 5.3 shows large peaks of $\mathrm{Mg}$ and small peaks of IMCs

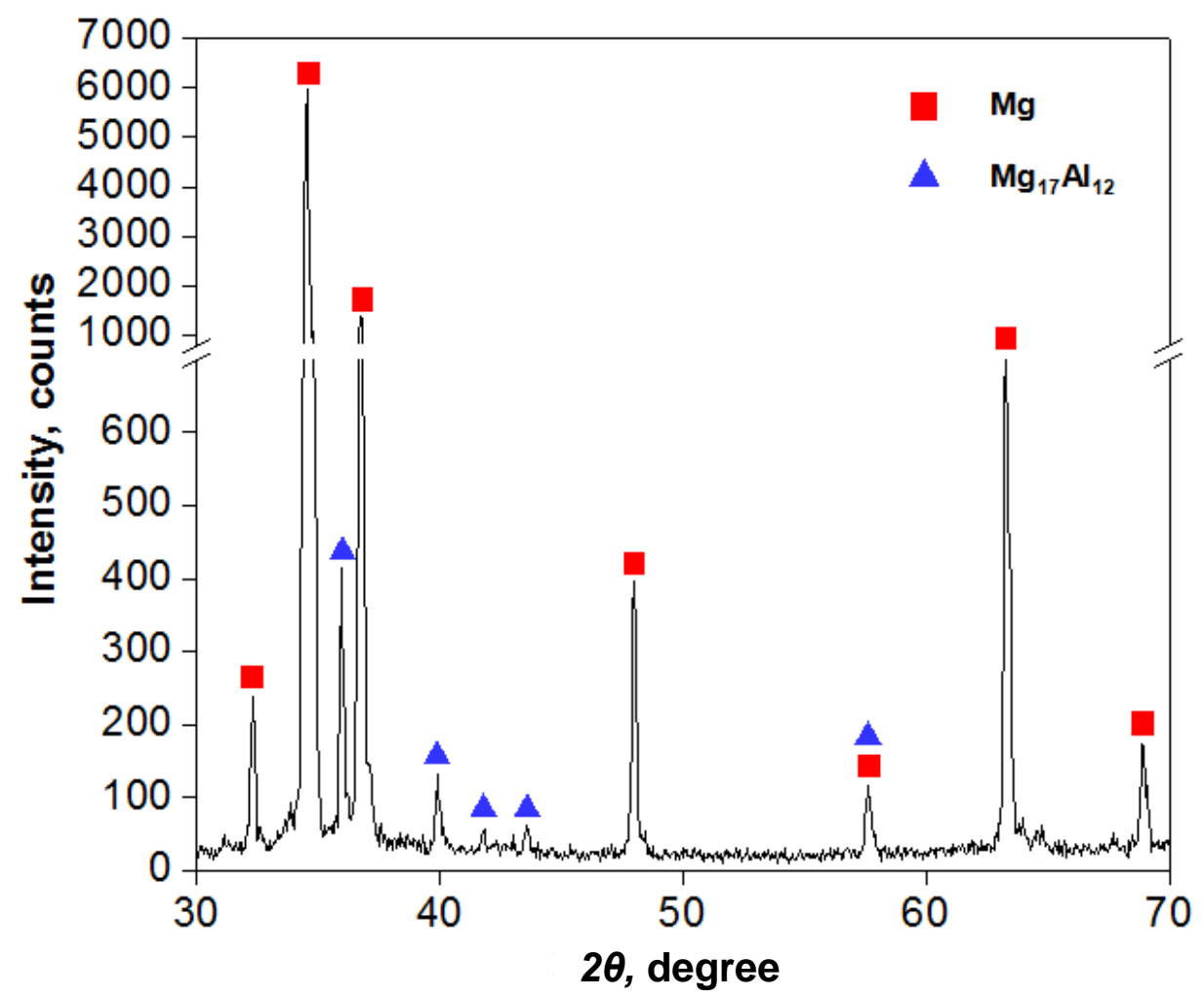

Figure 5.3: XRD on the fracture surface of the 1500 J energy input welded sample. 
$\mathrm{Al}_{12} \mathrm{Mg}_{17}$. These IMCs were considered to form by the inter-diffusion behavior of $\mathrm{Mg}$ and $\mathrm{Al}$ atoms during USW. The XRD spectrum confirms that the non-uniform IMC layer of the dissimilar weld contains a large volume of the intermetallic compound $\mathrm{Al}_{12} \mathrm{Mg}_{17}$. Similar results were also reported in the literature [88, 85, 131-133, 84]. Kostka et al. [129] have confirmed the presence of other phase $\mathrm{Al}_{3} \mathrm{Mg}_{2}$ in $\mathrm{FSW}$ using transmission electron microscope. However, XRD technique cannot detect the presence of very minor phases.

\subsubsection{Microhardness}

Unlike RSW, USW displays no clearly discernible fusion zone or heat affected zone that can degrade the strength of the metals being joined [24, 25]. It can be inferred that in USW, the HAZ is small because of poor conductivity of the welding tip (steel) compared to the thermal conductivity of the samples. The hardness profile across the non-uniform IMC layer, which was measured along the diagonal line, is shown in Figure 5.4. It can be seen that hardness decreases with increasing energy input, owing to increasing grain size at higher temperature. The non-uniform IMC layer in the weld center has hardness values between 200 and $300 \mathrm{HV}$. This higher hardness is due to the brittle IMCs of $\mathrm{Al}_{12} \mathrm{Mg}_{17}$ present in the center of the weld. Similar results were also obtained by other researchers [88, 131, 132, 93, 134]. Therefore,

the hardness test also verified the presence of the hard IMCs. Thus, USW of the Mg and Al alloys produces a brittle interfacial layer composed mainly of IMCs, which provide an easy fracture path. 


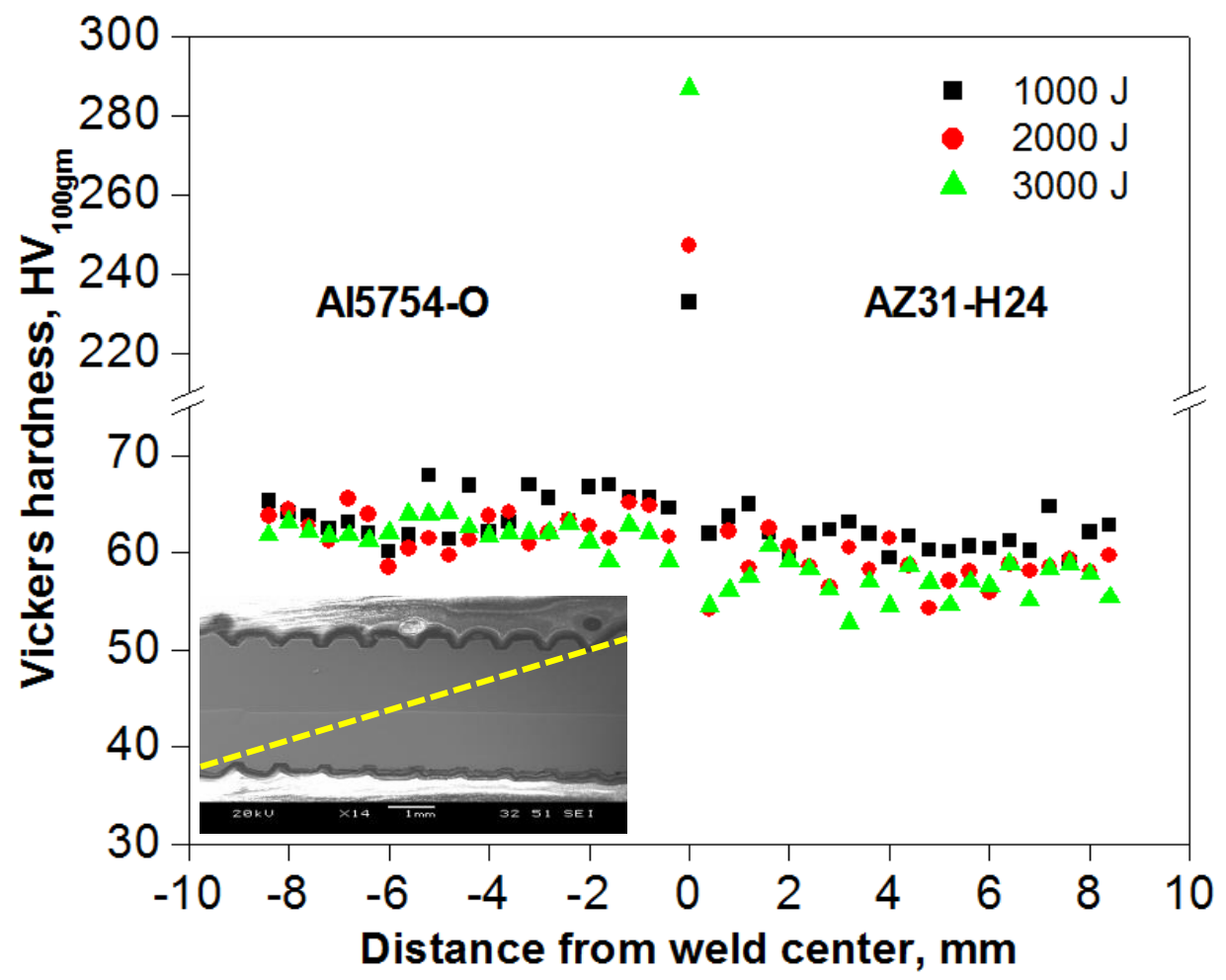

Figure 5.4: Microhardness profile in welded joints at different energy inputs.

\subsubsection{Lap shear tensile strength of joints}

The results of the lap shear tensile tests of the $\mathrm{Mg}$ and $\mathrm{Al}$ alloy weld joint are shown in Figure 5.5(a). The maximum lap shear strength was about $36 \mathrm{MPa}$ at $1250 \mathrm{~J}$ energy input (based on the maximum lap shear fracture load divided by the nugget area $8 \times 6 \mathrm{~mm}$ ), which is lower than the lap shear strengths (assumed as half of the tensile strength) of the AZ31H24 and Al5754-O base metals which are 135 and $145.5 \mathrm{MPa}$, respectively [135, 136]. With increasing energy input, lap shear strength was increased in the beginning owing to high temperatures and strain rate, which accelerated diffusion in between $\mathrm{Mg}$ and $\mathrm{Al}$ alloy, but it decreased at very high-energy inputs. It seems that the decrease in lap shear strength is 

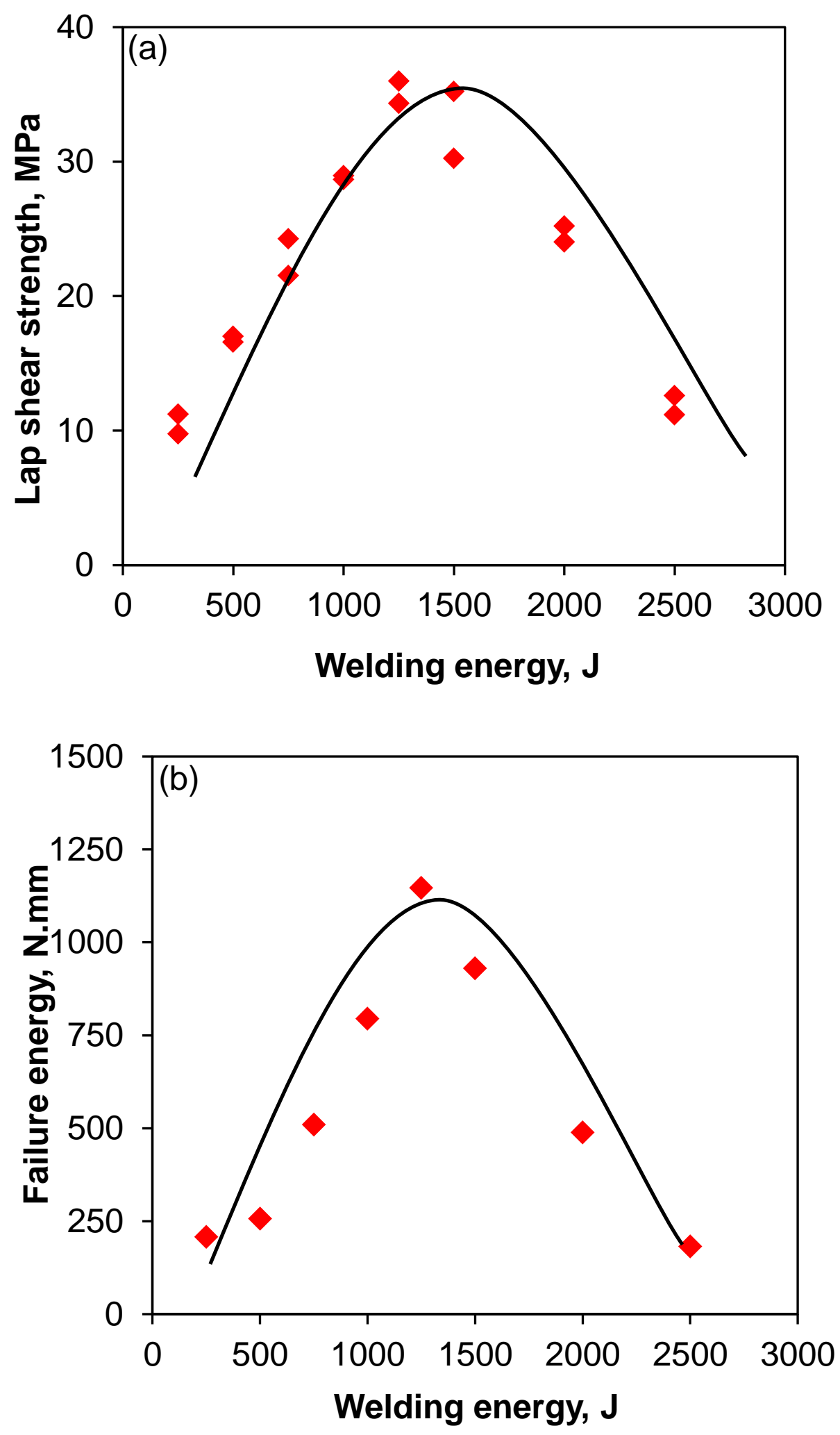

Figure 5.5: (a) Lap shear strength and (b) failure energy of welded joints at different energy inputs levels. 
related to the thickness and presence of cracks in the reaction layer. Therefore, as thickness of the brittle IMC layer increases, the lap shear strength decreases. This was a consequence of a competition between the increasing diffusion bonding arising from higher temperatures and the deterioration effect of the intermetallic layer of increasing thicknesses. Figure 5.5(b) shows the relationship between average value of the failure energy (as determined by integration of the lap shear fracture load curves) and welding energy input. It can be seen that at the beginning failure energy increases with the energy input and reaches a maximum around $1.14 \mathrm{kN} . \mathrm{mm}$ and then it decreases due to the larger brittle IMC layer. Based on these results (Figure 5.1(c) and Figure 5.5(a)), it can be concluded that the thickness of IMC was closely related to the strength of Mg-to-Al USW joint. In Figure 5.2(a), the fracture surface appeared coarse and dark gray. The fracture surfaces on the $\mathrm{Mg}$ alloy consisted of protuberances and cleavage cracks, which were considered as proof of brittle fracture mode.

\subsection{With tin (Sn) as an interlayer in-between the faying surface}

Now, Sn interlayer was placed in between the faying surfaces of $\mathrm{Mg}$ and $\mathrm{Al}$ and SEM, EDS, micro hardness test were performed on the weld cross section. Lap shear tensile test was also performed to check the effect of Sn interlayer on the joint properties.

\subsubsection{Microstructure}

Microstructural characterization was conducted across the weld line of the samples. Figures 5.6(a) and (b) show microstructures at the center of weld nugget of USW welded Mg-to-Al 

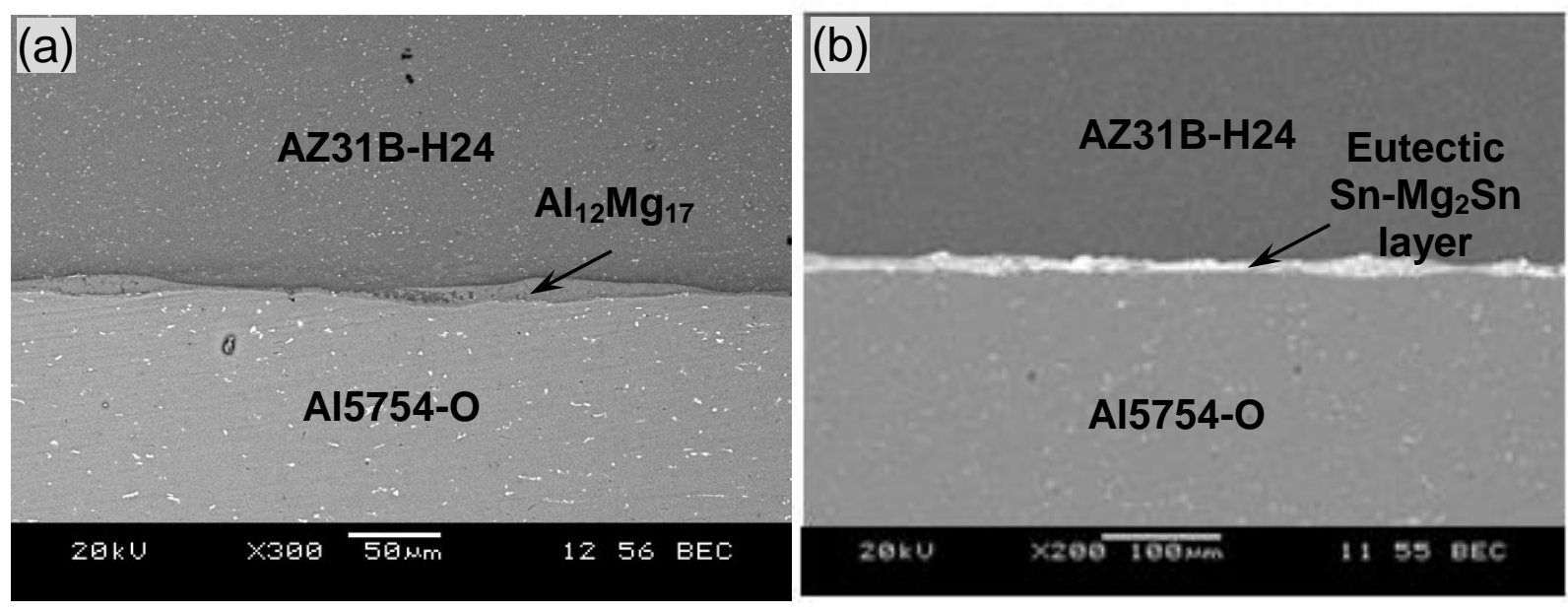

Figure 5.6: Microstructure of the dissimilar USW Mg/Al joints made with a welding energy of $1500 \mathrm{~J}$ in the middle of weld nugget (a) without and (b) with a Sn interlayer.

joints characteristic of the whole weld nugget without and with a Sn interlayer, respectively. A sound joint was obtained under most of the welding conditions since no large defects such as crack or tunnel type defects were present. It can be seen from Figure 5.6(a) that there was a heterogeneously distributed IMC layer between the $\mathrm{Mg}$ and $\mathrm{Al}$ alloy sheets. As seen in the our previous section 5.1 of USW of Mg-to-Al alloys without Sn interlayer, the non-uniform IMC layer had a solidified microstructure containing the brittle phase through the eutectic reaction, liquid $\rightarrow \mathrm{Al}_{12} \mathrm{Mg}_{17}+\mathrm{Mg}$. In the USW of $\mathrm{Mg}$-to-Al with a $\mathrm{Sn}$ interlayer, the IMCs of $\mathrm{Al}_{12} \mathrm{Mg}_{17}$ were not observed as the $\mathrm{Al}$ and $\mathrm{Mg}$ were separated by the $\mathrm{Sn}$ interlayer.

\subsubsection{Energy-dispersive X-ray spectroscopy analysis}

The IMC layer displayed a composite-like eutectic structure, as shown in Figure 5.7 at the center of the weld nugget, where the Sn-containing white fine particles were distributed homogeneously or as a network in the interlayer. This was roughly estimated via both EDS 

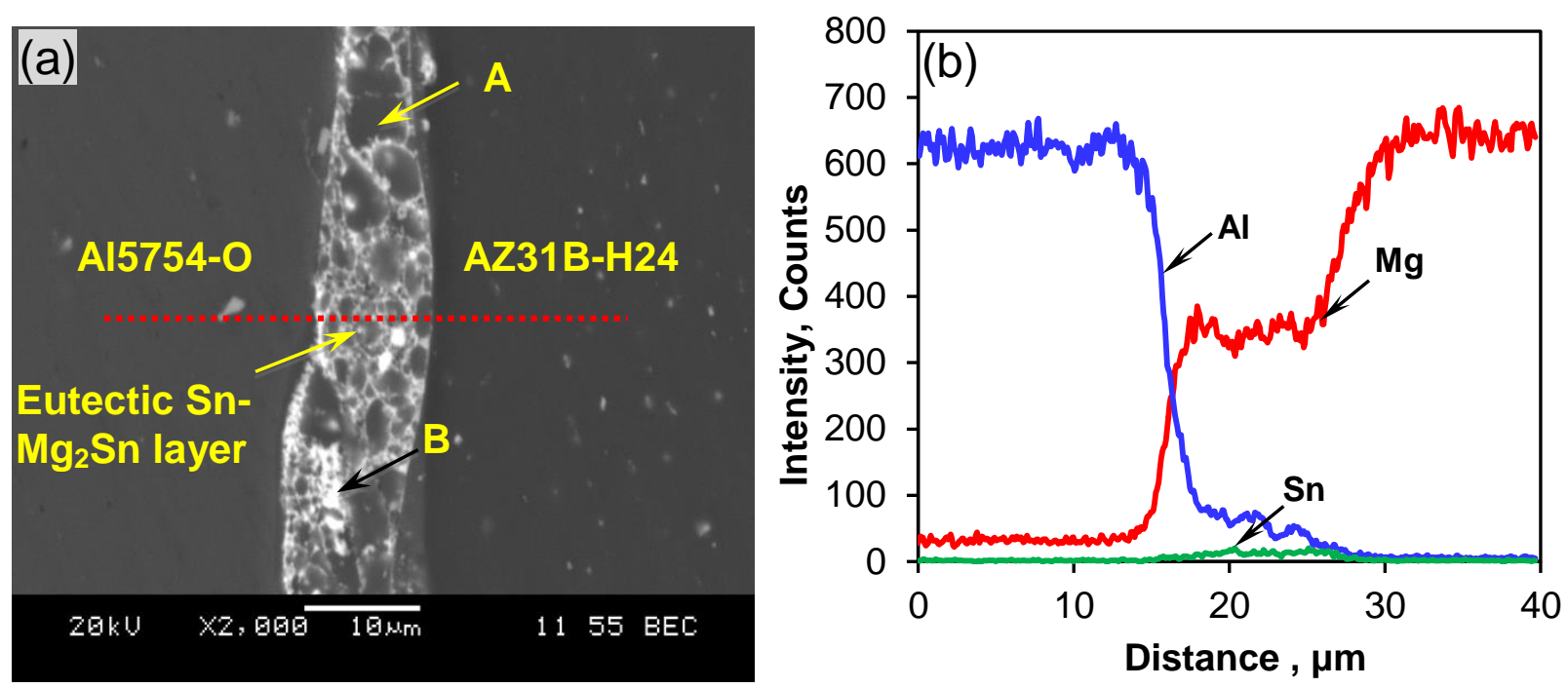

Figure 5.7: (a) Microstructure of the dissimilar USW Mg/Al joints made with a Sn interlayer at a welding energy of $1500 \mathrm{~J}$ in the middle of weld nugget at higher magnification, and (b) EDS line scan across the welded joint as indicated by the dashed line.

point analysis and line scan (Figure 5.7). The chemical composition (in at. wt. \%) at points A and $\mathrm{B}$ was $62.1 \% \mathrm{Mg}-36.0 \% \mathrm{Al}-1.9 \% \mathrm{Sn}$ and $64.9 \% \mathrm{Mg}-19.9 \% \mathrm{Al}-15.2 \% \mathrm{Sn}$, respectively, which suggests that the dark area (A) had less Sn than the light area (B). Figure 5.7(b) shows that the concentration of $\mathrm{Al}$ in the nugget zone is less than that of $\mathrm{Mg}$, owing to the higher solubility of $\mathrm{Sn}$ in $\mathrm{Mg}$ compared to $\mathrm{Sn}$ in Al. Therefore, these results (Figures 5.7(a) and (b)) in conjunction with the Mg-Sn phase diagram [90] suggest the presence of $\mathrm{Mg}_{2} \mathrm{Sn}$ phase, where the eutectic structure consisting of $\beta$-Sn (or Mg-Sn solid solution) and $\mathrm{Mg}_{2} \mathrm{Sn}$ would occur at a temperature of $203^{\circ} \mathrm{C}[90]$.

In the USW the simultaneous application of localized high-frequency vibratory energy and moderate clamping force leads to relative motion and friction heat at the interfaces $[24,15]$ between Al-Sn and Mg-Sn, which would cause the melting and coalescence of Sn. In the presence of the Sn interlayer in the USW, Al and Sn combine to form solid solutions, while 
$\mathrm{Mg}$ and $\mathrm{Sn}$ combine to form $\beta$-Sn and $\mathrm{Mg}_{2} \mathrm{Sn}$ IMCs. The $\mathrm{Mg}_{2} \mathrm{Sn}$ phase has an antifluoritetype $\left(\mathrm{CaF}_{2}\right) \mathrm{AB}_{2}$ crystal structure with a moderately high melting temperature of $770^{\circ} \mathrm{C}$ and a lattice parameter of $a=0.676 \mathrm{~nm}$ [137]. It is apparent that the large $\mathrm{Mg}_{2} \mathrm{Sn}$ particles resulted from the eutectic reaction ( $\mathrm{L} \rightarrow \beta \mathrm{Sn}+\mathrm{Mg}_{2} \mathrm{Sn}$ ). The formation of the IMCs of $\mathrm{Mg}_{2} \mathrm{Sn}$ implies that the exothermic chemical reaction $\mathrm{Mg}+\mathrm{Sn} \rightarrow \mathrm{Mg}_{2} \mathrm{Sn}+\mathrm{Q}$ must occur in the interlayer, where $\mathrm{Q}$ is the mole heat release of $\mathrm{Mg}_{2} \mathrm{Sn}$, which is -80.75 [138] $\mathrm{kJ} \mathrm{mol}^{-1}$, compared to the fusion heat of $\mathrm{Al}[139]$ and $\mathrm{Mg}$ [139] of 10 and $9 \mathrm{~kJ} \mathrm{~mol}^{-1}$ respectively. Thus, it is possible that the large particles of Al could be remelted by the heat formation of $\mathrm{Mg}_{2} \mathrm{Sn}$ and resolidify as smaller particles or disappear under the condition of rapid cooling during the welding process. The addition of Sn to the lap joint was observed to refine the grain size in the fusion zone and the base $\operatorname{Mg}$ alloy $[92,128]$ due to the presence of a eutectic structure, which restricts the growth of the Mg grains. Furthermore, it also improves the wetability of $\mathrm{Mg}$ and $\mathrm{Al}$ during the welding process [127]. Thus, the surface tension of the liquid is reduced so that more liquid spreads evenly over the surface of the base metal.

\subsubsection{X-ray diffraction analysis}

To further verify the above microstructural observations, XRD patterns obtained on both matching surfaces of $\mathrm{Al}$ and $\mathrm{Mg}$ sides after tensile shear tests are shown in Figures 5.8(a) and (b). It is clear that apart from strong peaks of $\mathrm{Al}$ on the $\mathrm{Al}$ side (Figure 5.8(a)) and strong peaks of $\mathrm{Mg}$ on the $\mathrm{Mg}$ side (Figure 5.8(b)), both $\mathrm{Sn}$ and $\mathrm{Mg}_{2} \mathrm{Sn}$ appeared on both sides without the presence of $\mathrm{Al}_{12} \mathrm{Mg}_{17}$. Thus, the addition of the $\mathrm{Sn}$ interlayer led to an effective elimination of the brittle IMCs of $\mathrm{Al}_{12} \mathrm{Mg}_{17}$, which was replaced by the formation of solid 


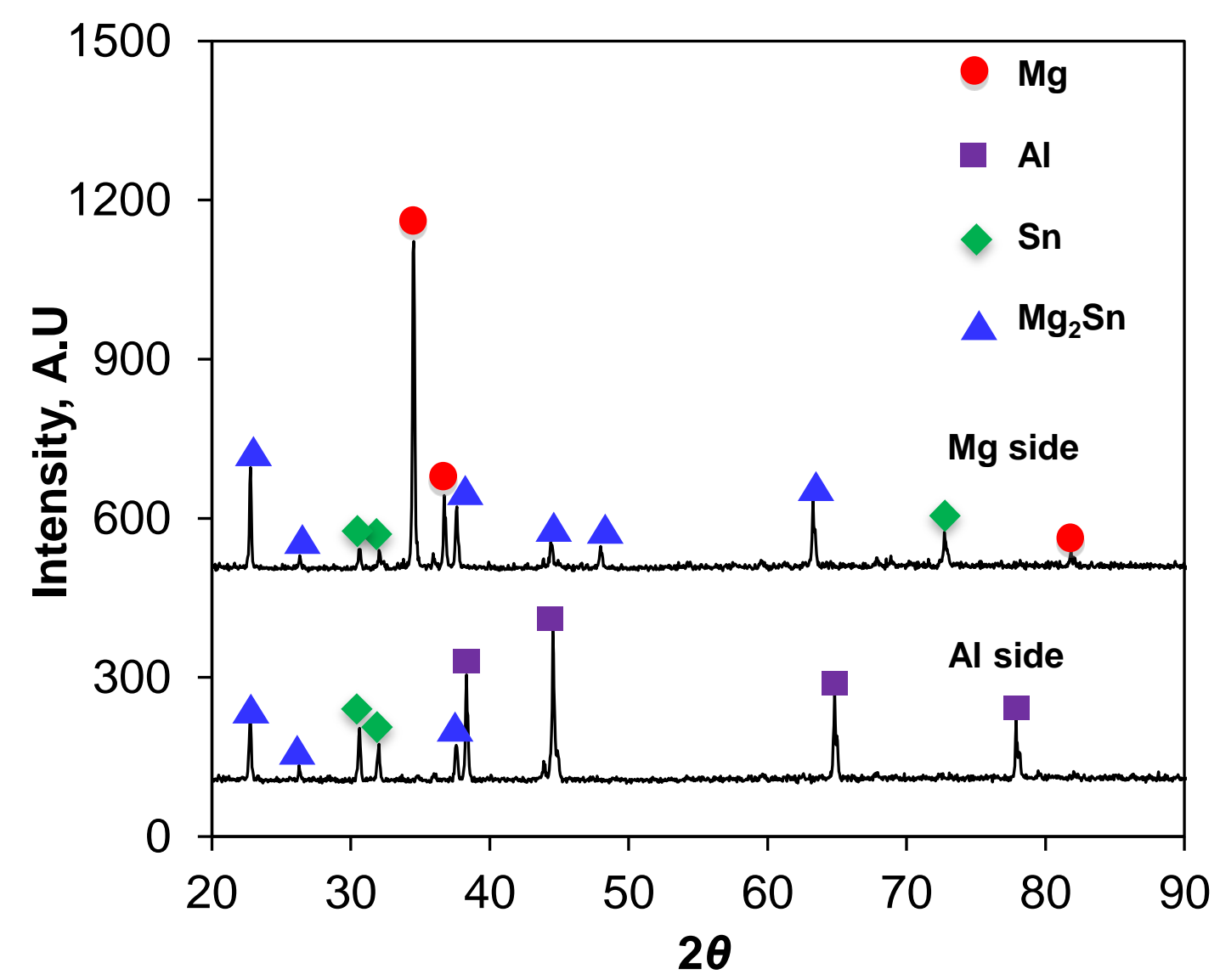

Figure 5.8: XRD patterns obtained from the matching fracture surfaces of (a) Al side and (b) $\mathrm{Mg}$ side at a welding energy of $1000 \mathrm{~J}$.

solutions of $\mathrm{Sn}-\mathrm{Mg}$ and $\mathrm{Sn}-\mathrm{Al}$, as well as the eutectic $\mathrm{Sn}+\mathrm{Mg}_{2} \mathrm{Sn}$ structure. This is in agreement with the SEM observation (Figure 5.7(a)) and EDS analysis (Figure 5.7(b)). Furthermore, these microstructural features of interlayer led to the tensile lap shear failure occurred predominantly through the interlayer (shown later in fractography section), rather than the debonding between the IMCs of $\mathrm{Al}_{12} \mathrm{Mg}_{17}$ and $\mathrm{Al}$ side in the previous study (section 5.1) without the interlayer. 


\subsubsection{Microhardness}

The hardness profile across the welded joint diagonally is shown in Figure 5.9. The hardness of the very thin IMC layer is the mean of measurements at three different locations along the

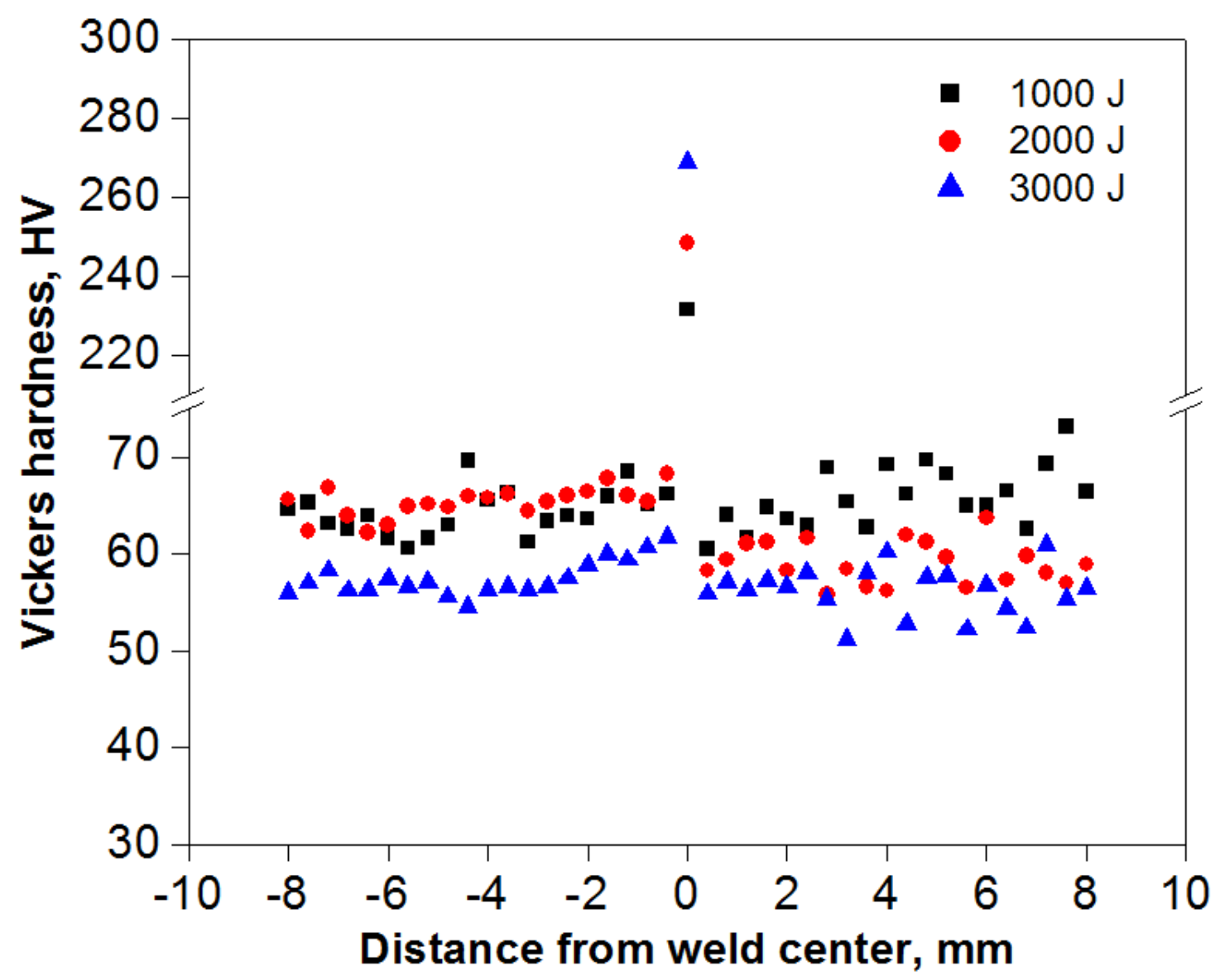

Figure 5.9: Microhardness profile across the welded joints at different energy inputs.

length of the IMC layer. It is seen that the hardness decreased with increasing energy input owing to increasing grain size with increasing temperature. The interlayer between $\mathrm{Mg}$ and Al sheets exhibited hardness values between 200 and $300 \mathrm{HV}$ due to the presence of $\mathrm{Mg}_{2} \mathrm{Sn}$. 


\subsubsection{Lap shear tensile strength of joints}

As shown in Figure 5.10(a), the maximum lap shear strength of Mg-to-Al USW joints with the addition of a $\mathrm{Sn}$ interlayer was improved $(\sim 41 \mathrm{MPa})$ when compared to that of a direct Mg-to-Al USW joints ( $\sim 35 \mathrm{MPa})$. In addition, the Sn interlayer also led to an energy saving since the optimal welding energy required to achieve the highest strength decreased from $\sim 1250 \mathrm{~J}$ to $\sim 1000 \mathrm{~J}$. The failure energy shows a similar trend as shown in Figure 5.10(b) where the maximum failure energy improvement due to the Sn interlayer was about $500 \mathrm{~N}$ $\mathrm{mm}$ (from $\sim 1200 \mathrm{~N}-\mathrm{mm}$ to $\sim 1700 \mathrm{~N}-\mathrm{mm}$ ). The increase in the lap shear strength and failure energy was attributed to the formation of solid solutions of $\mathrm{Sn}$ with $\mathrm{Mg}$ and $\mathrm{Al}$, and composite-like eutectic structure of $\mathrm{Sn}$ and $\mathrm{Mg}_{2} \mathrm{Sn}$ (Figures 5.7 and 5.8), instead of the brittle IMCs of $\mathrm{Al}_{12} \mathrm{Mg}_{17}$ as reported in previous section 5.1. In addition, it can be seen from Figures 5.10(a) and (b) that in the absence of Sn interlayer, the lap shear fracture load and failure energy increased with increasing energy inputs and reached the maximum at $1250 \mathrm{~J}$ energy input and then decreased. As discussed earlier in section 5.1, this was a consequence of the competition between the increasing diffusion bonding arising from higher temperatures at the higher energy inputs and the deteriorating effect of the brittle intermetallic layer of increasing thicknesses. Similarly, in the presence of Sn interlayer, at lower energy inputs the temperature was not high enough to soften or melt the Sn interlayer. On the other hand, at higher energy inputs, the weld specimen was subjected to higher temperatures under larger vibration amplitude for a longer time, resulting in more Sn interlayer being squeezed out. As a result, the lap shear strength and failure energy of the Mg-to-Al USW joints with a Sn interlayer also increased initially with increasing welding 
energy, reached the maximum values, followed by a decrease with further increasing welding energy. Figure 5.10(c) shows a summary of the maximum lap shear strength for different types of joints made at a welding energy of $1000 \mathrm{~J}$. It is seen that the USW Mg-toAl joint without a Sn interlayer was approximately 25\% lower than the USW Al-to-Al joint and $60 \%$ lower than the USW Mg-to-Mg joint. However, the USW Mg-to-Al joint with a Sn interlayer was approximately 5\% higher than the USW Al-to-Al joint and only $40 \%$ lower than the USW Mg-to-Mg joint. A further comparison of the lap shear strength of dissimilar Mg-to-Al joints produced with different joining techniques available in the literature $[84,85$, 86, 87, 88] is shown in Figure 5.10(d). It should be noted that the measured lap shear fracture loads of USW Mg-to-Al joints were converted to the lap shear strengths by using a nominal welding area corresponding to the area of the USW tip $\left(8 \times 6 \mathrm{~mm}^{2}\right)$. Likewise, the product of the shoulder diameter and width of the specimen for FSW, the shoulder area except the center hollow cylindrical area left by the pin exit was used for FSS, and the nugget diameter for RSW have been used to calculate the areas of the respective nugget zones. It is seen that USW joints with the addition of Sn interlayer displayed better lap shear strengths compared to the other techniques shown. However, it must be emphasized that there were differences in thickness of the samples and different $\mathrm{Mg}$ and $\mathrm{Al}$ alloys were used. More detailed studies are needed to identify the optimized processing parameters in different welding techniques. 

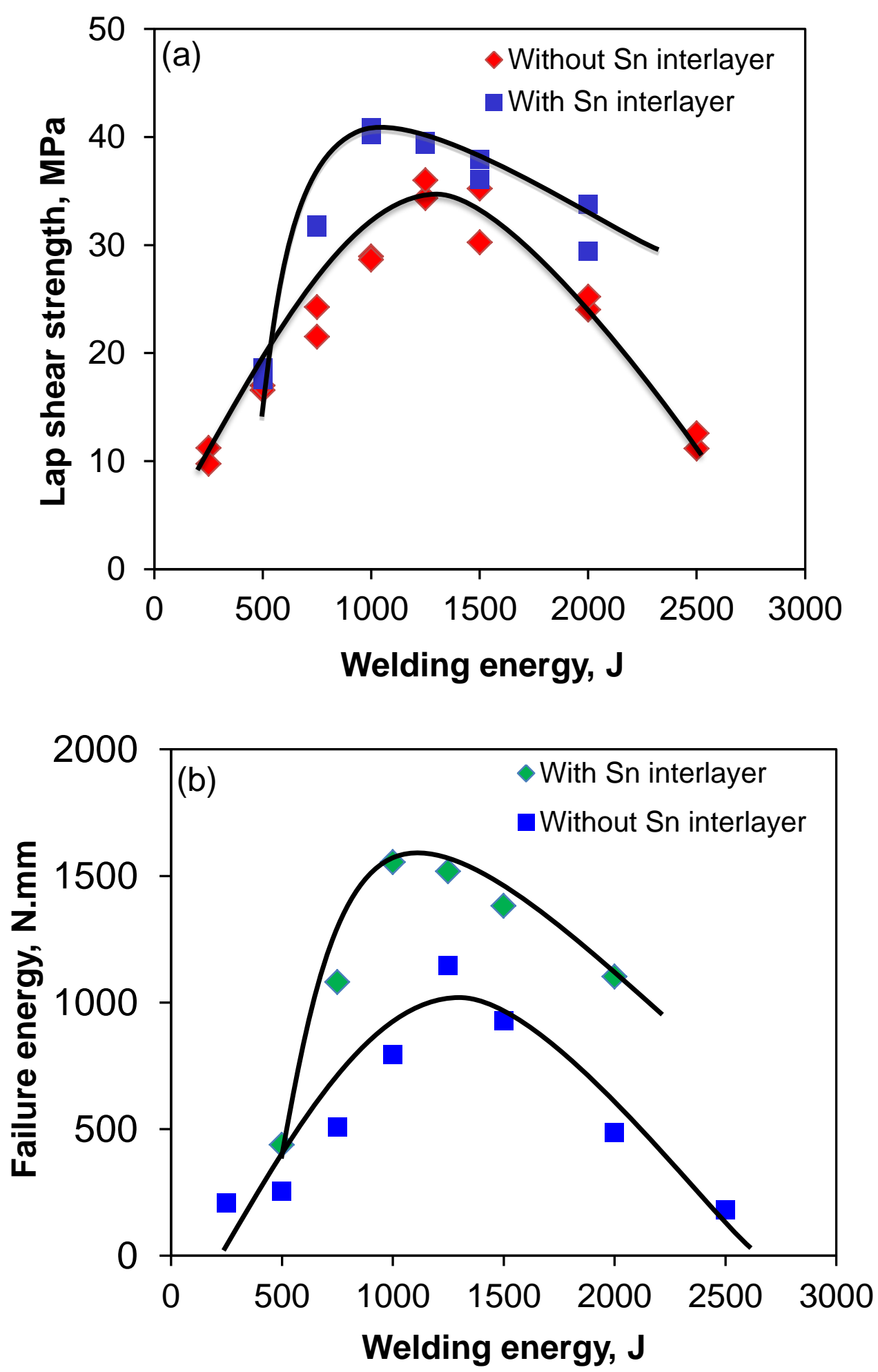

Figure 5.10: Comparison of (a) lap shear strength with and without a Sn interlayer as a function of energy input, (b) failure energy with and without a Sn interlayer as a function of energy input, (c) lap shear strength among different welded joints at an energy input of 1000 $J$, (d) lap shear strength of the dissimilar Mg-to-Al welded joints made with different welding techniques. 

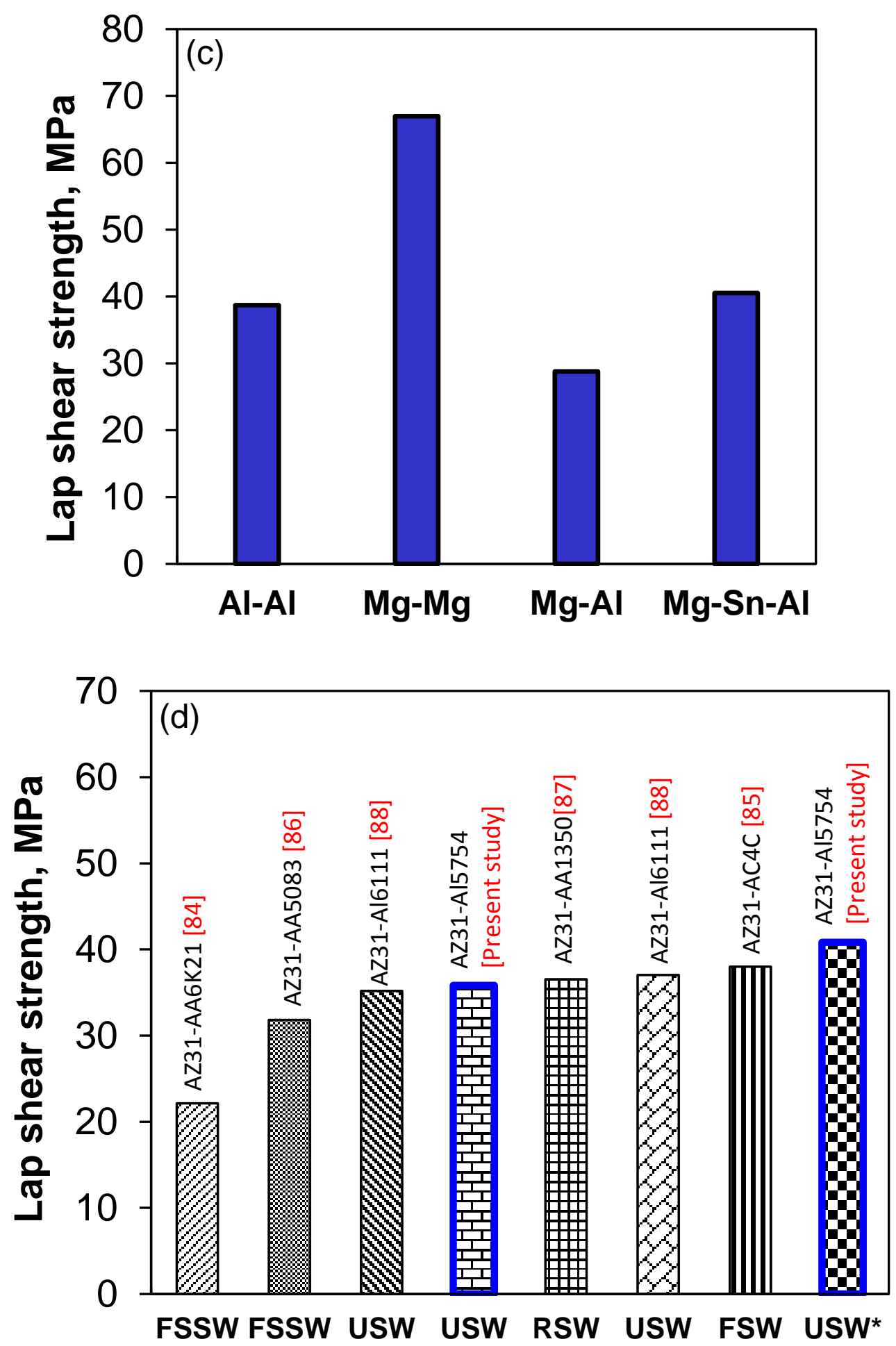

Figure 5.10 (cont'd): Comparison of (a) lap shear strength with and without a Sn interlayer as a function of energy input, (b) failure energy with and without a Sn interlayer as a function of energy input, (c) lap shear strength among different welded joints at an energy input of $1000 \mathrm{~J}$, (d) lap shear strength of the dissimilar Mg-to-Al welded joints made with different welding techniques. 


\subsubsection{Lap shear tensile fractography}

Figure 5.11(a) and (b) shows the matching fracture surface morphology of the Al side and $\mathrm{Mg}$ side at an energy input of $1000 \mathrm{~J}$. It can be seen that on both $\mathrm{Al}$ and $\mathrm{Mg}$ sides there was less $\mathrm{Sn}$ in the center compared to the edge of the nugget zone owing to the squeeze-out caused by the high temperature and moderate pressure generated during the USW hence the heterogeneity of the thickness of Sn interlayer, as shown in Figure 5.6 (b). This resulted in a fracture appearance on both $\mathrm{Al}$ and $\mathrm{Mg}$ surfaces consisting of protuberances and cleavage like features typical of brittle fracture mode in regions with low Sn (3.4 at.\% as determined by EDS analysis) as seen in region D in Figure 5.11(a) and in region F in Figure 5.11(b). On the other hand, in the high Sn regions (12.4 wt \% according to EDS analysis), fairly ductile and rough fracture surface appearance was seen as shown in region C in Figure 5.11(a) and
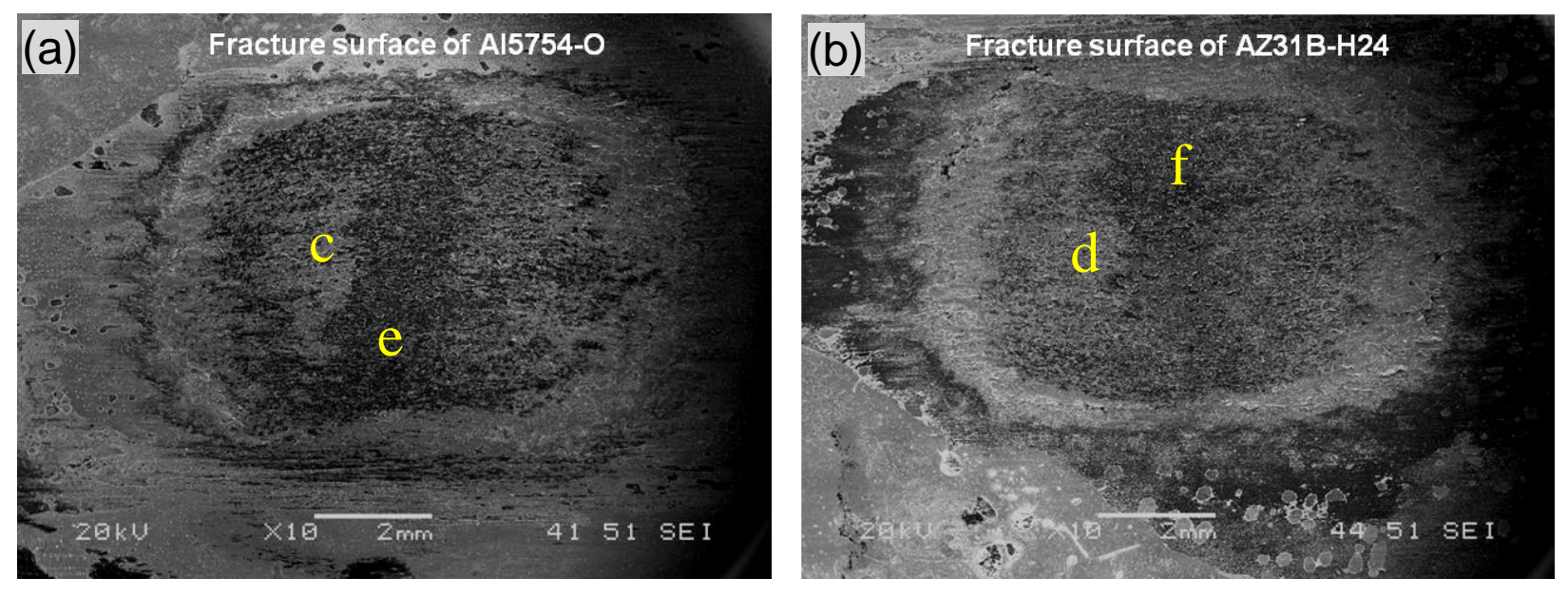

Figure 5.11: Matching fracture surfaces of (a) Al side and (b) Mg side of a welded sample (c) and (e) magnified image of region of (a), and (d) and (f) magnified image of region of (b) with a Sn interlayer at a welding energy of1000 J. 

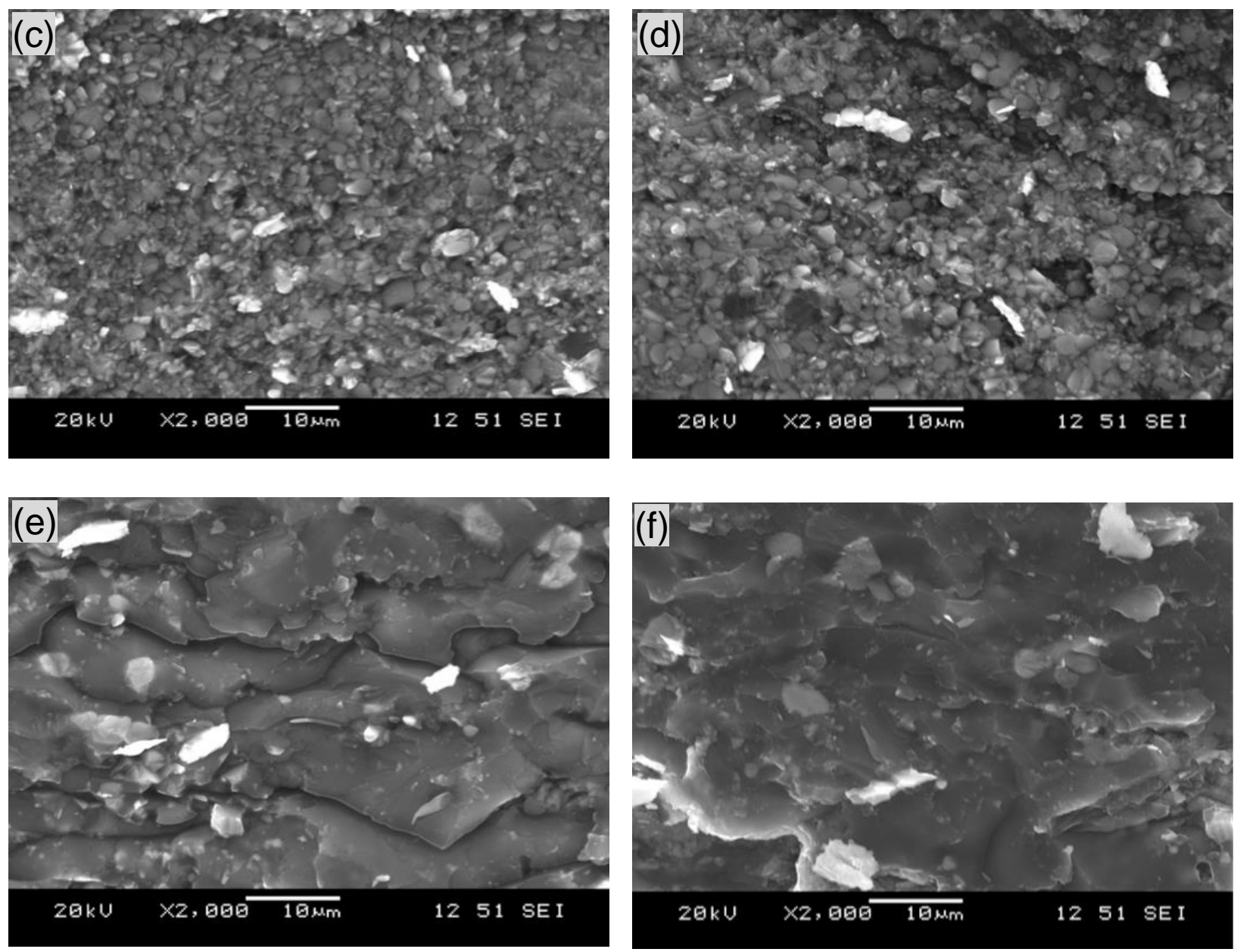

Figure 5.11(cont'd): Matching fracture surfaces of (a) Al side and (b) Mg side of a welded sample (c) and (e) magnified image of region of $(a)$, and (d) and (f) magnified image of region of (b) with a Sn interlayer at a welding energy of $1000 \mathrm{~J}$.

in region E in Figure 5.11(b), suggesting that the $\mathrm{Sn}$ and $\mathrm{Mg}_{2} \mathrm{Sn}$ eutectic structure (Figure

5.7(a)) played a significant role in strengthening the microstructure of the Sn interlayer joint, and thus improved its strength to be presented later. 


\subsection{Summary}

- In summary, sound joint of USW Mg alloy sheet to an $\mathrm{Al}$ alloy sheet was successfully achieved via Sn interlayer.

- In USW of Mg-to-Al (without interlayer) joint, the distribution and microstructure of the formed IMCs have been determined as mainly phases of $\mathrm{Al}_{12} \mathrm{Mg}_{17}$ and a eutectic structure consisting of $\mathrm{Al}_{12} \mathrm{Mg}_{17}$ and the $\mathrm{Mg}$ solid solution. This was confirmed by three different methods namely, EDS, XRD and microhardness test. As anticipated, the hardness of the IMCs is significantly higher than the base materials. As a consequence, brittle fractures occur at the IMCs. Cracking was found in the welded sample of $2500 \mathrm{~J}$ energy input and above. The maximum lap shear strength was 36 $\mathrm{MPa}$ at $1250 \mathrm{~J}$ energy input (which is much lower than the shear strength of AZ31H24 and A15754-O). This was a consequence of a competition between the increasing diffusion bonding arising from higher temperatures and the deterioration effect of the intermetallic layer of increasing thicknesses. Failure predominantly occurred in-between the aluminum alloy and the intermetallic layer or from the cracks of the IMCs in the reaction layer.

- In USW of Mg-to-Al (with Sn interlayer) joint, the maximum lap shear strength and failure energy of $\mathrm{Mg}$-to-Al with a $\mathrm{Sn}$ interlayer were achieved at a welding energy of about $1000 \mathrm{~J}$, which was significantly higher than those of Mg-to-Al joint without interlayer. This improvement was attributed to the formation of the solid solutions of $\mathrm{Sn}$ with $\mathrm{Mg}$ and $\mathrm{Al}$ as well as the composite-like $\mathrm{Sn}$ and $\mathrm{Mg}_{2} \mathrm{Sn}$ eutectic structure in the interlayer, instead of the brittle $\mathrm{Al}_{12} \mathrm{Mg}_{17}$ intermetallic compound present in $\mathrm{Mg}$ to 
$\mathrm{Al}$ joints without interlayer. The fact that $\mathrm{Sn}$ and $\mathrm{Mg}_{2} \mathrm{Sn}$ were located on both $\mathrm{Al}$ and Mg sides of matching fracture surfaces indicated that the tensile shear failure occurred through the interior of the interlayer. The presence of Sn on the fracture surfaces reduced the tendency for brittle cleavage-like fracture and encouraged fairly ductile type fracture behavior with rougher fracture surface. Compared to other welding techniques the dissimilar USW of Mg-to-Al alloys with a Sn interlayer displayed better lap shear strengths. Further research is needed to improve the strength of the dissimilar USW joints using other suitable interlayers.

In this study of USWed Mg-to-Al joints, Mg and Al has potential to be welded to each other since from their respective binary phase diagram both elements can be able to form IMCs of $\mathrm{Mg}_{17} \mathrm{Al}_{12}$ and $\mathrm{Al}_{3} \mathrm{Mg}_{2}$. However, to join two metals, which do not react with each other is challenging. Although steel is relatively heavy and costly to transport, there are significant and growing volumes of international trade in steel and steel products. Thus the achievement of sound joint between Mg-to-steel will play a key role to the transportation industry in order to maintain the structure's high strength and weight reduction. Next Chapter will focus on the characterization of the three combinations of Mg-to-steel joints (1) USWed Mg-to-bare steel (2) Mg-to-galvanized steel and (3) Mg-to-bare steel with Sn interlayer. 


\section{CHAPTER 6}

\section{ULTRASONIC SPOT WELDING OF MAGNASIUM-TO-STEEL ALLOYS}

As mentioned earlier (Sec. 2.2.2.2), according to the respective binary phase diagrams of $\mathrm{Mg}$ and Fe elements, they do not react with each other, thus many welding process failed to produce sound joints between these two to metals. Therefore, this Chapter shows how the USW process produces sound joint between $\mathrm{Mg}$ and steel alloys. In order to check the feasibility of $\mathrm{Zn}$ coating and $\mathrm{Sn}$ interlayer to join $\mathrm{Mg}$ and steel alloys via USW process, USWed Mg-to-bare steel, Mg-to-galvanized steel and Mg-to-bare steel with Sn interlayer (placed in-between $\mathrm{Mg}$ and bare steel) were studied and compared their microstructures and mechanical properties were compared. For the welding of Mg-to-bare steel, galvanized HSLA steel sheets were ground with emery paper by as much as $10 \mu \mathrm{m}$ to remove the $\mathrm{Zn}$ surface layer. For the Mg-to-bare steel with Sn interlayer, a $50 \mu \mathrm{m}$ thick pure Sn interlayer was placed in between the faying surfaces.

\subsection{Microstructure}

For solid state welding technologies of dissimilar metals, there are two key factors for controlling the welding performance. One is the intimate contact between the dissimilar materials, and the other is the microstructure, predominantly the nature of the formation of IMC layer. In the present experiments, microstructural characterization was conducted across the weld line of the samples to assess IMC layer. Figures 6.1(a), (b) and (c) shows the

\footnotetext{
* This chapter is based on the following publications of the author:

V.K. Patel, S.D. Bhole, D.L. Chen: 'Characterization of ultrasonic spot welded joints of Mg-to-galvanized and ungalvanized steel with a tin interlayer', Journal of Materials Processing Technology, 2014, Vol 214, 811-817.
} 
microstructure of the USW of Mg-to-bare steel, with galvanized steel and with Sn interlayer (placed in-between $\mathrm{Mg}$ and bare steel samples), respectively. The weld had no large defects, such as crack, void or tunnel type defects. In the $\mathrm{Mg}$ to bare steel joint there was no distinct interlayer found at the center of the joint as shown in Figure 6.1(a) since $\mathrm{Mg}$ and $\mathrm{Fe}$ do not react with each other based on their respective binary phase diagrams. There was a black layer present as indicated by white arrows at the interface of the Mg-to-steel joint. This layer was formed during the metallographic sample preparation because of the large difference in
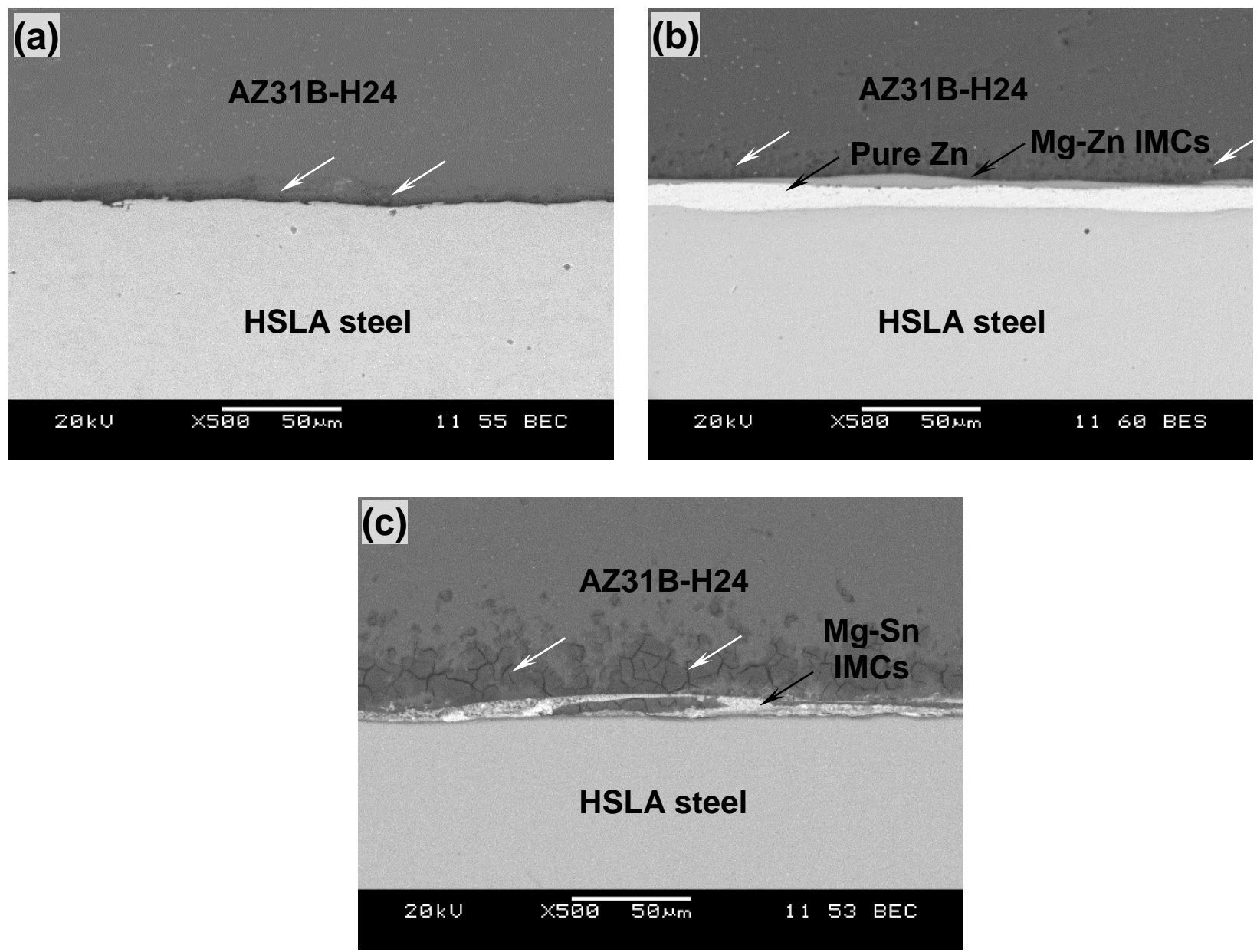

Figure 6.1: SEM micrograph of the dissimilar USWed (a) Mg-to-bare steel (b) Mg-togalvanized steel and (c) Mg-to-bare steel with Sn interlayer using $1000 \mathrm{~J}$ welding energy. 
hardness between the Mg alloy and the steel. It was later confirmed by EDS to be an $\mathrm{Mg}$ hydroxide compound $\left(\mathrm{Mg}(\mathrm{OH})_{2}\right.$ has white color but by mixing with polishing product it may have become dark). From the Figure 6.1(b) of USWed Mg-to-galvanized steel, it can be seen that the joint consists of four distinct layers, i.e. base metal of $\mathrm{Mg}$ alloy, a heterogeneously distributed intermetallic compound (IMCs) (gray region), Zn coating (white region) and base metal of steel. It can be seen that the galvanized steel sheet has about $\sim 10 \mu \mathrm{m}$ thick coating of $\mathrm{Zn}$. The IMCs are found mainly in-between the $\mathrm{Mg}$ and the $\mathrm{Zn}$ rich region, suggesting the formation of Mg-Zn IMCs. There were no IMCs found in-between the $\mathrm{Zn}$ and Fe matrix. A higher magnification image of that region and quantitative analysis of the chemical compositions by EDS revealed more information. Figure 6.1(c) showed the microstructure of the USWd Mg-to-bare steel joint with the Sn interlayer at the center of the nugget zone. This Sn interlayer was no longer pure Sn interlayer after USW. It became a layer of $\mathrm{Sn}-\mathrm{Mg}_{2} \mathrm{Sn}$ eutectic structure, which will be identified later.

\subsection{Energy-dispersive X-ray spectroscopy (EDS) analysis}

To identify the generation of phases during the USW, EDS line analysis has been performed across the center of the weld nugget of USWed Mg-to-bare steel, with galvanized steel and with Sn interlayer (placed in-between $\mathrm{Mg}$ and bare steel samples), respectively, and shown in Figure 6.2. It can be seen that Mg alloy and bare steel were tightly joined. No transitional layer between $\mathrm{Mg}$ and bare steel was detected, explaining the lower mechanical properties of the joint. EDS line analysis shows a higher content of Fe element in $\mathrm{Mg}$ sheet, which could be a sign of small steel particles in the Mg sheet. Similar result was reported in the FSWed 
Mg-to-bare steel by Schneider et al. [140]. Figures 6.2(c) and (d) show the concentration profiles of $\mathrm{Mg}, \mathrm{Zn}$ and $\mathrm{Fe}$ across the interface of the USWed Mg-to-galvanized steel joint. Two kinds of regions are present at the center of the welded zone, a massive dark grey region and a white substrate. Quantitative analysis of the chemical composition (in at.\%) by EDS shows that the dark grey (point A) region consists of $74.9 \% \mathrm{Mg}, 24.6 \% \mathrm{Zn}$ and $0.5 \% \mathrm{Fe}$ and the white substrate consists of $3.7 \% \mathrm{Mg}, 93.8 \% \mathrm{Zn}$ and $2.5 \% \mathrm{Fe}$. From this result and $\mathrm{Mg}-\mathrm{Zn}$ phase diagram, the dark grey region indicates the possible presence of $\mathrm{Mg}$ - Zn eutectic structures, which is primary $\operatorname{Mg}_{7} \mathrm{Zn}_{3}$ eutectic phase and the white substrate is mainly the pure $\mathrm{Zn}$ coating. This $\mathrm{Mg}_{7} \mathrm{Zn}_{3}$ eutectic phase was reported in the literature $[85,141]$. By closely observing the Figure 6.2(c), it can be seen that there was another IMC layer formed inbetween the $\mathrm{Mg}_{7} \mathrm{Zn}_{3}$ (dark grey region) and $\mathrm{Zn}$ coating (white region). Since it formed on the $\mathrm{Zn}$ matrix side, from the $\mathrm{Mg}-\mathrm{Zn}$ phase diagram it could possibly be the second lower eutectic phase $\mathrm{Mg}_{2} \mathrm{Zn}_{11}$, which is generated at $364^{\circ} \mathrm{C}$. As shown earlier in section 4.2 .2 work of temperature distribution in the USW, the peak temperature in the nugget zone reached about 500 to $550^{\circ} \mathrm{C}$. Such temperatures are lower than the melting points of the base metal of $\mathrm{Mg}$ and $\mathrm{Fe}\left(650^{\circ} \mathrm{C}\right.$ and $1538^{\circ} \mathrm{C}$, respectively), but higher than the $\mathrm{Zn}$ melting point and $\mathrm{Mg}-\mathrm{Zn}$ eutectic points $\left(420^{\circ} \mathrm{C}\right.$ and $339^{\circ} \mathrm{C}$, respectively). In other words, the peak temperature in the lap interface center is higher than $\mathrm{Zn}$ melting point and $\mathrm{Mg}-\mathrm{Zn}$ eutectic points, which results in the formation of a liquid-phase.

To better understand the diffusion process of Mg and Zn, USW process is divided into three stages. In the first stage, the oxide film on the surface of $\mathrm{Mg}$ alloy was destroyed by the 

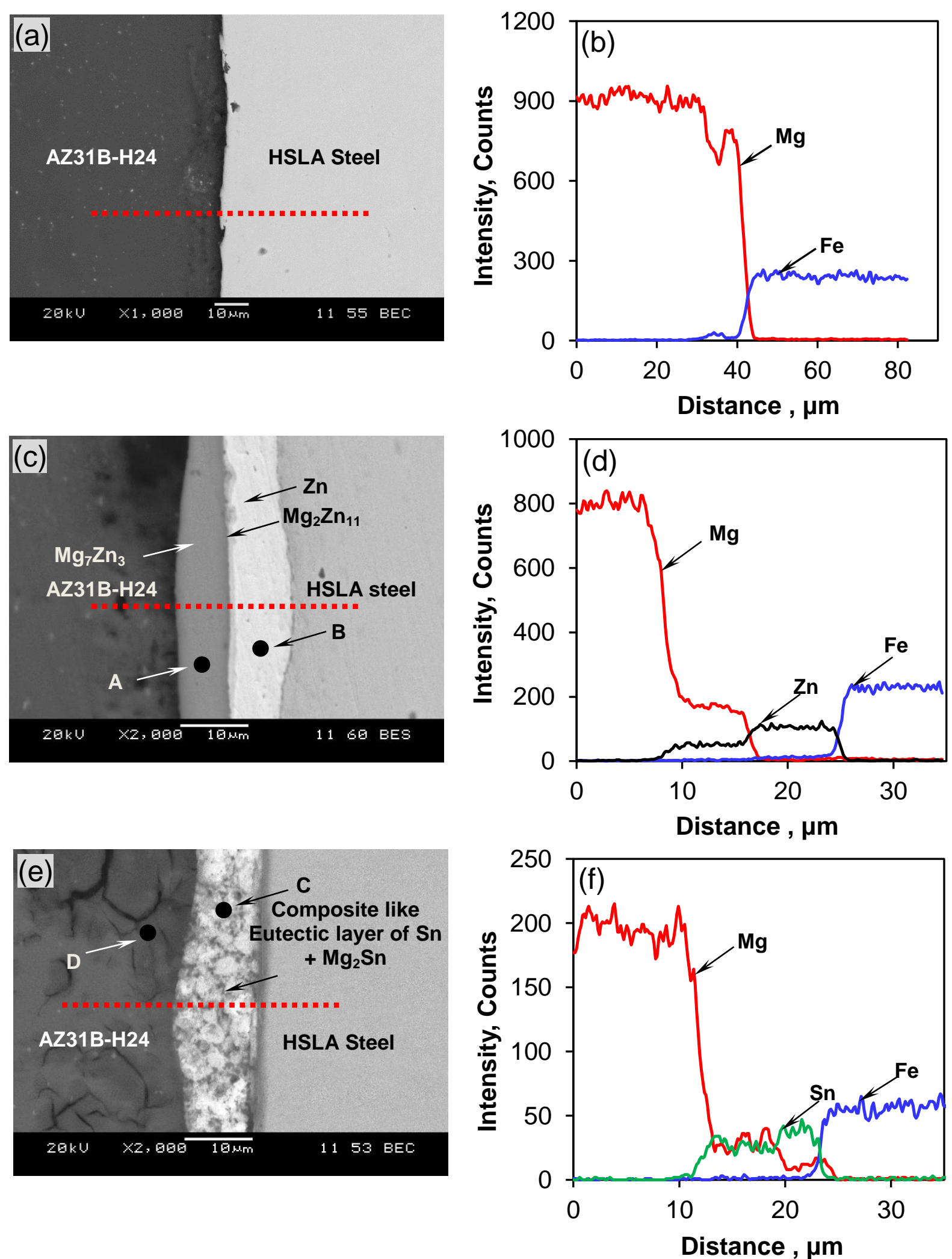

Figure 6.2: Magnified SEM micrograph at the center of USWed joint of (a) Mg-to-bare steel, (c) Mg-to-galvanized steel, (e) Mg-to-bare steel with Sn interlayer joints using $1000 \mathrm{~J}$ 
welding energy, and their respective (b), (d) and (f) are EDS line scan across the center of layer in (a), (c) and (e), respectively.

sonotrode compressive force, bringing it in direct contact of Mg-to-Zn. In the second stage, due to the high ultrasonic vibration under heavy pressure, mutual diffusion of elemental $\mathrm{Mg}$ and $\mathrm{Zn}$ occurs which leads to the formation of the $\mathrm{Mg}-\mathrm{Zn}$ eutectic liquid at the interface. In the third stage, if high ultrasonic vibration is applied for longer time (i.e high energy), the eutectic liquid is discharged outside by shear force of the high ultrasonic vibration. Some of the liquid still remains at the interface and in the clearance between the two sheets the liquid solidifies. The evidence of the discharge of the eutectic liquid on the outside surface of the nugget is presented later in the tensile fractography section where EDS analysis shows the higher concentration of $\mathrm{Zn}$ at the periphery of the nugget. As shown in Figures 6.1(c) and (d), no eutectic layer was detected between steel and $\mathrm{Zn}$, confirming that there was no melting on the steel side during the USW. This suggests that Mg and Zn combine to form Mg-Zn IMCs, while $\mathrm{Fe}$ and $\mathrm{Zn}$ combine to form a solid solution to create the weld joint. Figures 6.2(e) and (f) show the SEM image at the center of the NZ of USWed Mg-to-bare steel with a Sn interlayer, and its EDS line scan, respectively. The chemical compositions (in at.\%) at point C (Figure 6.2(e)) was 70.3\% Mg-29.7\% Sn, suggesting that only Mg and Sn elements were present in the interlayer. The chemical composition (in at.\%) at point D was $62.3 \% \mathrm{Mg}-37.7 \%$ $\mathrm{O}$, which suggested the presence of galvanic corrosion product by forming magnesium hydroxide $\mathrm{Mg}(\mathrm{OH})_{2}$ during the metallographic sample preparation as demonstrated by $[142$, 143]. The occurrence of galvanic corrosion was attributed to the large difference between $\mathrm{Mg}$ and Fe positions in the galvanic series. In both Figures 6.2(e) and (f), the IMC layer displayed a composite-like eutectic structure at the center of the weld nugget, where the Sn- 
containing fine white particles were distributed homogeneously or as a network in the interlayer. EDS line scan revealed that little or no Fe was present in the NZ of USWed Mgto-steel with Sn interlayer joint (Figure 6.2(e)). This was due to the higher solubility of Sn in $\mathrm{Mg}$ than $\mathrm{Sn}$ in Fe. These results (Figures 6.2(e) and (f)) in conjunction with the Mg-Sn phase diagram indicate the presence of $\mathrm{Mg}_{2} \mathrm{Sn}$ phase, which may be present separately as $\mathrm{Mg}_{2} \mathrm{Sn}$, as an eutectic of $\mathrm{Mg}_{2} \mathrm{Sn}$ and $\beta$-Sn which occurs at $203^{\circ} \mathrm{C}$ ), or as both.

Diffusivity data are not available to fully analyze the interdiffusion between AZ31B-H24 Mg alloy and $\mathrm{Zn}$ or Sn elements. Ganeshan et al. [144] have reported diffusion coefficient for $\mathrm{Zn}$ and $\mathrm{Sn}$ into $\mathrm{Mg}$. The diffusivity of $\mathrm{Zn}$ in solid $\mathrm{Mg}$ is $5 \times 10^{-19} \mathrm{~m}^{2} \mathrm{sec}^{-1}$ at $227^{\circ} \mathrm{C}$ and in liquid $\mathrm{Mg}$ is $6 \times 10^{-11} \mathrm{~m}^{2} \mathrm{sec}^{-1}$ at $727^{\circ} \mathrm{C}$. The diffusivity of $\mathrm{Sn}$ in the solid $\mathrm{Mg}$ is $8 \times 10^{-19} \mathrm{~m}^{2} \mathrm{sec}^{-1}$ at $227^{\circ} \mathrm{C}$ and in liquid $\mathrm{Mg}$ as $8 \times 10^{-12} \mathrm{~m}^{2} \mathrm{sec}^{-1}$ at $727^{\circ} \mathrm{C}$. Diffusion distance was calculated using the diffusion distance formula,

$$
D=\left(D_{o} t\right)^{1 / 2}
$$

where $D_{o}$ is the diffusion coefficient and $t$ is the diffusion time (here $0.5 \mathrm{~s}$ for $1000 \mathrm{~J}$ energy input is taken). Using the above formula the diffusion distance of $\mathrm{Zn}$ in the solid $\mathrm{Mg}$ was obtained as $0.0015 \mu \mathrm{m}$ and in liquid $\mathrm{Mg}$ as $5.48 \mu \mathrm{m}$, whereas diffusion distance of $\mathrm{Sn}$ in solid $\mathrm{Mg}$ was $0.00063 \mu \mathrm{m}$ and in liquid $\mathrm{Mg}$ was $2 \mu \mathrm{m}$. Thus, from the calculation of diffusion distance and from Figures 6.1 and 6.2 (thickness of IMCs), it can be concluded that interdiffusionin $\mathrm{Mg}-\mathrm{Zn}$ or $\mathrm{Mg}$-Sn couple would occur over micrometer-length distance in 0.5 s only if it occurred in liquid phase. 


\subsection{X-ray diffraction analysis}

To further verify the above microstructural observations, XRD data obtained on both matching fracture surfaces of USWed Mg-to-galvanized steel and Mg-to-bare steel with Sn interlayer joints after tensile shear tests are shown in Figure 6.3(a) (Mg side) and (b) (Fe side), respectively. In USWed Mg-to-galvanized steel, diffraction peaks from IMCs of $\mathrm{Mg}_{7} \mathrm{Zn}_{3}$ and $\mathrm{Mg}_{2} \mathrm{Zn}_{11}$ are detected on both $\mathrm{Mg}$ and $\mathrm{Fe}$ sides along with the $\mathrm{Mg}$, Fe and $\mathrm{Zn}$

elements. Similarly, in USWed Mg-to-bare steel joint with Sn interlayer, peaks from IMC of $\mathrm{Mg}_{2} \mathrm{Sn}$ is detected from both $\mathrm{Mg}$ and $\mathrm{Fe}$ sides along with the $\mathrm{Mg}, \mathrm{Fe}$ and $\mathrm{Sn}$ elements. Thus, USW of Mg-to-galvanized steel led to the formation of solid solutions of $\mathrm{Zn}-\mathrm{Mg}$ and $\mathrm{Zn}-\mathrm{Fe}$, as well as the $\mathrm{Mg}+\mathrm{Mg}_{7} \mathrm{Zn}_{3}$ and $\mathrm{Mg}+\mathrm{Mg}_{2} \mathrm{Zn}_{11}$ eutectic structures. Similarly, addition of $\mathrm{Sn}$ interlayer in USWed Mg-to-bare steel joint led to solid solutions of Sn-Mg and Sn-Fe, as well as the $\mathrm{Sn}+\mathrm{Mg}_{2} \mathrm{Sn}$ eutectic structures. This is in agreement with the SEM observations shown Figure 1(b) and (c), and EDS analyses shown in Figure 6.2(c), (d), (e) and (f). Chen and Nakata [85] (in friction stir lap welding), and Santella et al. [38] (in ultrasonic spot welding) have reported the presence of the brittle Al-Fe IMCs next to the $\mathrm{Mg}_{7} \mathrm{Zn}_{3} \mathrm{IMC}$ on the steel side of the Mg-to-steel welded samples. It is worth mentioning that no single peak of $\mathrm{Al}-\mathrm{Fe} \mathrm{IMC}$ has been identified by the XRD analysis. The presence of $\mathrm{Mg}_{7} \mathrm{Zn}_{3}$ and $\mathrm{Mg}_{2} \mathrm{Zn}_{11}$ (in Mg-to-galvanized steel joint) and $\mathrm{Mg}_{2} \mathrm{Sn}$ and $\mathrm{Sn}$ (in Mg-to-bare steel with $\mathrm{Sn}$ interlayer joint) eutectic structures on both sides of the fracture surfaces indicated that the failure occurred mainly through the interface. This type of failure is called "cohesive failure" as demonstrated by [145]. Failure in the USWed Mg-to-bare steel 

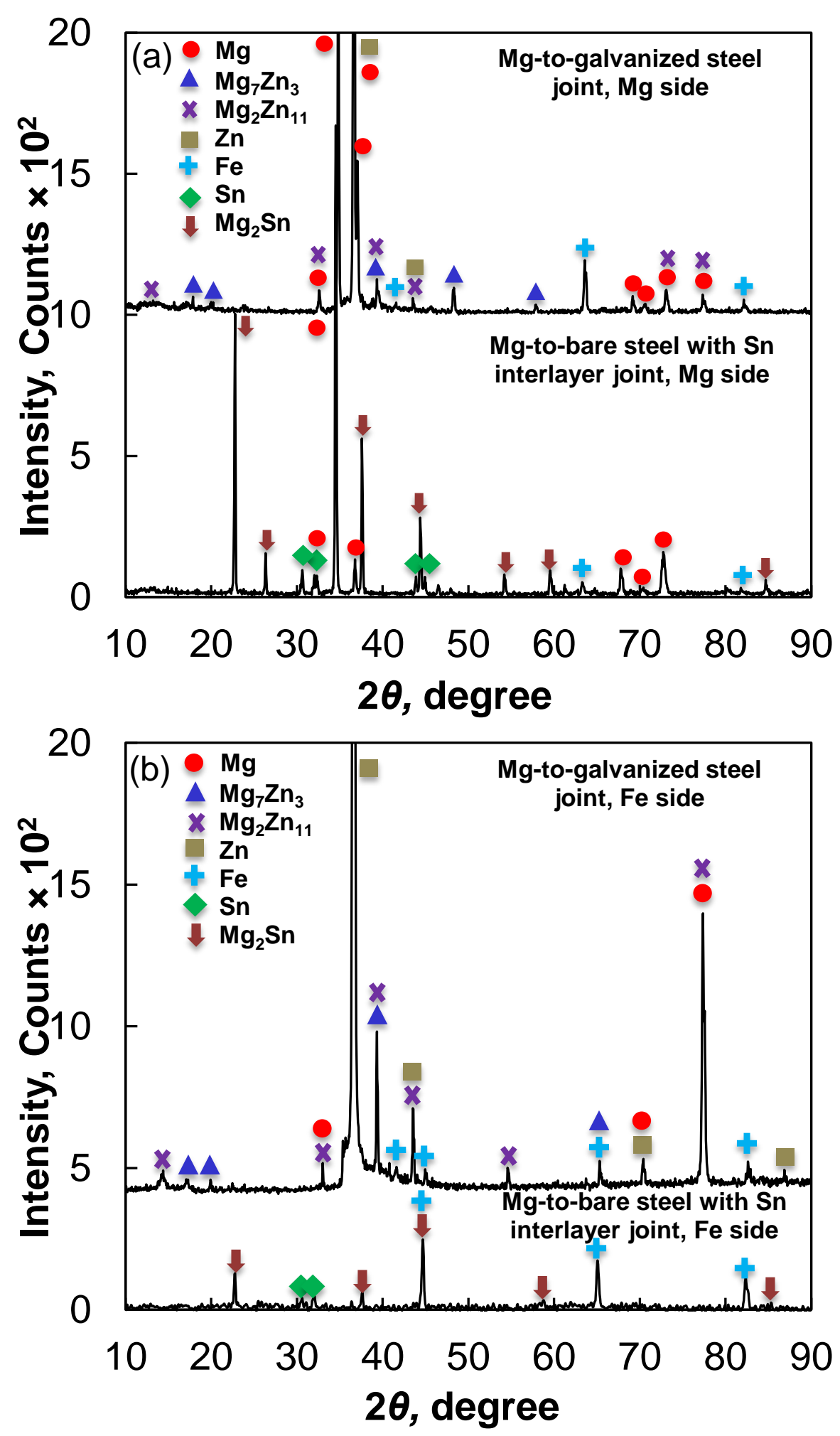

Figure 6.3: XRD patterns obtained from the matching fracture surfaces of Mg-to-galvanized steel and Mg-to-bare steel with Sn interlayer joints at a welding energy of $1000 \mathrm{~J}$, (a) Mg side and (b) Fe side. 
occurred as a combination of partial nugget pull-out mode and partial "cohesive failure" mode, giving rise to a higher tensile shear strength which will be seen in the following section.

\subsection{Microhardness}

The hardness profile diagonally across the welded joint is shown in Figure 6.4. It is seen that characteristic asymmetrical hardness profiles across the USWed Mg-to-galvanized steel and

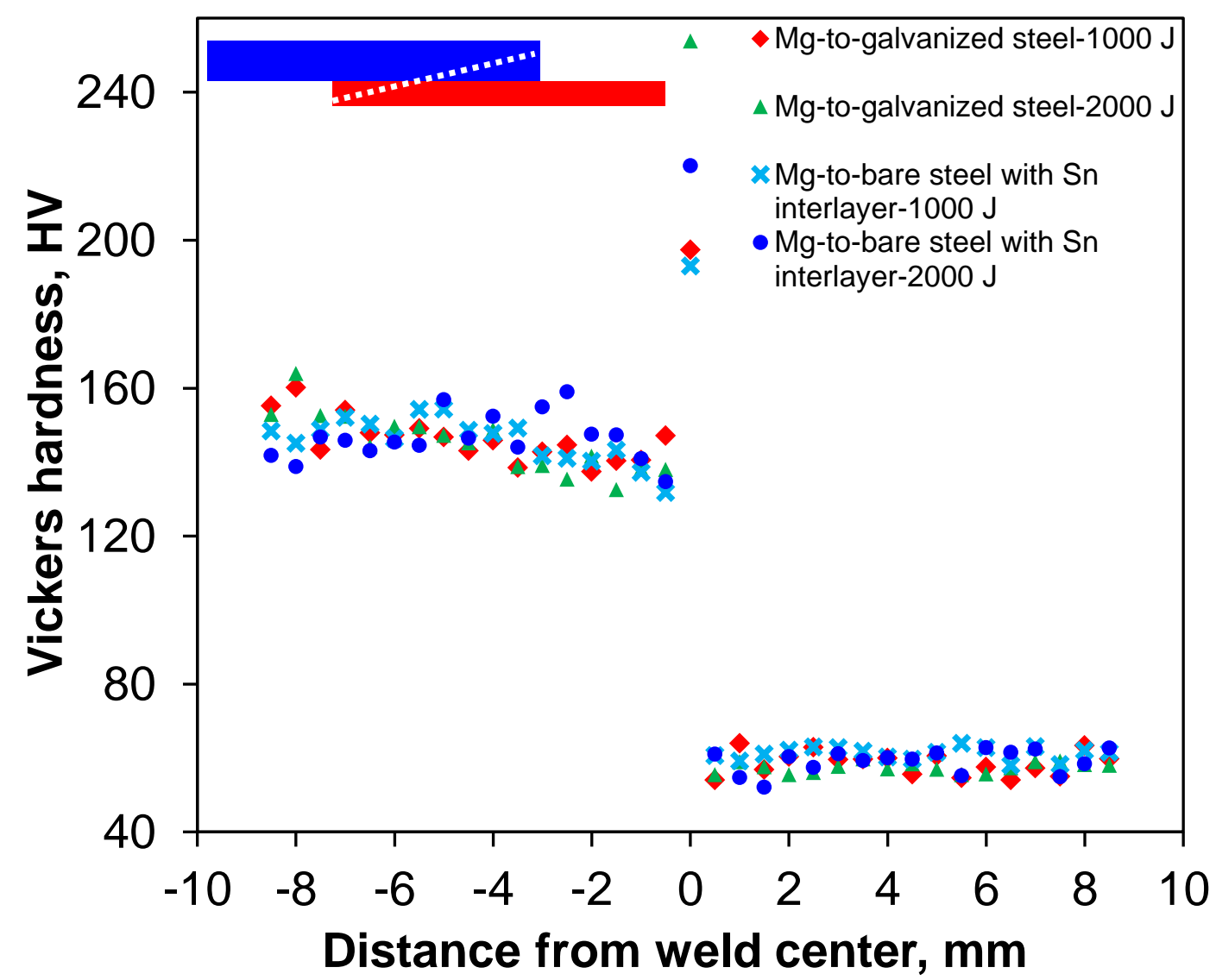

Figure 6.4: Microhardness profiles across the USWed Mg-to-galvanized steel and Mg-tobare steel with a Sn interlayer joints at a welding energy of 1000 and 2000 J joint. 
Mg-to-bare steel with Sn interlayer (1000 and $2000 \mathrm{~J}$ energy inputs) joints were obtained with an average hardness value of about $66 \mathrm{HV}$ on the AZ31B-H24 side and $144 \mathrm{HV}$ on the steel side. According to Jahn et al. [24], unlike RSW, USW displays no clearly discernible fusion zone or heat affected zone (HAZ) that can degrade the strength of the metals being joined. It can be expected that the HAZ in USW would be small because of the welding temperature is lower than the melting temperatures of both $\mathrm{Mg}$ and steel. High hardness values of about 200 to $240 \mathrm{HV}$ were observed in the interlayer of both Mg-to-galvanized steel and Mg-to-bare steel with $\mathrm{Sn}$ interlayer joints, as shown in Figure 6.4. This was obviously due to the presence of $\mathrm{Mg}_{7} \mathrm{Zn}_{3}$ and $\mathrm{Mg}_{2} \mathrm{Zn}_{11}$ (in Mg-to-galvanized steel joint) and composite-like eutectic structure of $\mathrm{Mg}_{2} \mathrm{Sn}$ and $\mathrm{Sn}$ (in Mg-to-bare steel joint with $\mathrm{Sn}$ interlayer) (Figures 6.2 and 6.3).

\subsection{Lap shear tensile strength of joints}

As shown in Figure 6.5(a), the addition of a Sn interlayer led to an increase in the lap shear strength of USWed Mg-to-bare steel dissimilar joints. For example, at a welding energy of $1500 \mathrm{~J}$ (Figure 6.5), the lap shear strength of USWed Mg-to-galvanized steel joints was $\sim 47$ $\mathrm{MPa}$, and it increased to $\sim 71 \mathrm{MPa}$ with the addition of a $\mathrm{Sn}$ interlayer. This represents an increase of $\sim 34 \%$ in the lap shear strength due to the Sn interlayer. Such a significant increase in the lap shear strength was attributed to the formation of solid solutions of $\mathrm{Sn}-\mathrm{Fe}$ and $\mathrm{Mg}-\mathrm{Sn}$, and especially the composite-like eutectic structure of $\mathrm{Sn}$ and $\mathrm{Mg}_{2} \mathrm{Sn}$ (Figures 6.1(c) and 6.2(e), (f)), instead of the brittle IMCs of $\mathrm{Mg}_{7} \mathrm{Zn}_{3}$ and $\mathrm{Mg}_{2} \mathrm{Zn}_{11}$ presented in Mgto-galvanized steel joints. It can be seen from Figure 6.5(a) that in USWed Mg-to-galvanized 

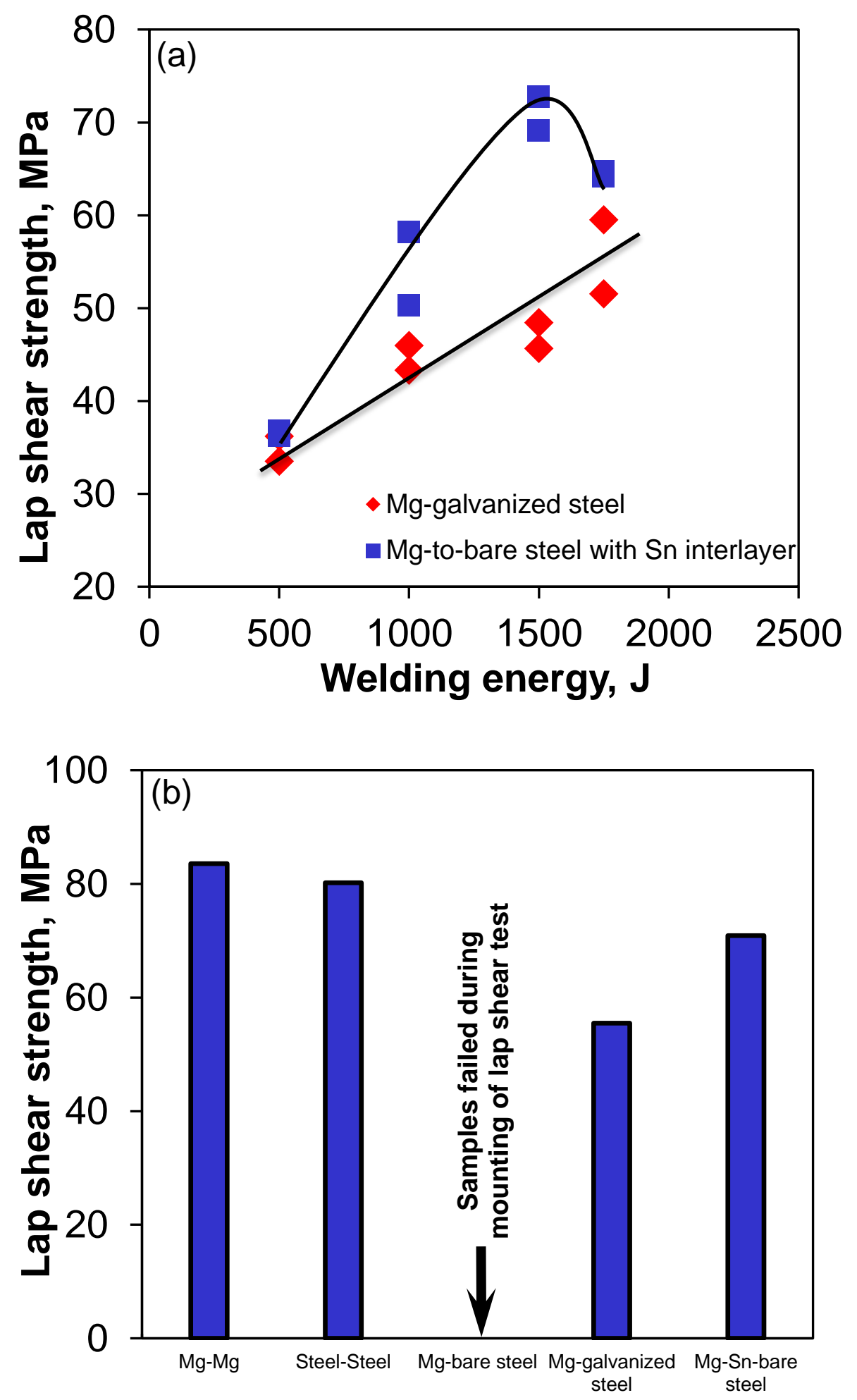

Figure 6.5: (a) Comparison of a lap shear strength of USWed Mg-to-galvanized steel and Mg-to-bare steel with an Sn interlayer joints as a function of energy input, (b) comparison of the highest lap shear tensile strength achieved by similar and dissimilar joints of $\mathrm{Mg}$ and steel using USW. 
steel the lap shear strength increased with increasing energy up to a welding energy of $\sim 1750$ $\mathrm{J}$, after which joining was not possible since the tip started to penetrate through the sheets. If higher energy input weld was possible it would likely show a decrease in lap shear strength based on previous experiments with Mg-to-Al. In the presence of Sn interlayer, the lap shear strength of USWed Mg-to-bare steel dissimilar joints initially increased with increasing welding energy, reached its peak value, followed by a decrease with further increasing welding energy. Such a change occurred due to the fact that at lower energy inputs the temperature was not high enough to soften or melt the Sn interlayer. At higher energy inputs, the specimen was subjected to higher temperatures at larger vibration amplitudes for a longer time, resulting in more Sn interlayer being squeezed out. As summarized in Figure 6.5(b), it is seen that the USWed similar joints of Mg-to-Mg and steel-to-steel had lap shear strengths of 84 and $80 \mathrm{MPa}$, respectively. The lap shear strength of the USWed Mg-to-galvanized steel

dissimilar joint was $56 \mathrm{MPa}$, which is below $70 \%$ that of the similar USWed joints. The USWed Mg-to-bare steel dissimilar joint with a Sn interlayer had a much better lap shear strength of $71 \mathrm{MPa}$ which is as high as $88 \%$ of the similar USWed joints. The addition of $\mathrm{Sn}$ interlayer led to an energy saving since the optimal welding energy required to achieve the highest strength decreased from $\sim 1750 \mathrm{~J}$ to $\sim 1500 \mathrm{~J}$ in the Mg-to-steel dissimilar joint.

\subsection{Lap shear tensile fractography}

Figure 6.6(a) and (b) show the matching fracture surface morphology of the Mg and steel sides at energy input of $1000 \mathrm{~J}$. It is seen that on both $\mathrm{Mg}$ and steel sides there was a gray region denoted as region "c" on the $\mathrm{Mg}$ side and region "d" on the steel side, and black 
region indicated as region "e" on the $\mathrm{Mg}$ side and region " $\mathrm{f}$ " on the steel side. EDS analysis in the region "c" showed a composition of (in at.\% ) $76.9 \% \mathrm{Mg}$ and $23.1 \% \mathrm{Sn}$, while in region "d" it was (in at.\% ) $23.3 \% \mathrm{Mg}, 12.2 \% \mathrm{Al}, 58.4 \% \mathrm{Fe}$ and $3.1 \% \mathrm{Sn}$, indicating that the region "c" in Figure 6.6(a) mainly contained $\mathrm{Sn}$ and $\mathrm{Mg}_{2} \mathrm{Sn}$ eutectic structure. In region "d" a smaller amount of $\mathrm{Sn}$ and $\mathrm{Mg}_{2} \mathrm{Sn}$ eutectic structure was present. This was in good agreement with the XRD results shown in Figure 6.3(b), where the peaks of $\mathrm{Mg}_{2} \mathrm{Sn}$ were largely present on the $\mathrm{Mg}$ side and not on the Fe side. The black region denoted as region "e" (Figure 6.6(a)) and "f" (Figure 6.6(b)) was magnified and is shown in Figure 6.6(e) and (f), respectively. EDS area scan of region "e" revealed a composition of (in at.\%) $97.8 \% \mathrm{Mg}$ and $2.2 \% \mathrm{Zn}$, while in region "f" it was (in at.\%) 94.5\% $\mathrm{Mg}, 2.7 \% \mathrm{Fe}$ and $2.8 \% \mathrm{Sn}$ present, suggesting that regions "e" and "f" contained mainly Mg matrix. Thus, partial nugget pullout failure mode occurred in the USWed Mg-to-bare steel dissimilar joint with a $\mathrm{Sn}$ interlayer, where shear type pattern was present as seen from the magnified images shown in Figures 6.6(e) and (f). This indicated a strong bonding between $\mathrm{Mg}$ matrix and the composite-like $\mathrm{Sn}$ and $\mathrm{Mg}_{2} \mathrm{Sn}$ eutectic structure, thus giving rise to significantly higher lap shear strength, as shown in Figure 6.5. Figure 6.6(g) shows the overall fracture surface image of USWed Mg-to- galvanized steel joint. EDS results, shown in Figure 6.6(h) at the region 1, showed a composition of $73.0 \% \mathrm{Mg}$ and $27 \% \mathrm{Zn}$ (in at. $\%$ ), while in region it was $257.2 \%$ of $\mathrm{Mg}$ and $42.8 \%$ of $\mathrm{Zn}$. This further verified the existence of the brittle IMCs of $\mathrm{Mg}_{7} \mathrm{Zn}_{3}$ and $\mathrm{Mg}_{2} \mathrm{Zn}_{11}$. Thus, as mentioned earlier, it confirmed that lap shear tensile fracture strength was limited because of the brittle $\mathrm{Mg}_{7} \mathrm{Zn}_{3}$ and $\mathrm{Mg}_{2} \mathrm{Zn}_{11}$ IMCs formed during the USW of Mg-to-galvanized steel joint. Moreover, EDS results show the squeeze-out effect of the Zn coating since, there was more $\mathrm{Zn}$ present at the edge of the nugget. 

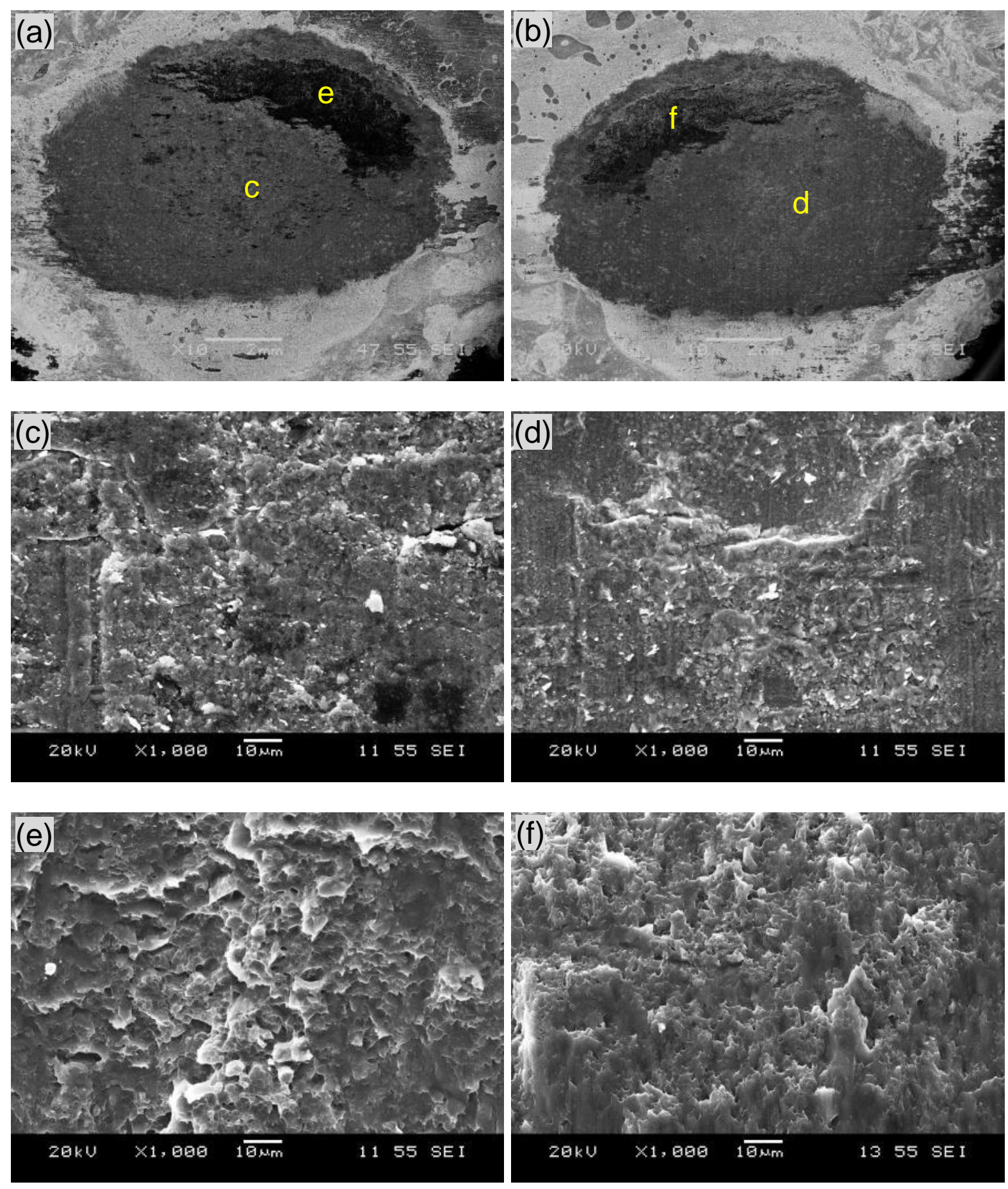

Figure 6.6: Matching fracture surfaces of (a) Mg side (b) bare steel side of a welded sample with Sn interlayer at a welding energy of $1000 \mathrm{~J}$, (c) flat and grey region at a larger magnification of Mg side (d) the corresponding region of bare steel, (e) pull-out (or black) region at a larger magnification of $M g$ side, (f) the corresponding region of bare steel side, (h) overall fracture surface of USWed Mg-to-galvanized steel of Mg side, (h) and (i) are magnified image at region $h$ in $(g)$ and i in (h), respectively. 

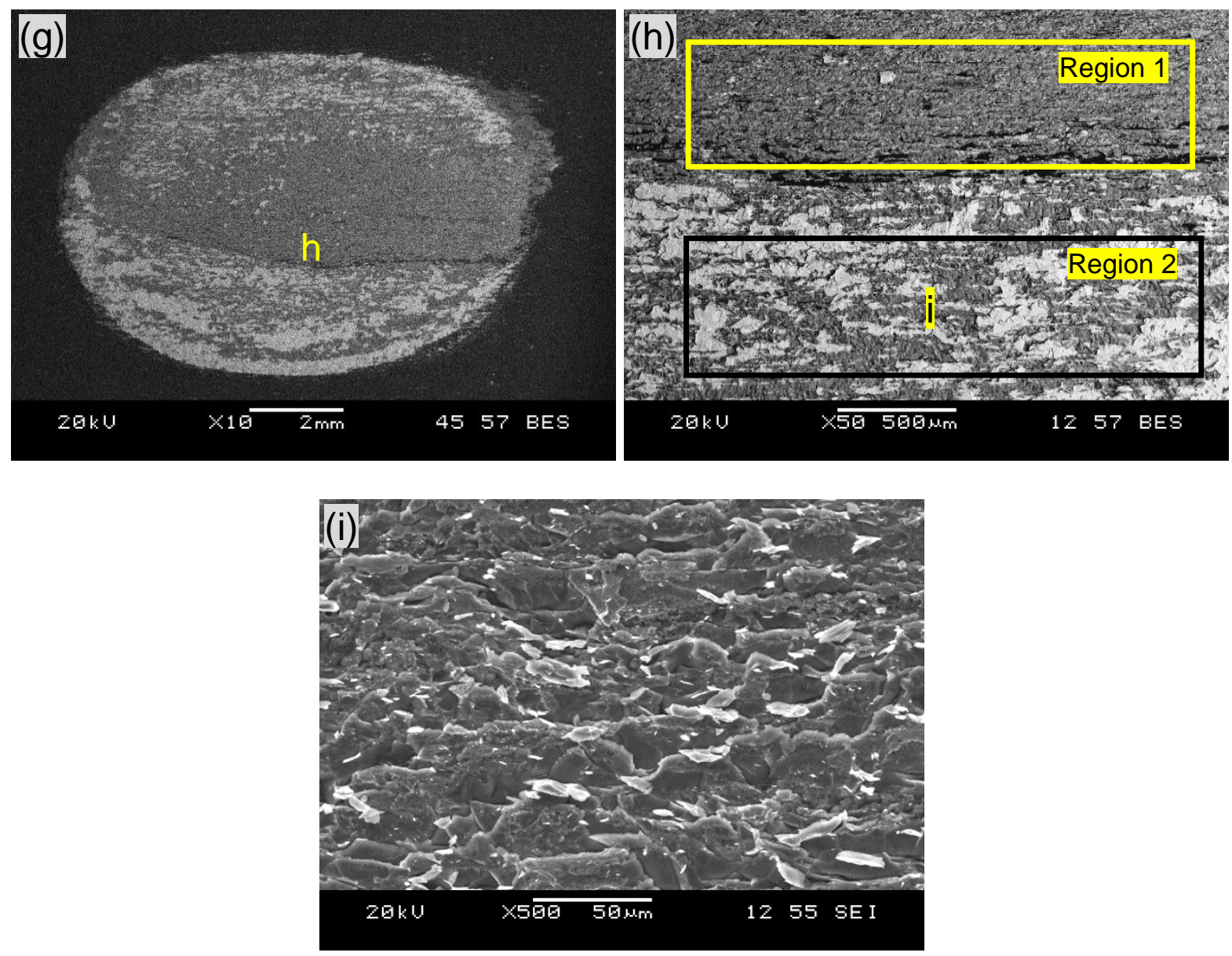

Figure 6.6 (cont'd): Matching fracture surfaces of (a) Mg side (b) bare steel side of a welded sample with Sn interlayer at a welding energy of $1000 \mathrm{~J}$, (c) flat and grey region at a larger magnification of $\mathrm{Mg}$ side (d) the corresponding region of bare steel, (e) pull-out (or black) region at a larger magnification of $\mathrm{Mg}$ side, (f) the corresponding region of bare steel side, (h) overall fracture surface of USWed Mg-to-galvanized steel of Mg side, (h) and (i) are magnified image at region $h$ in $(g)$ and $i$ in $(h)$, respectively.

\subsection{Summary}

- The lap shear strength of Mg-to-bare steel joint with a $\mathrm{Sn}$ interlayer was significantly higher than that of Mg-to-galvanized steel joint. This improvement was attributed to the formation of solid solutions of $\mathrm{Sn}$ with $\mathrm{Mg}$ and $\mathrm{Fe}$ as well as the composite-like $\mathrm{Sn}$ and $\mathrm{Mg}_{2} \mathrm{Sn}$ eutectic structure in the interlayer. 
- The presence of $\mathrm{Mg}_{7} \mathrm{Zn}_{3}$ and $\mathrm{Mg}_{2} \mathrm{Zn}_{11}$ IMCs on both sides of the fracture surfaces indicated that the tensile shear failure occurred through the interface in the mode of 'cohesive failure' in the USWed Mg-to-galvanized steel joint, while partial nugget pull-out failure mode occurred in the USWed Mg-to-bare steel with a Sn interlayer, suggesting strong bonding between $\mathrm{Mg}$ matrix and the composite-like $\mathrm{Sn}$ and $\mathrm{Mg}_{2} \mathrm{Sn}$ eutectic structure.

- The addition of Sn interlayer further led to energy saving since the welding energy required to achieve the maximum lap shear strength decreased from 1750 to $1500 \mathrm{~J}$ energy input.

In Chapters 5 and 6 for USWed Mg-to-Al and Mg-to-steel, respectively, it is seen that how USW process has potential to weld challenging dissimilar Mg-to-Al and Mg-to-steel. Now, it is also worth to characterize the most usable dissimilar combination in the automobile industry, Al-to-steel joints. Researchers have shown that effective sound joint can be produced by the RSW and FSSW. However, as discussed in literature review section, there are enormous disadvantages of FSSW and RSW process. Thus, there is an urgent need to develop alternative joining method for welding Al-to-steel. Many studies have shown that the major metallurgical problem of joining Al alloys with steels is the formation of brittle intermetallic compounds (IMCs) such as $\mathrm{Fe}_{3} \mathrm{Al}, \mathrm{FeAl}, \mathrm{FeAl}_{2}, \mathrm{Fe}_{2} \mathrm{Al}_{5}, \mathrm{FeAl}_{3}[22,98,146,37$, $147,148]$, which can seriously degrade the mechanical properties of the joint. Therefore, it is worth to study the feasibility of USW to join Al-to-steel. 


\section{CHAPTER 7}

\section{ULTRASONIC SPOT WELDING OF ALUMINUM-TO-STEEL ALLOYS ${ }^{\S}$}

Similar to the preceding chapter, this study was aimed to check the feasibility of USW process to form Al-to-steel joint. Here, since many studies have already shown that joining of $\mathrm{Al}$ and steel alloys produces brittle IMCs, in this study, only USW of Al-to-galvanized ( $\mathrm{Zn}$ coated) HSLA steel was conducted with aiming of minimizing the IMC thickness. In this Chapter, microstructural change and lap shear tensile load of dissimilar USWed joints of Alto-galvanized steel were also evaluated. Additionally, mechanical properties of the joint, fatigue resistance and failure mode are also discussed.

\subsection{Microstructure}

A typical cross-section of USWed Al-to-galvanized steel is shown in Figure 7.1(a). No crack or tunnel type defects were present in the samples under most of the welding conditions. A thin Al-Zn enriched non-uniform layer was observed at the interface between $\mathrm{Al}$ and Fe substrate in the $1000 \mathrm{~J}$ energy input sample. At higher energy inputs $(2000 \mathrm{~J})$, the weld specimen was subjected to higher temperatures under larger vibration amplitude for a longer time, resulting in more $\mathrm{Zn}$ interlayer being squeezed out, as shown by the arrows in Figure 7.1(b).

\footnotetext{
$\S$ This chapter is based on the following publications of the author: V.K. Patel, S.D. Bhole, D.L. Chen: 'Ultrasonic spot welding of aluminum to high strength low alloy steel: Microstructure, tensile and fatigue properties', Metallurgical and Materials Transactions A, 2013, Vol 45A, 2055-2066.
} 


\subsection{Energy dispersive spectroscopy analysis}

To identify the generation of phases during the USW of Al and galvanized steel, EDS point and line scans have been performed across the center of the nugget zone and shown in Figures 7.1(c) and (d). From the EDS point scan results, the chemical composition (in at.\%) at points $\mathrm{A}$ and $\mathrm{B}$ was $65 \% \mathrm{Al}-32.2 \% \mathrm{Zn}-2.8 \% \mathrm{Fe}$ and $70.6 \% \mathrm{Al}-26.9 \% \mathrm{Zn}-2.5 \% \mathrm{Fe}$, respectively, which suggests that only $\mathrm{Al}$ and $\mathrm{Zn}$ elements compared to the Fe elements in the center of the nugget zone, called region 1 (Figure 7.1(d)). According to the Al-Zn binary phase diagram and the EDS point and line analysis results, this region 1 could be the eutectic film of Al-Zn. From previous thermal measurement of USW joint in section 4.2.2, the weld temperature at the center of the join line would be expected to greatly exceed the Al- $\mathrm{Zn}$ eutectic melting point of $655 \mathrm{~K}\left(382^{\circ} \mathrm{C}\right)$. At the longer weld times this Al-Zn eutectic film is replaced by the resolidified eutectic liquid, which is squeezed out from the joint. As mentioned earlier, some of the eutectic liquid of Al-Zn squeezed off from the center of the welded joint during the USW process and settled down at the edge of the welded joint as shown in Figure 7.1(e). The formation of the Al-Zn eutectic liquid was also reported by Haddadi et al. [100] in USW and Ueda et al. [102] in RSW of Al-to-galvanized steel joint. Thus, it can be concluded that in the USW of Al-to-galvanized steel, only Al-Zn eutectic film was present at the interface. However, by closely observing Figure 1(c), there is a very thin IMC layer present in-between the Al-Zn eutectic film and Fe matrix, called region 2 (shown by the arrow in Figures 7.1(c) and (d)). As can be seen in the EDS line scan- Figure 1(c), at around $15 \mu \mathrm{m}$ distance, the 

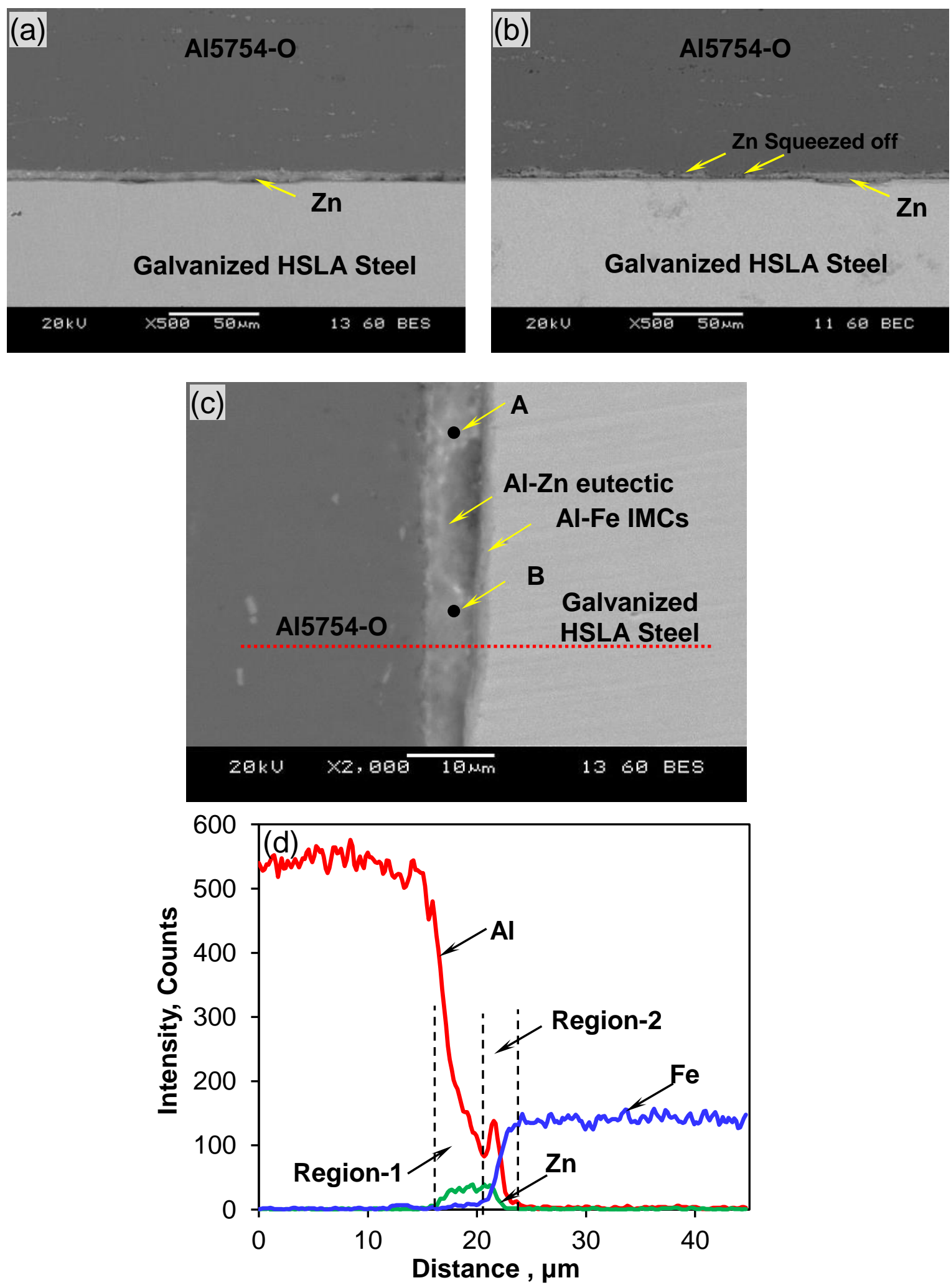

Figure 7.1: SEM micrograph of the dissimilar USWed Al-to-galvanized steel using (a) 1000 $J$ (b) $2000 J$ energy inputs in the middle of weld nugget (c) magnified SEM micrograph of (a), and (d) EDS line scan across the interlayer in (c), (e) SEM micrograph of Al-Zn eutectic liquid at the edge of the joint. 


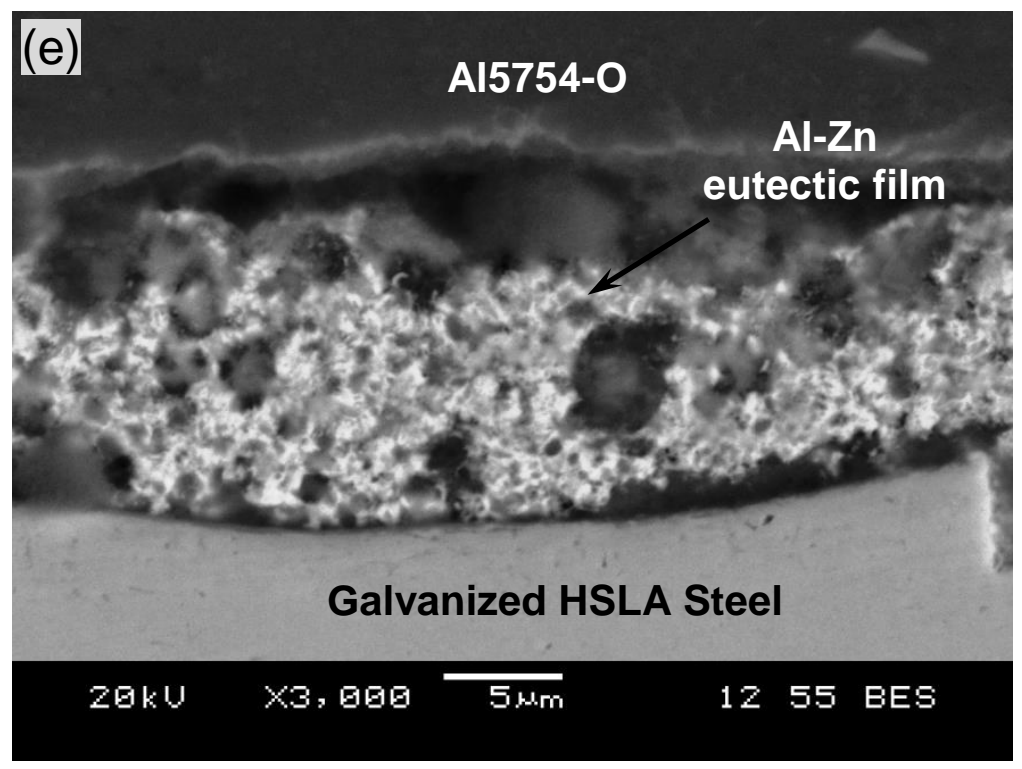

Figure 7.1(cont'd): SEM micrograph of the dissimilar USWed Al-to-galvanized steel using (a) $1000 \mathrm{~J}$ (b) $2000 \mathrm{~J}$ energy inputs in the middle of weld nugget (c) magnified SEM micrograph of (a), and (d) EDS line scan across the interlayer in (c), (e) SEM micrograph of Al-Zn eutectic liquid at the edge of the joint.

concentration of Al was starting to decrease and then suddenly spiked at a distance of approximately $21 \mu \mathrm{m}$ and then again decreased. Further the scan clearly shows the higher amount of Fe element and a low count of 0 to 10 of $\mathrm{Zn}$ elements at the particular region 2, which evidently suggests that this layer is the IMCs of Al and Fe elements. According to the binary phase diagram of $\mathrm{Al}$ and $\mathrm{Fe}$, these IMCs could be $\mathrm{Fe}_{2} \mathrm{Al}_{5}$ and $\mathrm{FeAl}_{3}$ phases, which were later confirmed by the XRD technique. Many studies have also reported the presence of these brittle phases during the welding of $\mathrm{Al}$ and steel, which is the main cause of fracture $[22,98,146,37,147,148]$. 

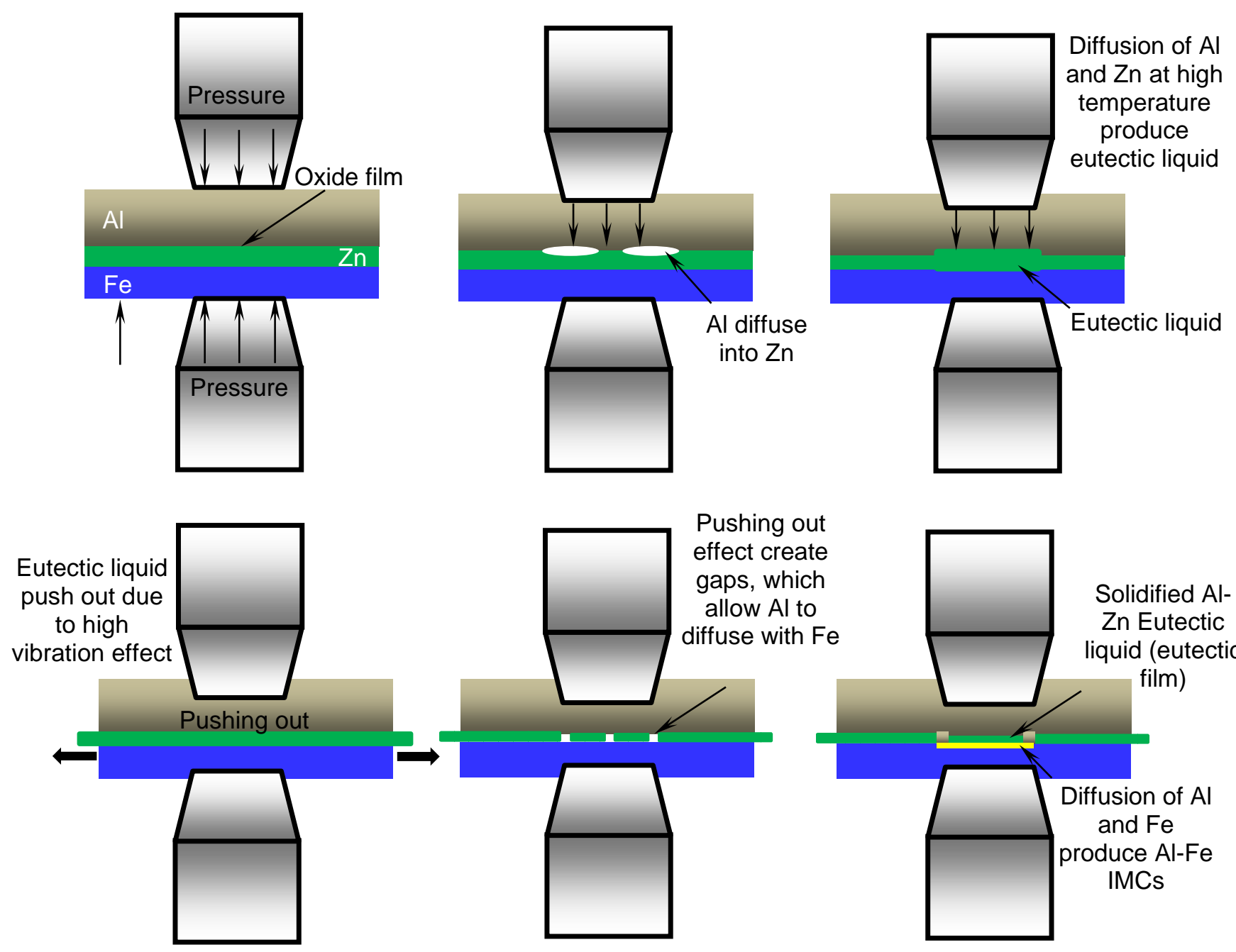

Figure 7.2: Schematic illustration of the bonding process of USWed Al-to-galvanized steel joint.

From the experimental results, the bonding mechanism of the Al-to-galvanized steel joints can be explained as follows. The schematic illustrations of the bonding process of Al-togalvanized steel joints are shown in Figure 7.2. Before USW, the oxide film exists on the Al and galvanized steel samples, even after the samples were polished by 120 emery paper and 
cleaned by ethanol, followed by acetone. In the first stage, the oxide film on the surface of Al and galvanized steel samples was destroyed due to the sonotrode compressive force, and direct contact of Al-to-Zn coating. In the second stage, due to the high ultrasonic vibration under moderate pressure, $\mathrm{Al}$ and $\mathrm{Zn}$ begin to react, and $\mathrm{Al}-\mathrm{Zn}$ eutectic liquid is formed at the interface. In the third stage, if high ultrasonic vibration is applied for a longer time (i.e. high welding energy), the eutectic liquid is discharged outside by the shear force of the high ultrasonic vibration. However, some of the liquid still remains at the interface as a solid solution of $\mathrm{Al}$ and $\mathrm{Zn}$ elements (Figures 7.1(c) (points $\mathrm{A}$ and $\mathrm{B}$ ) and (d), region 1). The evidence for the discharge of the eutectic liquid on the outside surface of the nugget is described later in the tensile fractography section, where EDS analysis shows the higher concentration of $\mathrm{Zn}$ followed by the $\mathrm{Al}$ at the periphery of the nugget. In the fourth stage, since some of the $\mathrm{Zn}$ is being squeezed out (Figure 7.1(b)), it makes multiple gaps, which allow the softer $\mathrm{Al}$ into direct contact with $\mathrm{Fe}$ element for further diffusion process between $\mathrm{Al}$ and Fe elements. Finally, IMCs of $\mathrm{Al}$ and Fe are formed (Figures 7.1(c) and (d), region 2) in-between the Al-Zn eutectic film and Fe matrix.

\subsection{X-ray diffraction analysis}

To further verify the above microstructural observations, XRD patterns obtained on both matching fracture surfaces of $\mathrm{Al}$ and galvanized steel sides after lap shear tensile test are shown in Figures 7.3(a) and (b). It is clear that apart from strong peaks of $\mathrm{Al}$ on the $\mathrm{Al}$ side (Figure 7.3(a)) and strong peaks of Fe on the steel side (Figure 7.3(b)), peaks of Al, $\mathrm{Zn}$ and IMCs such as $\mathrm{Fe}_{2} \mathrm{Al}_{5}$ and $\mathrm{FeAl}_{3}$ appeare on both sides of the fracture surfaces. As reported 

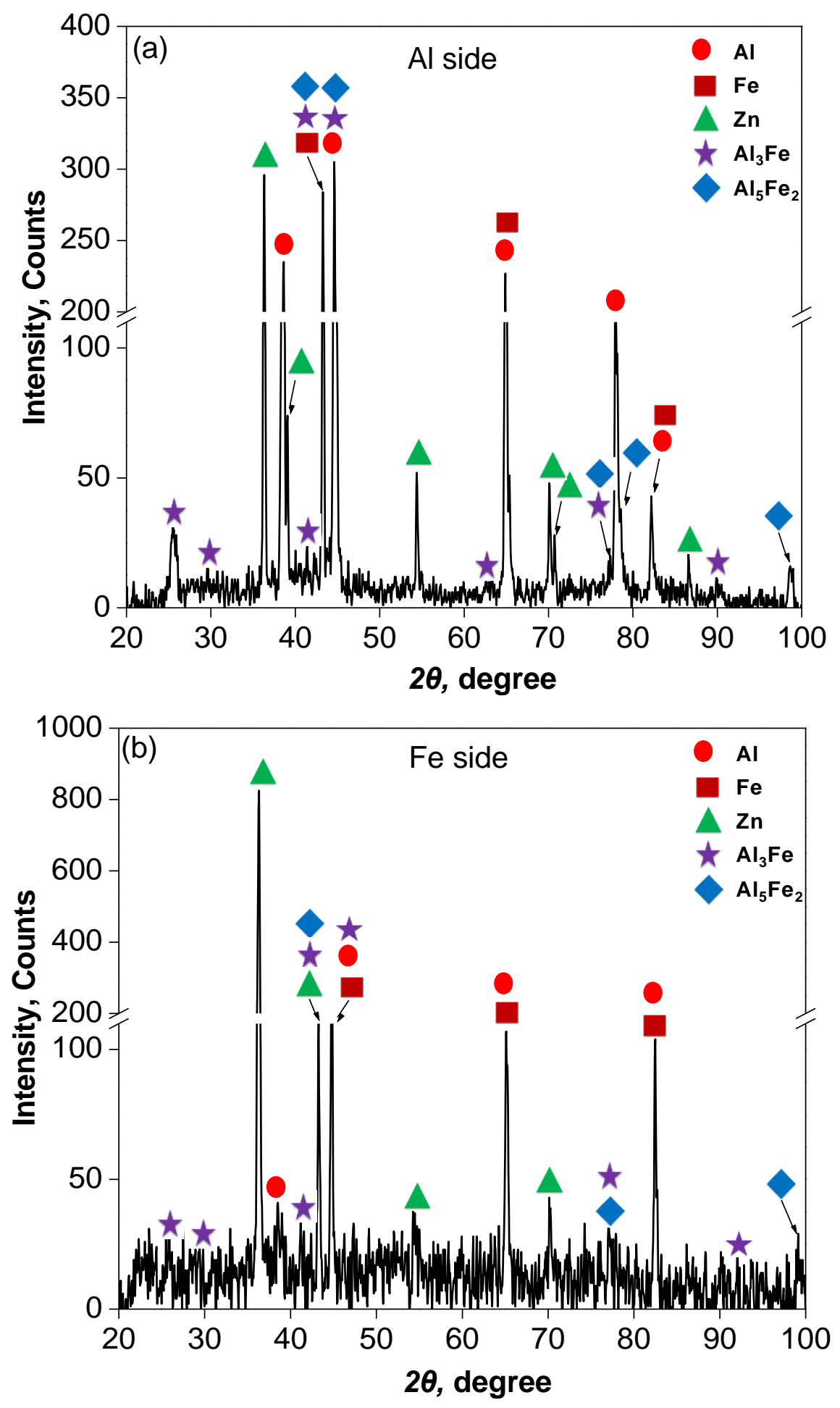

Figure 7.3: XRD patterns obtained from the matching fracture surfaces of (a) Al side and (b) Fe side at a welding energy of $2000 \mathrm{~J}$ 
earlier, many studies have reported the presence of $\mathrm{Fe}_{2} \mathrm{Al}_{5}$ and $\mathrm{FeAl}_{3}$ brittle phases during the welding of Al-to-steel [22, 37, 98, 146, 147, 148], even in the USW of Al-to-steel [22]. Haddadi et al. [100], have reported the formation of the brittle IMCs of $\mathrm{Fe}_{5} \mathrm{Zn}_{21}$ and $\mathrm{Fe}_{3} \mathrm{Zn}_{10}$ in the USW of Al-to-galvanized steel. However, in this present experiment, no peak was evident for the Fe-Zn IMCs. In the Al-Fe phase diagram [130], there are numerous Al-Fe IMCs, such as $\mathrm{FeAl}_{3}, \mathrm{FeAl}_{2}, \mathrm{Fe}_{2} \mathrm{Al}_{5}, \mathrm{Fe}_{3} \mathrm{Al}$, and $\mathrm{FeAl}$ that are present in the binary phase diagram of $\mathrm{Al}-\mathrm{Fe}$. The first phase generated during metal-to-metal interaction is the phase with the most negative heat of formation at the concentration of the lowest eutectic of the binary system. Now, these phases react with each other to form another phase. The lowest eutectic point in $\mathrm{Al}-\mathrm{Fe}$ binary phase diagram has at $0.02 \% \mathrm{Fe}$. At this particular composition, $\mathrm{FeAl}_{3}$ has the lowest effective free energy of formation and therefore, generation of $\mathrm{FeAl}_{3}$ phase is kinetically favored. Then the reaction between $\mathrm{Fe}$ and $\mathrm{FeAl}_{3}$ phases will occur to form another phase with a composition between that of the interacting phases and closest to that of the lowest eutectic point, which is in the order of $\mathrm{Fe}_{2} \mathrm{Al}_{5}, \mathrm{FeAl}_{2}, \mathrm{FeAl}, \mathrm{Fe}_{3} \mathrm{Al}$.

\subsection{Lap shear tensile strength of joints}

As shown in Figure 7.4, the maximum lap shear tensile strength of USWed Al-to-galvanized steel was $\sim 76 \mathrm{MPa}(\sim 3.7 \mathrm{kN})$. The lap shear tensile load increased with increasing energy inputs and peaked $2000 \mathrm{~J}$ energy input and then decreased. At lower energy inputs, the temperature was not high enough to soften or diffuse the $\mathrm{Zn}$ interlayer into the Al. On the other hand, at higher energy inputs, the weld specimen was subjected to higher temperatures under larger vibration amplitude for a longer time, resulting in more $\mathrm{Zn}$ interlayer being 


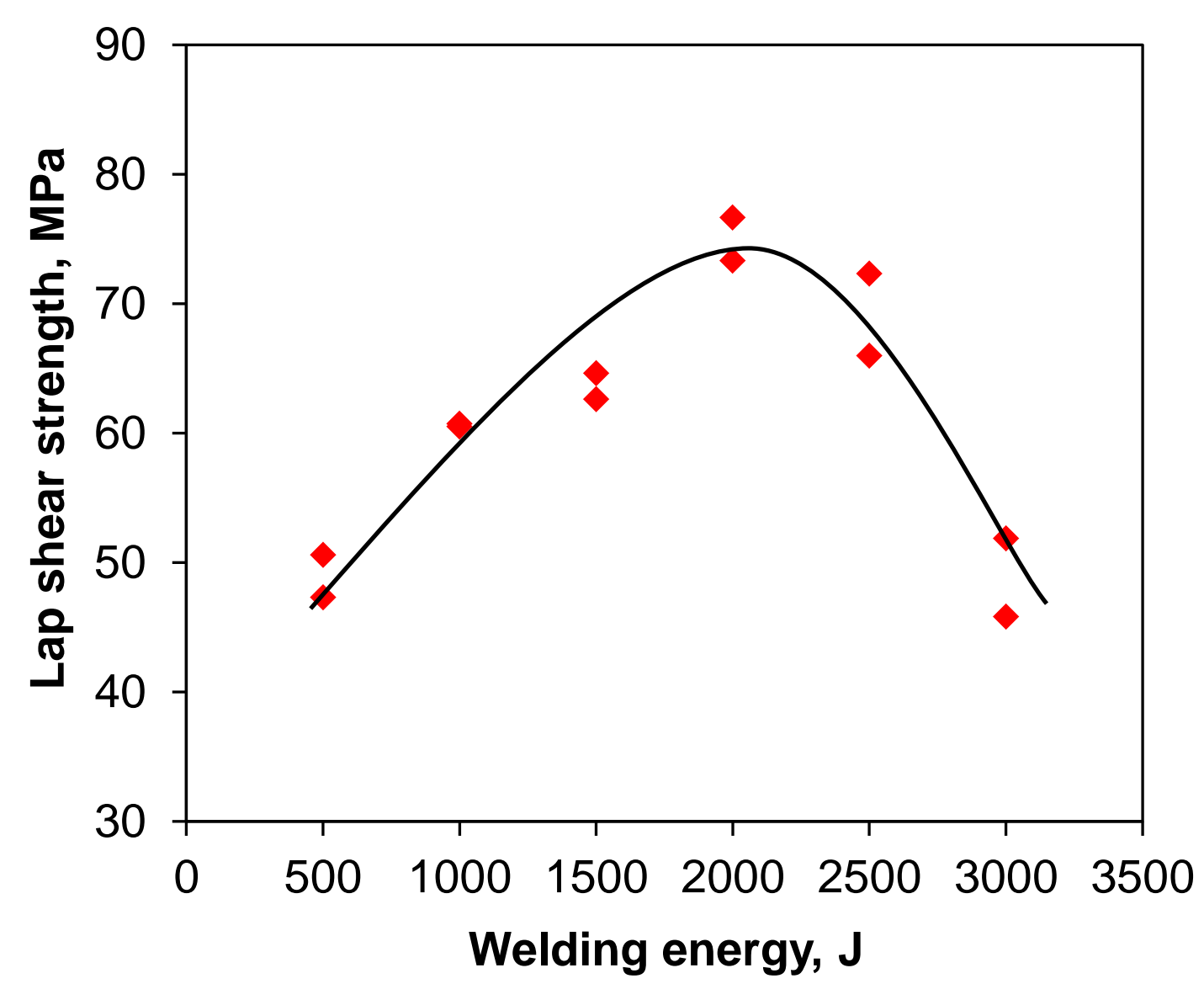

Figure 7.4: Lap shear tensile strength of USWed dissimilar Al-to-galvanized steel at different energy inputs.

squeezed out (Figure 7.1(b). As a result, more diffusion between Al and Fe occurred, which deteriorated strength. Thus, it can be concluded that this behavior was a consequence of the competition between the increasing diffusion bonding arising from higher temperatures at the higher energy inputs and the deteriorating effect of the brittle intermetallic layer of increasing thickness. Haddadi et al. [22] reported that the weld strength is limited by the development of an Al-Fe IMC layer, which increases in thickness with weld time. Thus, Watanabe et al. [37] obtained only a $0.6 \mathrm{kN}$ lap shear tensile load for welding time of $2.5 \mathrm{~s}$ for the USW of A5052 Al alloy-to-SS400 mild steel (without any coating or interlayer). Haddadi et al. [22] reported maximum lap shear strength of only $3.1 \mathrm{kN}$ for USW of A16111- 
to-hot dipped Zn coated steel and $2.7 \mathrm{kN}$ for USWed of Al6111-to-galvanized annealed steel. The reason for the above could be because of the presence of the brittle IMCs of $\mathrm{Fe}_{5} \mathrm{Zn}_{21}$, $\mathrm{F}_{3} \mathrm{Zn}_{10}$ and $\mathrm{FeZn} \mathrm{n}_{10}$ along with the Al-Fe IMCs at the welded joint. Moreover, Miyagawa et al. [149] obtained a $3.7 \mathrm{kN}$ lap shear tensile load of FSSWed A5052-to-Zn coated steel with welding time of $5 \mathrm{~s}$. Therefore, the present results suggest that USW offers a favorable solution for dissimilar metal joining since it requires only $1 \mathrm{sec}$ weld time to obtain $3.7 \mathrm{kN}$ ( $76 \mathrm{MPa}$ lap shear tensile strength) lap shear tensile load.

\subsection{Lap shear tensile fractography}

Typical SEM images of tensile fracture surfaces of USWed dissimilar Al-to-galvanized steel at $2000 \mathrm{~J}$ energy inputs are shown in Figures 7.5(a) and (b), respectively. To understand the tensile shear fractography, the fracture surfaces are divided in to the four parts (1) Znenriched region, (2) Al containing region (3) Al-Zn containing (Al-Zn eutectic film or liquid) region at $\mathrm{Al}$ side and $\mathrm{Al}-\mathrm{Fe} \mathrm{IMCs}$ region at galvanized steel side and (4) mixed region. Most of the $\mathrm{Zn}$-enriched region was present at the periphery of the nugget (Table 7.1, region $\mathrm{g}$ and j), due to the squeeze-out effect of the Zn coating as shown in Figure 7.1(b). Moreover, the concentration of $\mathrm{Al}$ element in region $\mathrm{g}$ ( $\mathrm{Al}$ side) and region $\mathrm{j}$ (steel side) was higher (Table 7.1), which is in agreement with the existence of the Al-Zn eutectic liquid and its pushing out effect as mentioned earlier (Figure 7.2). From the chemical composition of region i on $\mathrm{Al}$ side and 1 on galvanized steel side shown in Table 1, the Al-Zn containing region was found on the $\mathrm{Al}$ side, while $\mathrm{Al}-\mathrm{Fe} \mathrm{IMC}$ contain region was found on the galvanized steel side, which suggested that failure initially could have occurred in-between the Al-Zn region and 

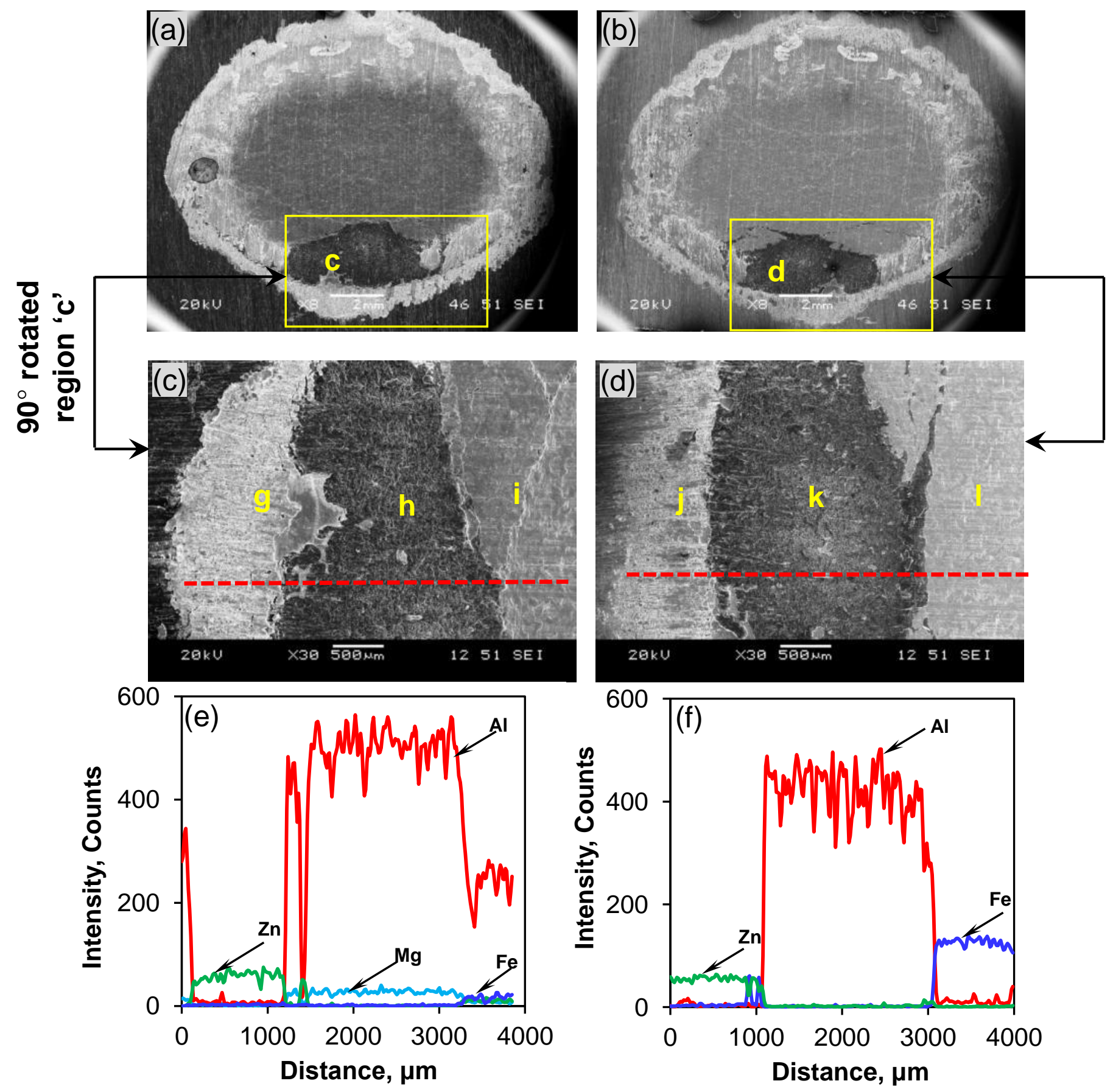

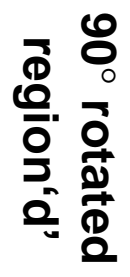

Figure 7.5: Typical SEM images of tensile fracture surface of USWed dissimilar Al-togalvanized steel (a) overall view Al side (b) galvanized steel side of $2000 \mathrm{~J}$, respectively, (c) and (d) shown in (a) and (b), respectively, are the magnified area (image rotated at $90^{\circ}$ ). (e) EDS line scan analysis across the line shown in (c) Al side, and (f) shown in (d) galvanized steel side. (g), (h) and (i) were higher magnification images of (c), and (j), $(k)$ and $(l)$ higher magnification images of $(d)$. 

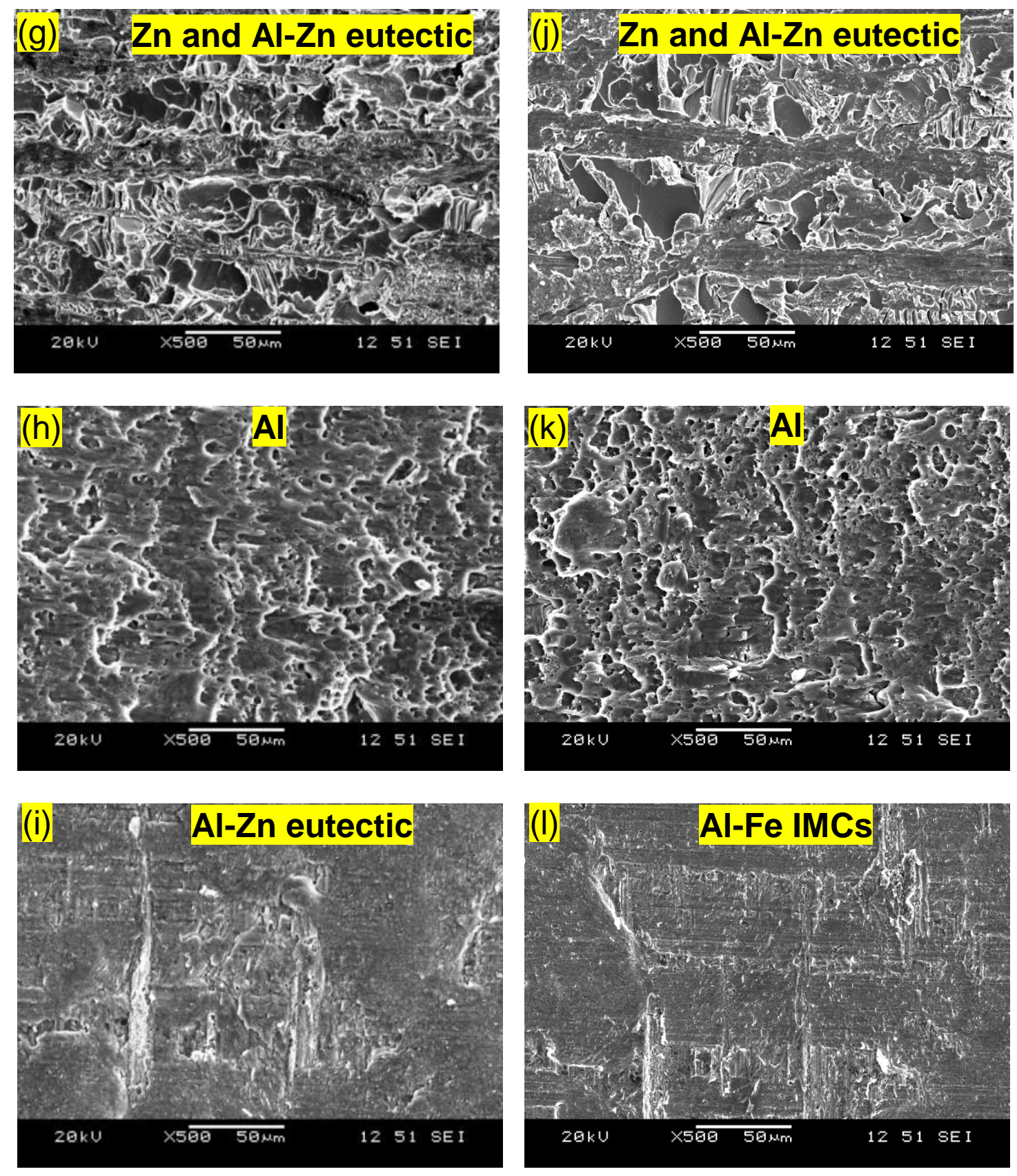

Figure 7.5 (cont'd): Typical SEM images of tensile fracture surface of USWed dissimilar Alto-galvanized steel (a) overall view Al side (b) galvanized steel side of $2000 \mathrm{~J}$, respectively, (c) and (d) shown in (a) and (b), respectively, are the magnified area (image rotated at $90^{\circ}$ ). (e) EDS line scan analysis across the line shown in (c) Al side, and (f) shown in (d) galvanized steel side. $(g),(h)$ and (i) were higher magnification images of $(c)$, and $(j),(k)$ and $(l)$ higher magnification images of $(d)$. 
Table 7.1: Elemental composition of different regions in Figure 7.5(c) and (d), in at.\%.

\begin{tabular}{ccccccc}
\hline Elements & Region g & Region h & Region i & Region j & Region k & Region l \\
\hline $\mathrm{Mg}$ & 2.5 & 4.2 & 3.1 & 12.2 & 4.3 & 0.8 \\
$\mathrm{Al}$ & 9.9 & 95.5 & 79.0 & 21.1 & 92.9 & 14.6 \\
$\mathrm{Fe}$ & 0.2 & 0.13 & 7.8 & 1.5 & 0.7 & 83.9 \\
$\mathrm{Zn}$ & 87.4 & 0.2 & 10.1 & 65.2 & 2.1 & 0.7 \\
\hline
\end{tabular}

IMCs of Al-Fe containing region. However, from the chemical composition of the region $\mathrm{h}$ and $\mathrm{k}$ (black region), Al was found as the main element on both sides of the fracture surfaces (Al and galvanized steel sides) at the edge of the sonotrode (Figures 7.5(a) and (b), black region shown in rectangular box), suggesting failure also occurred from this Al containing region.

To further verify the fracture location and chemical composition presented in the Table 7.1, EDS analysis was performed across the region c $\left(90^{\circ}\right.$ rotated image $)$ in Figure $7.5(\mathrm{a})$ and region $\mathrm{d}\left(90^{\circ}\right.$ rotated image) in Figure $7.5(\mathrm{~b})$. The EDS analysis results verify that the $\mathrm{Al}$ containing region was present on both fracture surfaces. Since the Al containing region was present on the steel side as well, strong bonding between Al with $\mathrm{Zn}$ or Fe elements could have occurred at the edge of the nugget. This could happen because at the edge of the nugget, deformation in both the sheets is higher due to the pressing action of the sharp edge of the sonotrode, resulting in more intimate mixing of $\mathrm{Al}$ elements into the $\mathrm{Zn}$ or Fe elements. Therefore, it can be inferred that fracture could initially occur in-between the regions $\mathrm{i}$ and 1 with a small applied load and then with continuing higher applied load, the joints failed from the $\mathrm{Al}$ containing region. This is also verified by the magnified regions $\mathrm{h}$ and $\mathrm{k}$ (Figure $7.5(\mathrm{~h})$ and $(\mathrm{k})$ ), where opposing shear-tear like fracture feature were found on Al and galvanized 
steel sides, suggesting that dimple-rupture failure mode occurred in-between the region $\mathrm{h}$ and $\mathrm{k}$, while there was interfacial de-bonding-like failure in-between the region $\mathrm{i}$ and 1.

\subsection{Fatigue behavior and failure mode}

Fatigue test results of the dissimilar USWed Al-to-galvanized steel joints obtained at room temperature, $\mathrm{R}=0.2$, and a frequency of $50 \mathrm{~Hz}$ are plotted in Figure 7.6(a). It can be seen that at the higher $\mathrm{P}_{\max }$ loads of 2.0, 2.5 and $3.0 \mathrm{kN}$ the 2000 and $3000 \mathrm{~J}$ samples showed higher fatigue resistance compared to the $1000 \mathrm{~J}$ welded samples. However, at the lower $\mathrm{P}_{\max }$

loads, especially at $1.0 \mathrm{kN}$ the $3000 \mathrm{~J}$ welded samples showed lower fatigue life compared to the 1000 and $2000 \mathrm{~J}$ welded samples. This is because at lower $\mathrm{P}_{\max }$ loads premature fatigue fracture, referred to here as transverse through-thickness crack growth mode, occurred at the edge of the nugget zone on the softer Al side, unlike interfacial fracture (in-between the $\mathrm{Al}$ and galvanized steel) which occurred at higher $\mathrm{P}_{\max }$ loads. Transverse through-thickness crack growth mode occurred (perpendicular to the loading direction) at the edge of the sonotrode in contact with the sample because higher welding energies led to substantially greater temperatures and the resulting softer $\mathrm{Al}$ sheet experienced a greater level of bending deformation in the weld zone compared to the base metal zone due to the outward flow of the material under the sonotrode tool indentation. This produced small micro level crack tip at the notch of the two sheets as indicated in [77]. Thus, this micro level crack experienced higher stress concentration effect during the cyclic loading which allowed the cracks to grow in the transverse direction of the Al sample. In $2000 \mathrm{~J}$ USWed sample, results of the fatigue tests were consistent with tensile results, which showed higher fatigue life compared to the 

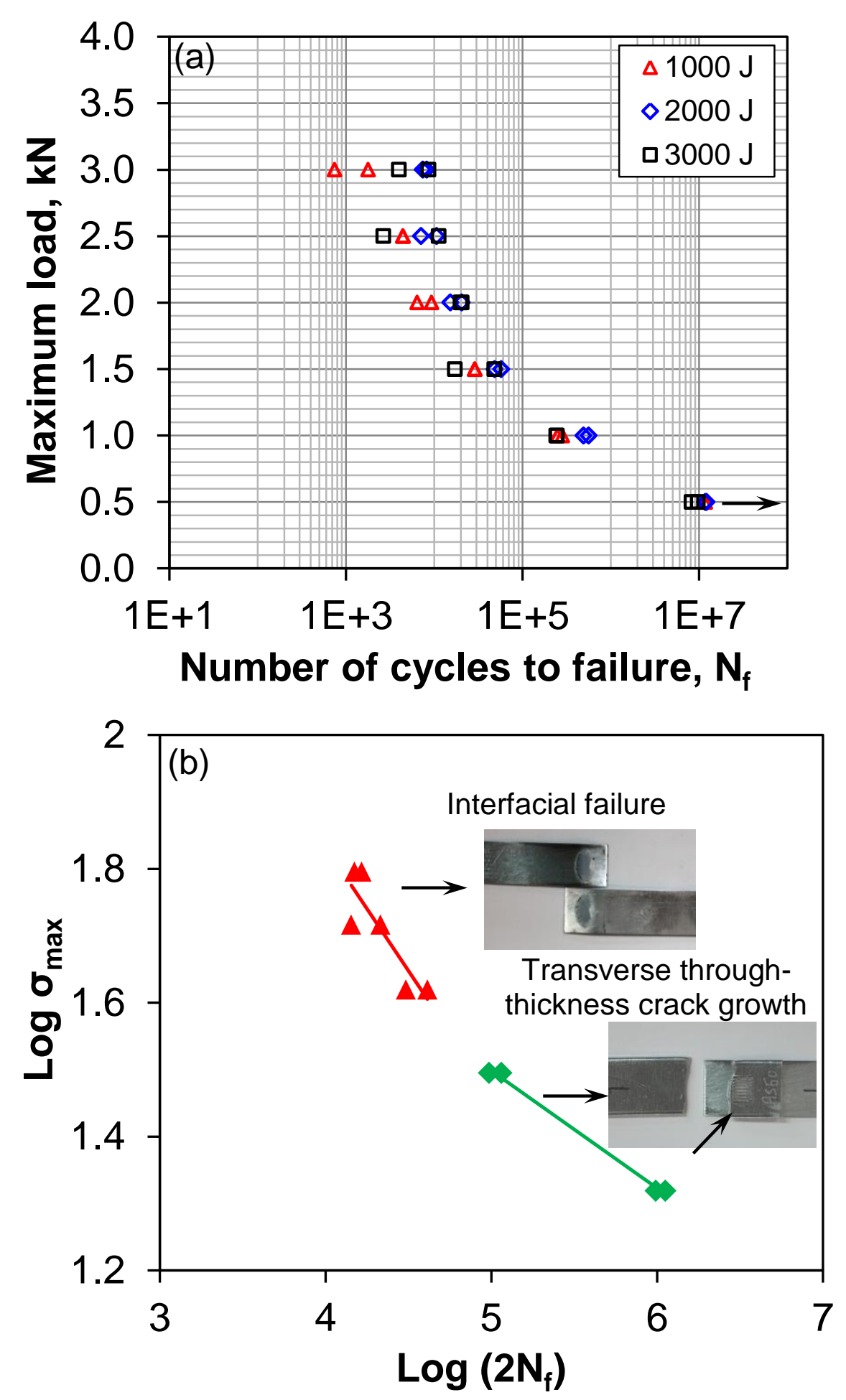

Figure 7.6: (a) $S$-N curves of the USWed Al-to-galvanized steel joint tested at $R T, R=0.2$, and a frequency of $50 \mathrm{~Hz}$, (b) the maximum tensile shear cyclic stress vs. the number of reversals to failure $\left(2 N_{f}\right)$ in the double-log scale for USWed Al-to-galvanized steel joint at 2000 J energy input. 
1000 and $3000 \mathrm{~J}$ energy inputs samples at applied $\mathrm{P}_{\max }$ load of $1.5 \mathrm{kN}$ or less. As can be seen from Figure 7.6(a) for all welding conditions the fatigue limit was $0.5 \mathrm{kN}$. Figure 7.6(b) presents the failure mode in conjunction with the logarithmic S-N plots in the form of the maximum tensile shear cyclic stress versus the number of reversals to failure $\left(2 \mathrm{~N}_{\mathrm{f}}\right)$ in terms of a Basquin type relationship for the $2000 \mathrm{~J}$ USWed samples. It should be noted that the run-out data for the non-failed samples at or over $1 \times 10^{7}$ cycles were not included in the curve fitting. For the $2000 \mathrm{~J}$ welded samples, interfacial failure mode was observed at the higher cyclic load levels where the slope was steeper, while transverse through-thickness crack growth mode at the Al side was observed at the lower cyclic load levels where the slope was flatter. Figure 7.7 shows typical fatigue failure location at the different $\mathrm{P}_{\max }$ load values of USWed Al-to-galvanized steel at $1000 \mathrm{~J}$ energy input. It can be seen that when samples were tested from cyclic load of 3.0 and $2.5 \mathrm{kN}$, interfacial failure occurred. In samples tested at 2.0 and $1.5 \mathrm{kN}$, interfacial failure also occurred, however initiation of crack was started at the circumference around the nugget (Figures 7.7(c) and (d)). At $1.0 \mathrm{kN}$ applied load, the crack propagated in a direction perpendicular to the loading direction. Once the remaining cross section could no longer sustain the shear overload, the heavily deformed nugget edge eventually experienced transverse through-thickness crack growth failure mode (Figure 7.7(e). In $1000 \mathrm{~J}$ samples, most of the failure occurred at the interface of the $\mathrm{Al}$ and galvanized steel sheet (except $1.0 \mathrm{kN}$ applied fatigue load where the failure was throughthickness). On the other hand, in the $3000 \mathrm{~J}$ welded samples most of the fractures occurred from the edge of the sonotrode nugget at the $\mathrm{Al}$ side (except $3.0 \mathrm{kN}$ applied fatigue load where the failure was interfacial). The $1000 \mathrm{~J}$ welded sample experienced lower sonotrode penetration (i.e no micro level cracks at the edge of nugget zone), however, the joint 

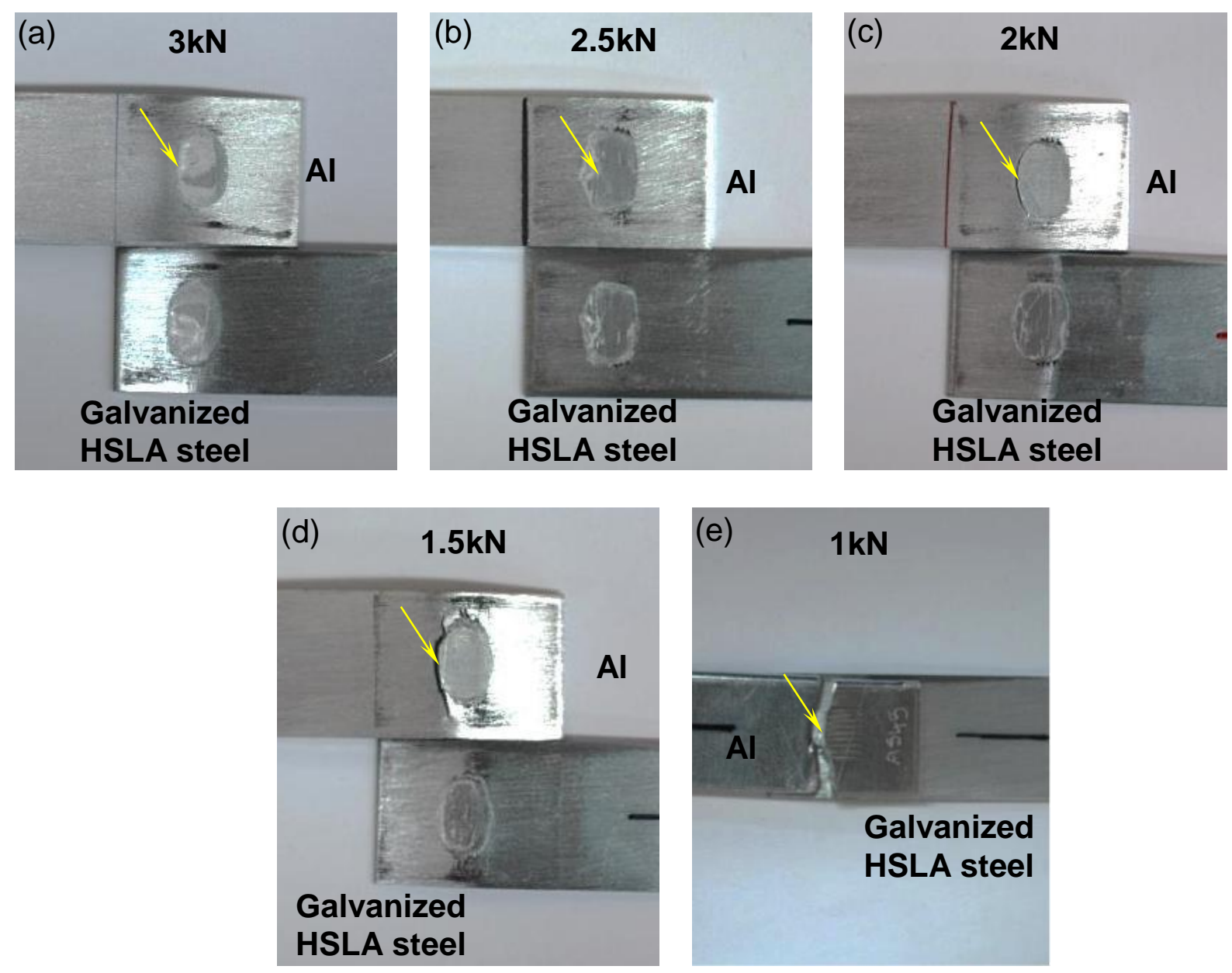

Figure 7.7: Typical fatigue failure locations at different $P_{\text {max }}$ values of USWed Al-togalvanized steel at $1000 \mathrm{~J}$ energy input (a) $3 \mathrm{kN}$ (interfacial failure mode) (b) $2.5 \mathrm{kN}$ (interfacial failure mode) (c) $2 \mathrm{kN}$ (interfacial failure mode, initiation of crack) (d) $1.5 \mathrm{kN}$ ((interfacial failure mode, crack start to propagating perpendicular to the loading direction) (e) $1 \mathrm{kN}$ (transverse through-thickness crack growth mode).

experienced weaker diffusion bonding; this was not the case in the $3000 \mathrm{~J}$ welded samples. Thus, during the USW process, with increasing energy input there is competition between the increasing diffusion bonding and the propagation of a crack in the Al sheet thickness.

The change of the failure mode from the transverse through-thickness crack growth mode to the interfacial failure occurred at $\log \sigma_{\max }=1.61$ or $\left(\sigma_{\max }=42 \mathrm{MPa}\right)$ in the $2000 \mathrm{~J}$ USWed 
joints (Figure 7.6(b)). Likewise, such a transition of failure mode from the deformed edge failure to the interfacial failure occurred at $\log \sigma_{\max }=1.49\left(\right.$ or $\sigma_{\max }=31 \mathrm{MPa}$ ) in the $1000 \mathrm{~J}$ samples and at $\log \sigma_{\max }=1.71$ (or $\sigma_{\max }=52 \mathrm{MPa}$ ) in the $3000 \mathrm{~J}$ welded samples (not shown in the Figure 7.6(b)). Thus, from these $\sigma_{\max }$ values of different welding energies, it can be concluded that the maximum cyclic stress at which transition of the fatigue fracture from transverse through-thickness crack growth mode to the interfacial failure mode occurs increases with increasing energy input.

\subsection{Fatigue fractography}

For a more detailed study of the fatigue fractures, SEM fracture surface images of the failed $1000 \mathrm{~J}$ welded samples of $\mathrm{Al}$ side are shown in Figure 7.8 which were tested at a minimum cyclic load of $1.0 \mathrm{kN}$ (Figure 7.8(a) to (e)) and at a maximum cyclic load of $3.0 \mathrm{kN}$ (Figure 7.8 (f) to (h)). It can be seen from Figure 7.8(a) that the fatigue crack developed from the region "b" and propagated at right angles to the loading direction along the $\mathrm{Al}$ sheet with increasing number of cycles and later experienced transverse through-thickness crack growth mode (Figure 7.7(e)). Figure 7.8(b) shows the location of the crack initiation and Figure 7.8(c) shows the magnified image of region "c" in Figure 7.8(b). The final crack propagation direction is shown in Figure 7.8(d). Fatigue crack propagation was mainly characterized by the formation of fatigue striations (Figure 7.8(e)), which usually appeared perpendicular to the fatigue crack propagation direction. Fatigue striations typically generate by a repeated

plastic blunting-sharpening process in the FCC materials, stemming from the glide of dislocations on the slip plane along the slip direction within the plastic region before the 

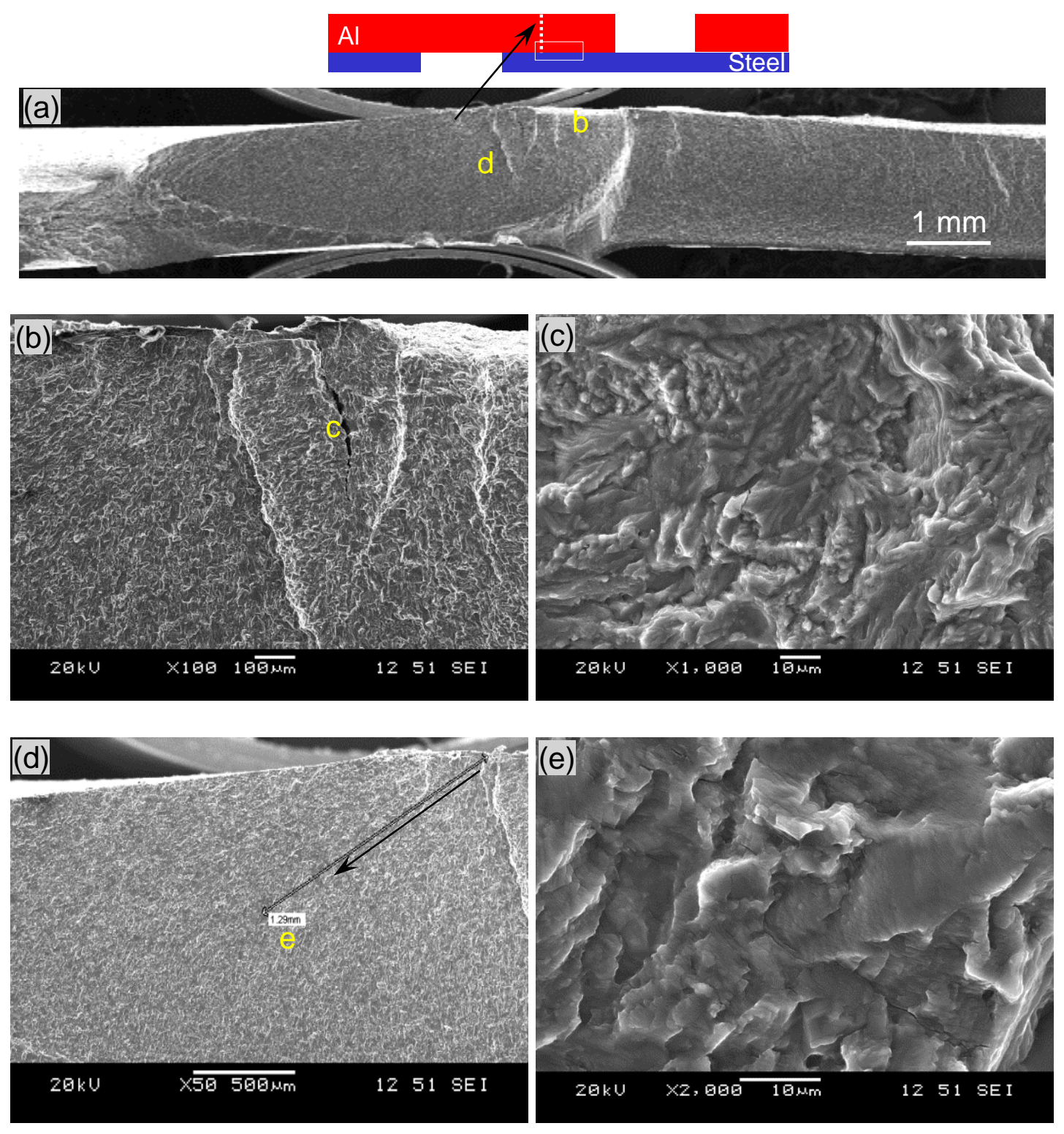

Figure 7.8: Typical SEM images of fatigue fracture surface of a USWed Al-to-steel joint using $1000 \mathrm{~J}$ tested at a $P_{\max } 1.0 \mathrm{kN}$, (a) overall view, (b) crack initiation area, (c) magnified image of crack initiation area, (d) final fast crack propagation area, (e) fatigue striations in the crack propagation zone at a higher magnification, (f) overall view of shear fracture surface at a higher $P_{\max }=3.0 \mathrm{kN}$, and $(g)$ shear fracture of region $g$ in (f) at a higher magnification, and (h) small isolated dimple-rapture failure zone of region $h$ in $(g)$ at a higher magnification. 

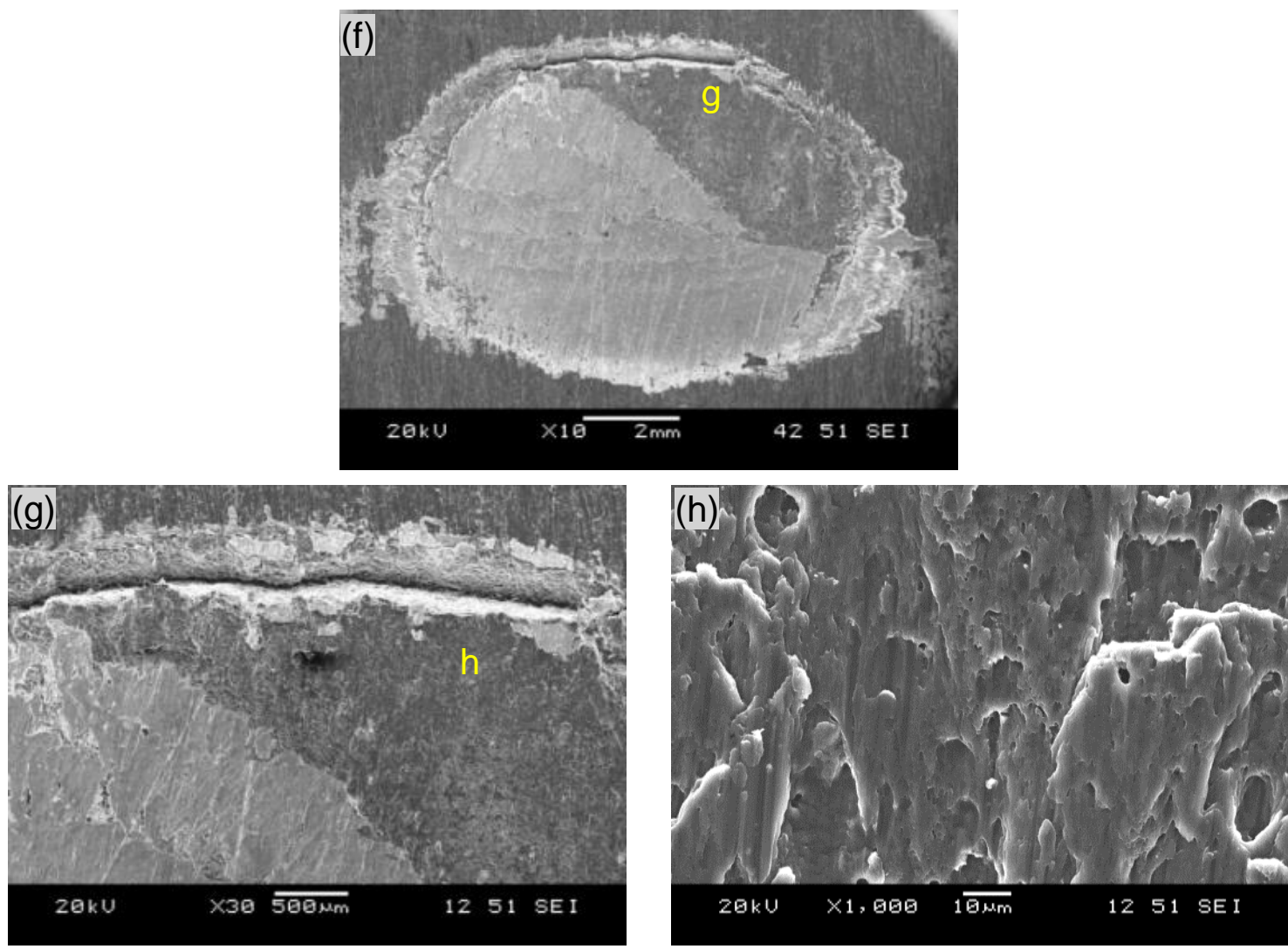

Figure 7.8 (cont'd): Typical SEM images of fatigue fracture surface of a USWed Al-to-steel joint using $1000 \mathrm{~J}$ tested at a $P_{\max } 1.0 \mathrm{kN}$, (a) overall view, (b) crack initiation area, (c) magnified image of crack initiation area, (d) final fast crack propagation area, (e) fatigue striations in the crack propagation zone at a higher magnification, (f) overall view of shear fracture surface at a higher $P_{\max }=3.0 \mathrm{kN}$, and $(\mathrm{g})$ shear fracture of region $\mathrm{g}$ in $(f)$ at a higher magnification, and (h) small isolated dimple-rapture failure zone of region $h$ in $(g)$ at a higher magnification.

crack tip [34]. Figure 7.8(f) presents Al side SEM images of fatigue fracture surfaces of the USWed Al-to-galvanized steel joints failed in interfacial fracture mode. Figure $7.8(\mathrm{~g})$ shows that the crack propagated circumferentially around the nugget (Figure 7.7(c) and (d)) and then failed in interfacial fracture mode. The shear-tear like features shown in Figure 8(h) are evidence of the interfacial failure in-between the $\mathrm{Al}$ and galvanized steel sheet. 


\subsection{Summary}

- USW of dissimilar A15754-O Al alloy-to-galvanized steel sheets was successfully achieved. Eutectic Al-Zn film was mainly present at the weld interface followed by the $\mathrm{Fe}_{2} \mathrm{Al}_{5}$ and $\mathrm{FeAl}_{3}$ IMCs, which was confirmed by the XRD analysis.

- The lap shear tensile strength increased with increasing energy inputs and reached the maximum $\sim 76 \mathrm{MPa}(\sim 3.7 \mathrm{kN}$ lap shear fracture load $)$ at $2000 \mathrm{~J}$ energy input and then decreased. EDS analysis on the fracture surfaces of both Al and galvanized steel sides suggested that failure could initially occur in-between the eutectic Al-Zn film and the IMCs of $\mathrm{Fe}_{2} \mathrm{Al}_{5}$ and $\mathrm{FeAl}_{3}$ and then with continuing higher applied load, it failed from the Al containing region on both matching fracture surfaces.

- For all welding conditions, the fatigue limit was $0.5 \mathrm{kN}$. The maximum cyclic stress at which transition of the fatigue fracture from transverse through-thickness crack growth mode to the interfacial failure mode occurs increases with increasing energy input. 


\section{CHAPTER 8}

\section{SUMMARY, CONCLUSIONS AND FUTURE WORK}

\subsection{Summary}

USW of similar Mg-to-Mg and dissimilar of Mg-to-Al, Mg-to-steel and Al-to-steel alloys sheets were performed. From Chapter 2, it was found that very limited work has been reported for USWed Mg alloy. Therefore, in Chapter 4, first initiative was taken to check the feasibility of USW process on Mg alloys and to characterize USW of Mg-to-Mg welds. The effect of higher shear strain rate and welding temperature on the dynamic recrystallization of grains was evaluated. A fundamental understanding of the deformation mechanism and dynamic recrystallization during USW and their influence on crystallographic texture formation and mechanical properties of USW Mg alloys, and the USW fatigue properties, in particular how and where the crack initiates and how it propagates up to the failure in the fatigue testing of USWed joints were studied. Further, a numerical model based on Newman and Dowling [78] was developed and validated with experimental fatigue data of USW of Mg-to-Mg. In Chapters 5, 6 and 7 characterizations of challenging dissimilar welding of Mg-to-Al, Mg-to-steel and Al-to-steel, respectively, were studied, where the formation of IMCs have been engineered using $\mathrm{Sn}$ interlayer and $\mathrm{Zn}$ coating with a view to improve mechanical properties like lap shear tensile and fatigue strength. 


\subsection{Contribution}

This study has demonstrated that USW can be used to produce satisfactory similar and dissimilar welds in difficult to weld light metals such as sheet $\mathrm{Mg}, \mathrm{Al}$ and steel. It has also been shown that using an appropriate interlayer such as $\mathrm{Sn}$ in dissimilar USW it is possible to achieve sound welds with good mechanical properties through the formation of non-brittle IMCs.

The research results should effectively promote the applications of lightweight $\mathrm{Mg}$ and $\mathrm{Al}$ alloys in the automotive industry and contribute to the reduction of green house gas emissions.

\subsection{Major conclusions}

Joining of dissimilar materials Mg-to-Al, Mg-to-steel and Al-to-steel was successfully achieved using USW process.

1. USW joints exhibited acceptable lap shear tensile fracture strength and fatigue life with only $\sim 5-10 \%$ hardness reduction at WZ.

2. In all joint combinations considered in this study, lap shear tensile strength of the joints increased with increasing energy inputs and then decreased.

3. Dynamic recrystallization was observed at the center of the Mg-to-Mg joints from 1000 J welding energy and onwards due to large shear strain rate and higher peak temperature which led to a more random crystallographic texture. 
4. In tensile and fatigue tests, all dissimilar joints failed from the interface while most of the similar joints failed at the edge of the NZ. USWed joints displayed higher lap shear tensile strength and longer fatigue life compared with other welding processes.

5. A life prediction model for spot welded lap joints based on Newman and Dowling [78] agreed well with the experimental results.

6. Dissimilar USW joints with interlayer exhibited higher lap shear tensile strength and consumed lower welding energy to achieve acceptable joints than dissimilar USW joints without interlayer.

7. The presence of suitable interlayer/coating ( $\mathrm{Sn}$ and $\mathrm{Zn}$ ) on the fracture surfaces reduced the tendency for brittle cleavage-like fracture and encouraged ductile type fracture behavior with rougher fracture surface.

8. The role of the interlayer in dissimilar USWed joints was to replace the formation of brittle IMCs in non-interlayer joints with solid solutions and non-brittle IMCs.

- In Mg-to-Al welds with Sn interlayer, the joints contained solid solution of Sn with $\mathrm{Mg}$ and $\mathrm{Sn}$ with $\mathrm{Al}$ as well as a $\mathrm{Sn}$ and $\mathrm{Mg}_{2} \mathrm{Sn}$ eutectic structure.

- In Mg-to-steel welds with Sn interlayer, the joints contained solid solution of $\mathrm{Sn}$ with $\mathrm{Mg}$ and $\mathrm{Sn}$ with $\mathrm{Fe}$ as well as a $\mathrm{Sn}$ and $\mathrm{Mg}_{2} \mathrm{Sn}$ eutectic structure.

- In Al-to-steel welds with $\mathrm{Zn}$ coating on steel surface, the joints contained Al$\mathrm{Zn}$ eutectic and thin IMCs of $\mathrm{FeAl}_{3}$ and $\mathrm{Fe}_{2} \mathrm{Al}_{5}$.

9. The desirable welding energy input for USW of light weight alloys in this study with sample thickness of 1-3 mm was found to be between $\sim 1000 \mathrm{~J}$ and $\sim 2000 \mathrm{~J}$. Exceeding the $2000 \mathrm{~J}$ energy input led to the thinning of the welding sheet and failure at the edge of the NZ. 


\subsection{Recommendations for future work}

A number of interesting extensions to the present work could be made in the future. These are listed below:

1 As seen earlier in the (Figure 4.11), lap shear tensile experiments of USWed $\mathrm{Mg}$ alloy, most of the welds failed from interface (between to weld faying surfaces). However, with similar welding conditions, others samples tested with high cycle fatigue test failed from the edge of the weld nugget (Figure 4.17) This crack initiation is thought to be caused by the extensive residual stress at the edge of the joints due to the simultaneous application of vibration and compressive pressures during USW process. However, the more research on the measurement of residual stress at the edge of the weld nugget will reveal information. Residual stresses are inherently introduced into materials through many mechanical, thermomechanical and thermal processes such as forming, heat treatment and welding. Excessive residual stresses are known to destroy the structural integrity and performance of components. Mainly, in welding assemblies, sudden failure is frequently caused by the combined consequence of applied loads and residual stresses.

2 With increasing applications of plastics and polymer based composites in the automotive and aerospace industries, metal-to-plastic joining becomes essential. The one of the future objectives is to join metal to plastic via an ultrasonic spot welding technique and evaluate their microstructure, microhardness, lap shear strength and fatigue strength. 
3 To increase the strength of the weld, hybrid-welding process, which is complete by two, different welding technique one is adhesive welding and another is ultrasonic spot welding technique, also can be considered. It is worth to check and compare the mechanical properties of the USWed $\mathrm{Al}$ and $\mathrm{Mg}$ alloys with different welding processing methods.

4 Since USW technology is new, minimum data available on USW on AWS database. Recommended spacing between successive welds and distances from a spot weld to component edges should be followed to acquire optimum weld strength and quality. Thus, this work also extends by finding optimum distance between two spots by experimentally, analytically and numerically. 


\section{References}

1 T.M. Pollock, Weight Loss with Magnesium Alloys, Science, 328 (2010) 986-987.

2 M. Wise, K. Calvin, A. Thomson, L. Clarke, B. Bond-Lamberty, R. Sands, S.J. Smith, A. Janetos, J. Edmonds, Implications of limiting $\mathrm{CO}_{2}$ concentrations for land use and energy, Science, 324 (2009) 1183-1186.

3 E. Alonso, T.M. Lee, C. Bjelkengren, R. Roth, R.E. Kirchain, Evaluating the potential for secondary mass savings in vehicle lightweighting, Environmental Science and Technology, 46(5) (2012) 2893-2901.

4 H.J. Kim, G.A. Keoleian, S.J. Skerlos, Economic assessment of greenhouse gas emissions reduction by vehicle lightweighting using aluminum and high-strength steel, Journal of Industrial Ecology, 15(1) (2011) 64-80.

5 H.J. Kim, C. McMillan, G.A. Keoleian, S.J. Skerlos, Greenhouse gas emissions payback for lightweighted vehicles using aluminum and high-strength steel, Journal of Industrial Ecology, 14(6) (2010) 929-46.

6 D. Shindell, G. Faluvegi, M. Walsh, S.C. Anenberg, R.V. Dingenen, N.Z. Muller, J. Austin, D. Koch, and G. Milly, Climate, health, agricultural and economic impacts of tighter vehicle-emission standards, Nature Climate Change, 1 (2011) 59-66.

7 D.A. Howey, A challenging future for cars, Nature Climate Change, 2 (2012) 28-29.

8 Q. Schiermeier, Increased flood risk linked to global warming, Nature, 316 (2011) $470-471$.

9 S.K. Min, X. Zhang, F.W. Zwiers1, G.C. Hegerl, Human contribution to moreintense precipitation Extremes, 470 (2011) 378-381. 
10 E. Aghion, B. Bronfin, D. Eliezer, The role of the magnesium industry in protecting the environment, Journal of Material Processing and Technology, 117 (2001) 381385.

11 B. Jordon, J.B. Gibson, M.F. Horstemeyer, H.EI. Kadiri, J.C. Baird, A.A. Luo, Effect of twinning, slip, and inclusions on the fatigue anisotropy of extrusion-textured AZ61 magnesium alloy, Material Science and Engineering A, 528(22-23) (2011) 6860-6871.

12 Q. Yu, J.X. Zhang, Y.Y. Jiang Q.Z. Li, Effect of strain ratio on cyclic deformation and fatigue of extruded AZ61A magnesium alloy, International Journal of Fatigue, 36 (2012) 47-58.

13 S. Begum, D.L. Chen, S. Xu A.A. Luo, Effect of strain ratio and strain rate on low cycle fatigue behavior of AZ31 wrought magnesium alloy, Material Science and Engineering A, 517(1-2) (2009) 334-43.

14 C.L. Fan, D.L. Chen, A.A. Luo, Dependence of the distribution of deformation twins on strain amplitudes in an extruded magnesium alloy after cyclic deformation, Material Science and Engineering A, 519(1-2) (2009) 38-45.

15 H.Y. Wu, J.C. Yang, J.H. Liao, F.J. Zhu, Dynamic behavior of extruded AZ61 Mg alloy during hot compression, Material Science and Engineering A, 535 (2012) 68-75.

16 S.J. Liang, H.F. Sun, Z.Y. Liu, E. Wang, Mechanical properties and texture evolution during rolling process of an AZ31 Mg alloy, Journal of Alloy and Compound, 472 (2009) 127-132.

17 J.B. Jiang and Z.D. Zhang, The study on the plasma arc weld bonding process of magnesium alloy, Journal of Alloy and Compound, 466 (2008) 368-72. 
18 Z. Zhang, X. Yang, J. Zhang, G. Zhou, X. Xu, B. Zou, Effect of welding parameters on microstructure and mechanical properties of friction stir spot welded 5052 aluminum alloy, Materials and Design, 32 (2011) 4461-4470.

19 V.X. Tran, J. Pan, T. Pan, Fatigue behavior of aluminum 5754-O and 6111-T4 spot friction welds in lap-shear specimens, International Journal of Fatigue, 30, (2008) $2175-2190$.

20 'Vision of Welding', American Welding Society, http://www.aws.org/research/vision.pdf

21 R. Qiu, C. Iwamoto, S. Satonaka, Interfacial microstructure and strength of steel/aluminum alloy joints welded by resistance spot welding with cover plate, Journal of Material Processing and Technology, 209 (2009) 4186-4193.

22 F. Haddadi, Y.C. Chen, P.B. Prangnell, Ultrasonic spot welding aluminum to steel for automotive applications-microstructure and optimization, Material Science and Technology, 27 (2011) 617-624.

23 J. Peng, S. Fukumoto, L. Brown, N. Zhou, Image analysis of electrode degradation in resistance spot welding of aluminium, Science and Technology of Welding and Joining, 9 (2004) 331-336.

24 R. Jahn, R. Cooper, D. Wilkosz, The effect of anvil geometry and welding energy of microstructures in ultrasonic spot welds of AA6111-T4', Metallurgical and Materials Transactions A, 38 A (2007), 570-583.

25 E. Hetrick, R. Jahn, L. Reatherford, Ultrasonic spot welding-a new tool for aluminum joining, Welding Journal, 84(2) (2005) 26-30. 
26 T. Watanabe, H. Itoh, A. Yanagisawa, M. Hiraishi, Ultrasonic welding of heattreatable aluminium alloy A6061 sheet, Welding International, 23(9) (2009) 633-639.

27 S.M. Allameh, C. Mercer, D. Popoola, W.O. Soboyejo, 'Microstructural characterization of ultrasonically welded aluminum', Journal of Engineering Materials and Technology, 127-1 (2005) 65-74.

28 H.P.C. Daniels, Ultrasonic Welding, Ultrasonics, 3(4) (1965) 190-196.

29 S. Elangovan, S. Semeer, K. Prakasan, Temperature and stress distribution in ultrasonic metal welding-An FEA-based study, Journal of Material Processing and Technology, 209(3) 2009 1143-1150.

30 B. Harsha, F. Hunt, K. Okamoto, R.S. Mishra, M.W. Mahoney, Friction stir welding process, ASM, (2007) 235-272.

31 D. Bakavos, P.B. Prangnell, Effect of reduced or zero pin length and anvil insulation on friction stir spot welding thin gauge 6111 automotive sheet, Science and Technology of Welding and Joining, 14 (2009) 443-456.

32 P.B. Prangnell, D. Bakavos, Novel approaches to friction spot welding thin aluminium automotive sheet, Material Science Forum, 638(642) (2010) 1237-1242.

33 V.K. Patel, S.D. Bhole, D.L. Chen, Friction stir spot and ultrasonic spot welding of dissimilar magnesium-to-aluminum alloys, Proceedings of the 24th CANCAM, June 2-6, 2013, Saskatoon, Saskatchewan, Canada.

34 S.H. Chowdhury, D.L. Chen, S.D. Bhole, X. Cao and P. Wanjara, Lap shear strength and fatigue life of friction stir spot welded AZ31 magnesium and 5754 aluminum alloys, Material Science and Engineering A, 556 (2012) 500-509. 
35 D. Bakavos and P.B Prangnell, Mechanisms of joint and microstructure formation in high power ultrasonic spot welding 6111 aluminum automotive sheet, Material Science and Engineering A, 527 (2010) 6320-6334.

36 M.J. Rathod, M. Kutsuna, Joining of aluminum alloy 5052 and low-carbon steel by laser roll welding, Welding Journal, 83 (2004) 16-26.

37 T. Watanabe, H. Sakuyama, A.Yanagisawa, "Ultrasonic welding between mild steel sheet and Al-Mg alloy sheet", Journal of Materials Processing Technology, Volume 209, Issues 15 - 16, Pages 5475-5480.

38 M. Santella, T. Franklin, J. Pan, T.Y. Pan, E. Brown, 'Ultrasonic Spot Welding of AZ31B to Galvanized Mild Steel', SAE International Journal of Material and Manufacturing, 3, (2010) 652-657.

39 D. Vries, Mechanics and Mechanisms of Ultrasonic Metal Welding, PhD Dissertation, The Ohio State University, (2004).

40 N. Ahmed, New Developments in Advanced Welding, Woodhead publishing (2005) ISBN: 978-1-85573-970-3.

41 A.Z. Shakeeb, A study of ultrasonic metal welding, PhD Dissertation, University of Glasgow, (2013).

42 M. Bloss, Ultrasonic Metal Welding: The Weldability of Stainless Steel, Titanium and Nickel-Based Super Alloys, PhD Dissertation, University of Ohio, (2008)

43 E. de Vries, Mechanics and mechanisms of ultrasonic metal welding, $\mathrm{PhD}$ Dissertation, University of Ohio, (2004).

44 S. Matsuoka and H. Imai, Direct welding of different metals used ultrasonic vibration, Journal of Materials Processing Technology, 209(2) (2009) 954-960. 
45 R.L. O'Brien, Welding Handbook: Welding Processes, American Welding Society, (1997)

$46 \mathrm{X}$. Cheng and $\mathrm{X}$. Li, Investigation of heat generation in ultrasonic metal welding using microsensor arrays', Journal of Micromechanics and Microengineering, 17 (2007) 273-282.

47 G.G. Harman, J. Albers, 'The Ultrasonic welding mechanism as applied to aluminum- and gold-wire bonding in microelectronics', IEEE Transaction, PHP13 (1977) 406-412.

48 I. Lum, J.P. Jung, Y. Zhu, Bonding mechanism in ultrasonic gold ball bondson copper substrate', Metallurgical and Materials Transactions A, 36A (2005) 12791286.

49 N. Murdeshwar and J.E. Krzanowski, A Microstructural study of dislocation substructures formed in metal foil substrates during ultrasonic wire bonding Metallurgical and Materials Transactions A, 28A (1997) 2663-2671.

50 "Welding of Magnesium-base Alloys", Keytometals, Article 35 http://www.keytometals.com/Article35.htm

51 F. Czerwinski, Welding and Joining of Magnesium Alloys in the book "Magnesium Alloys - Design, Processing and Properties", ISBN 978-953-307-520-4, In Tech, January 1, (2011).

52 B. Lang, D.Q. Sun, G.Z. Li, X.F. Qin, Effects of welding parameters on microstructure and mechanical properties of resistance spot welded magnesium alloy joints, Science and Technology of Welding and Joining, 13-8 (2008) 698-704. 
53 B.S. Naik, D.L. Chen, X. Cao, and P. Wanjara, Microstructure and Fatigue Properties of a Friction Stir Lap Welded Magnesium Alloy, Metallurgical and Materials Transactions A, 44A (2013) 3732-3746.

54 S. Fukumoto, S. Tanaka, T. Ono, H. Tsubakino, T. Tomita, M. Aritoshi, K. Okita, Microstructural Development in Friction Welded AZ31 Magnesium Alloy, Materials Transactions, 47(4) (2006) 1071-1076.

55 T.Y. Pan, M.L Santella, P.K. Mallick, A. Frederick, Spot friction welding of thin AZ31 magnesium alloy, Friction stir welding and processing IV (2007) 323-330.

56 K. Nakata, Friction stir welding of magnesium alloys, Welding International, 23(5) (2009) 328-332.

57 H. Luo, C. Hao, J. Zhang, Z, Gan, H. Chen and H. Zhang, Characteristics of Resistance Welding Magnesium Alloys AZ31 and AZ91, Welding Journal, 90 (2011) 249-257.

58 C.I. Chang, C.J. Lee, J.C. Huang, Relationship between grain size and ZenerHolloman parameter during friction stir processing in AZ31 Mg alloys, Scripta Materialia, 51 (2004) 509-514.

59 Z. Yu, H. Choo, Influence of twinning on the grain refinement during hightemperature deformation in a magnesium alloy, Scripta Materialia, 64 (2011) 434437.

60 Z. Yu, H. Choo, Z. Feng, S.C. Vogel, Influence of thermo-mechanical parameters on texture and tensile behavior of friction stir processed Mg alloy, Scripta Materialia, 63 (2010) 1112-1115. 
61 M. Ghosh, K. Kumar, R.S. Mishra, Analysis of microstructural evolution during friction stir welding of ultrahigh-strength steel, Scripta Materialia, 63 (2010) 851-854.

62 C. Zener and H.H. Hollomon, Effect of strain rate upon plastic flow of steel, Journal of Applied Physics, 15 (1944) 22-32.

63 Y.N. Wang, J.C. Huang, Texture analysis in hexagonal materials, Materials Chemistry and Physics, 81 (2003) 11-26.

64 A. Kouadri, L. Barrallier, Texture characterisation of hexagonal metals: Magnesium AZ91 alloy, welded by laser processing, Material Science and Engineering A, 429 (2006) 11-17.

65 A. Galiyev, R. Kaibyshev, G. Gottstein, Correlation of plastic deformation and dynamic recrystallization in magnesium alloy ZK60, Acta Materialia, 49 (2001) 1199-1207.

66 S.H. Chowdhury, D.L. Chen, S.D. Bhole, X. Cao, and P. Wanjara, Fiber laser welded AZ31 magnesium alloy: The effect of welding speed on microstructure and mechanical properties, Metallurgical and Materials Transactions A, 43(6) (2012) $2133-2147$.

67 Q. Yang, A.H. Feng, B.L. Xiao, Z.Y. Ma, Influence of texture on superplastic behavior of friction stir processed ZK60 magnesium alloy, Material Science and Engineering A, 556 (2012) 671-677.

68 S.H.C. Park, Y.S. Sato, H. Kokawa, Effect of micro-texture on fracture location in friction stir weld of Mg alloy AZ61 during tensile test, Scripta Materialia, 49 (2003) 161-166. 
69 Y.S. Sato, S.H.C. Park, A. Matsunaga, A. Honda, H.Kokawa, Novel production for highly formable Mg alloy plate, Journal of Material Science, 40 (2005) 637-642.

70 W. Woo, H. Choo, M.B. Prime, Z. Feng, B. Clausen, Microstructure, texture and residual stress in a friction-stir-processed AZ31B magnesium alloy, Acta Materialia, $56(2008) 1701-1711$.

71 W. Woo, H. Choo, D.W. Brown, P.K. Liaw, Z. Feng, Texture variation and its influence on the tensile behavior of a friction-stir processed magnesium alloy, Scripta Materialia, 54 (2006) 1859-1864.

72 Z. Zhu, B.P. Wynne, E. Ghassemieh, A. Siddiq, Microstructural analysis of ultrasonic welded AA6061 by Electron backscattered diffraction, Rare metal materials and engineering, 38(3) (2009) 147-151.

73 Z. Zhu, E. Ghassemieh, Microstructure and microtexture evolution of aluminum alloy 3003 under ultrasonic welding process for embedding SiC fibre, China Welding, 18(4) (2009) 6-9.

74 Z.W. Chen and S. Yazdanian, Friction stir lap welding: material flow, joint structure and strength, Journal of Achievements in Materials and Manufacturing Engineering, 55(2) (2012) 629-637.

75 L. Liu, L. Xiao, D.L. Chen, J.C Feng, S. Kim., Y. Zhou, Microstructure and fatigue properties of Mg-to-steel dissimilar resistance spot welds, Materials and Design, 45 (2013) 336-342.

76 V.X. Tran, J. Pan, T. Pan. Fatigue behavior of aluminum 5754-O and 6111-T4 spot friction welds in lap-shear specimens, International Journal of Fatigue, 30 (2008) 2175-2190. 
77 T. Franklin, J. Pan, M. Santella, T.Y. Pan, Fatigue behavior of dissimilar ultrasonic spot weld in lap-shear specimens of magnesium and steel sheets, SAE International Journal of Materials and Manufacturing, 4(1) (2011) 581-588.

78 J.A. Newman, N.E. Dowling, A crack growth approach to life prediction of spotwelded lap joints, Fatigue \& Fracture of Engineering Materials \& Structures, 21 (1998) 1123-1132.

79 P.C. Lin, J. Pan, T. Pan, Failure modes and Fatigue life estimations of friction spot welds in lap-shear specimens of aluminum 6111-T4 sheets, part 1: welds made by a concave tool. International Journal of Fatigue, 2008;30-1:74-89.

80 L.P. Pook, Fracture mechanics analysis of the fatigue behavior of spot welds, International Journal of Fracture, 11 (1975) 173-176.

81 S. Zhang, Stress intensities at spot welds, International Journal of Fracture 88 (1997) $167-185$.

82 S. Zhang, Approximate stress intensity factors and notch stresses for common spotwelded specimens. Welding Journal, 78 (1999) 173-179.

83 M.H. Swellam, G. Banas, F.V. Lawrence, A fatigue design parameter for spot welds. Fatigue \& Fracture of Engineering Materials \& Structures, 17 (1994) 1197-1204.

84 D. Choi , B. Ahn, C. Lee, Y. Yeon, K. Song, S. Jung, Formation of intermetallic compounds in $\mathrm{Al}$ and $\mathrm{Mg}$ alloy interface during friction stir spot welding, Intermetallics, 19 (2011) 125-130.

85 Y.C. Chen and K. Nakata, Friction stir lap joining aluminum and magnesium alloys, Scripta Materialia, 58 (2008) 433-436. 
86 Y.S. Sato, A. Shiota, H. Kokawa, K. Okamoto, Q. Yang, C. Kim, Effect of interfacial microstructure on lap shear strength of friction stir spot weld of aluminium alloy to magnesium alloy', Science and Technology of Welding and Joining, 15(4) (2010) 319-324.

87 F. Hayat, The effects of the welding current on heat input, nugget geometry, and the mechanical and fractural properties of resistance spot welding on $\mathrm{Mg} / \mathrm{Al}$ dissimilar materials, Materials and Design, 32 (2011) 2476-2484.

88 L. Panteli, Y. Chen, D. Strong, X. Zhang, P. Prangnell, Optimization of aluminum to magnesium ultrasonic spot welding, San Diego, USA, TMS 28th February 2011 Conference.

89 L. Liu and X. Qi, Strengthening effect of nickel and copper interlayers on hybrid laser-TIG welded joints between magnesium alloy and mild steel', Materials and Design, 31 (2010) 3960-3963.

90 A.K. Nayak and W. Oelsen, Thermal analysis of $\mathrm{Mg}-\mathrm{Sn}$ alloys by calorimetric measurements for the determination of the liquidus curve (Part-1)', TransactionsIndian Institute of Metals, 21 (1968) 15-20.

91 A.J. McAlister and D.J Kahan, Al-Sn (Aluminum-Tin)', Binary Alloy Phase Diagrams, 2nd Ed., Ed. T.B. Massalski, 1 (1990) 215-216.

92 L. Liu, X. Qi, Z. Wu, Microstructural characteristics of lap joint between magnesium alloy and mild steel with and without the addition of Sn element, Materials Letters, 64 (2010) 89-92. 
93 T. Watanabe and Y. Sugiyama, Resistance spot welding of a magnesium alloy AZ31B plate to a 1050 aluminum plate using Ag insert metal', The Japan Institute of Light Metals, 54(7) (2004) 293-297.

94 M. Wahbaa and S. Katayamac, Laser welding of AZ31B magnesium alloy to Zncoated steel, Laser welding of AZ31B magnesium alloy to Zn-coated steel, 35 (2012) 701-706.

95 L.M. Liu and X. Zhao, Study on the weld joint of Mg alloy and steel by laser-GTA hybrid welding. Materials Characterization, 59 (2008) 1279-1284.

96 L. Liu, L. Xiao, J.C. Feng, Y.H. Tian, S.Q. Zhou, Y. Zhou, The Mechanisms of resistance spot welding of magnesium to Steel. Metallurgical and Materials Transactions A, 41A (2010) 2651-2661.

97 Y. Wei, J. Li, J. Xiong, F. Huang, F. Zhang, Microstructures and mechanical properties of magnesium alloy and stainless steel weld-joint made by friction stir lap welding. Materials and Design, 33 (2012) 111-114.

98 S. Chen, J. Huang, K. Ma, H. Zhang, X. Zhao, Influence of a Ni-foil interlayer on Fe/Al dissimilar joint by laser penetration welding, Materials Letter, 79 (2012) 296299.

99 C. Maldonado, A. Medina-Flores, L. Bejar-Gomez, and A. Ruiz: Revista Mexicana De F'isica S, 2009, vol. 55-1, pp. 130-34.

100 F. Haddadi, D. Strong, P. B. Prangnell, Effect of zinc coatings on joint properties and interfacial reactions in aluminum to steel ultrasonic spot welding Journal of Material Science, 64(3) (2012) 407-413. 
101 Y.C. Chen, T. Komazaki, Y.G. Kim, T. Tsumura, K. Nakata, Interface microstructure study of friction stir lap joint of AC4C cast aluminum alloy and zinc-coated steel, Materials Chemistry and Physics, 111 (2008) 375-380.

102 K. Ueda, T. Ogura, S. Nishiuchi, K. Miyamoto, T. Nanbu, A. Hirose, Effects of Znbased alloys coating on mechanical properties and interfacial microstructures of steel/aluminum alloy dissimilar metals joints using resistance spot welding Materials Transactions, 52(5) (2011) 967-973.

103 J.C. Tan, M.J. Tan, Dynamic continuous recrystallization characteristics in two stage deformation of Mg-3Al-1Zn alloy sheet, Material Science and Engineering A. 339 (2003) 124-132.

104 S. M. Allameh, C. Mercer, D. Popoola, W. O. Soboyejo, Microstructural characterization of ultrasonically welded aluminum, Journal of Engineering Material Technology 127 (2005) 65-73.

105 I.E. Gunduz , T. Ando, E. Shattuck, P.Y. Wong, C.C. Doumanidis, Enhanced diffusion and phase transformations during ultrasonic welding of zinc and aluminum, Scripta Materialia, 52 (2005) 939-943

106 M.R. Sriraman, S.S. Babua, M. Short, Bonding characteristics during very high power ultrasonic additive manufacturing of copper, Scripta Materialia, 62 (2010) $560-563$.

107 P.J. Bates, J. MacDonald, V. Sidiropoulos, M. Kontopoulou, Comparison of experimental and analytical vibration welding meltdown-time profiles for nylon 66 and polypropylene, Polymer Engineering \& Science, 45(6) (2005) 789-797. 
108 T. Owa, T. Kondo, H. Takizawa, Production and bond strength of similar -titanium ultrasonic welded joints, Journal of the Japan Welding Society, 26(4) (2008) 264-268.

109 F. Balle, G. Wagner, D. Eifler, Ultrasonic spot welding of aluminum sheet/ carbon fiber reinforced polymer - Joints, Materialwissenschaft und Werkstofftechnik, 38 (11) (2007) 934-938.

110 R.V. Barsukov, S.V. Levin, I.I. Savin, Siberian Russian Workshop and Tutorials, Sec 4, 2002, pp. 39-41.

111 G. Gottstein, T.A. Samman, Texture development in pure Mg and Mg alloy AZ31, Material Science Forum, 495(497) (2005) 623-632.

112 A. Khan, A. Pandey, T. Herold, R.K. Mishra, Mechanical response and texture evolution of AZ31 alloy at large strains for different strain rates and temperatures, International Journal of Plastic, 27 (2011) 688-706.

113 H.T. Jeong, T.K. Ha, Texture development in a warm rolled AZ31 magnesium alloy, Journal of Material Processing Technology, 187(188) (2007) 559-561.

114 S. Huang, S. Zhang, D. Li, Y. Peng, Influence of extrusion parameters on grain size and texture distributions of AZ31 alloy, Journal of Material Processing Technology, 211(7) (2011) 1203-1209.

115 A. Jain, S.R. Agnew, Modeling the temperature dependent effect of twinning on the behavior of magnesium alloy AZ31B sheet, Material Science and Engineer A 462 (2007) 29-36.

116 L.Yu, K. Nakata, N. Yamamoto, J. Liao, Texture and its effect on mechanical properties in fiber laser weld of a fine-grained $\mathrm{Mg}$ alloy, Materials Letter 63(11) (2009) 870-872. 
117 B. Chang, Y. Shi, L. Liu, Studies on the stress distribution and fatigue behavior of weld-bonded lap shear joints, Journal of Material Processing Technology 108 (2001) $307-313$.

118 X.Z. Lin, and D.L. Chen, Strain controlled cyclic deformation behavior of an extruded magnesium alloy, Material Science and Engineer A, 496(1-2) (2008) $106-113$.

119 S. Begum, D.L. Chen, S. Xu, A.A. Luo, Strain-controlled low cycle fatigue properties of a newly developed extruded magnesium alloy, Metallurgical and Materials Transactions A, 39A (2008) 3014-3026.

120 J.B. Jordon JB, M.F Horstemeyer, S.R. Daniewicz, H. Badarinarayan, J. Grantham, Fatigue characterization and modeling of friction stir spot welds in magnesium AZ31 alloy, Journal of Engineering Materials and Technology, 132(4) (2010)

121 J.F. Cooper, R.A. Smith, Fatigue crack propagation at spot welds, Met Constr 18 (1986) 383-386.

122 D.A. Wang DA, P.C. Lin, J. Pan, Geometric functions of stress intensity factor solutions for spot welds in lap-shear specimens, International Journal of Solids and Structures, 42 (2005) 6299-6318.

123 K. Walker, The effect of stress ratio during crack propagation and fatigue for 2024T3 and 7075-T6 aluminum, Effects of Environment and Complex Load History on Fatigue Life, (1970) ASTM STP 462, ASTM, Philadelphia, PA, pp. 1-14.

124 Y. Ochi, K. Masaki, T. Hirasawa, X. Wu, T. Matsumura, Y. Takigawa, K. Higashi, High cycle fatigue property and micro crack propagation behavior in extruded AZ31 magnesium alloys, Material Transaction, 47-4 (2006); 989-994. 
125 S.H. Lin, J. Pan, P. Wung, J. Chiang, A fatigue crack growth model for spot welds under cyclic loading conditions, International Journal of Fatigue, 28 (2006) 792-803.

126 A.A Nayeb-Hashemi, J.B. Clark, The Mg-Sn (magnesium-tin) system, Bulletin of alloy phase diagram, 5 (1984) 466-475.

127 X.J. Liu, R.S. Huang, H.Y. Wang, S.H. Liu, Improvement of TIG lap weldability of dissimilar metals of $\mathrm{Al}$ and $\mathrm{Mg}$, Science and Technology of Welding \& Joining, 12 (2007) 258-260.

128 A.A. Luo, P. Fu, L. Peng, X. Kang, Z. Li and T. Zhu, Solidification microstructure and mechanical properties of cast magnesium-aluminum-tin alloys, Metallurgical and Materials Transactions A, 43 (2012) 360-368.

129 A. Kostka, R.S. Coelho, J.D. Santosb, A.R. Pyzalla, Microstructure of friction stir welding of aluminium alloy to magnesium alloy', Scripta Materialia, 60 (2009) 953956.

130 T.B. Massalski, H. Okamoto, Binary alloy phase diagram, 2nd edition, ASM International, Materials Park, Ohio, USA, 3 (1990).

131 Y. Sato, S. Hwan, C. Park, M. Michiuchi, H. Kokawa, Constitutional liquation during dissimilar friction stir welding of $\mathrm{Al}$ and Mg alloys, Scripta Materialia, 50 (2004) $1233-1236$.

132 D. Dietrich, D. Nickel, M. Krause, T. Lampke, M. P. Coleman, V. Randle, Formation of intermetallic phases in diffusion-welded joints of aluminum and magnesium alloys, Journal of Material Science, 46 (2011) 357-364.

133 Y. Sato, A. Shiota, H. Kokawa, K. Okamoto, Q. Yang, C. Kim, Effect of interfacial microstructure on lap shear strength of friction stir spot weld of aluminium alloy to 
magnesium alloy, Science and Technology of Welding \& Joining, 15-4 (2010) 319324.

134 A.B. Artzy, A. Stern, N. Frage, V. Shribman, Interface phenomena in aluminiummagnesium magnetic pulse welding, Science and Technology of Welding \& Joining, 13(4) (2008) 402-408.

135 S.D. Kore, J. Imbert, M.J. Worswick, Y. Zhou, Electromagnetic impact welding of Mg to Al sheets, Science and Technology of Welding \& Joining, 14(6) 2009 549-553

136 F. Ozturk, H. Pekel, H. S. Halkaci, The effect of strain-rate sensitivity on formability of AA 5754-O at cold and warm temperatures, Journal of Materials Engineering and Performance, 20-1 (2011) 77-81.

137 E. Doernberg, A. Kozlov, and R. Schmid-Fetzer, Experimental Investigation and Thermodynamic Calculation of $\mathrm{Mg}-\mathrm{Al}-\mathrm{Sn}$ Phase Equilibria and Solidification Microstructures, Journal of Phase Equilibria and Diffusion 28(6) (2007) 523-535

138 C.R. Clark, C. Wright, C. Suryanarayana, E.G. Baburaj, F.H. Froes, Synthesis of $\mathrm{Mg}, \quad \mathrm{X}(\mathrm{X}=\mathrm{Si}, \mathrm{Ge}$, or $\mathrm{Sn})$ intermetallics by mechanical alloying', Materials Letters, 33 (1997) 71-75.

139 R.S. Busk, Mechanical Engineers Handbook, 2nd edn., 1998, New York, Wiley.

140 C. Schneider, T. Weinberger, J. Inoue, T. Koseki, N. Enzinger, Characterization of interface of steel/magnesium FSW, Science and Technology of Welding \& Joining, 16(1) (2011) 100-107.

141 W. Xu, D.L. Chen, L. Liu, H. Mori, Y. Zhou, Microstructure and mechanical properties of weld-bonded and resistance spot welded magnesium-to-steel dissimilar joints, Material Science and Engineering A, 537 (2012) 11-24. 
142 C. Liu, D.L. Chen, S.D, Bhole, X. Cao, M. Jahazi, , Polishing-assisted galvanic corrosion in the dissimilar friction stir welded joint of AZ31 magnesium alloy to 2024 aluminum alloy. Material Characterization, 60 (2009) 370-376.

143 G.L. Song, B. Johannesson, S. Hapugoda, D. StJohn, Galvanic corrosion of magnesium alloy AZ91D in contact with an aluminum alloy, steel and zinc, Corrosion Science, 46 (2004) 955-977.

144 S. Ganeshan, L.G. Hector, Z.K. Liu, First-principles calculations of impurity diffusion coefficients in dilute $\mathrm{Mg}$ alloys using the 8-frequency model. Acta Materialia, 59 (2011) 3214-3228.

145 W. Xu, L. Liu, Y. Zhou, H. Mori, D.L. Chen, Tensile and fatigue properties of weldbonded and adhesive-bonded magnesium alloy joints, Material Science and Engineering A, 563 (2013) 125-132.

146 C.Y. Lee, D.H. Choi, Y.M. Yeon, S.B. Jung, Dissimilar friction stir spot welding of low carbon steel and Al-Mg alloy by formation of IMCs, Science and Technology of Welding \& Joining, 2009, vol. 14-3, pp. 216-20.

147 M. Watanabe, K. Feng, Y. Nakamura, S. Kumai, Growth manner of intermetallic compound layer produced at welding interface of friction stir spot welded aluminum/steel lap joint, Materials Transactions, 52(5) (2011) 953-959.

148 Y.C. Chen and K. Nakata, Effect of the surface state of steel on the microstructure and mechanical properties of dissimilar metal lap joints of aluminum and steel by friction stir welding, Metallurgical and Materials Transactions A 39A (2008) 19851992. 
149 K. Miyagawa, M. Tsubaki, T. Yasui, M. Fukumoto, Spot welding between aluminium alloy and Zn-coated steel by friction stirring, Welding International, 23(9) (2009) 648-653. 